\title{
ASSESSING NEAR-FIELD OUTDOOR CONCENTRATION VARIABILITY FROM RESIDENTIAL WOOD SMOKE COMBUSTION SOURCES
}

\author{
A Master's Thesis Presented to the Faculty
}

California Polytechnic University, San Luis Obispo

\author{
In Partial Fulfillment \\ of the Requirements for the Degree \\ Master of Science in \\ Civil and Environmental Engineering
}

by

Courtney Erin Ward

June 2009 
(C) 2008

Courtney Ward

ALL RIGHTS RESERVED 
COMMITTEE MEMBERSHIP

TITLE:

\begin{abstract}
ASSESSING NEAR-FIELD OUTDOOR CONCENTRATION VARIABILITY FROM

RESIDENTIAL WOOD SMOKE COMBUSTION

SOURCES
\end{abstract}

AUTHOR:

Courtney Ward

DATE SUBMITTED:

June 2009

COMMITTEE CHAIR: $\quad$ Tracy Thatcher, Ph.D.

COMMITTEE MEMBER: Beth Chance, Ph.D.

COMMITTEE MEMBER: Hal Cota, Ph.D.

COMMITTEE MEMBER: Yarrow Nelson, Ph.D. 


\begin{abstract}
Assessing Near-Field Outdoor Concentration Variability from Residential Wood Smoke Combustion Sources

Courtney Ward

The primary goal of this research was to determine whether near field effects from residential wood smoke emissions have a significant impact on acute and/or average $\mathrm{PM}_{2.5}$ concentrations, and therefore health risks. To this end, three primary research objectives were addressed: (1) measurement of the variability of wood smoke concentrations within a residential neighborhood with wood smoke sources, (2) establishment of whether the magnitude of near-source contributions to exposures can be estimated using typically available data, and (3) prediction of wood smoke concentrations using linear regression techniques on meteorological parameters.
\end{abstract}

This project was divided into 4 primary tasks. Neighborhood Selection (Task 1), Detailed Sample Plan and Method Validation (Task 2), Field Study to deploy equipment and personnel to the study area (Task 3), and Data Analysis (Task 4). The data analysis was divided into three sections: (1) evaluation of aethalometer black carbon (BC) variability, (2) regression and correlation analyses between meteorological factors and aethalometer BC, and (3) evaluation of the Personal Environmental Monitor (PEM) BC variability. 
$\mathrm{BC}$ concentrations, as measured by aethalometers, showed that near-source contributions to average concentrations varied widely within the $1 \mathrm{~km}^{2}$ study area, with measured BC differences up to $3.27 \mu \mathrm{g} / \mathrm{m}^{3}$ which corresponds to an estimated $\mathrm{PM}_{2.5}$ concentration ranging from 54.5 to $81.75 \mu \mathrm{g} / \mathrm{m}^{3}$. Consequently, BC concentrations, and therefore exposures, are dependent upon the location within a residential area and cannot be estimated well using measurements from a single location. Based on the results from this study, it is recommended that the standard method of measuring $\mathrm{PM}_{2.5}$ should be updated by either placing additional monitors throughout the region or estimating the variation of $\mathrm{PM}_{2.5}$ using meteorological data and an understanding of the factors leading to near source variability.

PEMs' BC measurements also showed that near-source contributions to average wood smoke concentrations vary widely over relatively short distances. Based on the BC variations between the eight to twelve monitored locations, it is unreasonable to assume that the $\mathrm{BC}$ measurements, and hence wood smoke $\mathrm{PM}_{2.5}$, are constant over a residential area. The maximum PEM BC difference of $0.76 \mu \mathrm{g} / \mathrm{m}^{3}$, or a $\mathrm{PM}_{2.5}$ concentration of 12.7 to $19.0 \mu \mathrm{g} / \mathrm{m}^{3}$ (depending on the $\mathrm{BC} / \mathrm{PM}_{2.5}$ fraction), could result in inappropriate measures being taken to protect the health of local residents. This research showed significant concentration variability associated with wood smoke burning within a residential neighborhood, with an average standard deviation of $0.10 \mu \mathrm{g} / \mathrm{m}^{3}$ and a relative standard deviation of $77.2 \%$. Since these average standard deviations and ranges of PEM 
$\mathrm{BC}$ concentration variability were calculated in Cambria, these $\mathrm{BC} / \mathrm{PM}_{2.5}$ fractions can only be applied to Cambria, in particular, the $1 \mathrm{~km}^{2}$ study area. Given the BC concentration differences between each PEM measured in the residential study area and the Cambria Fire Station, ranging from 0.09 to $0.45 \mu \mathrm{g} / \mathrm{m}^{3}$, it is evident that the central monitoring station is not a reasonable proxy for the average wood smoke concentrations to which people are exposed.

Using meteorological data to estimate $\mathrm{PM}_{2.5}$ concentrations from residential wood smoke is difficult because it requires knowledge the number of homes burning, distance from burners, wind speed, inversion conditions and other parameters that have spatiotemporal variability. The multiple regression analysis between the meteorological predictors and $\mathrm{BC}$ concentration did not detect a significant correlation for any of the meteorological factors or burning conditions. The correlation between meteorological factors and BC concentration was weak because the meteorological data was unlikely representative of the true conditions within the study area, and a lack of repeatable meteorological conditions between IOPs. Based on the meteorological data collected for the IOPs, wind directions and speeds varied considerably from 6 to 9 p.m., between IOPs, with wind directions coming from all directions and surface inversions occurring during half of the IOPs. 


\section{ACKNOWLEDGMENTS}

I would like to thank my thesis advisor, Tracy Thatcher, for her support and encouragement during the production of this thesis. Tracy made this project possible with her endless knowledge of air quality and ability to convey complex environmental engineering concepts. I feel incredibly fortunate to have had the opportunity to learn from someone as talented and passionate about air quality as Tracy.

My fantastic thesis committee members: Hal Cota, Yarrow Nelson, and Beth Chance must be acknowledged for all of their helpful suggestions. Hal's extensive background in the field of air quality provided me with the tools needed to ensure that all ends of the research tied together. With Yarrow's keen eye and knowledge in an array of fields, his review of my thesis helped me to present my complex data in a much more graspable manner. Beth is an incredibly talented statistician who guided me through the statistical analysis which represented a substantial portion of my thesis. Without her, the massive data set would have been an overwhelming obstacle.

I am extremely appreciative of my research partner, Chris Malejan, for his patience and good humor throughout the long hours at Cal Poly and in Cambria. His dedication and ability to look outside of the box helped make this project as detailed and thorough as it is.

The students by my side in the Civil and Environmental Engineering Grad Lab played a major role in keeping me going through the long hours on campus completing this thesis. Their support and ability to relate to the challenges of field work and Microsoft Office will always be appreciated and remembered.

In addition, I would like to thank Karen Brooks with the San Luis Obispo Air Pollution Control District for helping me keep this project afloat when I thought that it was impossible. Joel Craig could not have been more helpful in assisting with instrumentation and analytical support. Gary Arcemont was a gem with his climatology knowledge and eagerness to offer helpful suggestions.

I would especially like to thank the cooperative and encouraging residents of Cambria: Eugene and Margarita, whose biscotti and kindness made the field work feel more like vacation than work. Jackie, whose humor and stories were always something to look forward to. The hospitality and genuine thoughtfulness of Mary, Jim, Jack, Joni, and Gary made me feel at home in Cambria.

And finally, I would like to thank my family for their love and support throughout my college career.

Joint funding for this project was provided by the California Air Resources Board and San Luis Obispo Air Pollution Control District. 


\section{TABLE OF CONTENTS}

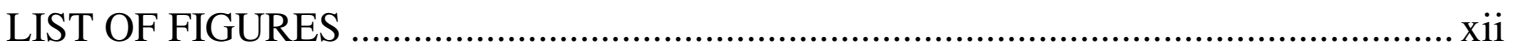

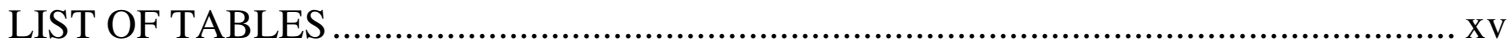

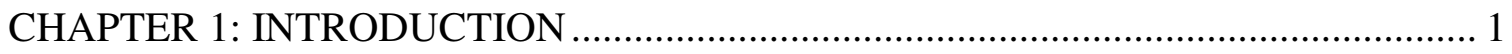

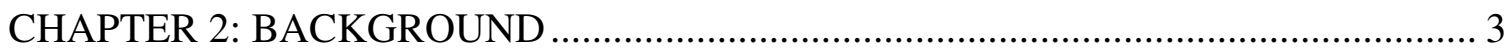

2.1. Adverse Health Effects of Particulate Matter ............................................................... 4

2.2. Spatial Variation of Wood Smoke ………………................................................... 4

2.3. Sampling and Analytical Method Comparisons …………………………….......... 8

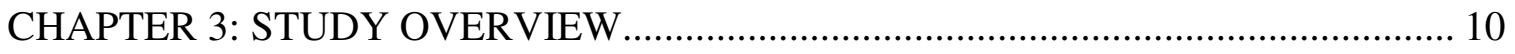

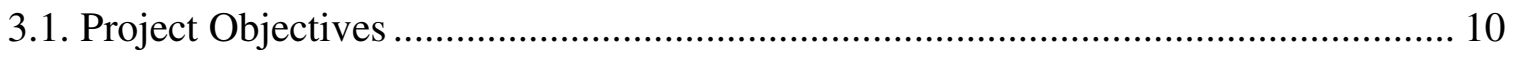

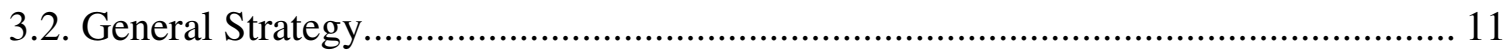

3.2.1 Neighborhood Selection Criteria .................................................................... 13

3.3. Selected Study Area .......................................................................................... 13

3.3.1. Cambria's Wintertime Climate ……………………………………………….... 17

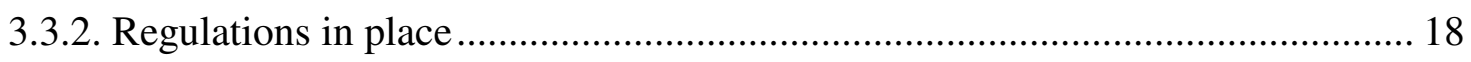

3.4. Approach to Achieving Study Objectives............................................................... 18

3.5. Intensive Operation Periods (IOPs) …………………..................................... 20

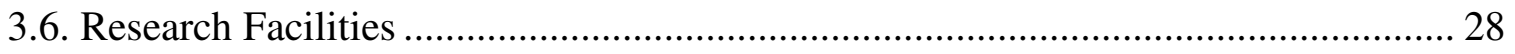

CHAPTER 4: MATERIALS AND METHODS ………………………………….... 29

4.1. Methods and Overview ...................................................................................... 29

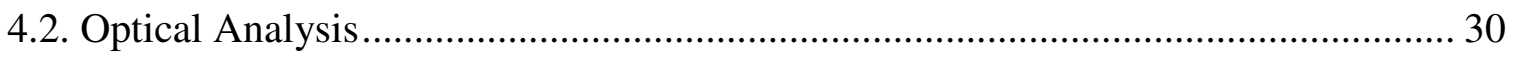

4.2.1. Aethalometers - Optical Analysis I.................................................................... 31

viii 
4.2.2. PEMs, Personal Environmental Monitors - Optical Analysis II 34

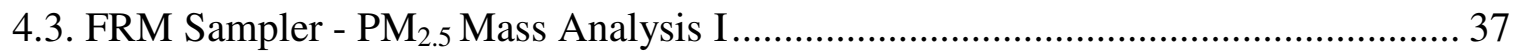

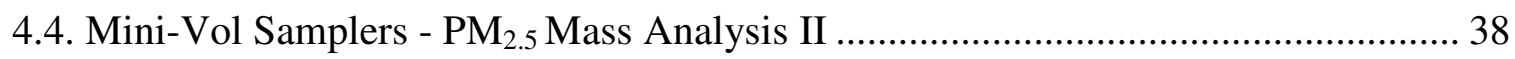

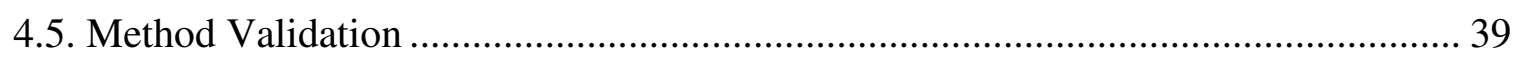

4.6. Locating Wood Smoke Combustion Sources .................................................. 44

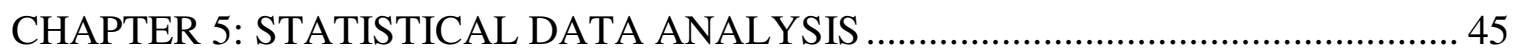

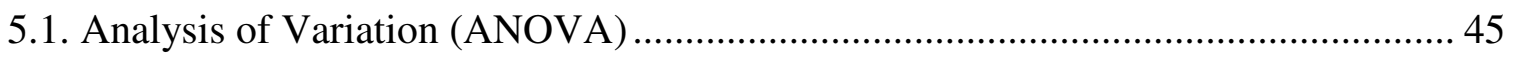

5.2. Parameters Used in Correlation Analyses....................................................... 47

5.3. Regression Correlation Analyses ................................................................. 48

CHAPTER 6: RESULTS AND DISCUSSION...................................................... 50

6.1. Aethalometer BC Variability Analysis ............................................................. 50

6.1 .1. Assessment of BC Variability: January 31, 2009 (IOP 1) .............................. 52

6.1 .2. Assessment of BC Variability: February 18, 2009 (IOP 2) ............................. 54

6.1.3. Assessment of BC Variability: February 27, 2009 (IOP 4) ..............................56

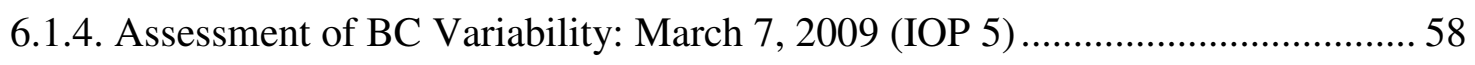

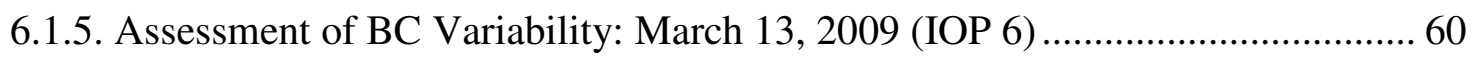

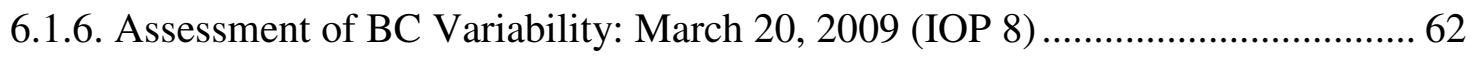

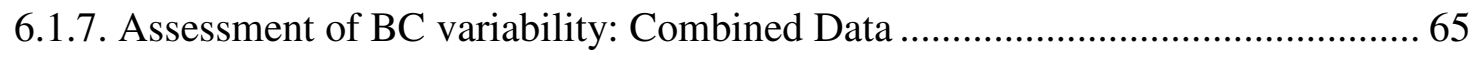

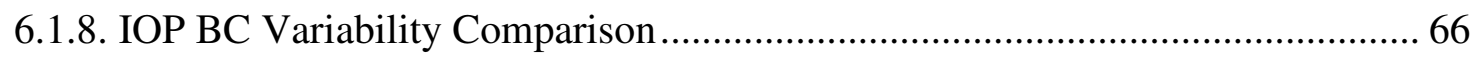

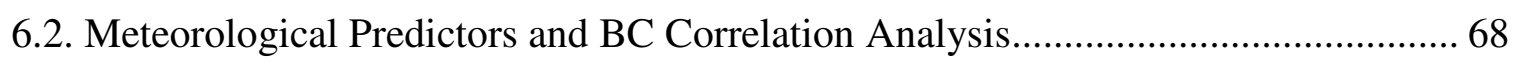

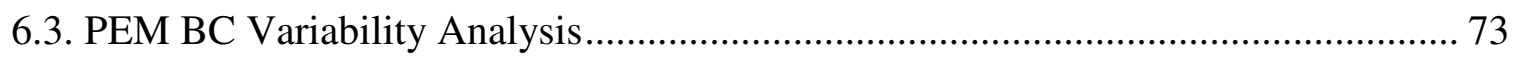

6.3 .1. Assessment of PEM BC Variability: January 31, 2009 (IOP 1) ...................... 75

6.3 .2. Assessment of PEM BC Variability: February 18, 2009 (IOP 2) .................... 76 
6.3.3. Assessment of PEM BC Variability: February 26, 2009 (IOP 3) ..................... 78

6.3 .4. Assessment of PEM BC Variability: February 27, 2009 (IOP 4) .................... 79

6.3 .5. Assessment of PEM BC Variability: March 15, 2009 (IOP 7) ......................... 81

6.3 .6. Assessment of PEM BC Variability: March 20, 2009 (IOP 8) ......................... 82

6.4 . PEM and Aethalometer Black Carbon Collection Comparison .......................... 84

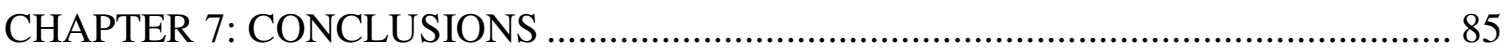

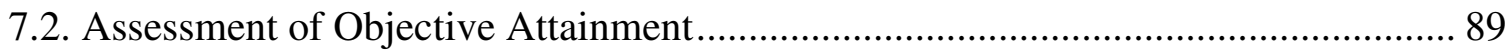

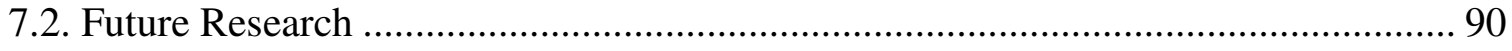

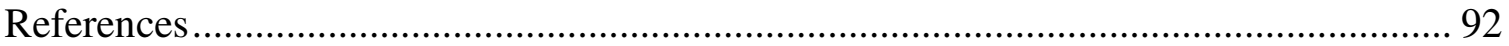

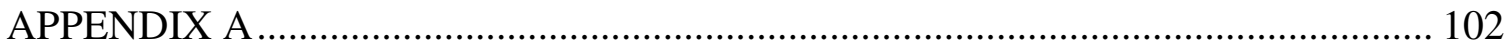

Aethalometer Comparisons................................................................................ 102

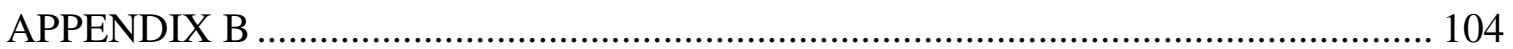

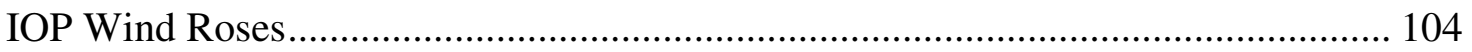

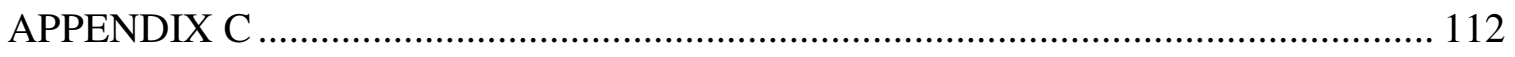

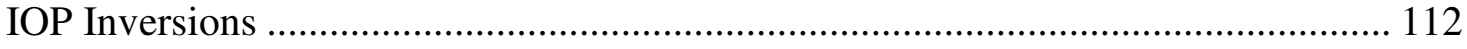

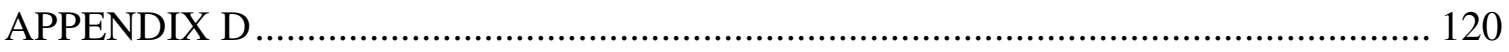

Sunset Lab's EC/OC Determination for PEMs ................................................ 120

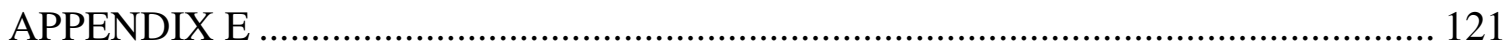

ANOVA MINITAB Results: January 31, 2009 IOP ......................................... 121

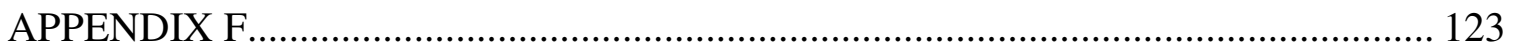

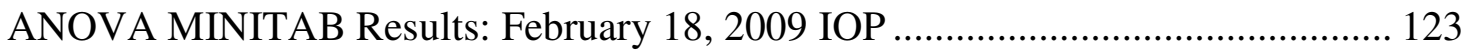

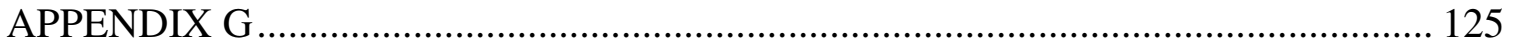

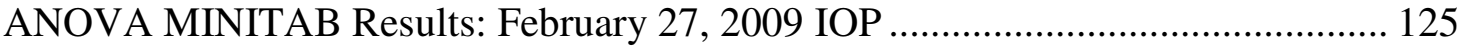




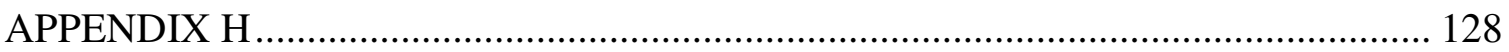

ANOVA MINITAB Results: March 7, 2009 IOP ................................................... 128

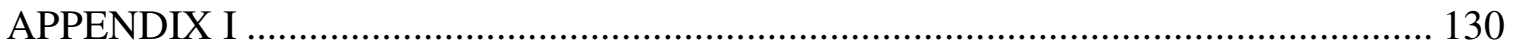

ANOVA MINITAB Results: March 13, 2009 IOP ................................................. 130

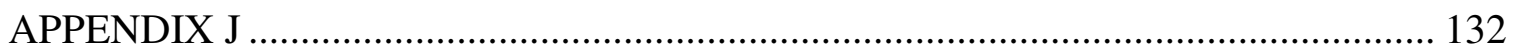

ANOVA MINITAB Results: March 20, 2009 IOP ................................................ 132

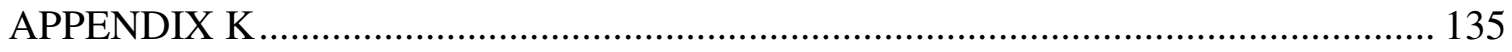

ANOVA MINITAB Results: Combined IOPs ………........................................... 135

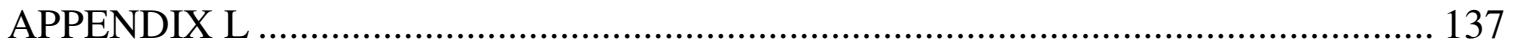

$\mathrm{PM}_{2.5}$ Results from Ventura lab for the Mini-Vol and FRM sampler filters............... 137

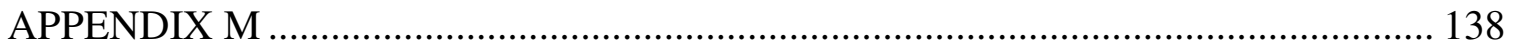

Spectral Attenuation Analysis (Repeats shown by red dashed line)........................... 138

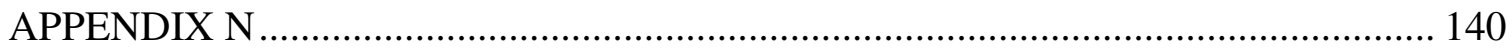

Spectral Attenuation Analysis: Strong Spectral Dependence ..................................... 140 


\section{LIST OF FIGURES}

Figure 1: Cambria Map (Chamber of Commerce).

Figure 2: Cambria study area of $1 \mathrm{~km} 2(0.62 \mathrm{mi} 2)$ and sampler layout. 101, 102, and 103 refer to location ID

Figure 3: First IOP: January 31, 2009. At least five homes burned wood south of the two aethalometer locations. The arrow represents the easterly wind direction with an average speed of $3.14 \mathrm{mph}$ from 6 to 9 p.m.

Figure 4: Second IOP: February 18, 2009. Seven homes burning around the two aethalometer locations with northwesterly ( $6-8$ p.m.) and northeasterly (8-9 p.m.) wind averaging at $0.86 \mathrm{mph}$.

Figure 5: Third IOP: February 26, 2009. Four homes burning south of the two aethalometer locations and one home burning further north. Northwesterly wind averaging at $5.8 \mathrm{mph}$.

Figure 6: Fourth IOP: February 27, 2009. Nine homes burning around the two aethalometer locations. The primary wind directions were southwesterly (67:30 p.m.) and southeasterly (7:30-9 p.m.) with an average wind speed of 0.3 $\mathrm{mph}$.

Figure 7: Fifth IOP/Method Comparison: March 7, 2009. Twelve homes burning around the three aethalometer locations with scattered wind directions averaging at $2.6 \mathrm{mph}$ from 6 to 9 p.m.

Figure 8: Sixth IOP: March 13, 2009. Eighteen homes burning around the three aethalometer locations with a westerly wind direction averaging at $3.9 \mathrm{mph}$ from 6 to 9 p.m.

Figure 9: Seventh IOP: March 15, 2009. Sixteen homes burning around the one aethalometer. The average wind speed of the westerly wind from 6 to 9 p.m. was $8.4 \mathrm{mph}$

Figure 10: Eighth IOP: March 20, 2009. Twelve homes burning around the two aethalometer locations with westerly wind averaging at $3 \mathrm{mph}$ from 6 to 9 p.m.

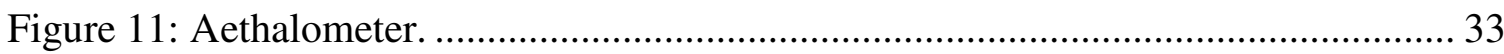

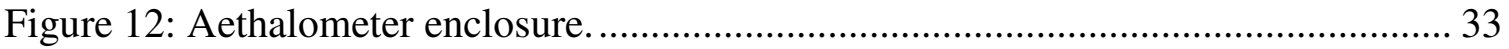

Figure 13: PEM setup from left to right: (1) PEM top, bottom, and impactor; (2) PEM top, impactor, and bottom with ring, screen, and second ring in place; (3) PEM top and impactor placed on the ring covering the screen; (4) final stage of PEM setup with top screwed on tightly to the bottom. ....................................... 35

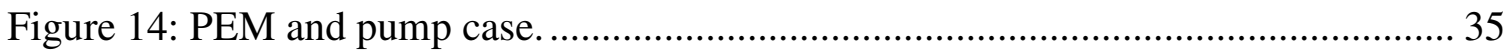

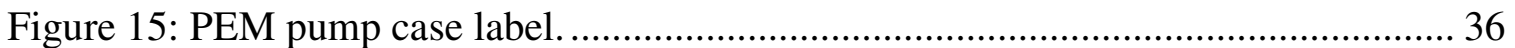




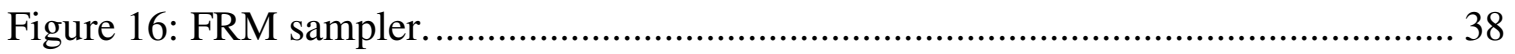

Figure 17: The four method validation sites......................................................... 40

Figure 18: Location 101 method validation set up consisting of 4 PEMs and their insulated pumps (left and right), 1 aethalometer (rear center), and 1 mini-vol (center).

Figure 19: Location 102 method validation set up consisting of 4 PEMs and their insulated pumps, 2 aethalometers, and 1 mini-vol.

Figure 20: Cambria Fire Department method validation set up consisting of 4 PEMs and their insulated pumps, 1 aethalometers, 1 mini-vol, and the FRM sampler. 42

Figure 22: BC mean readings for each evening (6 to 9 p.m.) at each location. 51

Figure 23: January 31, 2009, 6 - 9 p.m. (IOP 1): Location 101 BC vs. location 102

$\mathrm{BC}$

Figure 24: January 31- February 1, 2009 (IOP 1): Location 101 and $102 \mathrm{BC}\left(\mu \mathrm{g} / \mathrm{m}^{3}\right)$ vs. Day and time (30 min.).

Figure 25: February 18, 2009, 6 - 9 p.m. (IOP 2): Location 102 BC vs. location 101 $\mathrm{BC}$

Figure 26: February 18-19, 2009 (IOP 2): Location 101 and $102 \mathrm{BC}\left(\mu \mathrm{g} / \mathrm{m}^{3}\right)$ vs. day and time (30 min.)

Figure 27: 6 - 9 p.m., February 27, 2009 (IOP 4): location 103 BC vs. location 101 BC.

Figure 28: February 27-28, 2009 (IOP 4): Location 101 and 103 BC ( $\left.\mu \mathrm{g} / \mathrm{m}^{3}\right)$ vs. day and time (30 $\mathrm{min}$.$) .$ 58

Figure 29: March 7-8, 2009 (IOP 5): Location 101,102, 103 and Fire Station Log (BC conc.) vs. Day and time (30 min.).

Figure 30: 6-9 p.m., March 13, 2009 (IOP 6): location 102 BC vs. location 101 BC...... 61

Figure 31: March 13-14, 2009 (IOP 6): Location 101 and $102 \mathrm{BC}\left(\mu \mathrm{g} / \mathrm{m}^{3}\right)$ vs. day and time (30 min.).

Figure 32: 6 - 9 p.m., March 20, 2009: location 101 BC vs. location 102 BC. 64

Figure 33: March 20-21, 2009 (IOP 8): Location 101 and $102 \mathrm{BC}\left(\mu \mathrm{g} / \mathrm{m}^{3}\right)$ vs. day and Time (30 min.).

Figure 34: 6-9 p.m. IOP BC vs. (distance between the wood burners and aethalometer *sine of the angle between the wind direction vector)*wind speed)/(homes burning).

Figure 35: January $31^{\text {st }}$ IOP with 9 PEM locations (concentrations in white boxes) and $3.13 \mathrm{mph}$ easterly wind from 6-9 p.m.

Figure 36: February $18^{\text {th }}$ IOP with 10 PEM locations (concentrations in white boxes) and $0.86 \mathrm{mph}$ northeasterly and northwesterly wind from 6-9 p.m. 
Figure 37: February $26^{\text {th }}$ IOP with 8 PEM locations (concentrations in white boxes) and 5.8 mph northwesterly wind from 6-9 p.m.

Figure 38: February 27th IOP with 11 PEM locations (concentrations in white boxes) and $0.3 \mathrm{mph}$ southwesterly and southeasterly wind from 6-9 p.m................... 80

Figure 39: March $15^{\text {th }}$ IOP with 8 PEM locations (concentrations in white boxes) and 8.4 mph westerly wind from $6-9$ p.m. ............................................................. 82

Figure 40: March 20 $0^{\text {th }}$ IOP with 7 PEM locations (concentrations in white boxes) and 3 mph westerly wind from 6-9 p.m.

Figure 41: Spectral attenuation from a PEM filter which collected data from 6 p.m. to 6 a.m. (black line) and the spectral attenuation assuming $\mathrm{BC}$ is the only absorbing material (red line). 85 


\section{LIST OF TABLES}

Table 1. Aethalometer BC vs. mini-vol $\mathrm{PM}_{2.5}$ measured from 6 p.m. to 6 a.m. at locations 101, 102, 103, and the Cambria Fire Station (FS) .............................. 66

Table 2. Number of PEMs, $12 \mathrm{hr}$ BC concentration median, mean, minimum, and

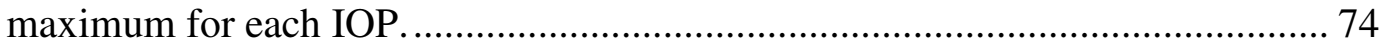

Table 3. PEM and aethalometer $12 \mathrm{hr}$ BC concentration comparisons..................84 


\section{CHAPTER 1: INTRODUCTION}

The use of wood has become popular as an alternative to conventional home heating fuels, partly due to uncertainty about the availability of fossil fuels (Larson \& Koenig, 1994). Fine particle emissions from the fireplace combustion of wood make a significant contribution to ambient fine particle levels in the United States. Emissions inventories compiled by the U.S. Environmental Protection Agency show that, in 1995, about 12\% of nonfugitive dust fine particle emissions in the U.S. came from residential wood combustion in fireplaces and wood stoves (National, 1998.). Other studies show that during winter months, $20-30 \%$ of the ambient fine particle mass concentration often can be attributed to wood smoke, with more than half of the fine particle concentration contributed by wood smoke on some occasions (Schauer, 2000). A better understanding of the spatial variability in urban wintertime wood smoke will not only aid in the siting of new regulatory air monitors focused on this pollutant mixture, but also help to interpret epidemiological studies that could be affected by spatial variability of pollutant concentration.

A primary purpose of air quality monitoring is to assess exposures and direct subsequent mitigation of potential health hazards. To obtain results that are representative of the overall concentrations in a region, air quality monitoring stations are usually deliberately located away from local sources. However, pollutants such as residential wood aerosols tend to be distributed in the near vicinity of (human) receptors and thus the regional monitoring stations may not provide an accurate representation of actual exposures. For these pollutants, near field exposures may significantly increase the risk associated with the pollutant emissions. Since the objective 
of air quality regulation is to protect the public from risks associated with pollutant exposures, an understanding of such local effects is important. As residential wood combustion occurs in areas where people spend a majority of their time, it is important to study and assess the population exposure to wood smoke. One of the primary components of concern from wood smoke is fine particulate matter. It is also now well established that wood-burning stoves and fireplaces as well as wildland and agricultural fires emit significant quantities of known health damaging pollutants, including several carcinogenic compounds. Two of the principal gaseous pollutants in wood smoke, $\mathrm{CO}$ and $\mathrm{NO}_{\mathrm{x}}$, add to the atmospheric levels of these regulated gases emitted by other combustion sources (Naeher et al., 2007).

Wood smoke from residential heating is a pollutant source that differs significantly from stationary industrial sources since it is highly concentrated in residential areas and is emitted from numerous locations. The area chosen for this study was Cambria, California, where wood combustion is a significant component of wintertime particulate matter with aerodynamic diameters smaller than $2.5 \mu \mathrm{m}\left(\mathrm{PM}_{2.5}\right)$. With wood smoke, the receptors of interest (people in their homes) are interspersed within a field of small sources. Wood burning for home heating occurs mostly at night and in the winter, periods when atmospheric mixing can be suppressed by low inversions and stagnant conditions. The variability in heat output and therefore plume rise from the individual sources adds a further layer of complication. Both Gorin et al. (2006) and Glasius et al. (2006) found an increase in wood smoke concentration in samples taken in residential areas. However, neither study provided the spatial resolution needed to determine the variation of concentrations within those residential areas. Overall, major gaps remain in the 
understanding of near-field exposure impacts across homes in residential areas with significant wood smoke sources.

The purpose of this study is to analyze the variability of black carbon (BC) concentrations on a residential scale during the winter time. This project will improve the understanding of the impact of near field combustion sources on individual exposures. The data will provide a better assessment of the accuracy of regional monitoring stations for estimating residential wood smoke contributions to $\mathrm{PM}_{2.5}$ and their representativeness for concentrations in different areas of an entire city. If wood smoke concentrations vary significantly within a residential area, then current modeling of $\mathrm{PM}_{2.5}$ for entire regions may need to be modified (e.g. place monitors throughout city or assume a certain $\mathrm{PM}_{2.5}$ range). Assuming that the measured $\mathrm{PM}_{2.5}$ at one location is representative over a large area may be an invalid assumption.

\section{CHAPTER 2: BACKGROUND}

This section gives an explanation of past research done to measure and forecast wood smoke concentrations. The analysis is divided into 2 parts, the first focusing on the variability of wood smoke concentrations at 3 sites within the $1 \mathrm{~km}^{2}$ study area and the second focusing on the meteorological parameters that influence the varying wood smoke concentrations. Method comparisons are required to ensure that the methods of wood smoke measurement are correct and comparable. 


\subsection{Adverse Health Effects of Particulate Matter}

Health effects of particles in ambient air have been investigated in numerous epidemiological studies. A two-year study conducted in the Seattle metropolitan area investigated the relationship between fine particulate matter and pulmonary function in young children. Analysis of the relationship between light scattering and lung function indicated that an increase in particulate air pollution was associated with a decline in asthmatic children's pulmonary function (Koenig et al., 1993). Further, residential wood smoke has been associated with a range of adverse respiratory health impacts (Naeher et al., 2007). Hoek's (2001) studies suggest that long-term exposure to particulate matter air pollution is associated with increased mortality from respiratory and cardiovascular disease and from lung cancer. Cardiopulmonary mortality was associated with living near a major road and, less consistently, with the estimated ambient background concentration. Miller et al. (2007) found each $\mathrm{PM}_{2.5}$ increase of $10 \mu \mathrm{g} / \mathrm{m}^{3}$ to be associated with a $24 \%$ increase in the risk of a cardiovascular event and a $76 \%$ increase in the risk of death from cardiovascular disease. The study was conducted on 65,893 postmenopausal women in 36 U.S. metropolitan areas, where $\mathrm{PM}_{2.5}$ exposure varied from 3.4 to $28.3 \mu \mathrm{g} / \mathrm{m}^{3}$ (mean, 13.5). The risk of cerebrovascular events was also associated with increased levels of $\mathrm{PM}_{2.5}$. These findings have important implications for air quality management.

\subsection{Spatial Variation of Wood Smoke}

A number of recent studies have shown that there can be substantial spatial variability of selected air pollutants within urban areas. Fischer et al. (2000) evaluated differences in concentrations of air pollutants outside and inside homes on streets with low and high traffic intensity in 
Amsterdam, the Netherlands and found outdoor $\mathrm{PM}_{10}$ and $\mathrm{PM}_{2.5}$ concentrations were 15-20\% higher than homes located in low traffic intensity streets. Hoek et al. (2002) conducted a study to assess the risk of long-term exposure to traffic-related air pollution for the development of inhalant allergy and asthma in children in Stockholm County, Munich and theNetherlands. To characterize spatial differences in annual average concentration between a large number of sites in each study area, a continuous measurement site was operated to remove potential bias due to temporal variation. The target weight for the control filters was defined as the moving average of the past 10 weighing sessions, to allow for systematic increases in filter weights. To adjust for remaining variation, all filter weights were adjusted for the deviation of the control filters during a weighing session from the 10-day moving average, for exposed and blank filters separately. To limit potential bias in the comparison of annual averages across sites due to temporal variation, an adjustment was conducted using data from the continuous measurement site. The adjustment procedure included calculation of the annual average concentration for the continuous measurement site (involving all 16 or more measurement periods); calculation for the continuous measurement site of the difference and the ratio of the measurement for period $t(t=1-16$ or more) from the annual average; multiplication of the measurement at site $\mathrm{i}(\mathrm{i}=1-40)$ in period $\mathrm{t}$ with the adjustment factor for period $\mathrm{t}$ (or addition of the difference for period $\mathrm{t}$ ) and finally calculation of the annual average concentration from the adjusted concentration values. Precision of the annual average concentrations was assessed as the standard error of the mean, calculated as the standard deviation of the four individual measurements divided by the square root of the number of measurements. Adjustment with data from the continuous measurement site improved the precision of the calculated annual averages, especially for $\mathrm{PM}_{2.5}$. Annual 
average $\mathrm{PM}_{2.5}$ concentrations ranged from 11 to $20 \mu \mathrm{g} / \mathrm{m} 3$ in Munich, from 8 to $16 \mu \mathrm{g} / \mathrm{m}^{3}$ in Stockholm and from 14 to $26 \mu \mathrm{g} / \mathrm{m}^{3}$ in the Netherlands. Larger spatial contrasts were found for the absorption coefficient of $\mathrm{PM}_{2.5} . \mathrm{PM}_{2.5}$ concentrations were on average 17-18\% higher at traffic sites than at urban background sites, but $\mathrm{PM}_{2.5}$ absorption coefficients at traffic sites were between $31 \%$ and $55 \%$ increased above background. This suggests that spatial variation of traffic-related air pollution may be underestimated if $\mathrm{PM}_{2.5}$ only is measured.

No prior research studies have assessed the distribution of wood smoke concentrations at local residences. In contrast to the well-known diurnal profile and relationship to urban density of traffic-related air pollution, wood stove/fireplace emissions peak later in the evening and occur in suburban residential areas (Larson et al., 1994). Previous attempts to spatially allocate wood smoke emissions have focused on the use of telephone surveys of wood stove/fireplace use (Tian et al., 2004), but the resulting models have not been compared with ambient monitoring data of similar spatial scale. Being able to better quantify the importance of the near-field exposure component to overall exposures is critical for understanding the relative exposure to wood smoke emissions. When assessing the health risks associated with wood smoke emissions, it is necessary to consider if monitoring station data is a reasonable proxy for the average wood smoke concentrations to which people are exposed. Most efforts to characterize and control ambient air pollution have focused on sources that degrade air quality over large portions of an air basin. Residential wood combustion is typically considered an "area source", since the wide distribution of small sources can be well characterized as an area source when concentrations are viewed at a regional scale. The California ARB defines an area source category as a collection 
of similar emission units within a geographic area (e.g. County). An area source category collectively represents individual sources that are small and numerous. However, when viewed on the scale of individual receptors (people) within a neighborhood, these sources may have significantly variable impacts based on the location of the receptor relative to the individual sources (Gorin et al., 2006). A single monitoring location, which may overestimate or underestimate PM concentrations, has the potential to mislead regulatory action.

Assessing how accurately monitoring stations reflect actual near-field exposure depends on the characteristics and variability of the near-field concentrations within an "area source" of residential wood burning. Currently, these questions cannot be answered because monitoring data are limited and modeling approaches are not well suited for this application. Gaussian plume models are ineffective in the near field and models based on computational fluid dynamics are expensive and unproven as near-field exposure-assessment tools (Sykes et al., 1986). One of the key assumptions of the Gaussian plume model is that over short periods of time (such as a few hours), steady-state conditions exist with regard to air pollutant emissions and meteorological changes. Air pollution is typically represented by an idealized plume coming from the top of a stack of some height and diameter (Karppinen et al., 2000; Sykes et al., 1986; Tuner, 1971). Occasionally, this model will be applied to non-point source emitters, such as exhaust from automobiles in an urban area. During the stagnant wind periods that often lead to high pollutant concentrations, the inputs used for these models are typically indeterminate. 


\subsection{Sampling and Analytical Method Comparisons}

Different sampling and analytical methods for particulate matter are known to have different strengths and weaknesses. There is no single method that is known to perfectly represent the actual particulate concentration. Even simple filter methods have documented positive and negative artifact issues due to filter handling, conditioning environments, and gas adsorption. The sample inlets of different sampling methods are known to behave differently under a variety of conditions. Two methods can agree well when sampling a preponderance of a particular type of particulate and then show stark disagreement when sampling a prevalence of another type of particulate. Even though no method produces a "true" representation of particulate concentration under all conditions, specific methods have been designated by the United States Environmental Protection Agency (EPA) as reference methods that are used to compare to state and federal health standards.

Elemental carbon and organic carbon (EC/OC) analyses provide important information about the overall levels and major dichotomy of carbonaceous aerosols, but the OC measurement is in no way specific to wood smoke. EC is conventionally the preferred term in conjunction with thermal and wet chemical determinations, which are deemed suitable for the selective measurement of the refractory component (Andreae \& Gelencser, 2006). Gasoline vehicle exhaust in particular can produce OC without corresponding EC and this would not be discernible using the standard EC/OC methods. Intercomparison of methods is a useful tool for understanding the relationship between and gaining confidence in the data from the various methods. Particulate carbon was analyzed by Kim et al. (2004) using the thermal optical 
reflectance method that divides carbon into four OC fractions, one pyrolized organic carbon (OP), and three EC fractions. This study indicated that the temperature resolved fractional carbon data can be utilized to enhance source apportionment studies, especially with respect to the separation of diesel emissions from gasoline vehicle sources (Chow et al., 2006).

Wood smoke is composed of multiple organic components, both BC and organics, as well as organic gases. BC is defined by 'blackness', an optical measurement. BC is commonly called soot and results from the incomplete combustion of fossil fuels and biomass. The term BC implies that this component is responsible for the absorption of visible light, and is generally used when optical methods are applied for its determination. Both "BC" and "EC" can only be regarded as "proxies" for the concentration of soot carbon, whose accuracies depend on the similarity between atmospheric soot particles and the species used for calibration. If atmospheric soot particles were pure graphite and all the methods were calibrated against graphite, "BC" and "EC" readings would give exactly the mass concentration of soot carbon as intended.

Wood smoke can be identified with high specificity by analysis for levoglucosan in PM samples collected on filters (Simoneit et al., 1999; Poore, 2002; Gorin et al., 2006). Levoglucosan has been shown to be a major organic component emitted in fine smoke particles resulting from biomass burning (Poore, 2002). Levoglucosan and the related degradation products from cellulose can be utilized as a specific and general indicator compounds for the presence of emissions from biomass burning in samples of atmospheric particulate matter. This enables the 
potential tracking of such emissions on a global basis. Levoglucosan is emitted at such high concentrations that it can be detected at considerable distances from the original combustion source (Simoneit et al., 1999). However, the analysis of levoglucosan is expensive and requires collection of substantial particulate matter mass that in turn requires use of obtrusive high volume samplers. The value of levoglucosan data is questionable because the amount of levoglucosan in wood smoke varies with wood type and burning conditions.

\section{CHAPTER 3: STUDY OVERVIEW}

This section discusses the research objectives and approach taken to achieve these objectives. A general description of the four primary tasks and the criteria required to complete these tasks are given below. Knowledge of the chosen study region, its wintertime climate, and current regulations in place is helpful in grasping the reasoning behind the study methods and objectives. Additionally, the intensive operation periods (IOPs) which were studied are explained. The IOPs were a key part of this study and were required to assess wood smoke variability and the meteorological parameters that influence the concentrations within the residential area.

\subsection{Project Objectives}

The goal of this research was to contribute to the understanding of near-source variability of wood smoke particulate matter concentrations within a residential area in which local wood burning was common and compare these concentrations to central monitoring site data. The study assessed the concentration variability associated with wood smoke within a residential neighborhood and whether or not near-source contributions can be properly estimated based on 
information on burning patterns, meteorology, and regional monitoring site data. Achievement of these objectives provides a better understanding of the contribution of wood smoke to overall $\mathrm{PM}_{2.5}$ concentrations, can increase our understanding of the variability of acute concentrations, and can improve the effectiveness of source control programs for reducing $\mathrm{PM}_{2.5}$ exposures.

\subsection{General Strategy}

Neighborhood Selection (Task 1), was required to assure that the neighborhood selected was a suitable study location and included as many of the desired study elements (house types, number and distribution of sources, etc) as possible. To determine the variability of concentrations within a neighborhood with wood burning, the first step was to identify and evaluate candidate neighborhoods for subsequent intensive study. Candidate sites were chosen in consultation with the APCD. After selecting the study area, Detailed Sample Plan and Method Validation (Task 2) provided a structured process to construct, obtain, calibrate, and test all of the necessary equipment and field deployment methods. In addition, two sampling method verification and testing runs were accomplished during this task. Field Study (Task 3) was comprised of 8 IOPs in which extensive sampling occurred over one night periods during the wood burning season. A combination of integrated and time-resolved samples were collected at approximately 13 fixed outdoor sites. Additional samples were collected at a location outside of the study area on the $5^{\text {th }}$ IOP $\left(\right.$ March $\left.7^{\text {th }}\right)$ to represent the differences in wood smoke measurements when measuring $\mathrm{PM}_{2.5}$ from a location that is representative of monitoring station distance from residential areas. Integrated samples were collected on filters and subsequently analyzed for spectrally-dependent light attenuation (over the range of 350 to $1000 \mathrm{~nm}$ ) to quantify variations in light-absorbing OC, 
an indicator for wood smoke. Semi-continuous data were acquired with two-wavelength aethalometers that measure light attenuation at $370 \mathrm{~nm}$ (a wavelength at which both black carbon and organic carbon absorb) and at $880 \mathrm{~nm}$ (a wavelength at which black carbon is the only significant PM component that absorbs). Information on burning activity during the measurement periods was obtained using an infrared camera and a global positioning system (GPS) to identify the locations of sampling sites and sources. Local meteorological data was attained from the Weather Underground Station at Marine Terrace, Cambria, California. Weather Underground is a website which consists of real-time meteorological data gathered from personal weather stations worldwide. This commercial weather service provides weather reports for most major cities, as well as local weather reports for newspapers and websites. While Weather Underground has the advantage of being free, it is not at official weather provider and therefore has the disadvantage of not having certified weather data.The final task (Task 4) completed the project with data analysis and reporting of results. The data analysis was divided into four sections, corresponding to the four study objectives: (1) method comparison, (2) evaluation of aethalometer black carbon (BC) variability, (3) regression and correlation analyses between meteorological factors and BC, and (4) evaluation of the PEM elemental carbon (EC) variability. The primary data analysis activity was to assess neighborhood scale variability in wood smoke exposures and the influence of nearby sources. The major product of this task was the database of results from the field study. 


\subsubsection{Neighborhood Selection Criteria}

A suitable study location is one that has homes representative of the majority of U.S. homes, significant wood burning activity, few competing PM sources, and meteorological conditions leading to elevated PM levels. According to the 2007 American Housing Survey for the United States, the median construction year of housing units was 1973, so one criteria was to find an area with a mixture of home ages within a typical age range (built between 1940 and 1990), representative of the majority of U.S. homes. It is expected that this variety of home ages will lead to a variety of wood stoves and chimneys construction styles that is representative of the housing stock. A desirable study area should also be largely covered by homes rather than open fields, buildings, highways, or forests. Although only $1.5 \%$ of Americans use wood for main house heating (U.S. Department of Housing, 2008), to effectively assess wood smoke variability, the study area must be in a location where residents burn wood in the winter. To facilitate sampler placement, study area residents should be willing to allow equipment to be placed in their neighborhoods and/or yards. An additional requirement for the study area is to be located in a safe neighborhood to ensure accessibility and equipment safety.

\subsection{Selected Study Area}

Cambria is a small town (about $3 \mathrm{mi}^{2}$ ) located on the central coast of California $\left(35^{\circ} 33^{\prime} 15^{\prime \prime} \mathrm{N}\right.$, $\left.121^{\circ} 5^{\prime} 15^{\prime \prime} \mathrm{W}\right)$ with elevations ranging from sea level to 200 feet (Chamber, 2009). Cambria was chosen as the research location because it best met the site selection criteria. Cambria has a significant residential wood smoke contribution with nearly no conflicting $\mathrm{PM}_{2.5}$ sources such as industry or vehicular traffic. Thus, Cambria is not impacted by industrial pollution. The 
principal economic activity in Cambria is tourism. There are no major freeways in the area. The largest road, Highway 1, is one lane each way and serves only local truck traffic. Since many residents use wood for heating and there are no significant additional sources, excellent sampling conditions were present during the daytime and the nighttime. Due to the age of the neighborhoods and the characteristics of the homes, a large percentage of the homes in Cambria have fireplaces and/or woodstoves. Additionally, given the close proximity of available wood and the nature of the community, many homes use wood for a significant portion of their heating needs.

The Cambria location yielded many opportunities for relatively easy access to study locations and excellent support from the SLO APCD. Cambria is a small town (6,500 inhabitants) where it was uncomplicated to disseminate information regarding the study. An added benefit of choosing the Cambria study region was that the APCD had a logged history of complaints regarding wood smoke levels from several residents in the area, and therefore had a ready list of potentially cooperative home owners. Given the community concern over their air quality, there were a high number of community members willing to place wood smoke measurement devices in their yards, resulting in more test runs and continuous measurement instruments located over extended periods. Cambria's meteorological conditions lead to elevated PM levels since there are substantial inversions caused by oceanic upwelling along the California coast. These inversions result in a weak vertical mixing of the air mass and a weak air mass transport from other locations. Additionally, Cambria has little rain and fog, which presents many opportunities for sampling. 
The primary study area was approximately $1 \mathrm{~km}^{2}$ and focused in portions of northern Cambria known as "Leimert" and "Happy Hill" (south of Leimert), encompassing about 400 homes. This section of Cambria was chosen because it was representative of typical Cambria neighborhoods, with prevalence of chimneys, chimney use, and homes ranging from 1 to 50 years old. Figure 1 displays street names and the seven neighborhoods (Leimert, Happy Hill, Pine Knolls, Park Hill, Seaclift Estates, Lodge Hill, and Marine Terrace) in Cambria. Knowledge of the prevalence of chimney use and variation in particulate concentrations throughout the neighborhood was based on thermal imaging and wood smoke concentration measurements over several evenings under different meteorological conditions. Once this area was confirmed to be secure, daytime visits were made to determine more sampling locations. The Cambria contacts helped to distribute the word about the research project, facilitating access to more homes. Figure 2 shows the $1 \mathrm{~km}^{2}$ $\left(0.62 \mathrm{mi}^{2}\right)$ study area super-imposed on a Cambria map and the locations of the monitoring devices. The primary study area was approximately 1.75 miles northwest of the Federal Reference Method (FRM) sampler, which was placed at the Cambria Fire Department. The Pine Knolls neighborhood was chosen as the backup study area because it also had many concerned residents willing to place monitoring equipment at their homes. It was not chosen as the primary study area because it is located closer to downtown which has restaurants and more vehicular traffic, increasing the potential difficulty of separating wood smoke $\mathrm{PM}_{2.5}$ concentrations from those of other PM sources. 


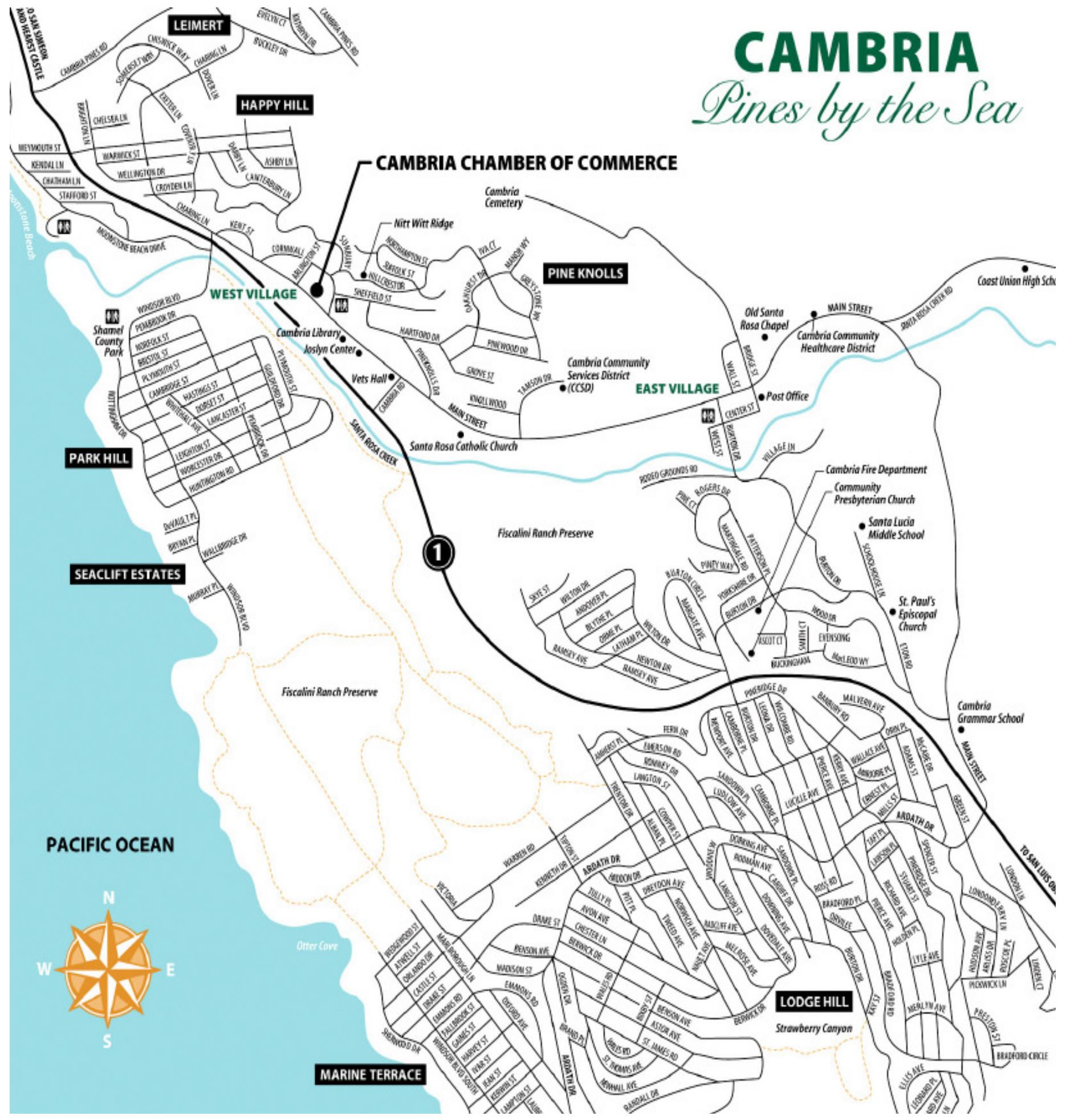

Figure 1: Cambria Map (Chamber of Commerce). 


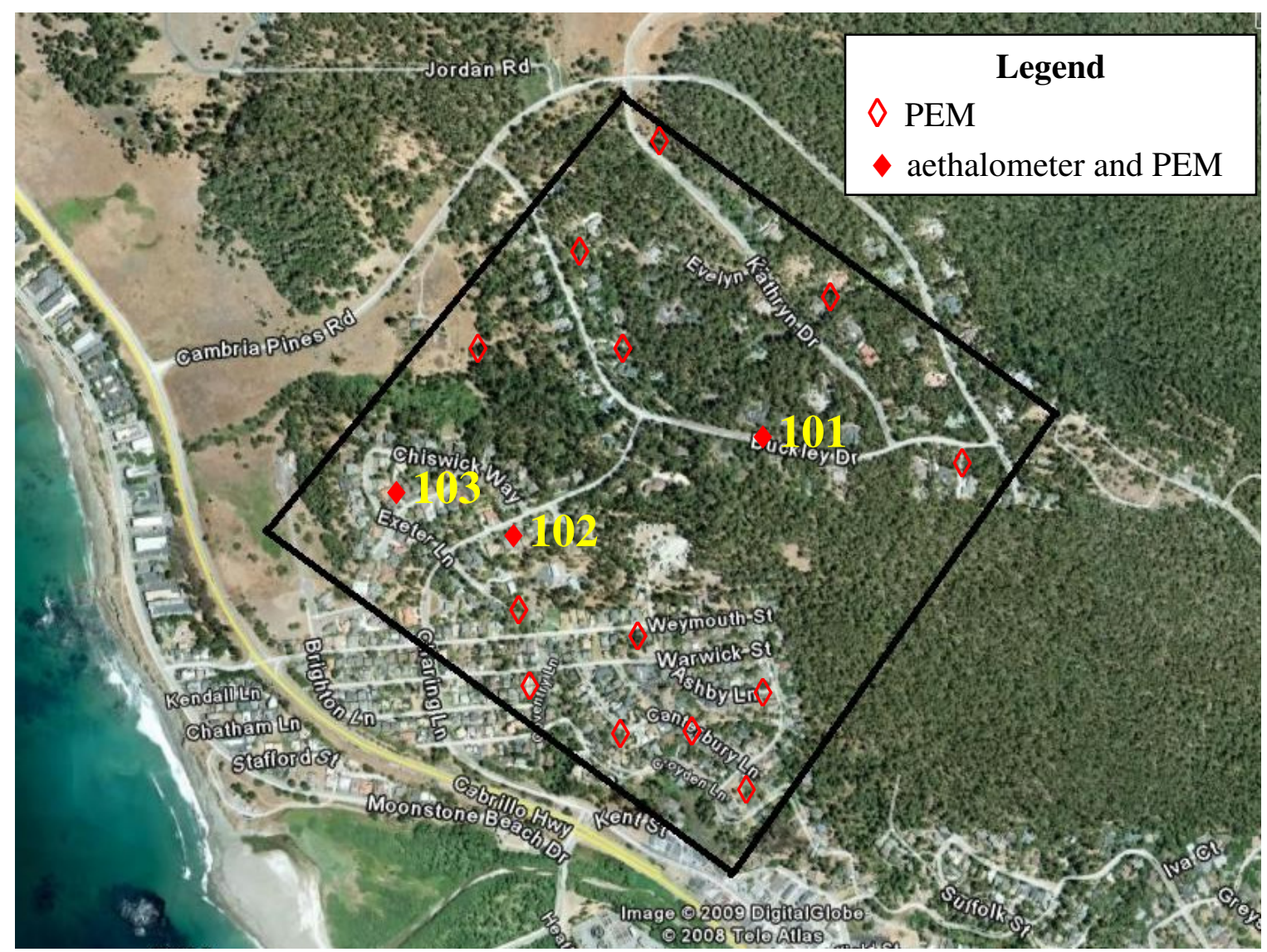

Figure 2: Cambria study area of $1 \mathrm{~km} 2$ (0.62 mi2) and sampler layout. 101, 102, and 103 refer to location ID.

\subsubsection{Cambria's Wintertime Climate}

Cambria experiences significant and sustained wintertime inversions, the type of weather of most concern for significant enhancement of near-field exposures. In addition, with relatively little rain and fog, Cambria presents many days and nights with opportunities for sampling. From November 2008 to March 2009, the mean temperature was 53.3 degrees Fahrenheit $\left({ }^{\circ} \mathrm{F}\right)$. The coldest month of the year is December with an average minimum temperature of $41.8^{\circ} \mathrm{F}$. Temperature variations between night and day tend to be fairly limited during winter with an average difference of $19^{\circ} \mathrm{F}$. The average 
precipitation during the four month winter campaign was 2.98 inches per month. The wettest month of the year is February with an average rainfall of 3.69 inches.

\subsubsection{Regulations in place}

The Residential Wood Combustion Rule 504 (SLO APCD, 1993) was adopted by the APCD Board in 1993 to reduce emissions from incomplete combustion of wood in residential wood stoves and fireplaces throughout the county. The current rule allows District approved wood burning devices (San, 2008) in new and remodeled construction. Wood burning devices in existing homes are not affected by the rule, and there are no conditions placed on continued use of those devices upon the sale of an existing home. Retailers are required to distribute literature containing clean burning tips and other relevant information with each sale of a wood burning device. A voluntary curtailment program may be implemented by the District in which residents without approved devices are asked not to burn on days where pollution levels are predicted to be high.

\subsection{Approach to Achieving Study Objectives}

A method of spectrally-dependent light attenuation of BC collected on filter substrates was used to assess spatial variability of wood smoke concentrations. This method was applied to both integrated, overnight samples and resolution on a time scale of minutes using aethalometers. The light attenuation approach, described below, offers distinct advantages over other methods that could be used to estimate wood smoke variability. Wood smoke can be identified with high specificity by analysis for levoglucosan in particulate matter (PM) samples collected on filters (Simoneit et al., 1999; Poore, 2002; \& Gorin et al., 2006). The analysis of levoglucosan is costly and varies depending on 
burning conditions. Such equipment is inconvenient for overnight deployment at many sites in a residential neighborhood. The expense would limit the number of samples and the resolution of data would be limited to integrated overnight periods. Since this project focuses on periods during which wood smoke comprises a large fraction of total organic carbon PM, a combination of integrated and time-resolved thermal analysis for elemental carbon and organic carbon (EC/OC) for assessing wood smoke concentrations was considered. Integrated sample analysis for EC/OC (e.g. by Sunset laboratories or IMPROVE thermal optical methods) is substantially less expensive than levoglucosan analysis and there is an instrument (R\&P 5400 Ambient Carbon Particulate Monitors; Rupprecht \& Patashnick, Albany, NY) that can provide half-hourly resolution of EC and OC values (e.g. as reported in Chow et al., 2006). These approaches provide important information about the overall levels and major dichotomy of carbonaceous aerosols, but the OC measurement is in no way specific to wood smoke. Gasoline vehicle exhaust in particular can produce OC without corresponding EC (or BC) and this would not be discernible using the standard EC/OC methods. Based on the expense of the R\&P equipment and time required for the laboratory based thermal methods, this approach would also be more expensive than the selected one.

The optical approach selected for use in this study may be applied to integrated sample loadings obtained with unobtrusive and relatively inexpensive equipment that is suitable for deployment in residential neighborhoods. Sample analysis is relatively inexpensive and sensitive enough for resolution on samples with low loading. The aethalometer offers a relatively inexpensive option to collect time-resolved data on both the UV- 
absorbing OC from wood smoke and BC from diesel PM. Integrated and time-resolved samples are analyzed with the same fundamental method. Near-UV light attenuation is more specific to wood smoke than standard OC analysis methods because motor vehicle generated OC does not absorb in this region (Kirchstetter \& Novakov, 2004). Existing Lawrence Berkeley National Laboratory (LBNL) aethalometers were used in this study to expand collection sites for time-resolved data. The custom spectrometer used to analyze integrated filter samples at LBNL provided additional information about the spectral dependence of light attenuation.

\subsection{Intensive Operation Periods (IOPs)}

Sampling during eight intensive operation periods (IOPs) was conducted between January and March 2009. During each of these IOPs, extensive sampling occurred in which a combination of integrated and time-resolved samples was collected over a single night at locations within an area of approximately $1 \mathrm{~km}^{2}$. The setup consisted of a combination of 7 - 11 PEM sites and 2 - 3 aethalometers. The figures below show aethalometer locations (red balloons), PEM locations (empty diamonds), and homes burning (flame image) between 6 and 9 p.m. for each IOP. The arrows represent the dominant wind direction(s) and speed (mph). 


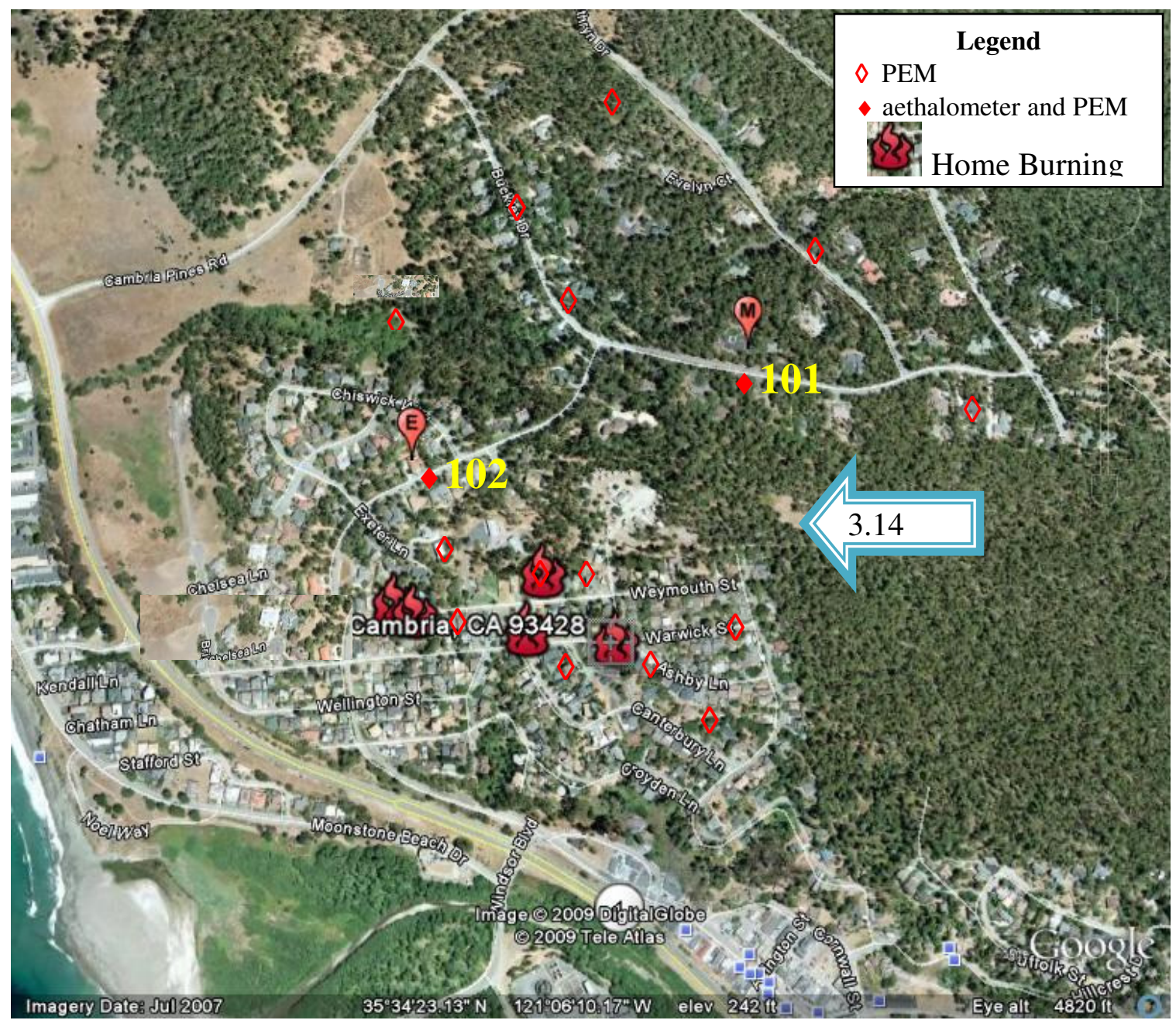

Figure 3: First IOP: January 31, 2009. At least five homes burned wood south of the two aethalometer locations. The arrow represents the easterly wind direction with an average speed of $3.14 \mathrm{mph}$ from 6 to 9 p.m. 


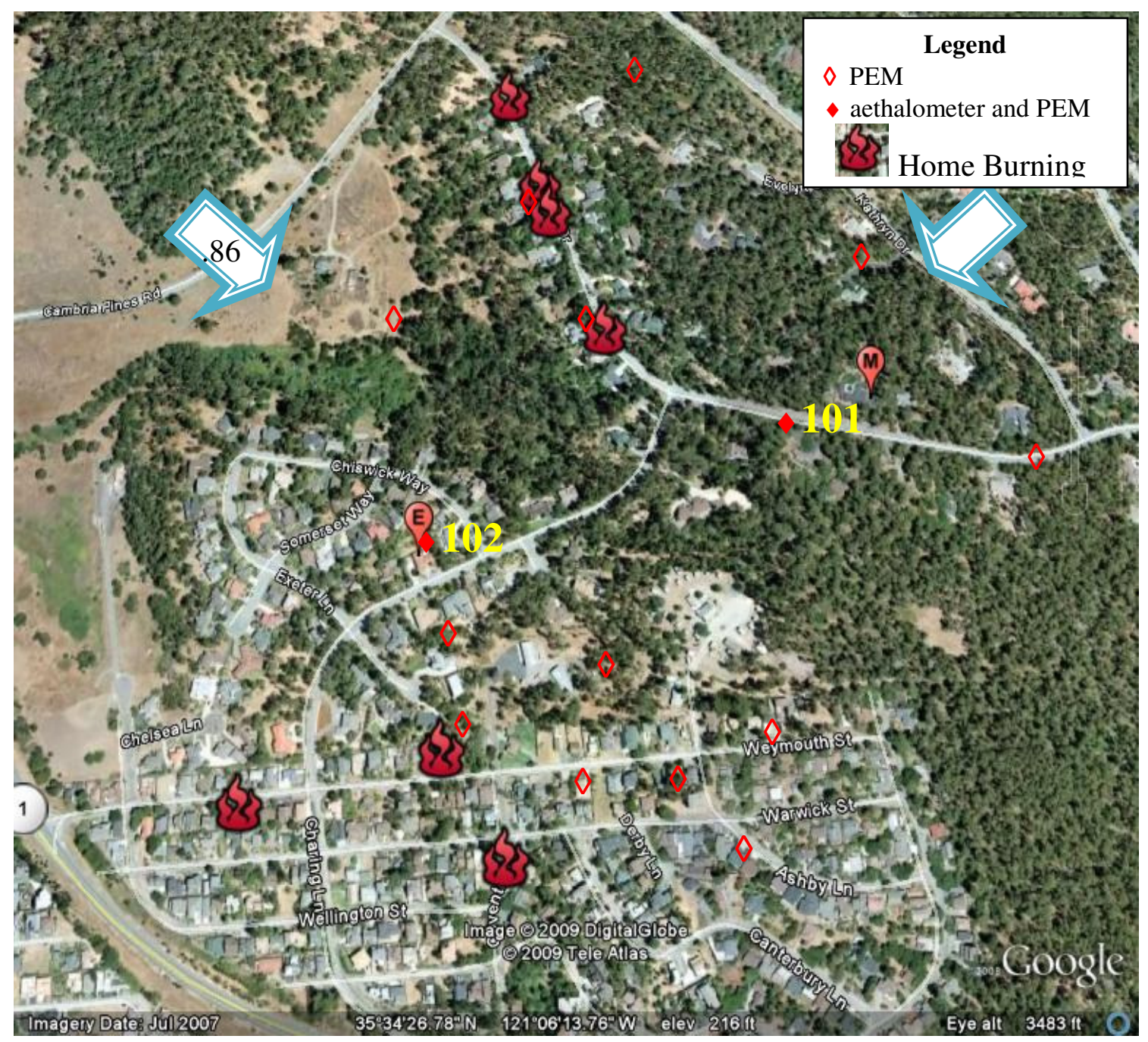

Figure 4: Second IOP: February 18, 2009. Seven homes burning around the two aethalometer locations with northwesterly $(6-8$ p.m.) and northeasterly (8-9 p.m.) wind averaging at $0.86 \mathrm{mph}$. 


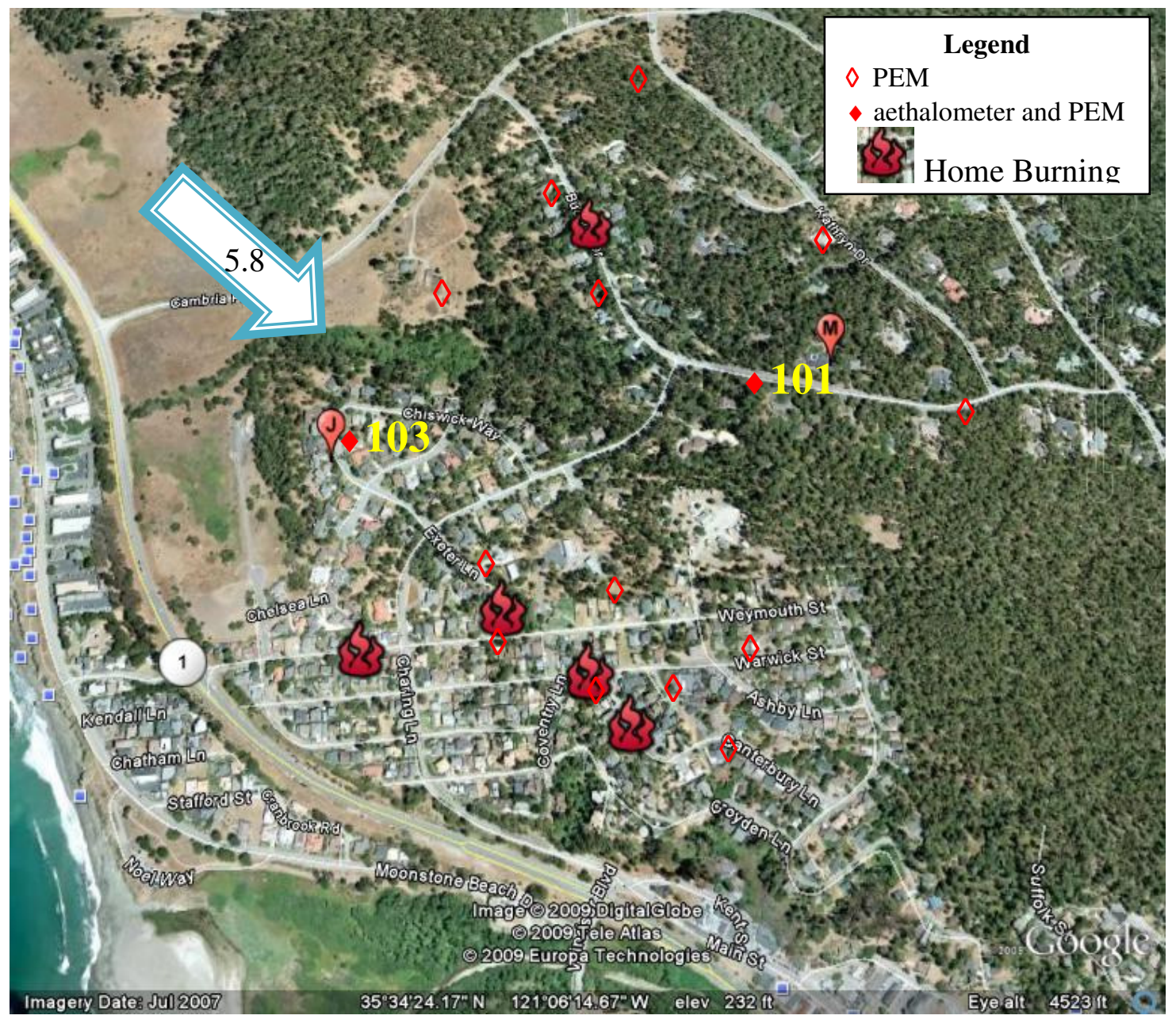

Figure 5: Third IOP: February 26, 2009. Four homes burning south of the two aethalometer locations and one home burning further north. Northwesterly wind averaging at $5.8 \mathrm{mph}$. 


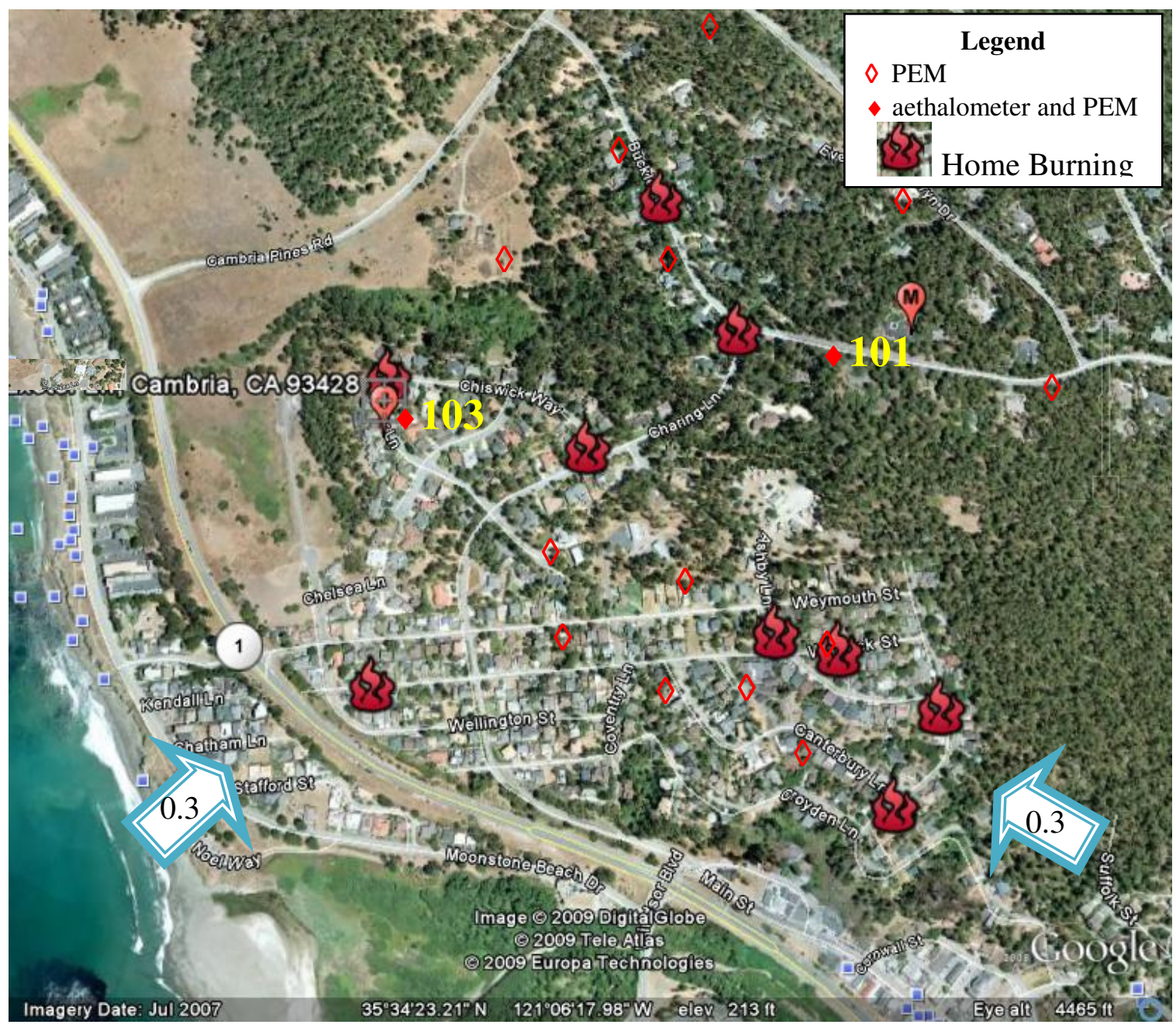

Figure 6: Fourth IOP: February 27, 2009. Nine homes burning around the two aethalometer locations. The primary wind directions were southwesterly (6-7:30 p.m.) and southeasterly (7:30-9 p.m.) with an average wind speed of $0.3 \mathrm{mph}$. 


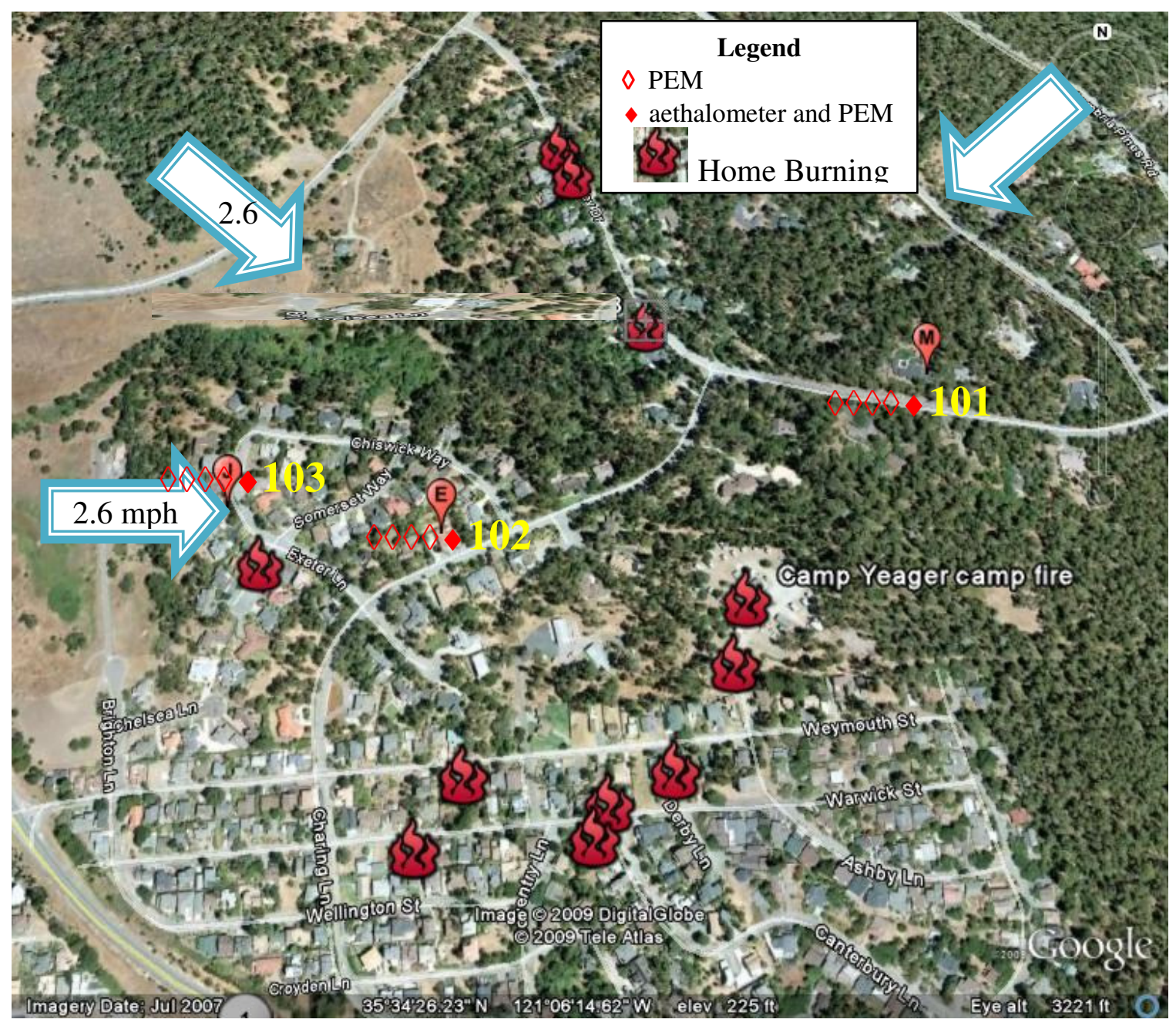

Figure 7: Fifth IOP/Method Comparison: March 7, 2009. Twelve homes burning around the three aethalometer locations with scattered wind directions averaging at $2.6 \mathrm{mph}$ from 6 to 9 p.m. 


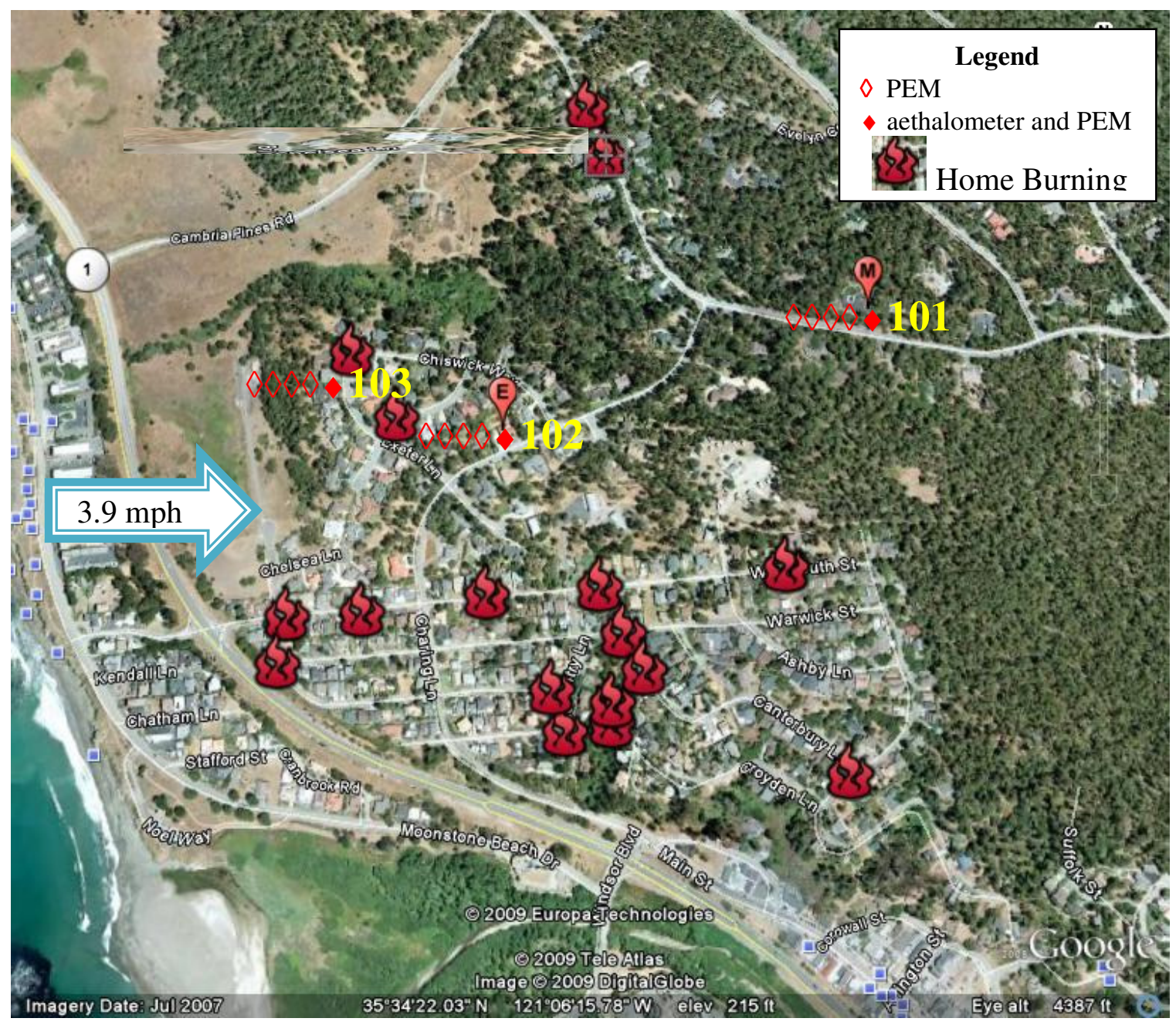

Figure 8: Sixth IOP: March 13, 2009. Eighteen homes burning around the three aethalometer locations with a westerly wind direction averaging at $3.9 \mathrm{mph}$ from 6 to 9 p.m. 


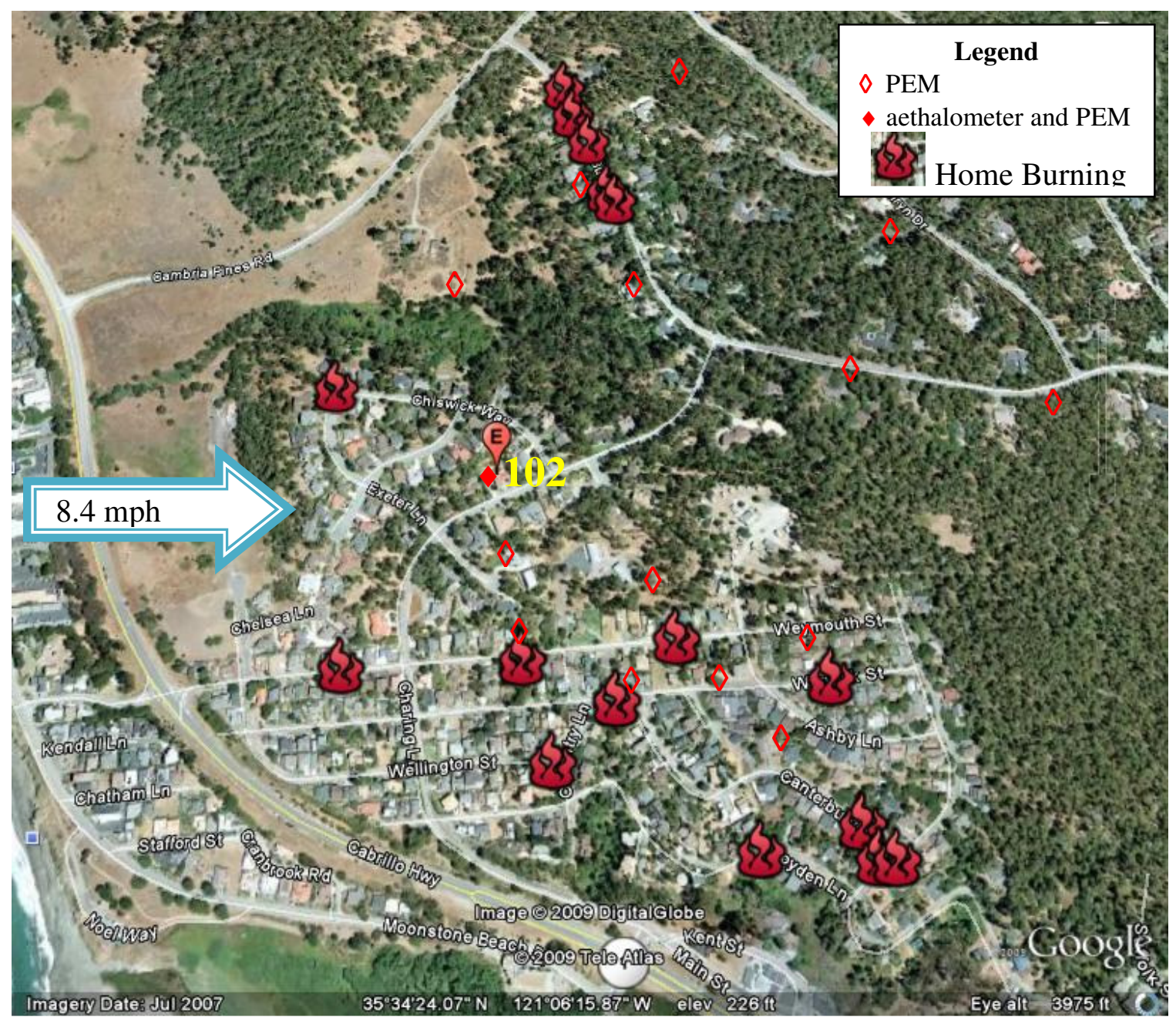

Figure 9: Seventh IOP: March 15, 2009. Sixteen homes burning around the one aethalometer. The average wind speed of the westerly wind from 6 to 9 p.m. was 8.4 mph. 


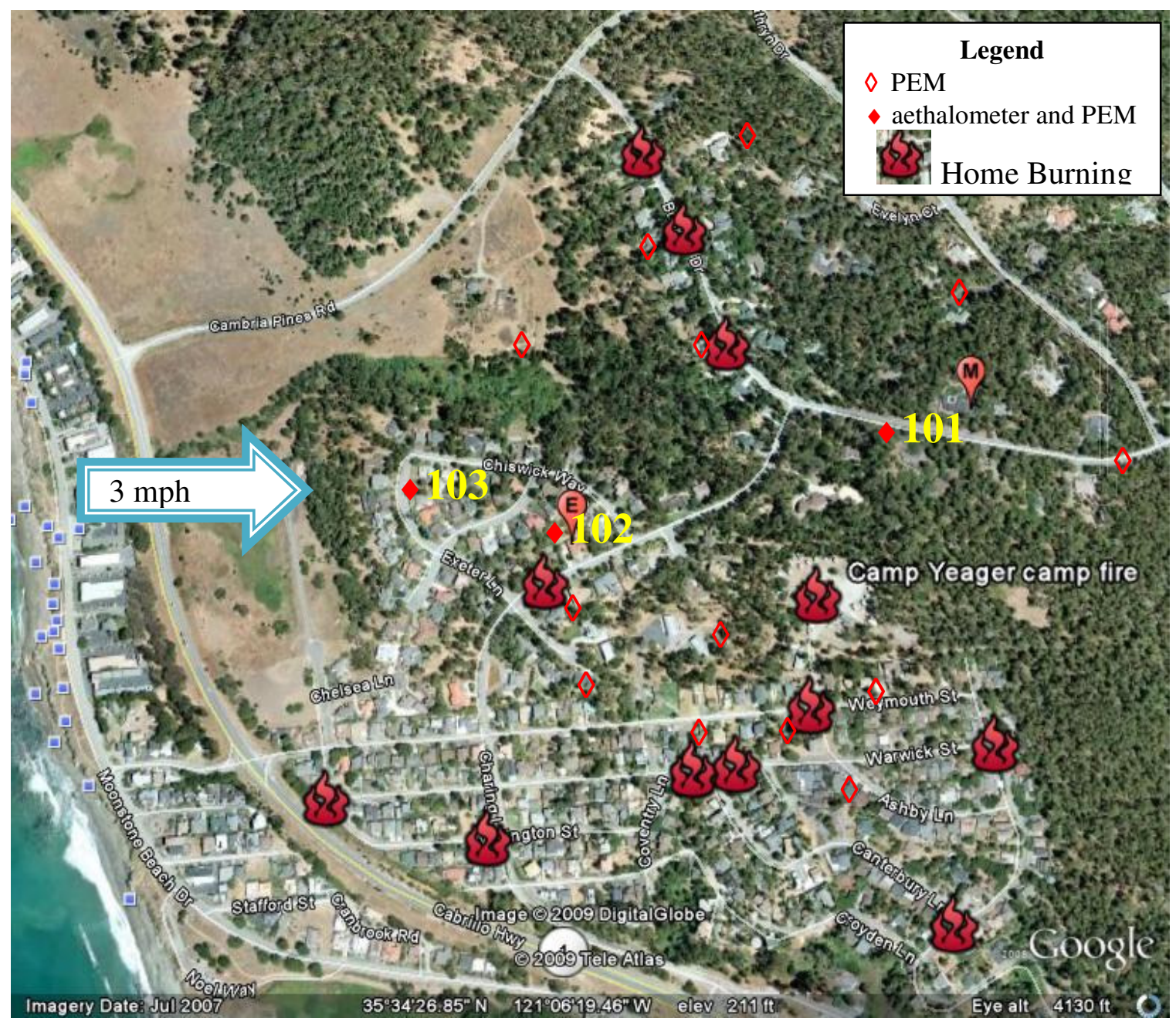

Figure 10: Eighth IOP: March 20, 2009. Twelve homes burning around the two aethalometer locations with westerly wind averaging at $3 \mathrm{mph}$ from 6 to 9 p.m.

\subsection{Research Facilities}

The study utilized five dual-wavelength aethalometers and a custom optical spectrum transmissometer for filter analysis. Equipment testing and calibration and filter handling and analysis was used both at Cal Poly and at Lawrence Berkeley National Laboratory (LBNL). The Air Resources Board (ARB) funded two aethalometers and loaned 10 mini-vols. Cal Poly provided an infrared camera for identifying homes within the study area actively burning, a Federal Reference Method (FRM) $\mathrm{PM}_{2.5}$ sampler, and facilities for staging and mobilizing equipment for the intensive operational periods (IOPs). The 
San Luis Obispo Air Pollution Control District (SLO APCD) substantially assisted the project by offering use of their vehicles for travel, information on local neighborhoods, expertise on monitoring equipment, and filter storage and shipping costs. The District also provided expertise on neighborhoods, possible study sites, and local agencies and community groups that were interested in or concerned about the study. Due to the concerns expressed to the APCD Board in 2007 regarding the health impacts of wood smoke, the project assisted the APCD in implementing its outreach campaign to inform residents countywide on the health effects of wood smoke from fireplaces and strategies to reduce these impacts. Key components of this campaign included dispersing an APCD flyer and an ARB handbook identifying energy efficient heating strategies, health impacts of wood burning, and tips for burning a clean and efficient fire. The APCD was especially interested in measuring the wintertime $\mathrm{PM}_{2.5}$ concentrations using a FRM sampler or semi-FRM samplers to determine whether or not the community $\mathrm{PM}_{2.5}$ levels exceeded or came close to the fine PM 24 hour Federal Standard of $35 \mu \mathrm{g} / \mathrm{m}^{3}$. To this end, the study utilized the ARB's mini-vols to measure $\mathrm{PM}_{2.5}$ using a semi-FRM method and Cal Poly's FRM PM 2.5 sampler.

\section{CHAPTER 4: MATERIALS AND METHODS}

\subsection{Methods and Overview}

Cambria wood smoke concentrations were measured from mid-November 2008 to midMarch 2009. Samples were collected using integrated and semi-continuous methods which recorded varying levels of collected $\mathrm{PM}_{2.5}, \mathrm{EC}$, and OC. Duplicate samples were collected for some measurements. One or more aethalometers were operated during each 
integrated sampling period to provide additional information about the collected BC. All integrated sampling systems and aethalometers were uniquely identified to ensure that any systematic sampling biases could be determined and identified during data analysis. Following each field deployment, filter samples were cataloged and then analyzed for spectrally-dependent light attenuation.

\subsection{Optical Analysis}

The light attenuation (optical) approach offers distinct advantages over other methods that could be used to estimate wood smoke variability. The primary reasons for using optical analysis are that (a) integrated samples can be analyzed at much lower cost than chemical analysis for the wood smoke marker levoglucosan, (b) the analysis provides information about black carbon and organic carbon, and (c) the data can be readily compared with time-resolved measurements made with a dual-wavelength aethalometer (Poore, 2002). Measurement of light attenuation has long been a standard approach for the determination of elemental or black carbon; specific variations include measurement of the change in visible light reflectance or transmission that occurs when PM is collected on a sample filter or other substrate. Light attenuation (ATN) is calculated from measurements of the light transmission intensity through a filter containing a collected sample (I) and a clean section of the same filter $\left(\mathrm{I}_{0}\right)$, as shown in equation 1:

$$
\mathrm{ATN}=-100 * \ln (\mathrm{I} / \mathrm{Io})
$$

According to Kirchstetter et al. (2004), attenuation can be converted to a mass concentration (mass per volume of air) by considering the specific attenuation cross- 
section for the aerosol BC deposit on the filter $\sigma\left(\mathrm{m}^{2} / \mathrm{g}\right)$, the area A over which the sample was deposited on the filter, and the sample volume V:

$$
\mathrm{BC}=(\mathrm{ATN} * \mathrm{~A}) /(\sigma * \mathrm{~V})
$$

Sigma $(\sigma)$ is wavelength dependent and its value must be ultimately related to a chemical or other standard measurement. According to Andreae and Gelencser (2006), even if the only absorbing substances in aerosols were BC, an uncertainty of about a factor of two in the estimation of $\mathrm{BC}$ would result from the variability of sigma itself.

\subsubsection{Aethalometers - Optical Analysis I}

Integrated samples of black carbon were collected using aethalometers. An aethalometer (Figure 11) is an instrument that provides a real-time readout of the concentration of black or elemental carbon aerosol particles in an air stream. Aethalometers are the most widely used instrument for the real-time measurement of aerosol BC. Aethalometers operate by measuring the intensity of light transmitted through a quartz filter tape. The tape automatically advances when the light transmittance is diminished to a preset level due to filter loading. The instrument records light transmission through the quartz tape and reports $\mathrm{BC}$ concentrations in $\mathrm{ng} / \mathrm{m}^{3}$, using an empirical coefficient based on studies of aerosols near combustion sources in urban areas and in remote regions. The coefficient is similar for all aerosol types $\left(\sim 2000 \mathrm{~m}^{2} / \mathrm{g}\right)$ (Kirchstetter and Novakov, 2007).

When BC concentrations are extremely low, instrumental noise can lead to computed values of $\mathrm{BC}$ that are slightly negative. This is a natural consequence of the algorithm and does not imply malfunction of the instrument. Since organic vapors can sorb onto the tape and decrease light transmission, for relatively clean air changes in the 
concentration of organic vapors, can cause some organic vapors to desorb from the filter fibers into the passing clean air stream. This will result in a loss of UV-absorbing material from the filter deposit, which the algorithm will interpret as a negative signal in the UV data (Hansen, 2005). This is not an instrumental error, rather it is an indication that UV-absorbing gaseous material was deposited on the filter spot during the sampling event and then desorbed from the filter spot afterwards.

Aethalometer measurements were logged every minute. Integrated and time-resolved samples were analyzed with the same fundamental method. Near-UV light attenuation is more specific to wood smoke than standard OC analysis methods because motor vehicle generated OC does not absorb in this region (Kirchstetter and Novakov, 2007). Semicontinuous data was acquired with two-wavelength aethalometers that measure light attenuation at $370 \mathrm{~nm}$ (a wavelength at which both black carbon and organic carbon absorb) and at $880 \mathrm{~nm}$ (a wavelength at which black carbon is the only significant PM component that absorbs). The aethalometer draws the air sample through the inlet port, typically at a flow rate of $4 \mathrm{~L} / \mathrm{min}$, using a small pump. The flow rate is monitored by an internal mass flow meter and is stabilized electronically to the setpoint value entered in software. To protect the aethalometers from rain damage, they were placed inside of a plastic enclosure with a $6 \mathrm{~mm}$ diameter black OD tube outlet for the air sample inlet port (Figure 12). 


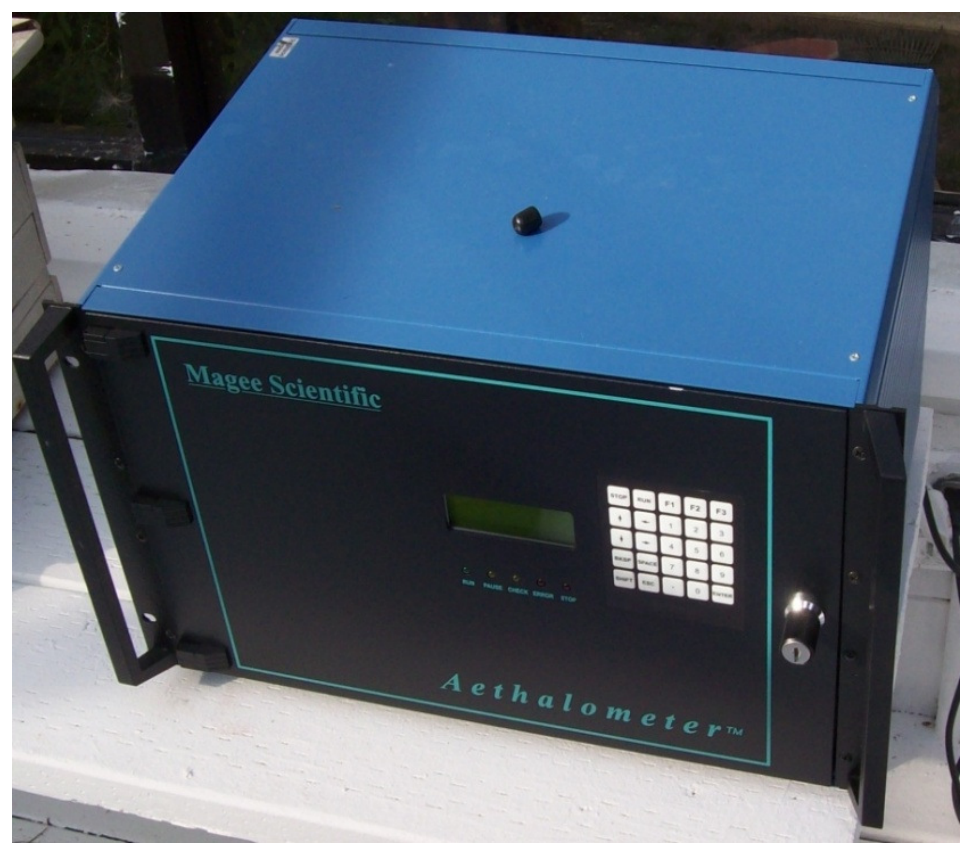

Figure 11: Aethalometer.

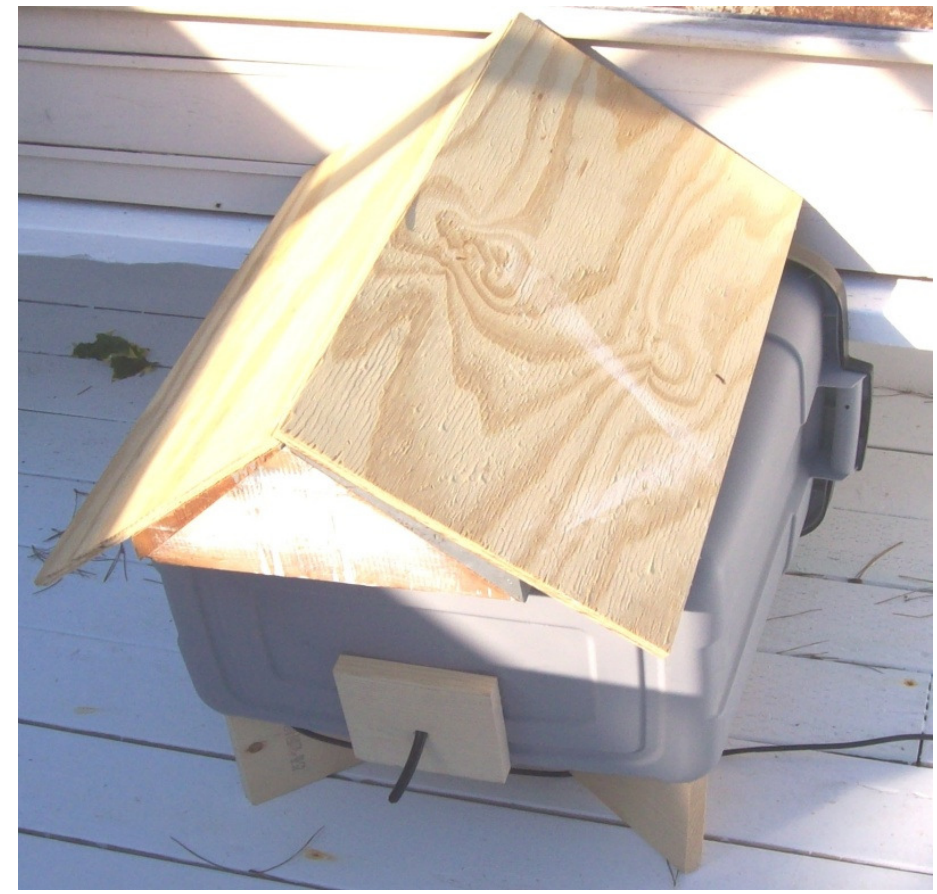

Figure 12: Aethalometer enclosure. 
The five aethalometers were run side-by-side for five days to ensure that they gave comparable $\mathrm{BC}$ readings. Appendix A displays the aethalometer results from a test run February $8^{\text {th }}-9^{\text {th }}$, before and after adjusting the specific attenuation cross section. Specific attenuation is wavelength dependent and must be adjusted based on the wavelength measurement. Determination of BC content of the aerosol deposit for each aethalometer was consistent after adjusting the value of the specific attenuation for the combination of filter and optical components. All of the aethalometers were properly calibrated after adjusting the specific attenuations of aethalometers 1, 2, 3, 4, and 5's standard deviations of $52.8,99.5,134.0,108.3$, and $52.6 \mathrm{~m}^{2} / \mathrm{g}$, respectively.

\subsubsection{PEMs, Personal Environmental Monitors - Optical Analysis II}

Samples were collected on quartz filters (Pallflex Fiberfilm) using flow-controlled sampling pumps (Leland Legacy model, SKC Inc.) and impactors (10 L/min, SKC Inc. Model 200 Personal Environmental Monitors (PEMs)), to select for particles having aerodynamic diameters smaller than $2.5 \mu \mathrm{m}$. The PEMs were designed for sampling at $10 \mathrm{~L} / \mathrm{min}$ to provide a sufficient sample volume over the integrated 12 hour sampling period, providing a total sample volume of approximately $7200 \mathrm{~L}$. The PEMs were outfitted with ring-shaped aluminum masks to both clearly define the area over which particles were collected on the filter $\left(3.14 \mathrm{~cm}^{2}\right)$ and to improve method sensitivity. The measured diameter of the deposit on the filters was $2.0035 \mathrm{~cm}$, slightly larger than the 2 $\mathrm{cm}$ mask, which means the deposit area was $3.25 \mathrm{~cm}^{2}$, slightly larger than the opening of the mask. To load the PEMs, the impact surfaces were first cleaned and greased with mineral oil. After placing screen, a ring, filter, and second ring in the bottom of the PEM, 
the impact surface was placed on the top ring and the inlet was screwed securely on top of the PEM. The stages of PEM loading are shown in Figure 13.

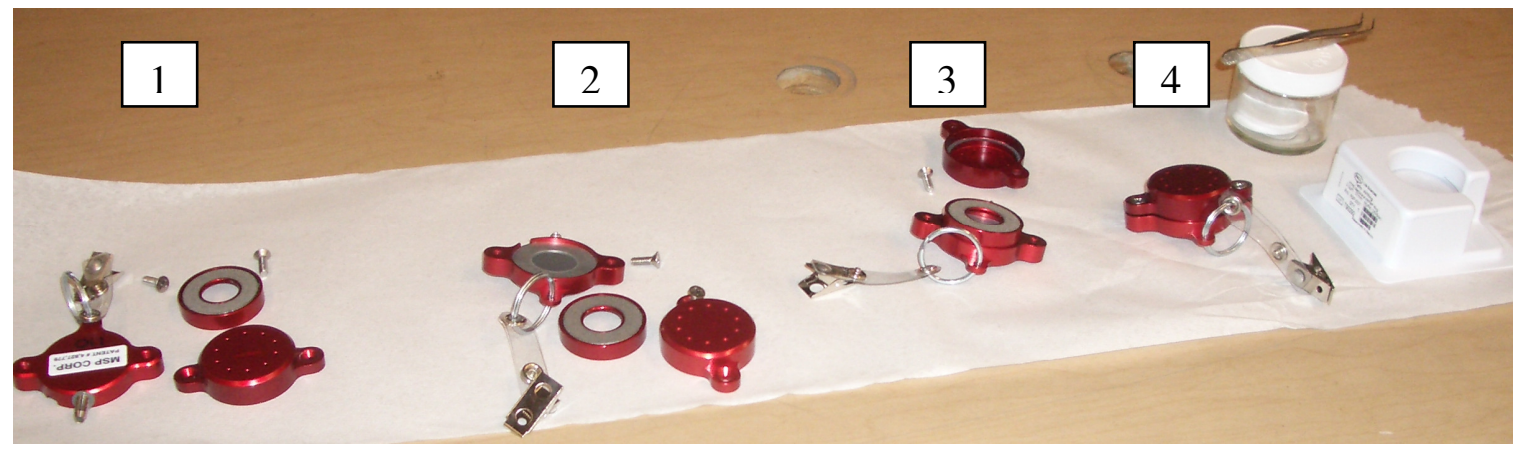

Figure 13: PEM setup from left to right: (1) PEM top, bottom, and impactor; (2) PEM top, impactor, and bottom with ring, screen, and second ring in place; (3) PEM top and impactor placed on the ring covering the screen; (4) final stage of PEM setup with top screwed on tightly to the bottom.

Each of the 16 Leland Legacy pumps was calibrated using a Bios DryCal DC-2 calibrator (Model DC-HC-1). The pumps were programmed to run from 6 p.m. to 6 a.m., and placed in plastic cases with foam to dampen their noise and avoid disturbing Cambria residents (Figure 14).

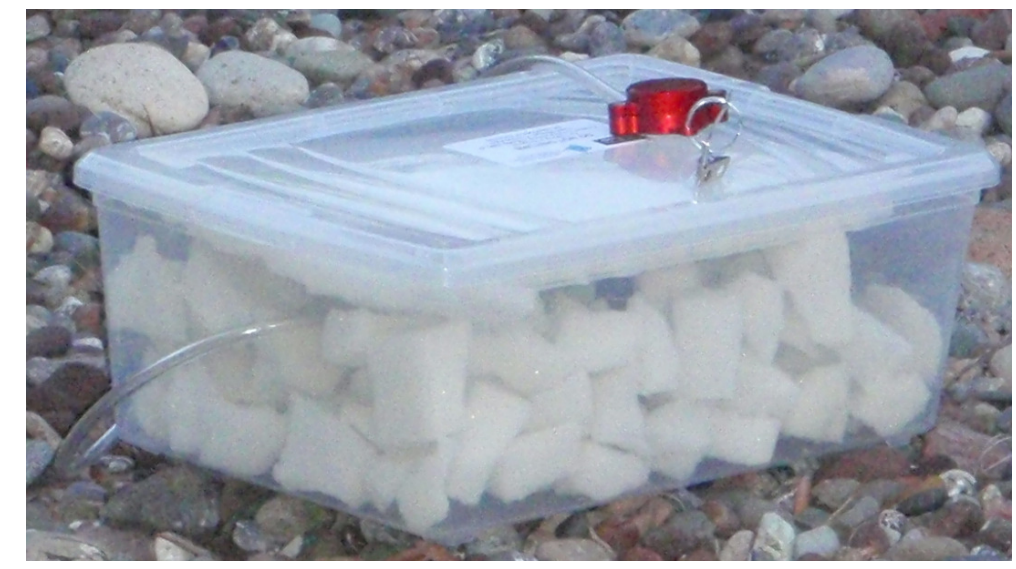

Figure 14: PEM and pump case. 
To ensure that the PEMs and pumps did not alarm Cambria residents, a label was placed on each case (see Figure 15 below) with contact information. The 112 in the upper right hand corners refers to the pump number 112.

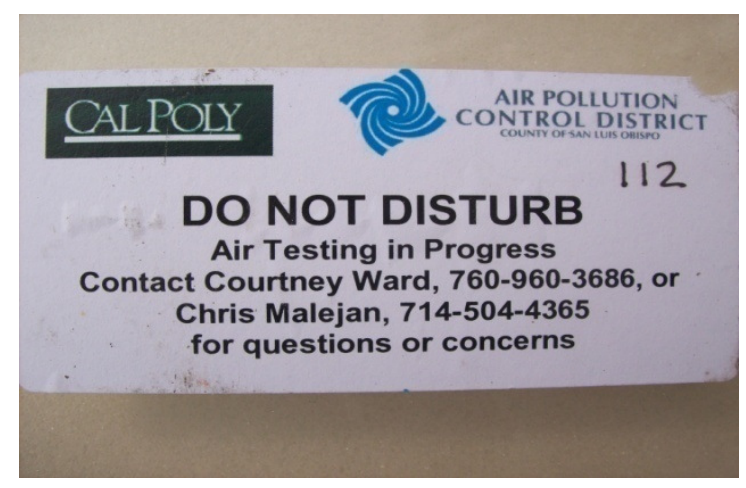

Figure 15: PEM pump case label.

The filters were analyzed for light attenuation using a custom built transmissometer that combines anarray of light emitting diodes (LED) ranging from the near ultraviolet (350 $\mathrm{nm})$ to the near infrared (1000 nm) with an Ocean Optics, model S2000 spectrometer (Lawrence Berkeley National Laboratory; Kirchstetter et al., 2004). The cross-sectional area used to determine the PEM BC concentration at the near infrared (IR) wavelength of $880 \mathrm{~nm}$ (wavelength at which BC is the only significant PM component absorbed) was $16.6 \mathrm{~m}^{2} / \mathrm{g}$ (Kirchstetter et al., 2004). The wavelength versus attenuation graphs in Appendix $\mathrm{N}$ signify the fact that the samples were dominated by wood smoke, given that the spectral attenuation analysis shows strong spectral dependence with little absorbance near IR and much absorbance near ultraviolet (UV).

Field and method blanks were taken throughout the study to ensure filter handling and shipping were not substantially biasing the $\mathrm{PM}_{2.5}$ measurements. Method blanks were 
collected by selecting an unexposed filter at random and submitting the filter for analysis. Field blanks were collected by selecting an unexposed filter at random, then loading into a PEM, transporting to the field with the next runs PEMs and placing it next to an operating PEM during the sampling interval, recovering the field blank filter with the normal PEM filters, and submitting for analysis.

\subsection{FRM Sampler - $\mathbf{P M}_{2.5}$ Mass Analysis I}

The Anderson RAAS2.5-100 single filter $\mathrm{PM}_{2.5}$ FRM sampler (Figure 16) monitors and regulates the flow rate using a dry gas meter, a variable speed pump, and ambient temperature and pressure sensors, all controlled by the sampler's microprocessor and software. The $\mathrm{PM}_{2.5}$ FRM sampler was calibrated using an EPA approved Delta Cal, which provided a direct indication of volumetric flow rate, barometric pressure, ambient temperature and filter temperature in one instrument. The standard requires a fixed flow rate of $16.67 \mathrm{~L} / \mathrm{min}$ using a specified $\mathrm{PM}_{10}$ inlet, tubing (downtube), secondary sizeselective impactor, filter holder, and filter cassette. The sampler draws ambient air through its $\mathrm{PM}_{10}$ inlet, $\mathrm{PM}_{2.5}$ Well Impactor Ninety-Six (WINS), and a $46.2 \mathrm{~mm}$ diameter Teflon sample filter which traps the $\mathrm{PM}_{2.5}$ fraction. The sample filter was conditioned and weighed before and after sampling at Ventura APCD and the resulting difference was the collected $\mathrm{PM}_{2.5}$ mass. Electronic systems in the sampler are designed to monitor and maintain the flow rate as well as record the elapsed sampling time enabling the sampler to calculate the total sample volume. With this information, the average $\mathrm{PM}_{2.5}$ concentration for the 24 hour sampling period was calculated. 


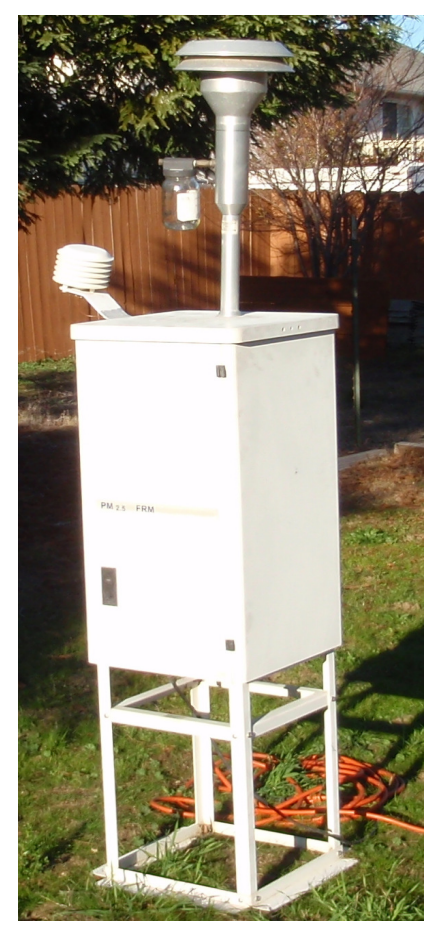

Figure 16: FRM sampler.

\subsection{Mini-Vol Samplers - $\mathbf{P M}_{2.5}$ Mass Analysis II}

A mini-vol is basically a pump controlled by a programmable timer which can be used to make up to six "runs" within 24 hours, or throughout a week. The mini-vols were set to sample the particulate matter at an air flow rate of $6 \mathrm{~L} / \mathrm{min}$. In the PM sampling mode, air is drawn through a particle size separator and then through a $47 \mathrm{~mm}$ diameter Teflon sample filter. Particle separation is achieved by impaction, with a first stage of $\mathrm{PM}_{10}$, and a second stage of $\mathrm{PM}_{2.5}$. The filter mass was calculated at the Ventura APCD using the same set-up as used for the FRM sample. A mini-vol is displayed in the center of Figure 18. While not a reference method sampler, the mini-vol portable sampler gives results that closely approximate data from FRM samplers. The mini-vol samplers used for $\mathrm{PM}_{2.5}$ sampling, while known to be reasonably accurate, do not have federal reference or equivalent method certification, and therefore cannot be used to demonstrate state or 
federal air quality standard compliance or violation. Various studies have indicated that $\mathrm{PM}_{2.5}$ data from mini-vol samplers compare favorably to data from FRM samplers. CARB performed comparisons between $\mathrm{PM}_{2.5}$ mini-vols and $\mathrm{PM}_{2.5} \mathrm{FRM}$ samplers in Bakersfield, California in the winter of 1998 that showed a close agreement between the $\mathrm{PM}_{2.5}$ mini-vol and FRM samplers. Other studies have shown approximately a $10 \%$ difference between $\mathrm{PM}_{2.5}$ mini-vol and FRM sampler data (Kingham et al., 2006).

\subsection{Method Validation}

To verify that the optical (light attenuation) technique is quantitative and appropriate to the conditions of this study, a series of co-located samples were collected that were analyzed for EC, OC, and levoglucosan. Method comparisons are helpful in validating data and providing a greater understanding of the level of confidence and applicability of the data. In this study, intercomparisons of the aethalometers, PEMs, and mini-vols were performed on March $7^{\text {th }}$ and $13^{\text {th }}$ at three locations within the $1 \mathrm{~km}^{2}$ study area and one location at the Cambria Fire Department, 1.75 miles southeast of the study area (Figure 17). All four method validation sites consisted of four PEMs, one aethalometer, and one mini-vol (Figures 18-21). These experiments were conducted to determine the quantitative relationship between light attenuation at 370 and $880 \mathrm{~nm}$ and measured levels of EC/OC and levoglucosan. The ratio of attenuations were compared to the measured average for all of the sampling platforms. The March $7^{\text {th }}$ and $13^{\text {th }}$ method comparison EC/OC results from Sunset Laboratory are displayed in Appendix D. 


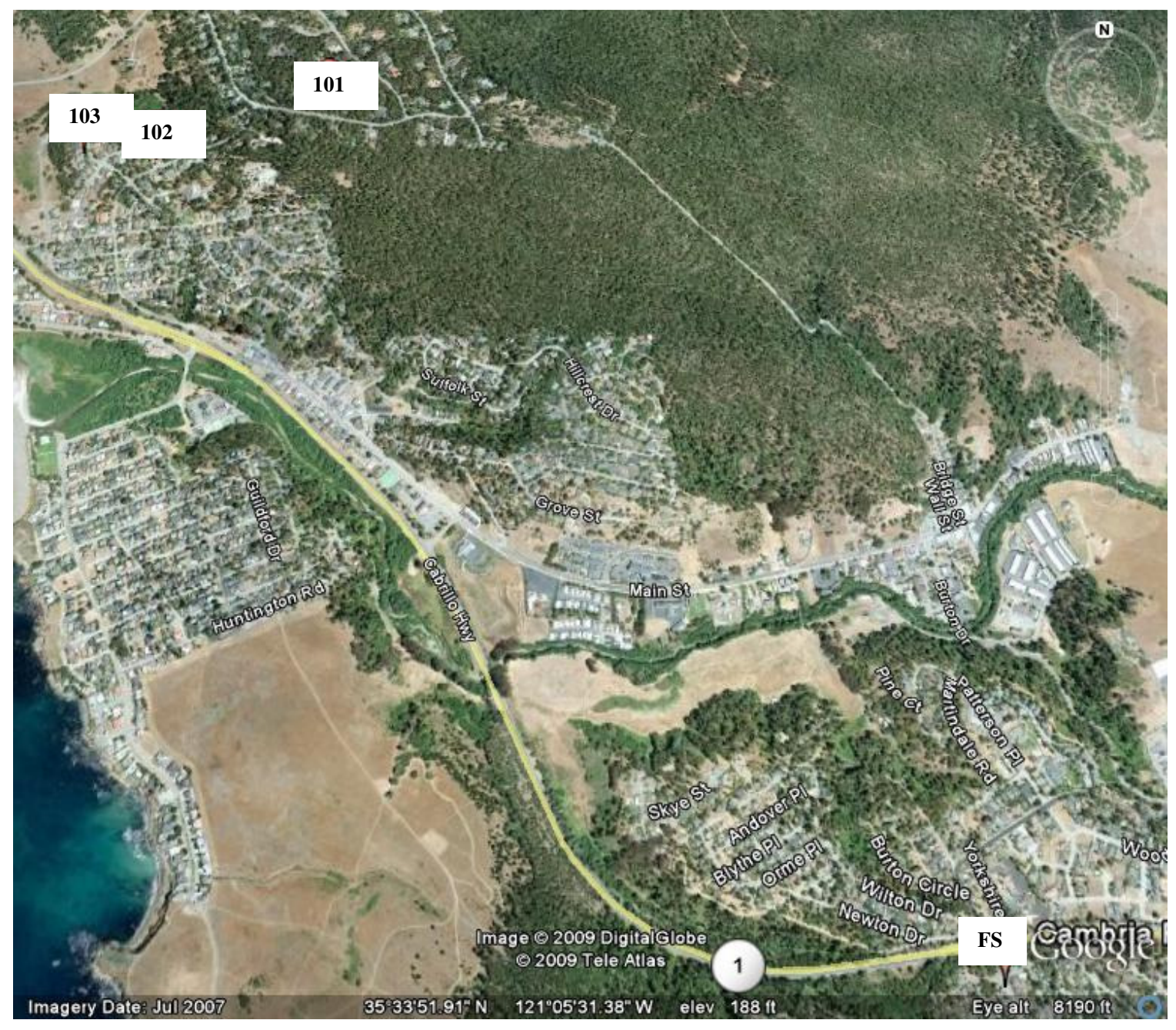

Figure 17: The four method validation sites. 


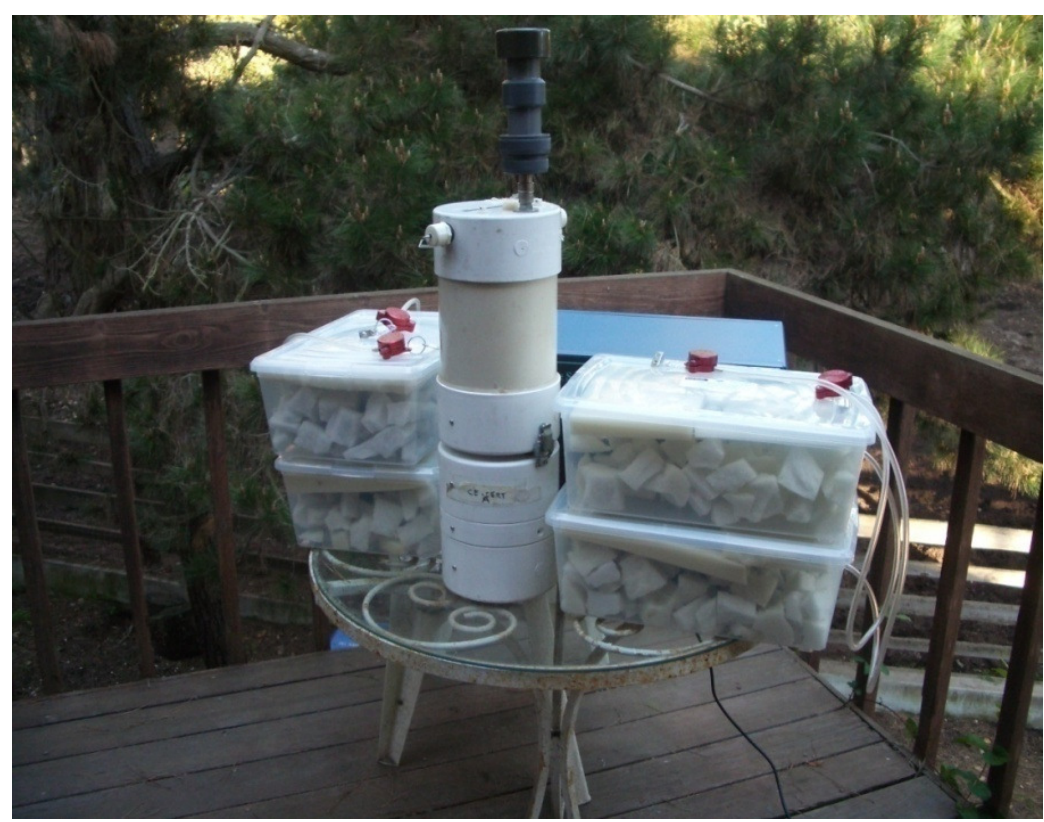

Figure 18: Location 101 method validation set up consisting of 4 PEMs and their insulated pumps (left and right), 1 aethalometer (rear center), and 1 mini-vol (center).

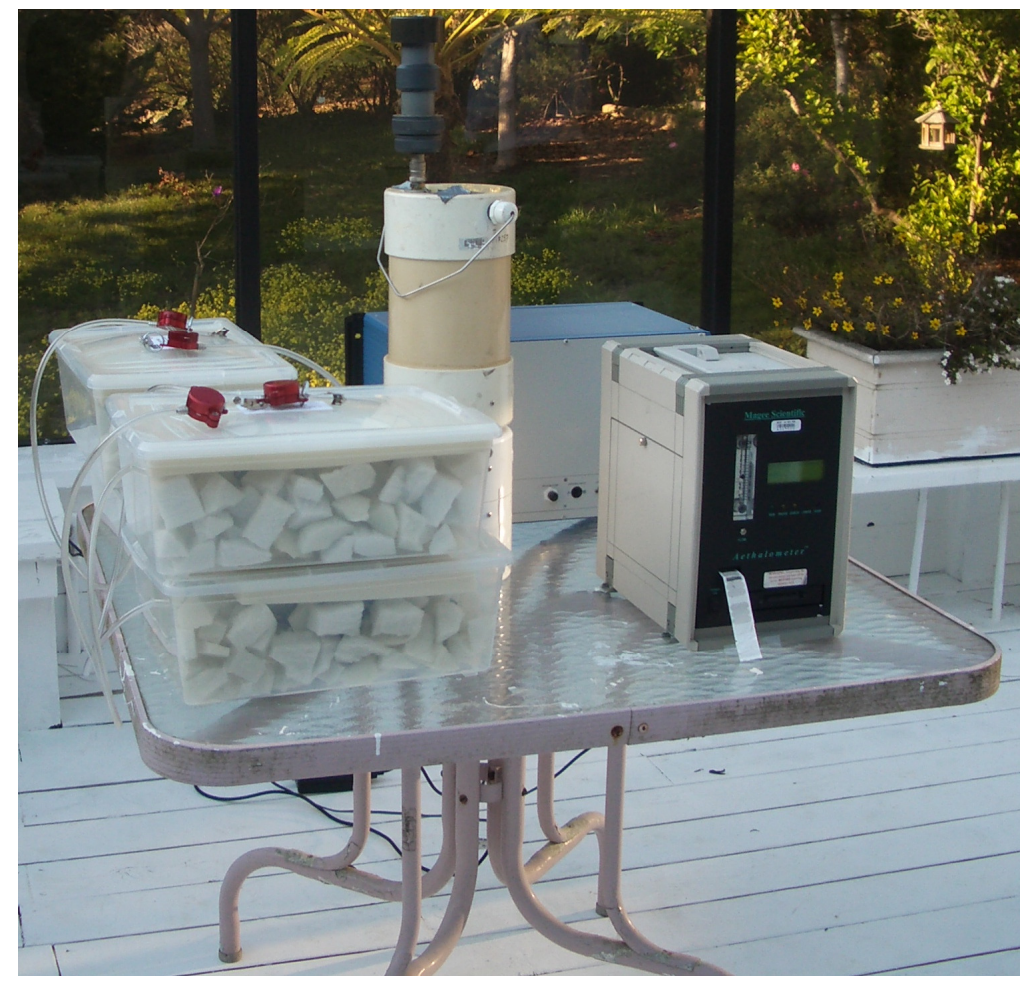

Figure 19: Location 102 method validation set up consisting of 4 PEMs and their insulated pumps, 2 aethalometers, and 1 mini-vol. 


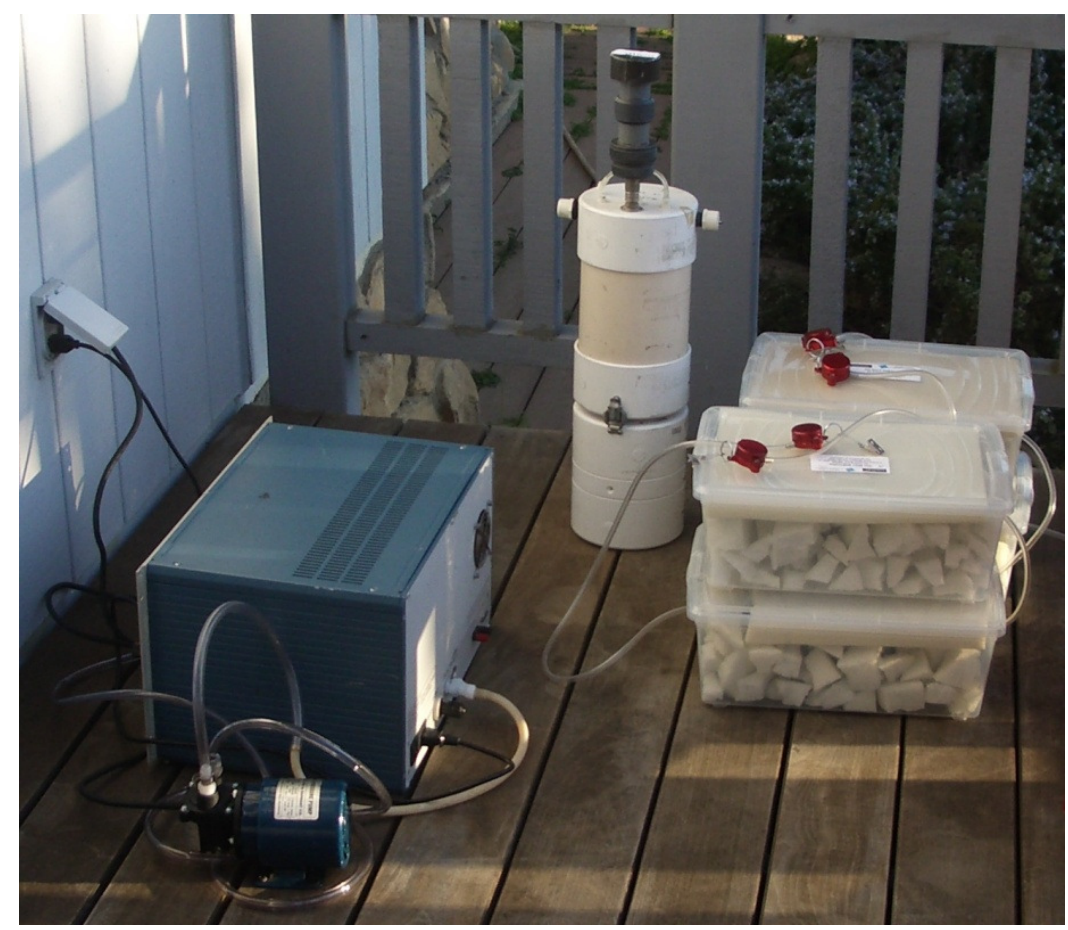

Figure 20: Location 103 method validation set up consisting of 4 PEMs and their insulated pumps, 2 aethalometers, and 1 mini-vol.

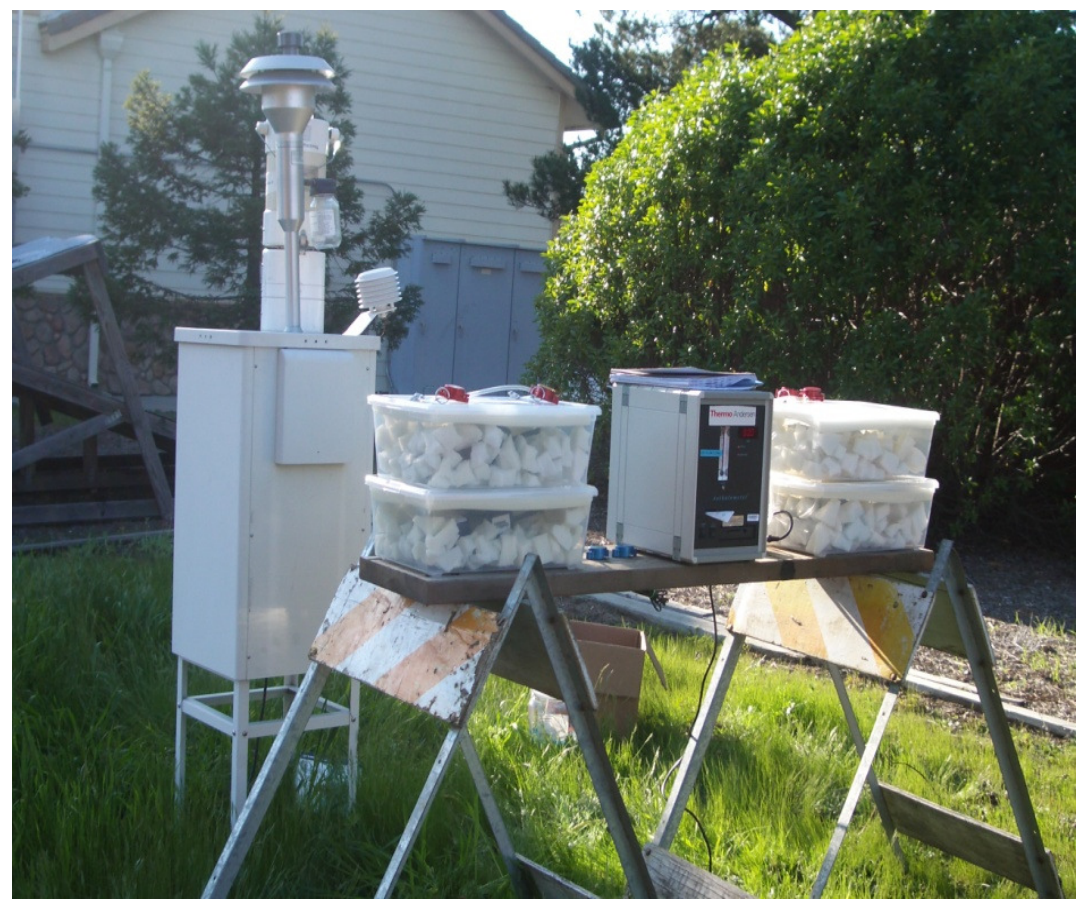

Figure 20: Cambria Fire Department method validation set up consisting of 4 PEMs and their insulated pumps, 1 aethalometers, 1 mini-vol, and the FRM sampler. 
Each of the site's four PEMs consisted of one quartz filter to be sent to LBNL for the usual spectral analysis, one quartz filter for levoglucosan analysis, one quartz filter for EC/OC, and one quartz filter placed beneath a Teflon-coated glass fiber filter (Pallflex Fiberfilm) to give gaseous OC artifact. The quartz filter alone gives the EC/OC particle phase measurement. The quartz filter placed beneath the Teflon filter gives the positive artifact from the organic gases that are absorbed on the quartz filter and are incorrectly interpreted as particulate OC. By subtracting the 'Teflon/quartz' OC from the 'plain quartz' OC, a more accurate representation of the particulate OC is detected. Samples were sent to Sunset Laboratory for EC/OC determination. Levoglucosan samples were collected for chemical speciation since it is considered an organic marker which is very specific to wood smoke. Levoglucosan analysis was performed by the Wisconsin State Laboratory of Hygiene. Results of these experiments informed the development of a specific sample and data analysis plan. The ratio of attenuation in the near-UV (e.g. at $370 \mathrm{~nm})$ to attenuation in the near-IR (e.g. $880 \mathrm{~nm})$ is expected to be directly related to the level of levoglucosan (a specific marker for wood smoke) in the collected PM samples (Poore, 2002). Validating this alternative method of quantifying wood smoke concentrations would prove that the impractical levoglucosan analysis is unnecessary. Additionally, proving that the absorbed OC light attenuation method gives similar results as levoglucosan analysis would confirm that light attenuation could be used to track emissions on a global basis. The results for light attenuation at 370 and $880 \mathrm{~nm}, \mathrm{EC} / \mathrm{OC}$, levoglucosan, and $\mathrm{PM}_{2.5}$ were compared in a further study which is not discussed here. 


\subsection{Locating Wood Smoke Combustion Sources}

The evening of each IOP, a Fluke TI25 infrared camera was used to identify homes

within the study area which were actively burning, to display the chimney temperature. The infrared camera has a temperature range of $14^{\circ}$ to $482^{\circ} \mathrm{F}$, with an accuracy of $\pm 2 \%$ or $\pm 35.6^{\circ} \mathrm{F}$. Thermal images were recorded for each active site and the location of the image was recorded on a study area map. The number of homes found burning on each of the eight IOPS (ranging from 5 to 20 homes) and the distance from the monitors were used in the $\mathrm{PM}_{2.5}$ regression and correlation analysis. Figure 22 below is an example of thermal images used to identify homes burning wood.

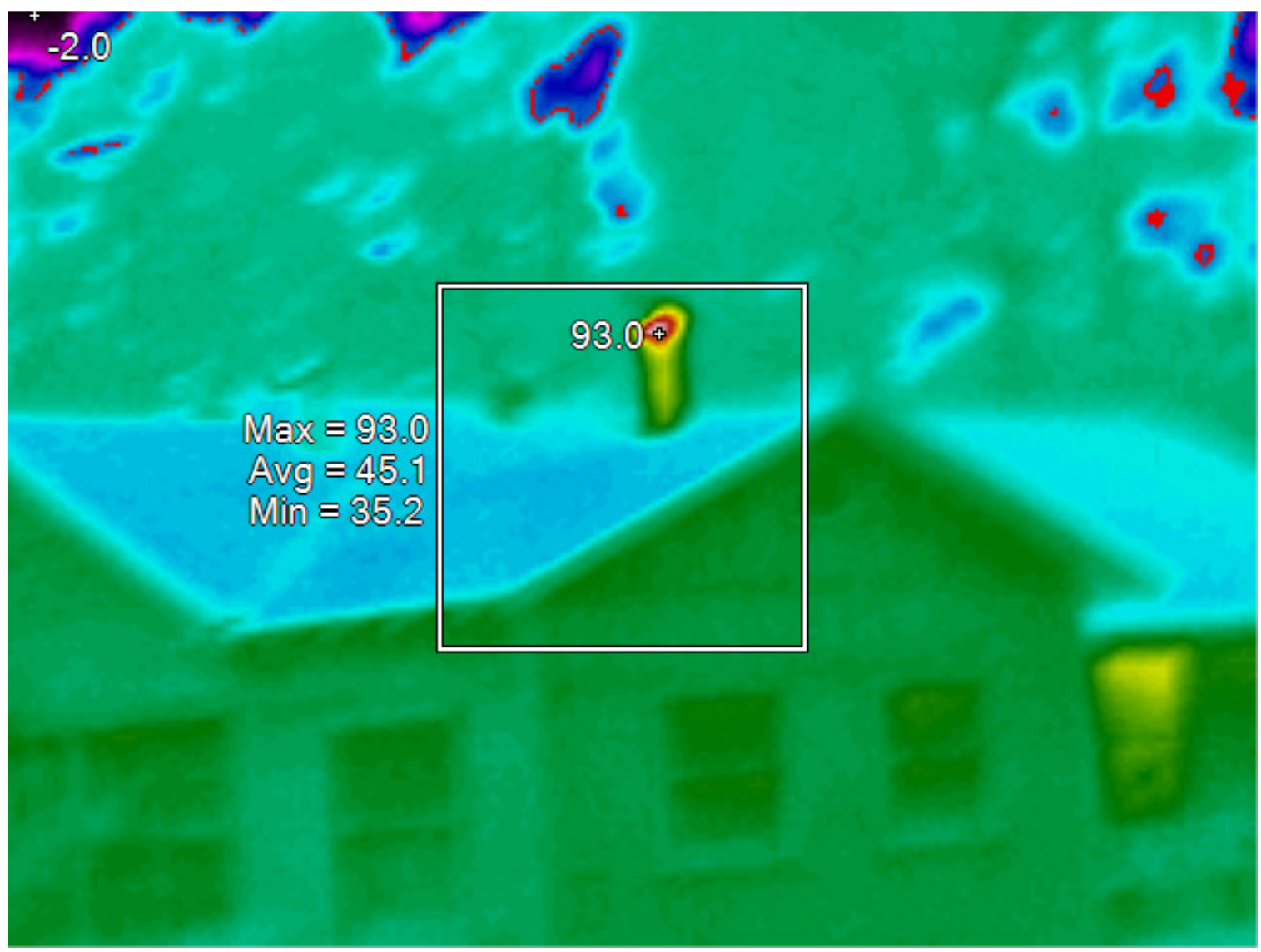

Figure 21: Thermal image of home burning during March $15^{\text {th }}$ IOP at 8 p.m. 


\section{CHAPTER 5: STATISTICAL DATA ANALYSIS}

This section identifies the statistics used to assess the wood smoke variability and the meteorological parameters that correlate to $\mathrm{PM}_{2.5}$ in Cambria. To assess the variability between each 30 minute average aethalometer BC concentration on all IOPs, a General Linear Model (GLM) to perform Repeated Measures Analysis of Variation (ANOVA) was run in MINITAB. The twelve hour BC concentration variability between each PEM was evaluated using a simple comparison analysis. To assess the meteorological factors and burning habits (information attained from Cambria Weather Underground and IOPs) correlated to BC, the data collected from 6 to 9 p.m. was analyzed by MINITAB using linear multiple regression.

\subsection{Analysis of Variation (ANOVA)}

A General Linear Model (GLM) to perform Repeated Measures ANOVA was run in MINITAB using the $\mathrm{BC}$ concentration versus aethalometer location, date, and time (30 minute intervals from the weather station). The 30 minute time periods were treated as independent observations. Repeated Measures ANOVA carries the standard set of assumptions associated with an ordinary analysis of variance, extended to the matrix case: multivariate normality, homogeneity of covariance matrices, and independence. Violations of independence produce a non-normal distribution of the residuals, which results in invalid $\mathrm{F}$ ratios. As with any ANOVA, Repeated Measures ANOVA tests the equality of means. However, Repeated Measures ANOVA is used when all members of a random sample are measured under a number of different conditions. As the sample is exposed to each condition in turn, the measurement of the dependent variable is repeated. 
Using a standard ANOVA in this case is not appropriate because it fails to model the correlation between the Repeated Measures (Berry, 1987).

Multivariate analysis requires that the assumptions be tested twice: first, for the separate variables, and second, for the multivariate model variate, which acts collectively for the variables in the analysis and thus must meet the same assumptions as individual variables. If the data fail to meet the assumptions required by the analysis, transformations can be applied to variable to correct the problem. Transformations (a single function applied to each data value) are applied to correct problems of nonnormality or unequal variance. For example, taking logarithms of sample values can reduce skewness to the right. Transforming all the samples to remedy nonnormality often results in correcting unequal variances, and in eliminating interactions (e.g., creating a simple additive model for blocks and treatments); however, a transformation that corrects nonnormality may create interactions where none existed before. The same transformation should be applied to all samples (Berry, 1987). Transforming variables is a trial and error process. It is not usually possible to be certain in advance that the transformation will correct the problem; sometimes it only reduces the degree of the violation. Even when the transformation might decrease the violation of the assumption, it may not be implemented in the analysis because of the increased complexity it adds to the interpretation and discussion of the results.

The GLMs ran to detect variability in this study often violated the normality assumption. Departures from normality can suggest the presence of outliers in the data, or of a non- 
normal distribution in one or more of the samples. The histogram conveys the relative frequency of different ranges of values for the variable. The normality test will give an indication of whether the populations from which the samples were drawn appear to be normally distributed, but will not indicate the cause(s) of the nonnormality. The smaller the sample size, the less likely the normality test will be able to detect a normality violation.

\subsection{Parameters Used in Correlation Analyses}

Parameters that quantify wind speed (mph), wind speed gust (mph), wind direction (degrees), temperature $\left({ }^{\circ} \mathrm{F}\right)$, dew point $\left({ }^{\circ} \mathrm{F}\right)$, barometric pressure (in. $\mathrm{Hg}$ ), humidity $(\%)$, surface inversion conditions, and the number and location of homes burning were used in the correlation analysis for this project. The ten minute averaged meteorological data was collected from the Cambria Weather Underground site in Marine Terrace (Weather, 2009). Marine Terrace is located 1.89 miles south of the study area (Figure 1). These meteorological parameters generally quantify dispersion. Theoretically, inversion strength and wind speed are good indicators of dispersion (Shipp, 1995). Vertical dispersion is limited by inversions; therefore, good quantitative indicators of vertical dispersion are inversion base, top, and strength. Surface temperatures were paired with wood smoke concentrations and run in regression models because it was expected that residential heating using wood combustion is greater on colder nights. Wind speed is a measure of horizontal dispersion. Theoretically, lower wind speeds are indicative of poor dispersion and higher pollution potential. Wind speed and wind direction were important parameters used in the regression and correlation analysis since they have a strong influence on the $\mathrm{PM}_{2.5}$ concentrations. The evening time frame $(6-11$ p.m. $)$ is the period 
that the wind rose images in Appendix B represent because it is at this time when the majority of wood burning takes place. Horizontal dispersion is limited when wind speeds are light; therefore, wind speed is a good indicator of $\mathrm{PM}_{2.5}$ pollution potential. High winds generally indicate good dispersion conditions.

Knowledge of inversion patterns on each IOP is essential since atmospheric mixing can be suppressed by low inversions and stagnant conditions. Persistent and strong temperature inversions in Cambria were frequently caused by oceanic upwelling along the California coast. These inversions resulted in a weak vertical mixing of the air mass and a weak air mass transport from other locations. Daily inversions were recorded using the "NPS Coastal Wind Profiler Page" (Naval, 2008). Each IOP inversion is displayed in Appendix C. This website displays daily (Greenwich Mean Time) data in Point Piedras Blancas, California from 0 to 1500 meters consisting of wind direction, speed (knots), and temperature. Although these data are for Point Piedras Blancas, it can be used to understand Cambria's inversions since it is located just 12 miles up the coast from Cambria. Inversion conditions for each IOP were classified as either no inversion, inversion below 500 feet (surface inversion), inversion between 501 and 1000 feet, or inversion anywhere above 1000 feet.

\subsection{Regression Correlation Analyses}

Regression was used to find a linear relationship between wood smoke concentrations and meteorological parameters and develop equations that can be used to forecast $\mathrm{PM}_{2.5}$ levels in Cambria. A multiple regression model shows all the possible predictor variables and the response variable. Forecasting is performed by first predicting the 
meteorological parameter that is related to $\mathrm{PM}_{2.5}$ concentration, then plugging this parameter into the regression equation. The product of the equation is a $\mathrm{PM}_{2.5}$ concentration. This $\mathrm{PM}_{2.5}$ concentration can be used as a tool to predict concentrations taking into account the uncertainty of the regression equation and the forecasting of the meteorological parameters. Since this was an observational study, all of the relationships described are only associations - not cause-and-effect conclusions.

Regression analyses were performed to quantify the correlation between $\mathrm{PM}_{2.5}$ and meteorological factors. To perform regression analyses, meteorological data was reformatted in spreadsheets and read by the MINITAB statistical program in order to predict $\mathrm{PM}_{2.5}$. Single regression correlation matrices were produced to analyze the relationships of all the parameters. Single and multiple linear regression models were run on the data. Non-linear regression models were not used due to the complex nature of the relationship between wood smoke concentrations and meteorology. It is not general practice to force-fit data using non-linear models without first finding a theoretical basis for the regression equations (Shipp, 1995).

Determining the variability and scale of the near-source contribution to overall average wood smoke concentrations to which people are exposed does not require the ability to precisely model the concentration at specific locations given a large amount of data. It essentially requires the opposite, the ability to infer general trends given sparse data. A variety of methods were used to obtain information that will be generally applicable and usable on the large scale. These methods included multi-variable regression, spatial source receptor analysis, and spatiotemporal analysis between aethalometer sites. 


\section{CHAPTER 6: RESULTS AND DISCUSSION}

This section includes analyses of three main results collected in this study. First, the

GLM results from the aethalometer IOP BC concentrations are analyzed. This was done by taking aethalometer measurements at three different locations. Second, the results from $\mathrm{BC}$ and meteorological predictors and burning habits correlation analysis are discussed. Finally, the PEM BC concentrations measured on each IOP are analyzed to assess the variability between each of the eight to twelve locations.

\subsection{Aethalometer BC Variability Analysis}

In order to gain a general overview of the wood smoke variability between three different locations, measurements were taken simultaneously at three different locations and compared. A combination of two out of the three aethalometer sites were compared in six of the IOPs and all three aethalometer sites were compared on March $7^{\text {th }}\left(5^{\text {th }} \mathrm{IOP}\right)$. The $\mathrm{BC}$ mean for each location from 6 to 9 p.m. is displayed in Figure 22 below. Many Cambria residents burn during this time period, which is why this was when locations had the most significant differences in BC concentration. The three aethalometer locations were identified by 101, 102, and 103 (shown in Figures 2-10). 


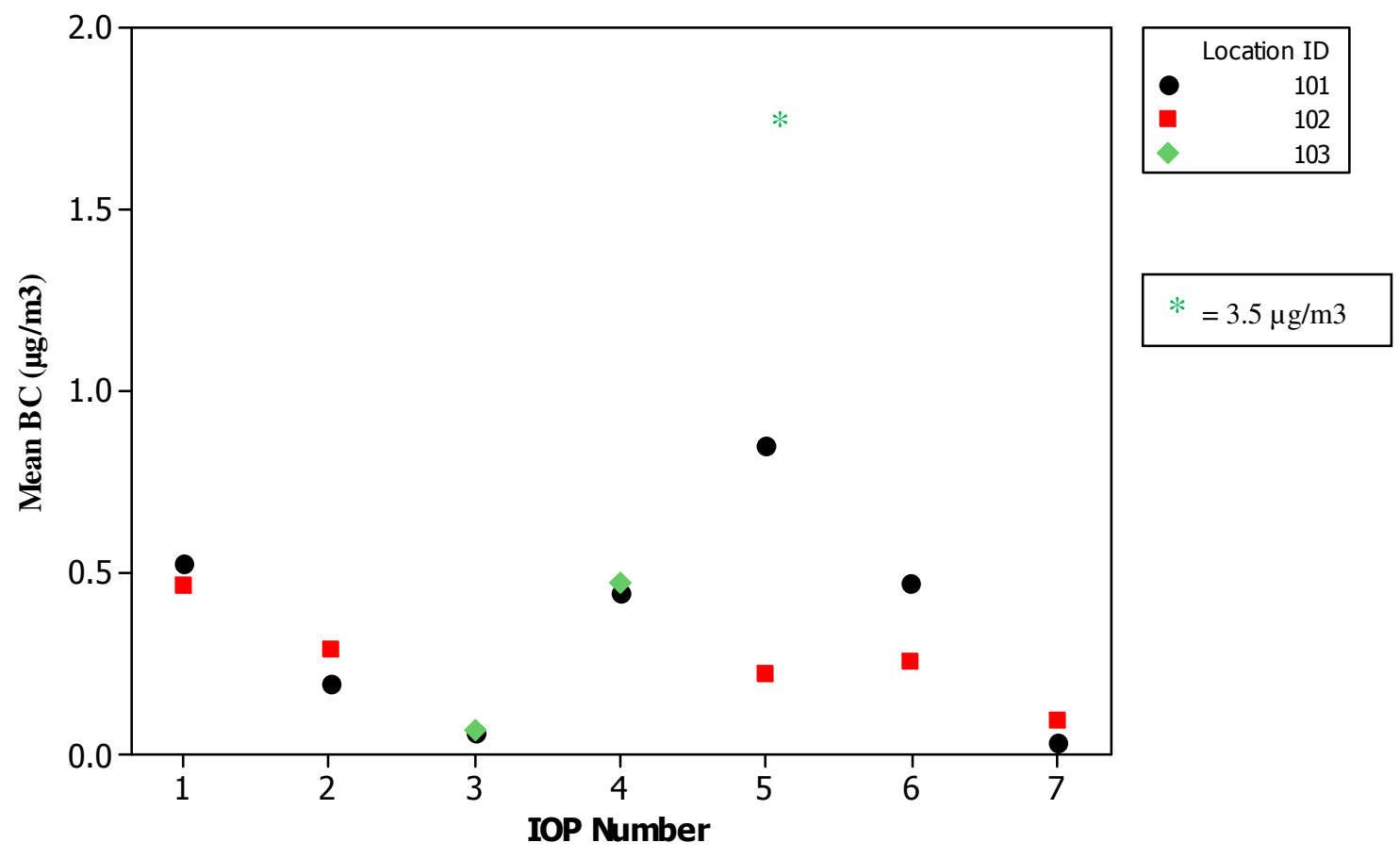

Figure 22: BC mean readings for each evening (6 to 9 p.m.) at each location.

A GLM to perform Repeated Measures ANOVA was run in MINITAB on each IOP individually and for the IOPs combined. The February $26^{\text {th }}$ IOP $\left(3^{\text {rd }}\right.$ IOP) was not analyzed in a separate GLM because there were only 5 observations (due to aethalometer malfunctions). Instead, the 5 observations for this IOP were analyzed in the combined analysis of BC variability. Likewise, the March $15^{\text {th }}$ IOP $\left(7^{\text {th }}\right.$ IOP $)$ was not ananlyxed because there was only one aethalometer location. It is discussed in the PEM variability section, where BC concentrations measured at twelve PEM locations are compared. The purpose of the ANOVA was to see if there was significant BC variability between the two to three location sites in the $1 \mathrm{~km}^{2}$ study area and quantify the $\mathrm{BC}$ variability between each location. The results below vary due to different locations and numbers of homes 
burning with respect to the aethalometers, inversion conditions, wind speed, and wind direction.

\section{1 .1. Assessment of BC Variability: January 31, 2009 (IOP 1)}

The aethalometer BC variability is represented in Figure 24, which exhibit considerable differences in evening BC. The R-square $\left(\mathrm{R}^{2}\right)$ of 0.22 shows that there is no correlation between the readings at the two locations. This result is in agreement with the ANOVA p-value. The near surface inversion may have resulted in the high BC concentrations, ranging from 0.02 to $0.91 \mu \mathrm{g} / \mathrm{m} 3$. The mean difference between the aethalometers was $0.07 \mu \mathrm{g} / \mathrm{m}^{3}$ (37\%), with a tendency for lower readings at location 102 . From 6 to 7 p.m., location 101 was $43 \%$ higher than location 102 and from 7 to 8:30, location 102 was $46 \%$ higher than location 101 (Figure 23). A GLM to perform Repeated Measures ANOVA was run in MINITAB using the BC concentration data collected in the January $31^{\text {st }}$ IOP vs. aethalometer location, date, and time (Appendix E). These 30 minute measurements yielded no extreme outliers, high leverage, or high influence observations. The residual

plots were analyzed for violations of the ANOVA assumptions. The residual plots shown in Appendix E did not display violations of any of the four ANOVA assumptions. The pvalue for aethalometer location was 0.053 , which is just higher than the chosen significance level of 0.05 , signifying that there is weak evidence of a difference between the two aethalometers. This result is consistent with the fact that the wind direction was easterly and the homes burning were located south of each of the aethalometers. Therefore, the two aethalometers were measuring background air samples. 


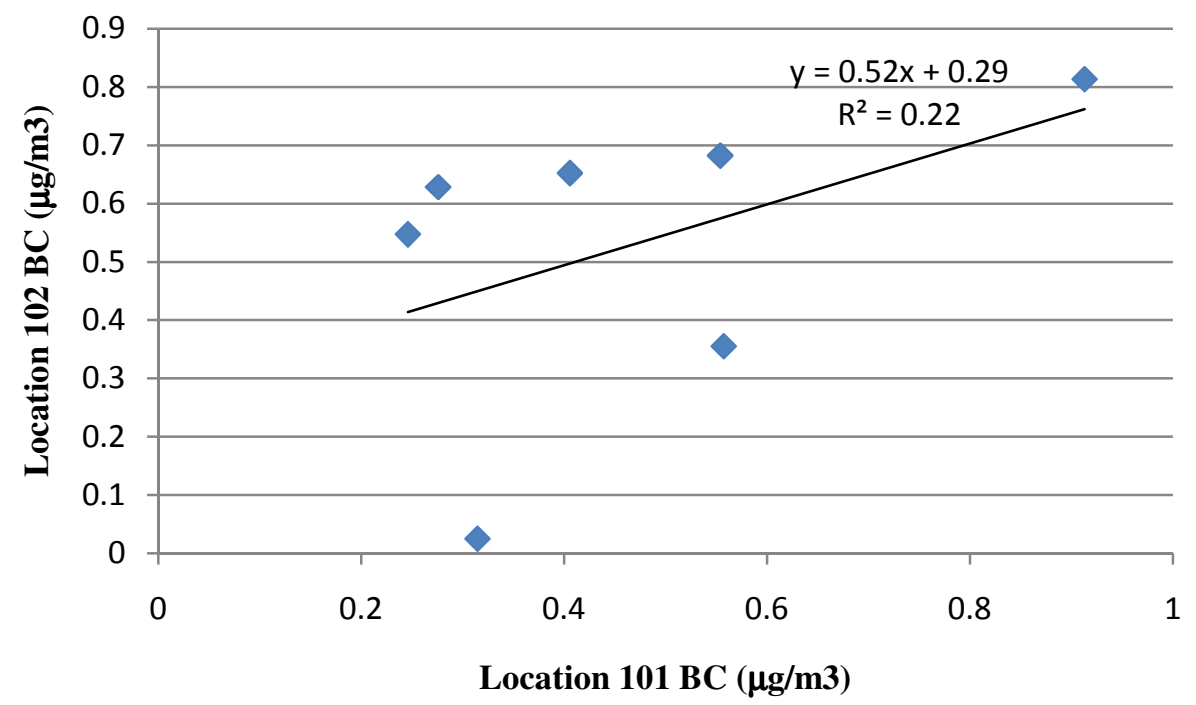

Figure 23: January 31, 2009, 6 - 9 p.m. (IOP 1): Location 101 BC vs. location 102 BC.

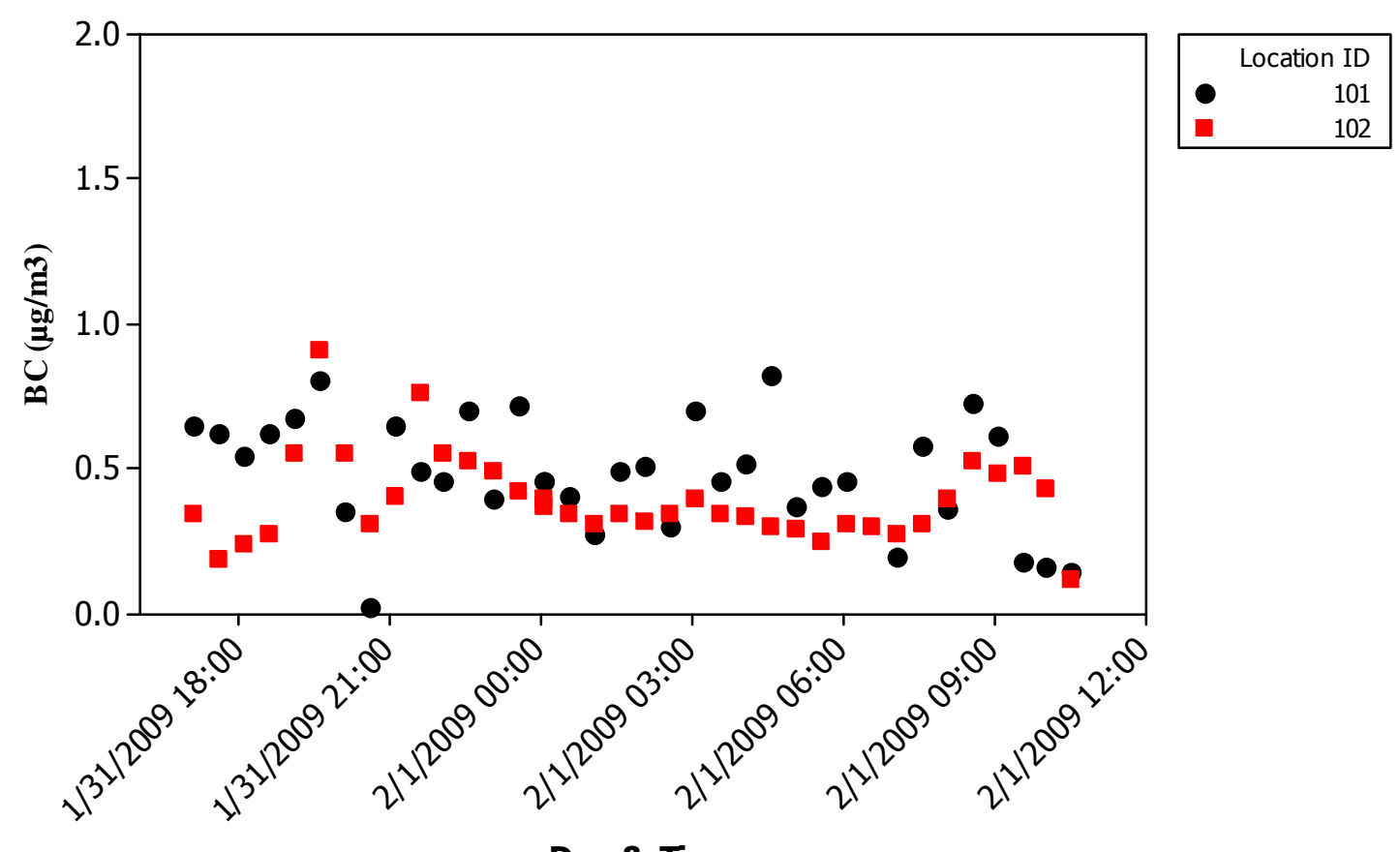

Day \& Time

Figure 24: January 31- February 1, 2009 (IOP 1): Location 101 and $102 \mathrm{BC}\left(\mu \mathrm{g} / \mathrm{m}^{3}\right)$ vs. Day and time (30 min.). 


\section{1 .2. Assessment of BC Variability: February 18, 2009 (IOP 2)}

The $\mathrm{BC}$ variability is represented in Figure 26 below, which shows substantial differences in the $\mathrm{BC}$ measurements of the two aethalometers in the evening when residents are burning and $\mathrm{BC}$ agreement from $10 \mathrm{p} . \mathrm{m}$. to $7 \mathrm{a} . \mathrm{m}$. because of the relatively smoke-free air. The variability between aethalometers was greater than before because there were northwesterly (6-8 p.m.) and northeasterly winds (8-9 p.m.) combined with homes burning wood located west of location 101 and north and south of location 102. Therefore, different sources had different effects on the two aethalometer BC readings. Cambria residents also burn when they awake in the morning, which is why the $\mathrm{BC}$ agreement between locations ends at 7 a.m. On average, the locations' $\mathrm{BC}$ concentrations varied by 26\%. From 6 to 9 p.m. location 102 was $29 \%$ higher than 101 (Figure 25).

A GLM run with BC concentration vs. aethalometer location and time on the February $18^{\text {th }}$ IOP from 6:04 p.m. to 11:34 a.m. yielded 1 extreme outlier at 9:34 a.m. on February $19^{\text {th }}$. This corresponded to a BC level of $0.01 \mu \mathrm{g} / \mathrm{m}^{3}$ at location 101 and $0.57 \mu \mathrm{g} / \mathrm{m}^{3}$ at location 102. This high BC concentration at location 102 had a strong influence on the model but was not thrown out because it was not an inaccurate measurement and was most likely due to a morning wood burner near the aethalometer. To check for violations of normality, constant variance, and independence (ANOVA assumptions), the residual plots were analyzed. The residual plots shown in Appendix F displayed a violation of normality since the points curve off of the line, defying a linear pattern in the normal probability plot. This was caused by the presence of "outliers" in the data, caused by 
spikes in BC concentration. These apparent outliers were not removed from the ANOVA model because they were genuine $\mathrm{BC}$ readings that represent the increase/decrease in wood smoke levels depending on surrounding Cambria residents burning habits. The MINITAB detection of "outliers" or "unusual observations" was used to assess the variability between wood smoke concentrations ate each location in the $1 \mathrm{~km}^{2}$ study area. In order to obey the ANOVA assumptions, a log transformation was applied to the BC concentration. The new p-value of 0.003 signified a strong evidence of a difference between $\mathrm{BC}$ concentrations at the two locations.

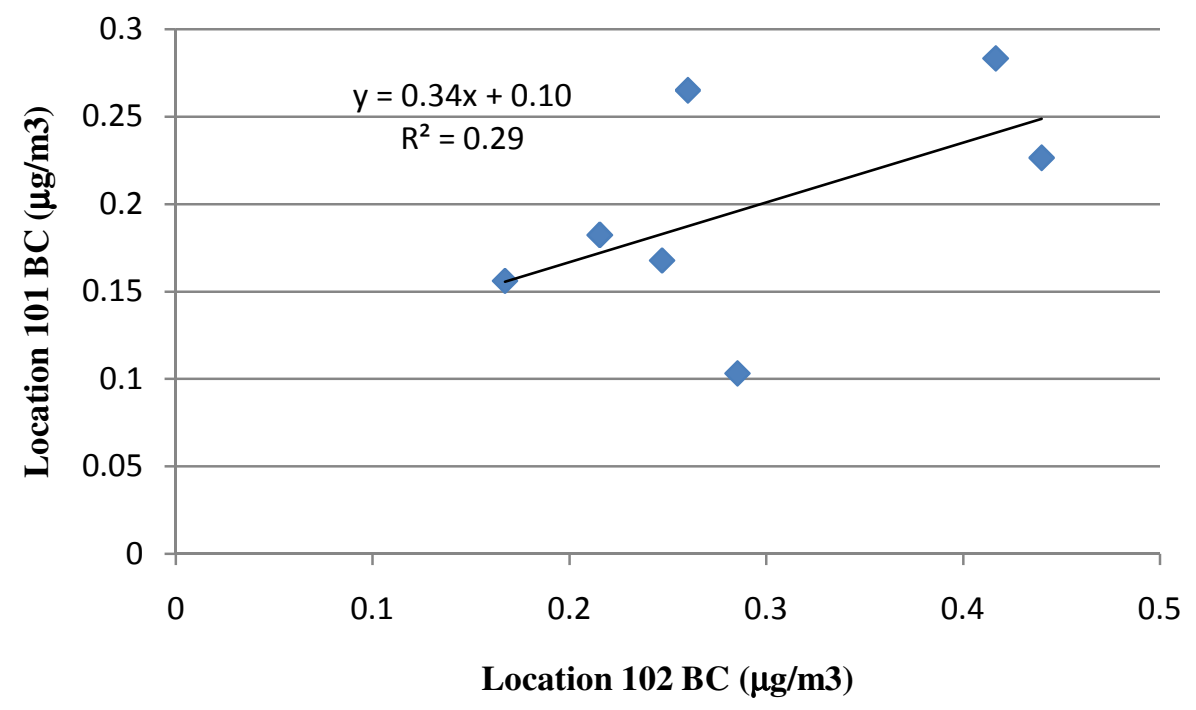

Figure 25: February 18, 2009, 6 - 9 p.m. (IOP 2): Location 102 BC vs. location 101 BC. 


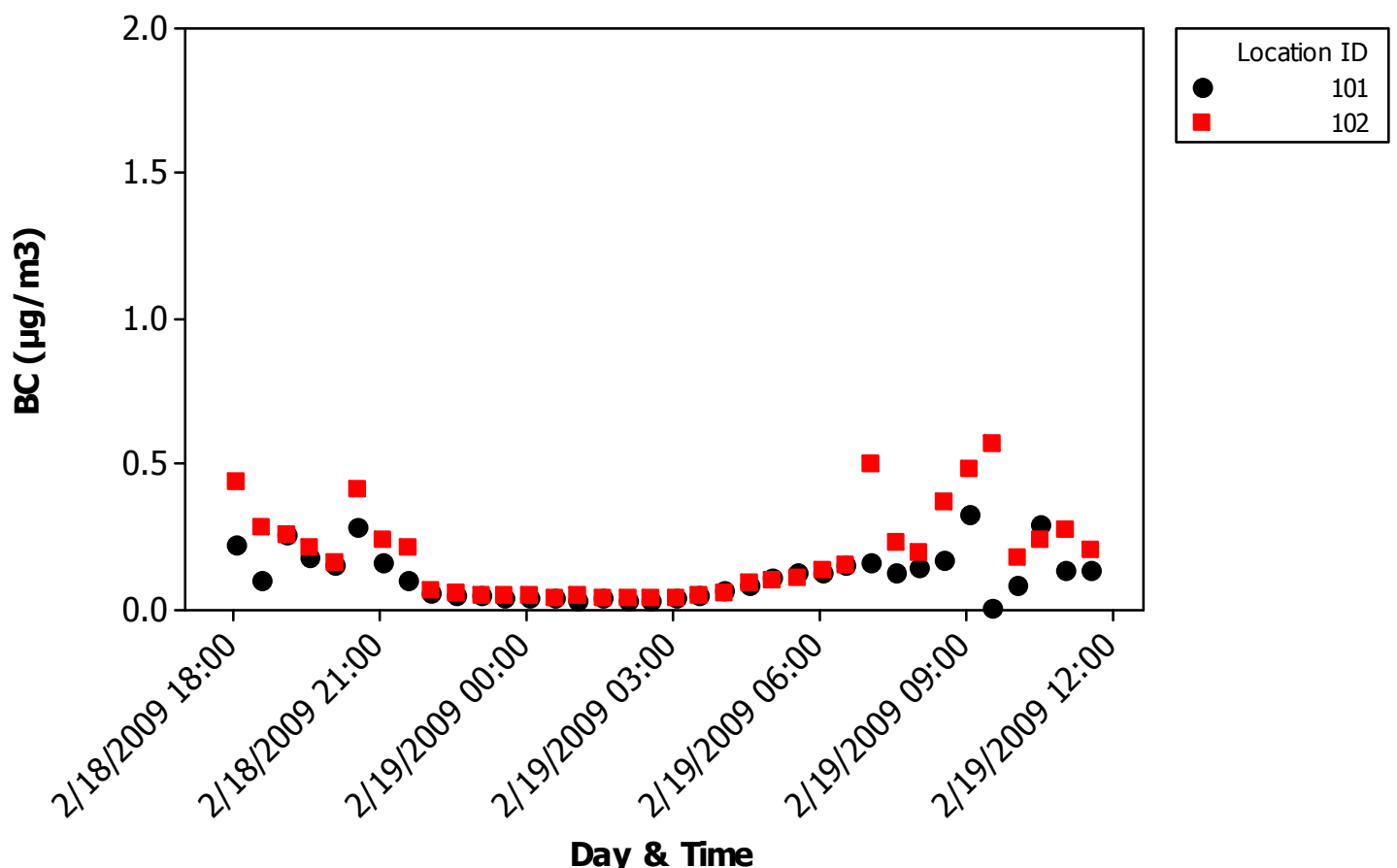

Figure 26: February 18-19, 2009 (IOP 2): Location 101 and $102 \mathrm{BC}\left(\mu \mathrm{g} / \mathrm{m}^{3}\right)$ vs. day and time (30 min.).

\subsubsection{Assessment of BC Variability: February 27, 2009 (IOP 4)}

The variation in wood smoke concentration between the two monitoring sites was apparent from the February $27^{\text {th }}$ IOP data analysis. Figure 27 depicts this substantial evening $\mathrm{BC}$ variability between the 2 aethalometers. The aethalometers were accurately reading the varying $\mathrm{BC}$ concentrations being blown in as wind direction and the number of homes burning wood changed with time. The low $\mathrm{R}^{2}$ means that there was no correlation between the aethalometer $\mathrm{BC}$ readings at the two locations, which agrees with the ANOVA result. The graph shown in Figure 28 displays the significant evening wood smoke concentration variability. Given that the ANOVA assumptions were satisfied, no transformations needed to be applied. The GLM detected two extreme outliers, 
observations 3 and 54 (Appendix G). Observation 3 corresponded to a BC level of 0.05 $\mu \mathrm{g} / \mathrm{m}^{3}$ at $10: 34$ a.m. on February $27^{\text {th }}$ at location 103 . Observation 54 corresponded to a BC level of $-1.23 \mu \mathrm{g} / \mathrm{m}^{3}$ at $10: 34$ a.m. on February $27^{\text {th }}$ at location 101 . This negative value was due to the attenuation increase being smaller than the fluctuations, due to low BC levels. The average difference between the locations was $63 \%$. From 6 to 7 p.m., location 101 was $60 \%$ higher than location 10 and from 7 to 8 p.m., location 103 was $57 \%$ higher than location 101. The GLM ran on the BC concentration versus location and time resulted in an $\mathrm{R}^{2}$ (adj) of $30.60 \%$. The location ID p-value was 0.004 , clearly less than the 0.05 significance level, suggesting that location has a considerable impact on the $\mathrm{BC}$ concentration. This inference of large $\mathrm{BC}$ variability between the two locations is to be expected due to the southwesterly (6-7:30 p.m.) and southeasterly $(7: 30$ - 9 p.m.) wind directions paired with wood burning homes west of location 101 and northeast of location 103 .

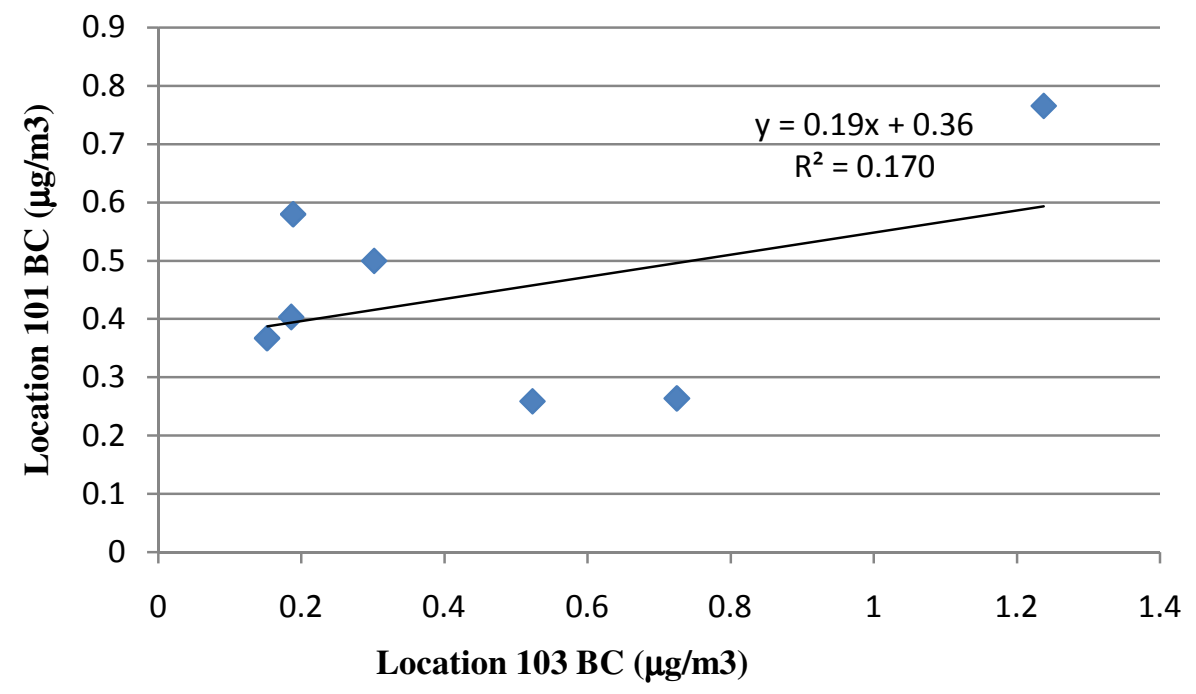

Figure 27: 6 - 9 p.m., February 27, 2009 (IOP 4): location 103 BC vs. location 101 BC. 


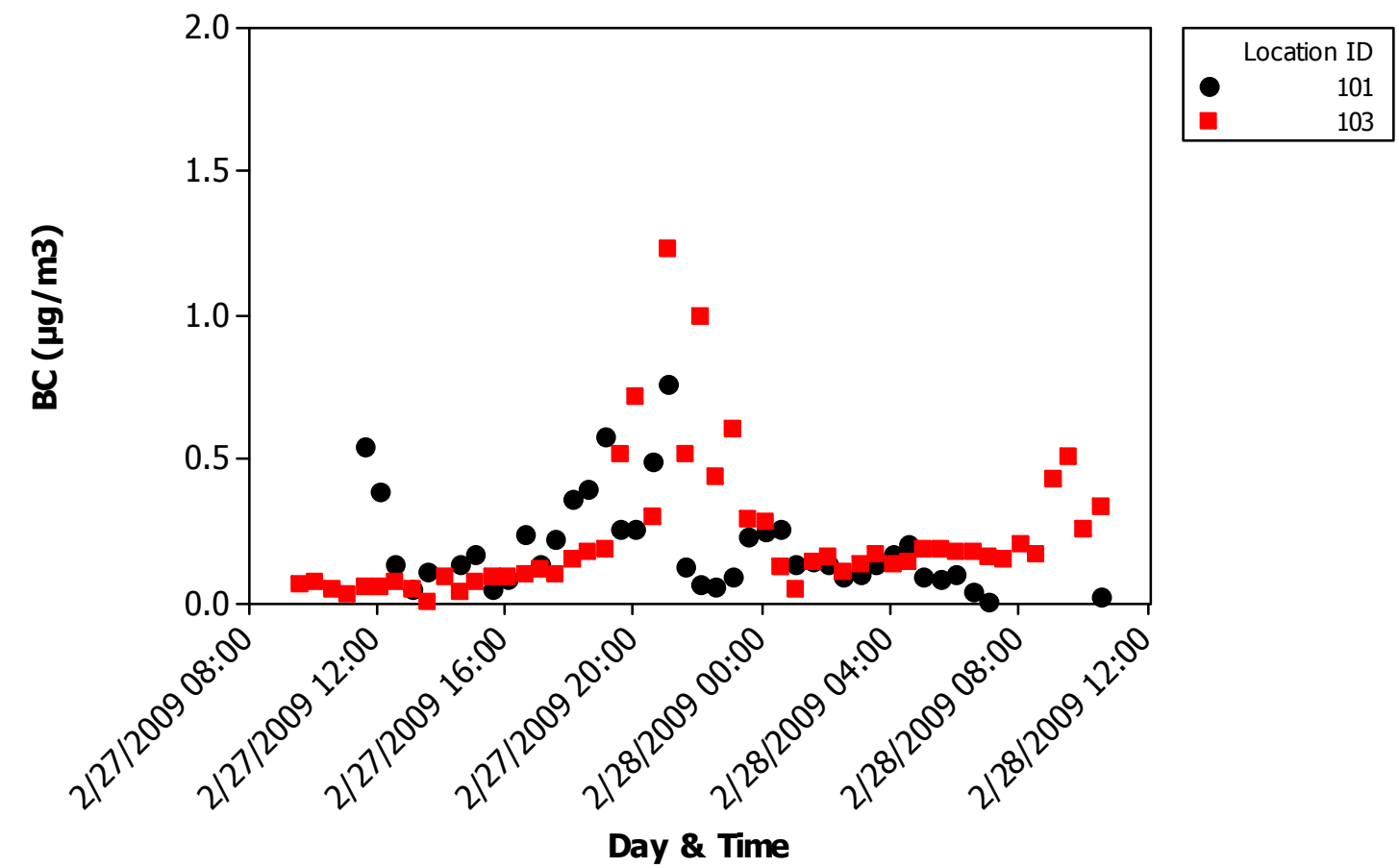

Figure 28: February 27-28, 2009 (IOP 4): Location 101 and $103 \mathrm{BC}\left(\mu \mathrm{g} / \mathrm{m}^{3}\right)$ vs. day and time (30 min.).

\subsubsection{Assessment of BC Variability: March 7, 2009 (IOP 5)}

A GLM for March $7^{\text {th }}$ BC concentrations vs. aethalometer location and time included three locations within the study area and one location outside. To check for violations of the ANOVA assumptions, the residual plots were analyzed. The residual plots shown in Appendix $\mathrm{H}$ displayed a violation of normality since the points curve off of the line. This was caused by the presence of outliers in the data, caused by spikes in BC concentration, inconsistent with the typical BC levels. These "outliers" were not thrown out because they accurately represent the high level of $\mathrm{BC}$ measured by the aethalometer when a nearby home was burning. To improve the ANOVA assumptions, a log transformation 
was applied to the response variable, BC. The normality assumption was greatly improved with the use of the log transformation. "Extreme outliers" were detected by MINITAB at location 103 from 6 to 7:30 p.m. Once again, detection of what MINITAB sees as outliers, or observations that are numerically distant from the rest of the data, can be used to detect when the locations' BC concentrations significantly vary. At 6 p.m., a BC concentration of $9.45 \mu \mathrm{g} / \mathrm{m}^{3}$ was measured at location 103. As seen in Figure 29 below, location 103 had significantly higher BC levels than the other locations at 6 p.m. (230 times higher than location 102 and 6 times higher than location 101). On average, the $\mathrm{BC}$ at location 101 was $0.08 \mu \mathrm{g} / \mathrm{m}^{3}$ lower than location 103 and location 102 was 0.15 $\mu \mathrm{g} / \mathrm{m}^{3}$ lower than location 103. This IOP evening had the highest BC readings out of all of the IOPs, most likely due to the fact that the aethalometer was located in the center of homes burning coupled with wind blowing from the direction where the majority of wood smoke burning homes were located. Another possible explanation for these higher than usual BC readings could be the fact that Yeager camp had a campfire that same evening. Since the p-value (0.035) for location was less than the chosen significance level of 0.05 , it is evident once again that $\mathrm{BC}$ varies significantly from location to location.

This IOP was very important because the aethalometer data collected in the residential study area was compared to the data collected at the Cambria Fire Station, 1.75 miles southeast of the study area, to represent the central monitoring site. The mean evening $\mathrm{BC}$ concentration measured at the fire station was 0.43 and $3.07 \mu \mathrm{g} / \mathrm{m}^{3}$ lower than the evening mean BC measured at locations 101 and 103, respectively. Yet it was 0.20 
$\mu \mathrm{g} / \mathrm{m}^{3}$ higher than the evening mean BC measured at location 102. Clearly, central monitoring station data is not a reasonable proxy for the average wood smoke concentrations to which people are exposed.

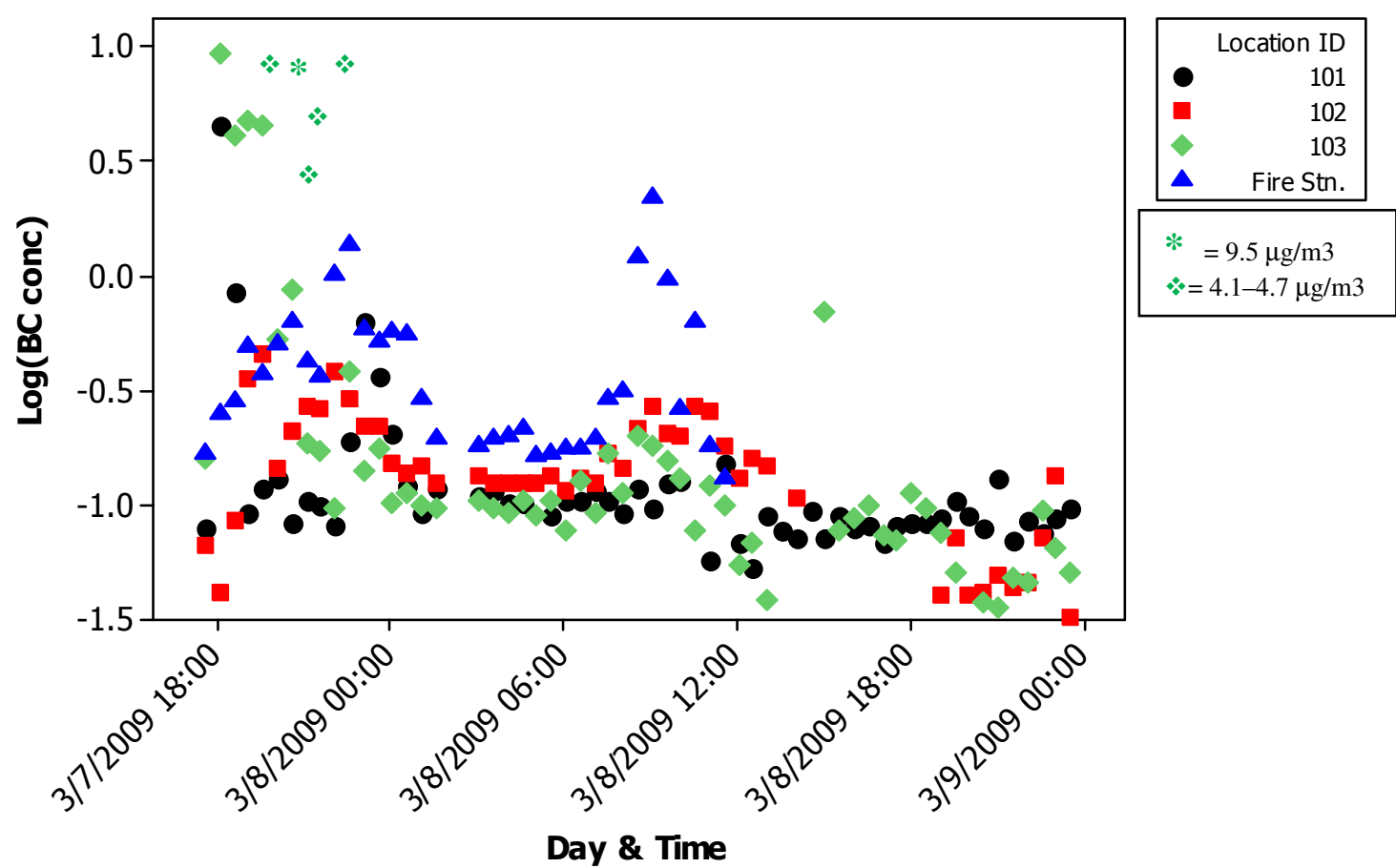

Figure 29: March 7-8, 2009 (IOP 5): Location 101,102, 103 and Fire Station Log (BC conc.) vs. Day and time (30 min.).

\subsubsection{Assessment of BC Variability: March 13, 2009 (IOP 6)}

This IOP evening had a mild westerly wind and an equivalent number of wood burning homes located west of each aethalometer, resulting in very comparable $\mathrm{BC}$ readings at each location. The $\mathrm{R}^{2}$ displayed in Figure 30 below shows that there is not a correlation between readings at the two locations. As expected, there is a peak in the evening (only for location 101) when the majority of Cambria residents burn wood. Location 102 showed a morning peak in BC concentrations. The residual plots for the GLM ran with 
BC concentrations vs. aethalometer location and time displayed a violation of normality. A log transformation was applied to BC to improve the ANOVA assumptions. The normality assumption was greatly improved with the use of the log transformation. The weak correlation between location and $\mathrm{BC}$ concentration resulted in a p-value of 0.240 , which is greater than the 0.05 significance level. Unlike the previous IOPs, this result is not in agreement with the aethalometer scatterplot result which showed a weak correlation between the readings at each location. On average, location 101 was 0.04 $\mu \mathrm{g} / \mathrm{m}^{3}$ lower than location 102 (Appendix I). From 6 to 9 p.m., the BC at location 102 was 54\% lower than the $\mathrm{BC}$ at location 101 (Figure 31).

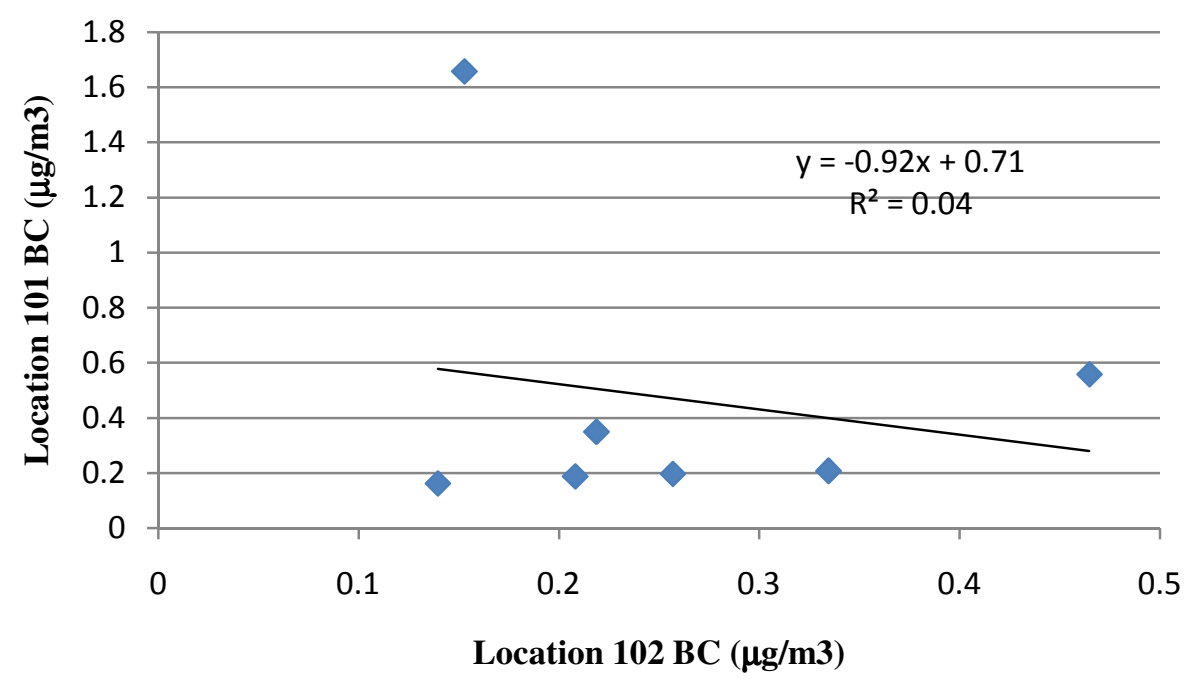

Figure 30: 6-9 p.m., March 13, 2009 (IOP 6): location 102 BC vs. location 101 BC. 


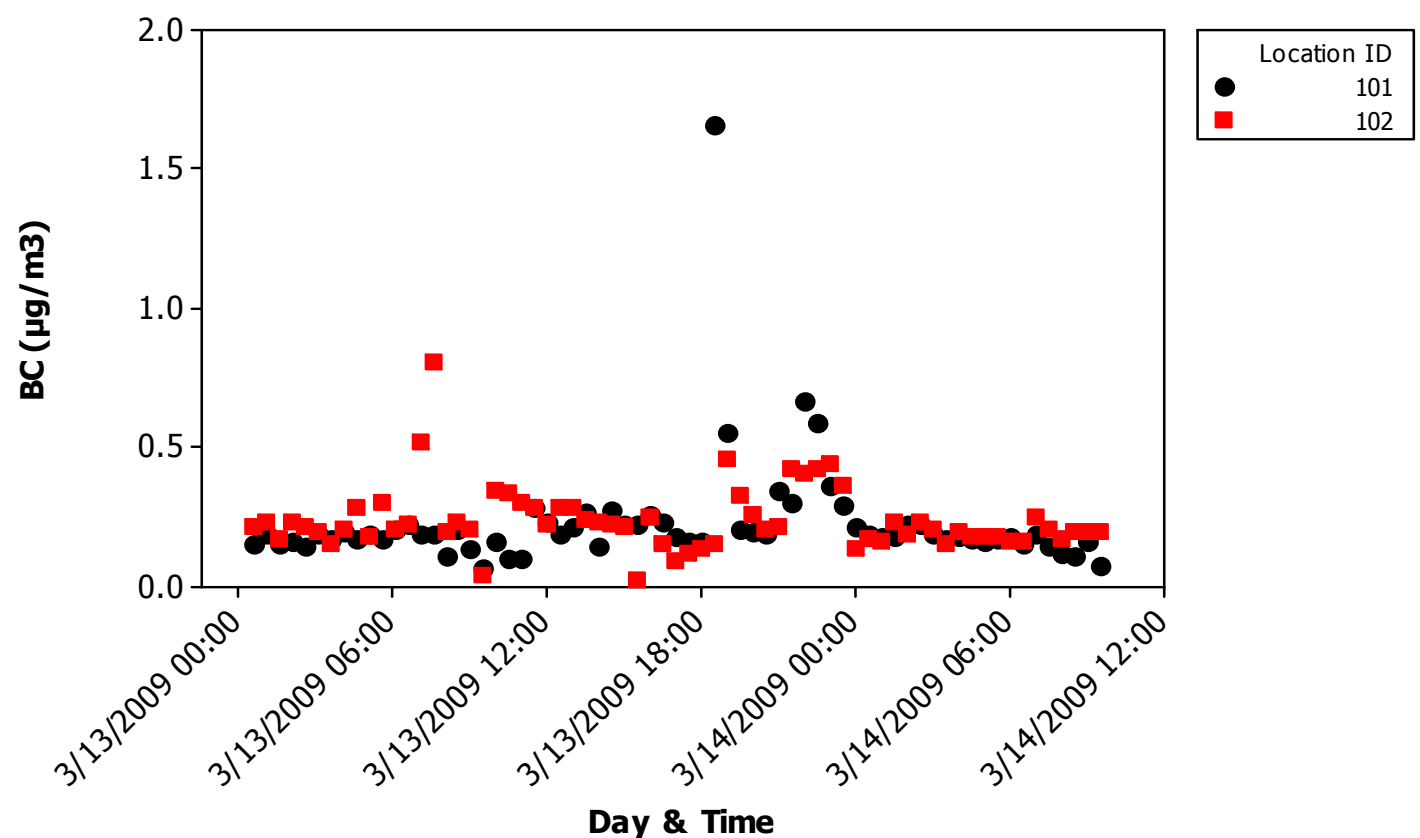

Figure 31: March 13-14, 2009 (IOP 6): Location 101 and $102 \mathrm{BC}\left(\mu \mathrm{g} / \mathrm{m}^{3}\right)$ vs. day and time (30 min.).

\subsubsection{Assessment of BC Variability: March 20, 2009 (IOP 8)}

Figure 33 below shows no correlation between the aethalometer $\mathrm{BC}$ concentrations from 6 to 9 p.m., given the low $\mathrm{R}^{2}$. However, Figure 33 shows similar aeth readings at all times except 6 to 11 a.m. The ANOVA result would be in better agreement with the aethalometer scatterplot result if a higher significance level had been used in the model. On average, location 101 was 56\% higher than location 102 from 6 to 9 p.m. Overall, from 12:30 a.m. March 20 th to $10: 00$ a.m. March $21^{\text {st }}$, location 101 was $0.0005 \mu \mathrm{g} / \mathrm{m}^{3}$ lower than location 102.

A GLM for BC concentrations vs. aethalometer location and time from March $20^{\text {th }}, 12: 30$ a.m. to 10:00 a.m. on March $21^{\text {st }}$ produced a p-value of 0.907. Because the residual plots 
displayed a violation of normality, a log transformation was applied to the response variable, $B C$. The new p-value was 0.195 , which does not signify statistically significant $\mathrm{BC}$ variability between the two locations. Yet, similar to the first IOP, had a higher significance level been chosen, this p-value result would have meant that there was statistical significance between the $\mathrm{BC}$ concentrations at each location. There were 8 high leverage observations: 10, 36, 37, 53, 56, 67, 131, and 136 (Appendix J), meaning that at these times the $\mathrm{BC}$ exerted a great deal of potential influence on the path of the fitted equation. All but two of these observations correspond to BC concentrations measured in the morning. Interestingly, none of the previous transformed models had high leverage observations. The explanation for these "high leverage" observations is that those observations were negative, and the log of a negative number is seen as an empty observation in MINITAB, resulting in a BC measurement at one site and not the other. High leverage points have the potential to dominate a regression analysis. If a point has high leverage, then removing it can have a substantial effect on the estimates of the coefficients and on the fitted values of Y, especially if the point also has a relatively large residual (Utts and Heckard, 2002). When the GLM was run without these "high leverage" observations, the p-value stayed the same. The GLM was also run by adding $0.8 \mu \mathrm{g} / \mathrm{m}^{3}$ (lowest BC reading was $-0.79 \mu \mathrm{g} / \mathrm{m}^{3}$ ) to each observation in order to ensure that all of the $\mathrm{BC}$ concentrations were positive. Again, this did not change the p-value. Therefore, running the GLM with all of the observations (positive and negative) is acceptable. 


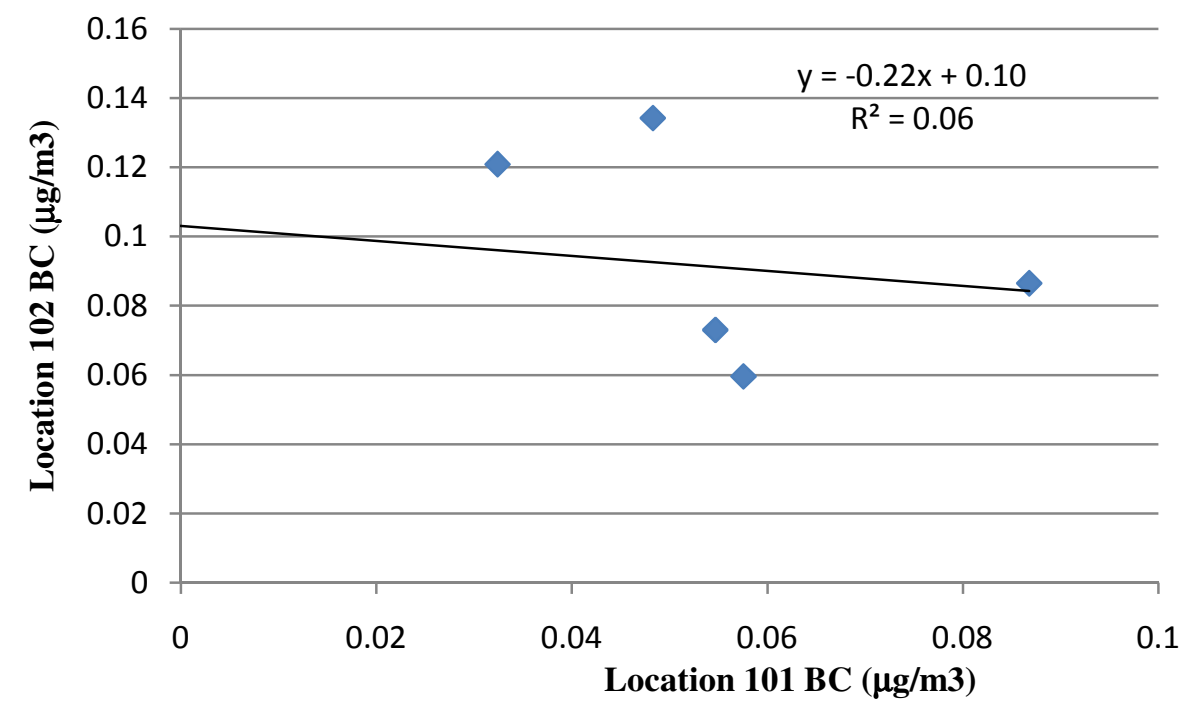

Figure 32: 6 - 9 p.m., March 20, 2009: location 101 BC vs. location 102 BC.

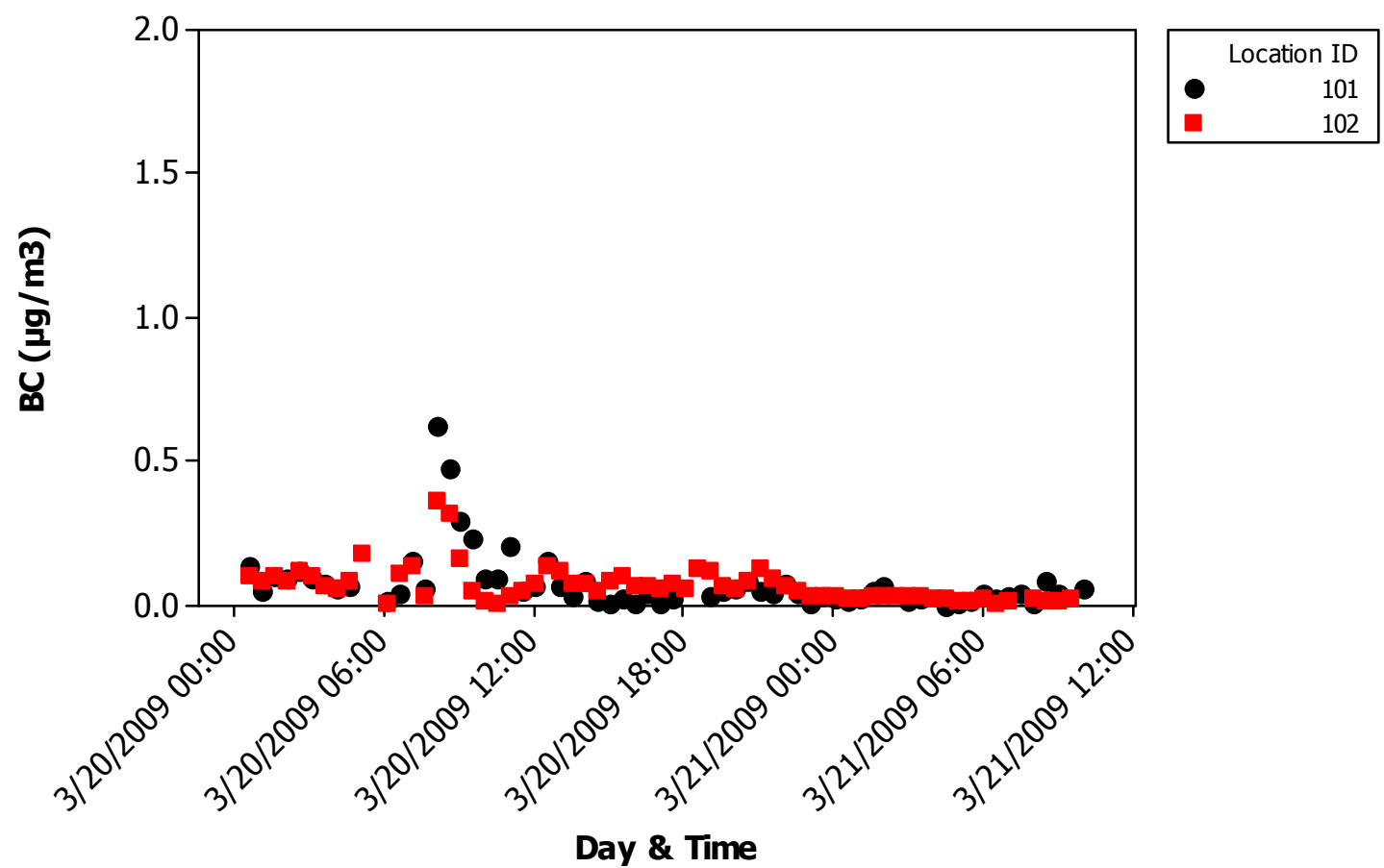

Figure 33: March 20-21, 2009 (IOP 8): Location 101 and $102 \mathrm{BC}\left(\mu \mathrm{g} / \mathrm{m}^{3}\right)$ vs. day and Time (30 min.). 


\subsubsection{Assessment of BC variability: Combined Data}

A GLM ran with BC concentration vs. aethalometer location and time contained aethalometer data from seven IOPs (Appendix K). A log transformation was applied to the BC to see if it would improve the residual plots. Since this transformation did not improve the normal probability plot, the untransformed model was used. The GLM generated the same extreme outliers that were detected when the model ran on each IOP

day individually. Namely, on March $7^{\text {th }}$ from 6 to 7:30 p.m., when location 103 had significantly higher BC concentrations even though it is only 0.31 miles from location 101 and 0.14 miles from location 102 . This is exactly when the majority of wood burning takes place. There were no high leverage or high influence observations detected by the MINITAB GLM "Unusual Observations" output displayed in Appendix K. The pvalue for aethalometer location was 0.000 , making it evident that a receptor distance of as little as 0.14 miles had a significant impact on the BC concentration. The conclusion to be drawn is that $\mathrm{BC}$ concentration, and thus $\mathrm{PM}_{2.5}$, can significantly vary within a small area, especially when the wind is blowing from wood burning homes to the monitor. BC variability depends on the location of homes burning in proximity to the aethalometers and the wind direction. Therefore, the ARB's current method of simply using one FRM monitoring site to measure and forecast $\mathrm{PM}_{2.5}$ levels over a large area is unrepresentative of the actual concentrations at homes located a limited distance from the FRM monitoring site. 


\subsubsection{IOP BC Variability Comparison}

The IOP results discussed above varied because each night had different wind patterns and different homes burning wood. According to Fine et al. (2004), BC represents 4 to $6 \%$ of $\mathrm{PM}_{2.5}$. The comparisons of aethalometer $\mathrm{BC}$ and mini-vol $\mathrm{PM}_{2.5}$ ran side-by-side from 6 p.m. to 6 a.m. on March $7^{\text {th }}$ and March $13^{\text {th }}$ at four different locations demonstrated that the mean aethalometer $\mathrm{BC}$ fraction of $\mathrm{PM}_{2.5}$ was $5 \%$, exactly in the range seen in previous studies (Table 1). $\mathrm{PM}_{2.5}$ results for the nine mini-vol runs and one FRM sampler run are displayed in Appendix L. It was expected that the $\mathrm{BC} / \mathrm{PM}_{2.5}$ fraction would be higher than seen in past research because Cambria's main source of $\mathrm{PM}_{2.5}$ was wood smoke, making it an ideal site for accurately measuring the wood burning $\mathrm{PM}_{2.5}$ contribution. Therefore, wood smoke is a large portion of the $\mathrm{PM}_{2.5}$ in Cambria. The PEM results discussed below support the fact that the samples were dominated by wood smoke from the spectral attenuation analysis (Appendix N), which shows strong spectral dependence with little absorbance near IR and much absorbance near UV (Kirchstetter, 2004).

Table 1. Aethalometer BC vs. mini-vol $\mathrm{PM}_{2.5}$ measured from 6 p.m. to 6 a.m. at locations 101, 102, 103, and the Cambria Fire Station.

\begin{tabular}{|c|c|c|c|c|c|c|c|c|}
\hline Date & $\begin{array}{c}\text { Location } \\
\text { ID }\end{array}$ & $\begin{array}{c}\text { Sunset } \\
\text { Lab OC } \\
(\boldsymbol{\mu g} / \mathbf{m 3})\end{array}$ & $\begin{array}{c}\text { Sunset } \\
\text { Lab EC } \\
(\boldsymbol{\mu g} / \mathbf{m 3})\end{array}$ & $\begin{array}{c}\text { Aeth. } \\
\mathbf{B C} \\
\left(\boldsymbol{\mu g} / \mathbf{m}^{\mathbf{3}}\right)\end{array}$ & $\begin{array}{c}\text { Mini. } \\
\mathbf{P M}_{\mathbf{2 . 5}} \\
(\boldsymbol{\mu} \mathbf{g} / \mathbf{m})\end{array}$ & $\begin{array}{c}\text { Sun } \\
\text { EC/ } \\
\mathbf{P M 2 . 5}\end{array}$ & $\begin{array}{c}\text { Aeth } \\
\mathbf{B C} / \\
\mathbf{P M 2 . 5}\end{array}$ & $\begin{array}{c}\text { Aeth } \\
\mathbf{B C} / \\
\text { Sun } \\
\mathbf{E C}\end{array}$ \\
\hline $3 / 7 / 2009$ & 101 & 1.11 & 0.21 & 0.28 & 5.79 & 0.04 & 0.05 & 1.31 \\
\hline $3 / 7 / 2009$ & 102 & 5.34 & 0.10 & 0.18 & 3.94 & 0.03 & 0.05 & 1.72 \\
\hline $3 / 7 / 2009$ & Fire Stn. & 1.66 & 0.16 & 0.41 & 6.48 & 0.02 & 0.06 & 2.61 \\
\hline 3/13/2009 & 101 & 0.07 & 0.13 & 0.33 & 8.33 & 0.02 & 0.04 & 2.52 \\
\hline MEAN & & 2.05 & 0.15 & 0.30 & 6.14 & 0.03 & 0.05 & 2.04 \\
\hline
\end{tabular}


Thus a very approximate method of conservatively converting $\mathrm{BC}$ to $\mathrm{PM}_{2.5}$ is to divide the $\mathrm{BC}$ measurement by $6 \%$ :

$$
P M=\frac{B C}{0.06}
$$

Based on previous studies that show $\mathrm{BC}$ represents 4 to $6 \%$ of $\mathrm{PM}_{2.5}$, a non-conservative method of converting $\mathrm{BC}$ to $\mathrm{PM}_{2.5}$ is to divide the $\mathrm{BC}$ by $4 \%$ :

$$
P M=\frac{B C}{0.04}
$$

Thus there is a range of possible $\mathrm{PM}_{2.5}$ concentrations to be calculated when using $\mathrm{BC}$ as an indicator of wood smoke $\mathrm{PM}_{2.5}$. For example, the mean $\mathrm{BC}$ measured at location 101 and 102 from 6 to 9 p.m. on January $31^{\text {st }}$ was 0.53 and $0.47 \mu \mathrm{g} / \mathrm{m}^{3}$, respectively. Applying equations 3 and 4, the mean evening $\mathrm{PM}_{2.5}$ at location 101 and 102 would range from 8.8 to 13.3 and 7.8 to $11.8 \mu \mathrm{g} / \mathrm{m}^{3}$, respectively. Thus the $\mathrm{PM}_{2.5}$ concentration at location 101 was just 1.0 to $1.5 \mu \mathrm{g} / \mathrm{m}^{3}$ higher than the $\mathrm{PM}_{2.5}$ at location 102 . The largest measured mean evening (6-9 p.m.) difference in BC was on March $7^{\text {th }}$, with a difference of $3.27 \mu \mathrm{g} / \mathrm{m}^{3}\left(54.5\right.$ to $\left.81.8 \mu \mathrm{g} \mathrm{PM}_{2.5} / \mathrm{m}^{3}\right)$ between location 102 and 103 . That same evening, location 101 had a BC concentration that was $2.64 \mu \mathrm{g} / \mathrm{m}^{3}$ (44.0 to $66.0 \mu \mathrm{g}$ $\mathrm{PM}_{2.5} / \mathrm{m}^{3}$ ) less than the $\mathrm{BC}$ concentration at location 103. The narrowest measured mean evening (6-9 p.m.) difference in BC was on February $26^{\text {th }}$, with a difference of just 0.008 $\mu \mathrm{g} / \mathrm{m}^{3}$ or 0.1 to 0.2 micrograms of $\mathrm{PM}_{2.5}$ per cubic meter, between location 101 and 103 . Averaging the results from the 7 IOPs, the mean evening BC concentration measured at location 101 was $0.29 \mu \mathrm{g} / \mathrm{m}^{3}$ less than location 103's BC and location 102 was 0.65 $\mu \mathrm{g} / \mathrm{m}^{3}$ less than the $\mathrm{BC}$ at location 103. Applying equations 3 and 4 , the mean evening 
$\mathrm{PM}_{2.5}$ at location 101 was 4.8 to $7.3 \mu \mathrm{g} / \mathrm{m}^{3}$ less than location 103 's BC and location 102

was 10.8 to $16.3 \mu \mathrm{g} / \mathrm{m}^{3}$ less than the $\mathrm{PM}_{2.5}$ concentration at location 103 .

The conclusion to be drawn is that if the wood smoke concentrations measured in this 1 $\mathrm{km}^{2}$ study area can have a large range of variability, then it is likely that the spatiotemporal variability of $\mathrm{PM}_{2.5}$ is significant in other residential areas where wood burning is prevalent. Thus, measuring $\mathrm{PM}_{2.5}$ at just one monitoring site is not a reasonable proxy for the average wood smoke concentrations to which people are exposed. Depending on the baseline $\mathrm{PM}_{2.5}$ concentration, the large variation in wood smoke levels throughout a small area could lead to meeting or exceeding fine particulate matter ambient air quality standards. Conversely, overestimating or underestimating the $\mathrm{PM}_{2.5}$ levels can lead to inappropriate measures being taken to ensure clean air. As Miller (2007) stated, each $\mathrm{PM}_{2.5}$ increase of $10 \mu \mathrm{g} / \mathrm{m}^{3}$ can lead to a $24 \%$ increase in the risk of a cardiovascular event and a $76 \%$ increase in the risk of death from cardiovascular disease. It is imperative that the wood smoke concentrations are accurately measured and assessed.

\subsection{Meteorological Predictors and BC Correlation Analysis}

This section explores the influence of meteorological predictors on the BC concentration. Multiple regression was the chosen mode of analysis used to find a linear relationship between the $\mathrm{BC}$ response variable and several possible predictor variables. Data collected from each IOP was used in this analysis. BC variability was found to depend primarily on the location of homes burning in proximity to the aethalometers and the 
wind direction. Given that the majority of wood burning takes place from 6 to 9 p.m. and the burning sources were identified during this timeframe using the infrared camera, the regression analysis was done on $\mathrm{BC}$ readings from $6-9$ p.m. Knowing where the sources are located with respect to the aethalometers enables more accurate correlations to be drawn between the $\mathrm{BC}$ and meteorological factors. Before making this determination, a variety of analyses were run on the data.

The first attempt to find a correlation between the meteorological factors and BC utilized all of the aethalometer data collected over the study from November 16, 2008 to March 21, 2009. The analysis was run by individually analyzing data from the three locations. The full model predictor variables used in the multiple regression were hour of day, an indicator variable for evening ( 1 if 6-11 p.m., 0 if not), temperature, westerly wind, wind speed, wind speed gust, dew point, barometric pressure, and humidity. The sixteen wind directions were grouped into two directions to find the wind direction (westerly wind) with the greatest influence on $\mathrm{BC}$. The multiple regression resulted in only the evening indicator variable and barometric pressure showing a significant p-value (less than 0.05), meaning that these variables had a significant influence on $\mathrm{BC}$ after adjusting for all the other variables. In addition to these findings, the Variance Inflation Factors (VIFs) for temperature, dew point, and humidity were extremely large, showing a correlation between the three variables. There were large correlations between these predictor variables and others in the model because there is a relationship between relative humidity and the dew point temperature in moist air. To check for violations of the multiple regression assumptions, the residual plots were analyzed (similarly to ANOVA 
assumptions). The residual plots display violations in normality, constant variance, and linearity. To improve the regression model, a log transformation was applied to the BC response variable. The log transformation did not show any additional predictor variables to have significant influence on BC nor did it affect the VIFs. The major impacts of the transformation were seen in the residual plots, with improvement for each of the assumptions. A final attempt to find a relationship between the $\mathrm{BC}$ concentrations and meteorological predictors was to remove irrelevant meteorological variables (e.g. dew point) that were highly correlated with other predictor variables. After removing dew point, there was no longer a strong correlation between predictor variables. The predictors that should influence the wood smoke concentration were not showing a significant impact (e.g. hour, temperature, westerly wind, and wind speed). The model may have been ineffective because there were other factors that needed to be taken into consideration when predicting the wood smoke concentrations. Or the lack of correlation indicates there is just a lot of random variability. With wood smoke, there are frequent down drafts, eddies, etc. that cause wildly fluctuating smoke levels.

In the second attempt to model the correlation between meteorological variables and $\mathrm{BC}$, only the data collected between 6 to 9 p.m. on each IOP was used. This added the benefit of knowing the location of homes burning during this time frame. The multiple regression full model included the same predictor variables as in the previous model (except for the evening and westerly wind indicator variable) plus the number of homes burning, an indicator variable for surface inversions, an indicator variable for wind blowing from the direction of homes burning towards the monitor, time (30 min.), and 
average distance from homes burning (miles). The regression model did not have any pvalues that were less than the chosen significance level of 0.05 , signifying weak evidence of correlations between $\mathrm{BC}$ concentrations and the predictors that were expected to have a strong influence (e.g. number of homes burning and distance) on the wood smoke concentrations. The next attempt to improve the model was to take the log transformation of $\mathrm{BC}$ (after adding 0.18 to all of the concentrations to ensure that all of the $\mathrm{BC}$ readings were positive) and remove predictor variables that should not influence the $\mathrm{BC}$ concentration. The transformation did not demonstrate that the number of homes burning wood had a dominant positive or negative influence on the BC. The last attempt to find a relationship between the $6-9$ p.m. IOP BC concentrations and meteorological predictors was to create an interaction variable between the wind direction indicator variable ( 1 if the wind is blowing in a direction that pushes the home's wood smoke toward the monitor and 0 if not) and the number of homes burning in order to only include the number of homes burning that were in the range of wind blowing from the wood burner's home to the monitor. Running the multiple regression model with the new interaction variable still did not show a correlation between the number of homes burning and $\mathrm{BC}$ concentration. Only the surface inversion indicator variable had a positive influence on the BC. Even after removing five "outliers" that MINITAB showed had large standardized residuals, the number of homes burning wood did not significantly influence the BC. One explanation for this unexpected result could be that a broader sample of meteorological predictors is needed to see the influence on $\mathrm{BC}$ concentration. Another possibility is that each of the predictor variables needed to be manipulated to discern a linear influence on $\mathrm{BC}$ concentration. 
To further explore the predictor variables' influence on the $\mathrm{BC}$ concentration, the wind speed (Ws), distance between the wood burners and aethalometer (d), and the sine (sin) of the angle $(\theta)$ between the wind direction vector and the homes burning $(n)$ were manipulated into the following weighted function $(\mathrm{w})$ :

$$
\mathrm{w}=\frac{d * \operatorname{Sin}(\Theta) * W s}{n}
$$

The wood smoke concentration is expected to be lower when there was an increase in the distance between the wood burners and the receptor, angle between the wind direction and homes burning, or wind speed. Hence, as the weighted function increases, it should be associated with a decrease in the BC concentration. Plotting the 6 to 9 p.m. IOP BC concentration against the weighted function resulted in a decrease of $0.86 \mu \mathrm{g} / \mathrm{m}^{3}$ times the mean BC with each increase in the weighted function (Figure 34). This result confirms the assumption that wood smoke decreases when the distance between the wood burners and the receptor, angle between the wind direction and homes burning, or wind speed increases. 


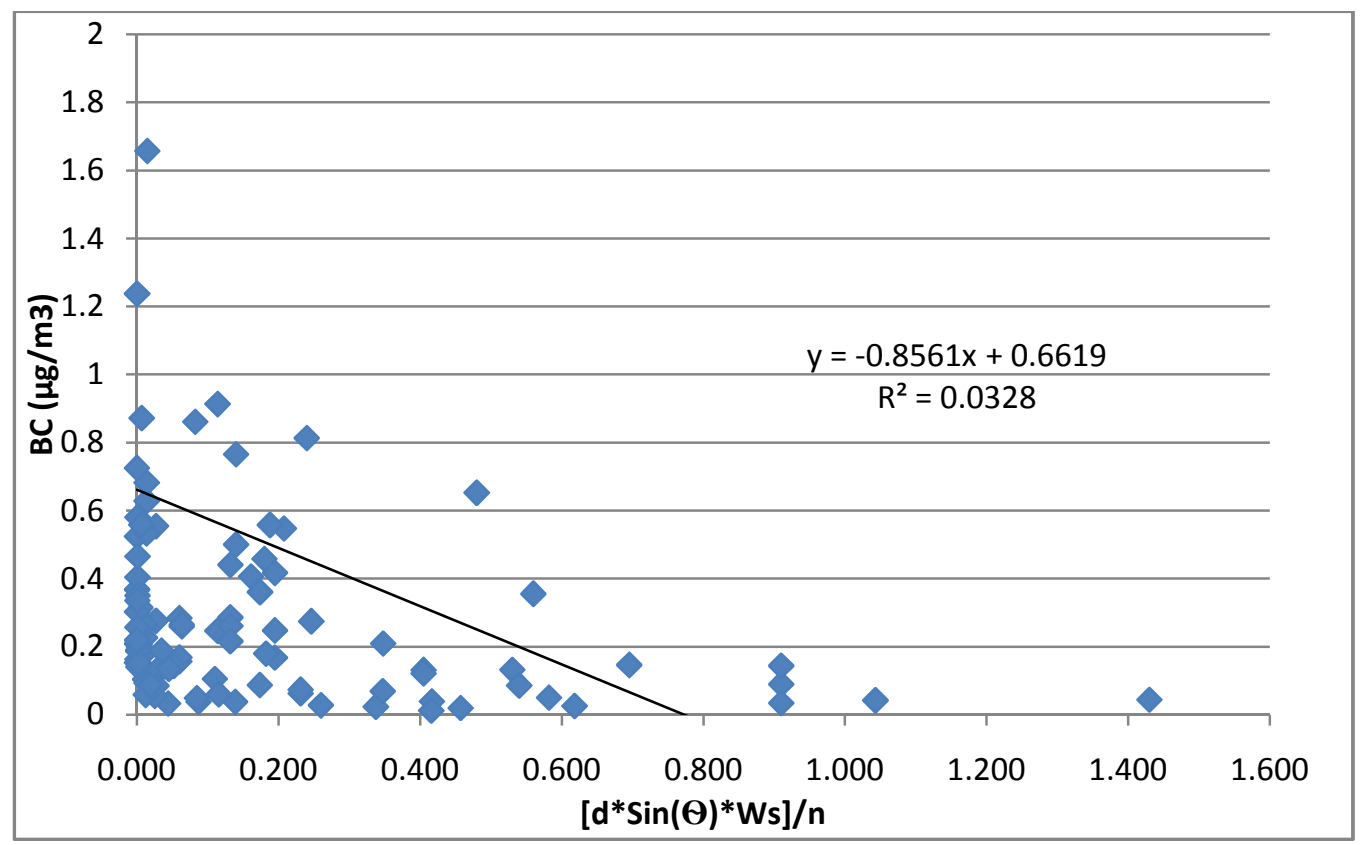

Figure 34: 6-9 p.m. IOP BC vs. (distance between the wood burners and aethalometer *sine of the angle between the wind direction vector)*wind speed)/(homes burning).

\subsection{PEM BC Variability Analysis}

Six IOPs were conducted between January and March, 2009. During each of these IOPs, extensive sampling occurred in which eight to twelve PEM samples were collected over a single night at locations within the $1 \mathrm{~km}^{2}$ study area. The $\mathrm{BC}$ collected on each PEM filter was analyzed using spectrally-dependent light attenuation to determine the BC accumulated over 12 hours. Based on the 10 repeat spectral attenuation analyses (displayed with red dashed lines), the accuracy of the results are \pm 1 unit of attenuation (Appendix M). As discussed in section 4.2, the attenuation at $880 \mathrm{~nm}$ (wavelength at which $\mathrm{BC}$ is the only significant PM component absorbed) can be converted to a $\mathrm{BC}$ concentration (mass per volume of air) by considering the absorption cross section $\sigma$ (units of area per mass), the area A over which the samples was deposited on the filter, and the sample volume V. Negative attenuation values which made up 5 out of 60 of the collected PEM samples were assumed to be BC concentrations of $0 \mu \mathrm{g} / \mathrm{m}^{3}$. The median, 
mean, minimum, and maximum $\mathrm{BC}$ concentrations from each IOP confirm that the $\mathrm{BC}$ concentrations have large spatial-variability over a residential area (Table 2). The largest PEM BC concentration difference was seen on February $18^{\text {th }}$, with a minimum 12 hour BC concentration of $0.03 \mu \mathrm{g} / \mathrm{m}^{3}$ and a maximum BC concentration of $0.79 \mu \mathrm{g} / \mathrm{m}^{3}$. The mean 12 hour BC concentration for all IOPs was $0.16 \mu \mathrm{g} / \mathrm{m}^{3}$ and the median was 0.13 $\mu \mathrm{g} / \mathrm{m}^{3}$. The lowest measured 12 hour BC concentration among the IOPs was $0 \mu \mathrm{g} / \mathrm{m}^{3}$ and the highest was $0.8 \mu \mathrm{g} / \mathrm{m}^{3}$. The average standard deviation of PEM BC concentrations was $0.10 \mu \mathrm{g} / \mathrm{m}^{3}$ and the average relative standard deviation was $77.18 \%$. Based on the results from the PEM BC analysis of variation, it is evident that wood smoke concentrations substantially vary over a residential area based on meteorological factors and wood burning conditions. Below, the results from six IOPs with eight to twelve PEM sites are discussed in too much detail.

Table 2. Number of PEMs, 12 hr BC concentration median, mean, minimum, and maximum for each IOP.

\begin{tabular}{|c|c|c|c|c|c|c|}
\hline IOP \# & 1 & 2 & 3 & 4 & 7 & 8 \\
\hline Date & $1 / 31 / 2009$ & $2 / 18 / 2009$ & $2 / 26 / 2009$ & $2 / 27 / 2009$ & $3 / 15 / 2009$ & $3 / 20 / 2009$ \\
\hline Sample & $\begin{array}{c}\mathrm{BC} \\
(\mu \mathrm{g} / \mathrm{m} 3)\end{array}$ & $\begin{array}{c}\mathrm{BC} \\
(\mu \mathrm{g} / \mathrm{m} 3)\end{array}$ & $\begin{array}{c}\mathrm{BC} \\
(\mu \mathrm{g} / \mathrm{m} 3)\end{array}$ & $\begin{array}{c}\mathrm{BC} \\
(\mu \mathrm{g} / \mathrm{m} 3)\end{array}$ & $\begin{array}{c}\mathrm{BC} \\
(\mu \mathrm{g} / \mathrm{m} 3)\end{array}$ & $\begin{array}{c}\mathrm{BC} \\
(\mu \mathrm{g} / \mathrm{m} 3)\end{array}$ \\
\hline \# of PEMs & 9 & 10 & 8 & 11 & 12 & 9 \\
\hline Median & 0.33 & 0.09 & 0.07 & 0.26 & 0.03 & 0.01 \\
\hline Mean & 0.34 & 0.17 & 0.08 & 0.31 & 0.04 & 0.02 \\
\hline Minimum & 0.3 & 0.03 & 0.03 & 0.09 & 0 & 0 \\
\hline Maximum & 0.42 & 0.79 & 0.12 & 0.74 & 0.14 & 0.05 \\
\hline $\begin{array}{c}\text { Std. } \\
\text { Deviation }\end{array}$ & 0.11 & 0.23 & 0.03 & 0.18 & 0.04 & 0.02 \\
\hline $\begin{array}{c}\text { Rel. Std. } \\
\text { Dev. (\%) }\end{array}$ & 32.55 & 135.57 & 40.11 & 59.65 & 111.88 & 83.32 \\
\hline
\end{tabular}




\section{3 .1. Assessment of PEM BC Variability: January 31, 2009 (IOP 1)}

The variation in wood smoke concentration between the nine PEM locations (Figure 35) was apparent on the January $31^{\text {st }}$ IOP. The difference between each PEMs' BC concentration and the mean BC concentration ranged from 0.00 to $0.13 \mu \mathrm{g} / \mathrm{m}^{3}$. The PEM placed outside of the study region, at the Cambria Fire Station, measured a concentration that was twice as high as the mean 12 hour BC concentration measured with PEMs in the study area. The monitoring station location was not a reasonable proxy for the average wood smoke concentrations. Since this was the first IOP, knowledge of the operation of the infrared camera was limited which may have lead to an inaccurate count of the number of homes burning wood between 6 and 9 p.m. It is likely that there were more than five homes burning during this IOP, although there is no way to confirm this assumption. The average standard deviation was $0.11 \mu \mathrm{g} / \mathrm{m}^{3}$ (relative standard deviation of $32.55 \%$ ) and the largest BC concentration difference was $0.12 \mu \mathrm{g} / \mathrm{m}^{3}$. The PEM on Weymouth Street had the highest BC concentration $(0.42 \mu \mathrm{g} / \mathrm{m} 3)$ presumably due to the fact that it was located next to four homes burning wood. As a result of the easterly wind and proximity to homes burning wood, the PEM located in the eastern section of the study area had the lowest BC concentration $(0.30 \mu \mathrm{g} / \mathrm{m} 3)$. The near-surface inversion is expected to have increased BC concentrations, with a mean of $0.34 \mu \mathrm{g} / \mathrm{m}^{3}$ and a median of $0.33 \mu \mathrm{g} / \mathrm{m}^{3}$ (Table 2). 


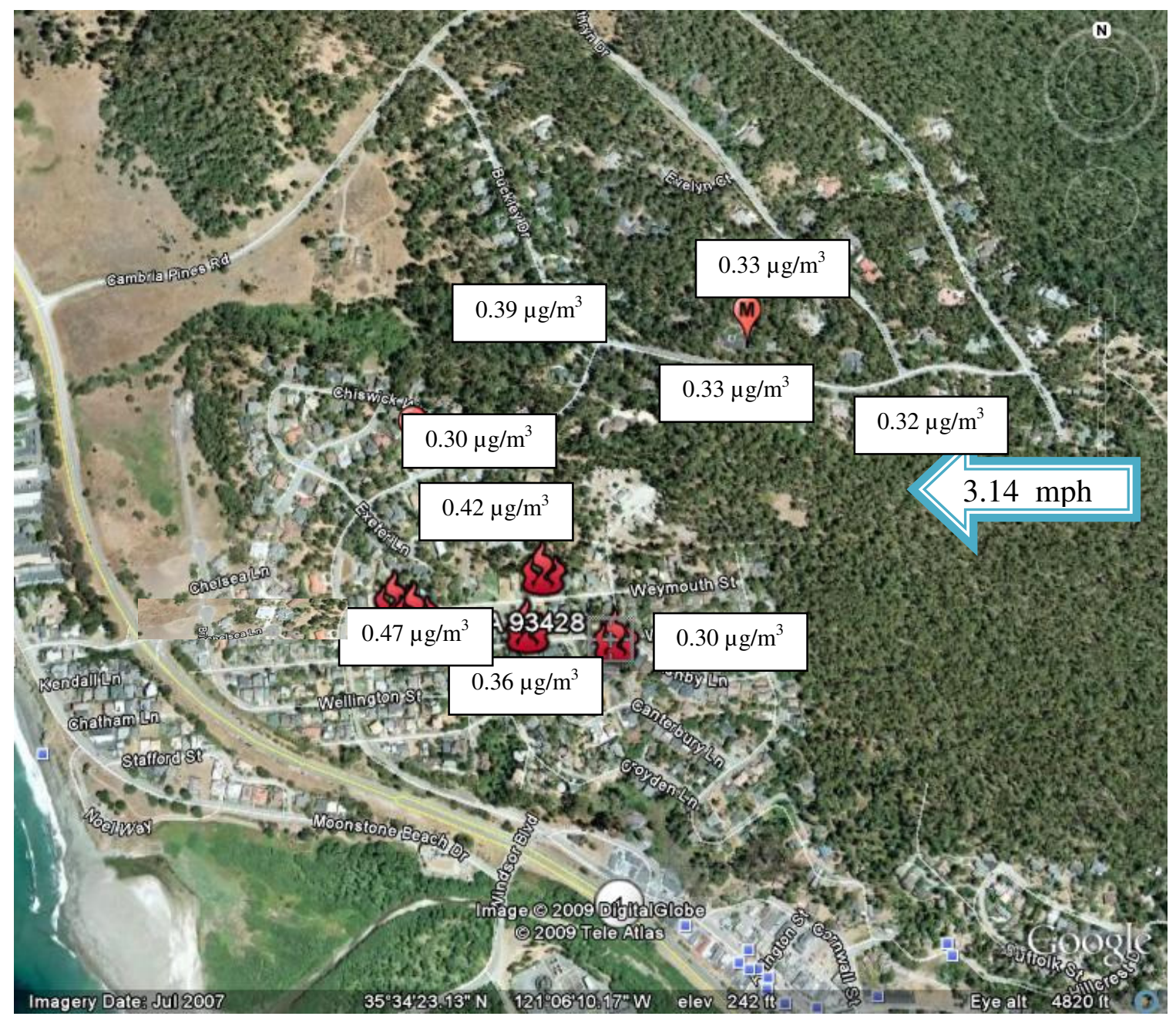

Figure 35: January $31^{\text {st }}$ IOP with 9 PEM locations (concentrations in white boxes) and $3.13 \mathrm{mph}$ easterly wind from 6-9 p.m.

\section{3 .2. Assessment of PEM BC Variability: February 18, 2009 (IOP 2)}

Ten PEMs were placed within the study area during the February $18^{\text {th }}$ IOP (Figure 36).

This IOP had large BC concentration variability (up to 77\% difference from the mean), with a minimum 12 hour concentration of $0.03 \mu \mathrm{g} / \mathrm{m}^{3}$ and a maximum concentration of $0.79 \mu \mathrm{g} / \mathrm{m}^{3}$. The standard deviation between PEM BC concentrations was $0.23 \mu \mathrm{g} / \mathrm{m}^{3}$, with a relative standard deviation of $135.57 \%$. The difference between each PEMs' BC concentration and the mean ranged from 0.01 to $0.63 \mu \mathrm{g} / \mathrm{m}^{3}$. The PEM on Warwick 
Street had the highest BC concentration since it was located downwind of homes burning.

Seven homes were sighted burning throughout the study area between 6 and 9 p.m. The

12 hour median BC concentration was $0.09 \mu \mathrm{g} / \mathrm{m}^{3}$ and the mean BC concentration was

$0.17 \mu \mathrm{g} / \mathrm{m}^{3}$ (Table 2). The strong surface inversion and low wind speeds resulted in high

BC concentration variability between the ten PEM locations. This IOP had the largest wood smoke variability, with a BC concentration difference of $0.76 \mu \mathrm{g} / \mathrm{m}^{3}$.

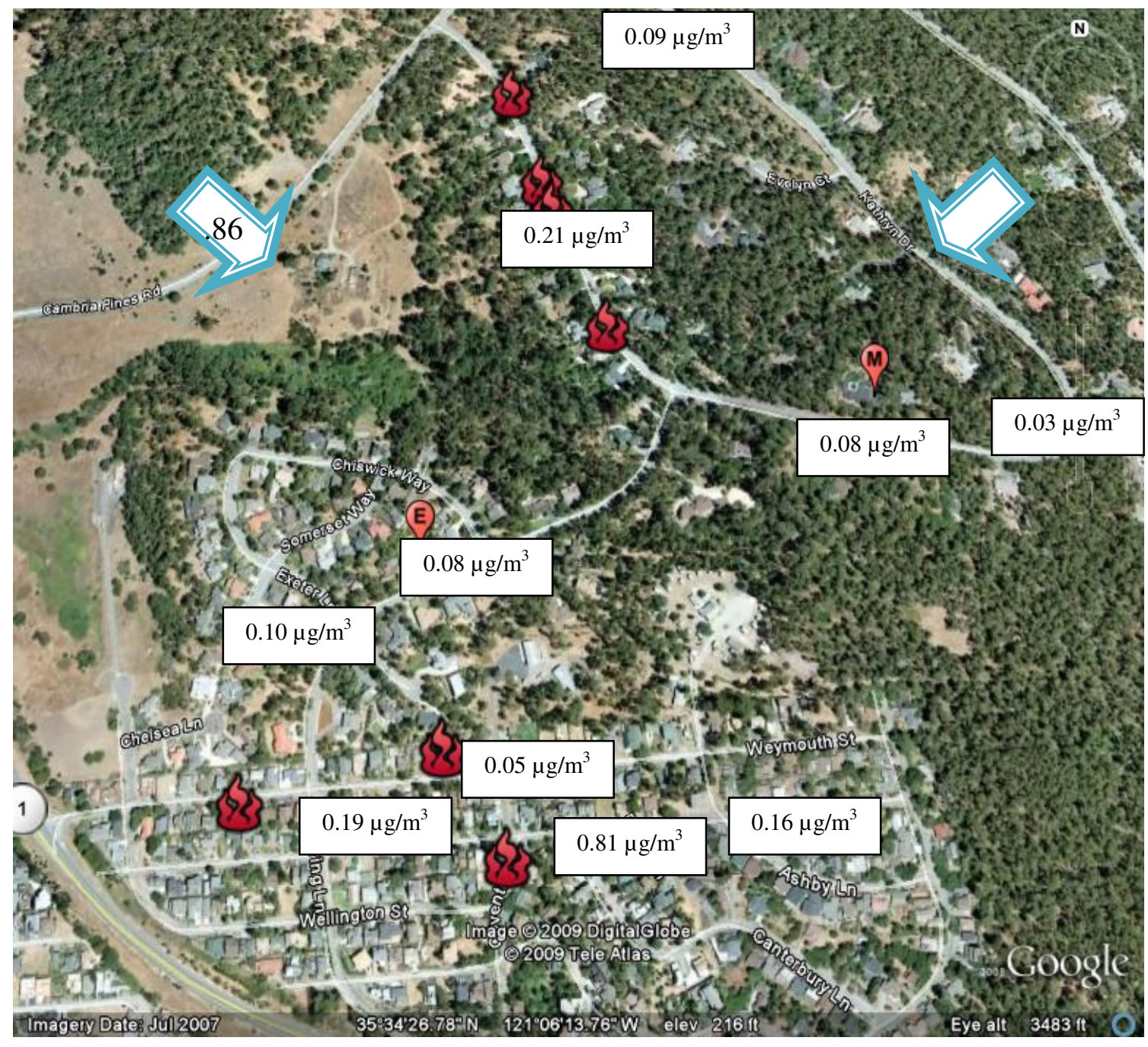

Figure 36: February $18^{\text {th }}$ IOP with 10 PEM locations (concentrations in white boxes) and $0.86 \mathrm{mph}$ northeasterly and northwesterly wind from 6-9 p.m. 


\subsubsection{Assessment of PEM BC Variability: February 26, 2009 (IOP 3)}

Using the infrared camera, five homes were seen burning within the study area and eight PEMs sampled between 6 and 9 p.m. during this IOP (Figure 37). The median and mean 12 hour BC concentrations were 0.07 and $0.08 \mu \mathrm{g} / \mathrm{m}^{3}$, respectively (Table 2 ). The PEM located on Warwick Street had the highest BC concentration, $0.12 \mu \mathrm{g} / \mathrm{m}^{3}$, and the PEM located on Buckley Street had the lowest BC concentration, $0.03 \mu \mathrm{g} / \mathrm{m}^{3}$, which is to be expected given their location relative to the homes burning. The lower 12 hour BC concentrations seen during this IOP may have resulted from dilution by the higher wind speeds. The standard deviation of PEM BC concentrations was $0.03 \mu \mathrm{g} / \mathrm{m}^{3}$ and the relative standard deviation was $40.11 \%$. The difference between PEM BC concentrations and the mean ranged from 0.00 to $0.05 \mu \mathrm{g} / \mathrm{m}^{3}$. This IOP had the smallest variability fraction, a $12 \%$ average $\mathrm{BC}$ concentration difference. The maximum $\mathrm{BC}$ concentration was almost five times higher than the minimum $\mathrm{BC}$ concentration. Given the relative standard deviation, it is evident that the wood smoke concentrations have substantial spatial variability within the $1 \mathrm{~km}^{2}$ residential study area. 


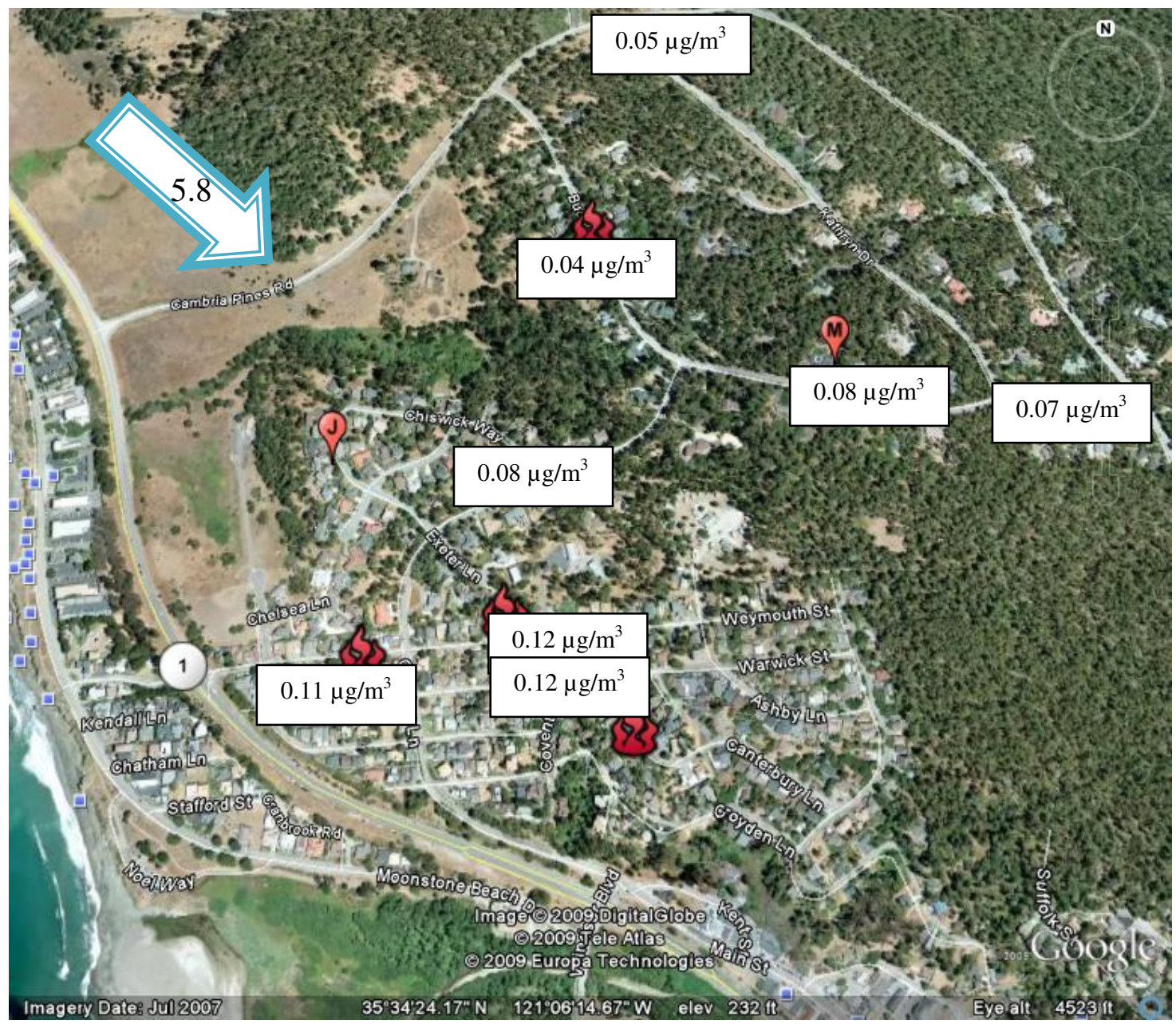

Figure 37: February $26^{\text {th }}$ IOP with 8 PEM locations (concentrations in white boxes) and $5.8 \mathrm{mph}$ northwesterly wind from 6-9 p.m.

\section{3 .4. Assessment of PEM BC Variability: February 27, 2009 (IOP 4)}

In this fourth IOP there were nine homes burning and eleven PEM locations (Figure 38).

The minimum 12 hour BC concentration was $0.09 \mu \mathrm{g} / \mathrm{m}^{3}$ and the maximum was 0.74 $\mu \mathrm{g} / \mathrm{m}^{3}$ (Table 2). This variability with a difference of $48 \%$ is important because it signifies that $\mathrm{BC}$ concentrations within a small area can be twice as large as the reading less than $1 \mathrm{~km}$ away. These large $\mathrm{BC}$ concentration differences are to be expected since some of the PEMs were located near homes burning and others were not. Additionally, the PEMs located northwest (downwind) of homes burning had the highest BC 
concentrations. This IOP had the second largest wood smoke concentration variability, with a maximum BC concentration difference of $0.63 \mu \mathrm{g} / \mathrm{m}^{3}$. The mean 12 hour BC concentration was $0.30 \mu \mathrm{g} / \mathrm{m}^{3}$ and the median was $0.25 \mu \mathrm{g} / \mathrm{m}^{3}$. The standard deviation was $0.18 \mu \mathrm{g} / \mathrm{m}^{3}$, with differences between PEM BC concentrations and the mean ranging from 0.01 to $0.43 \mu \mathrm{g} / \mathrm{m}^{3}$. The near surface inversion and low wind speeds may have contributed to the strong BC concentration variability.

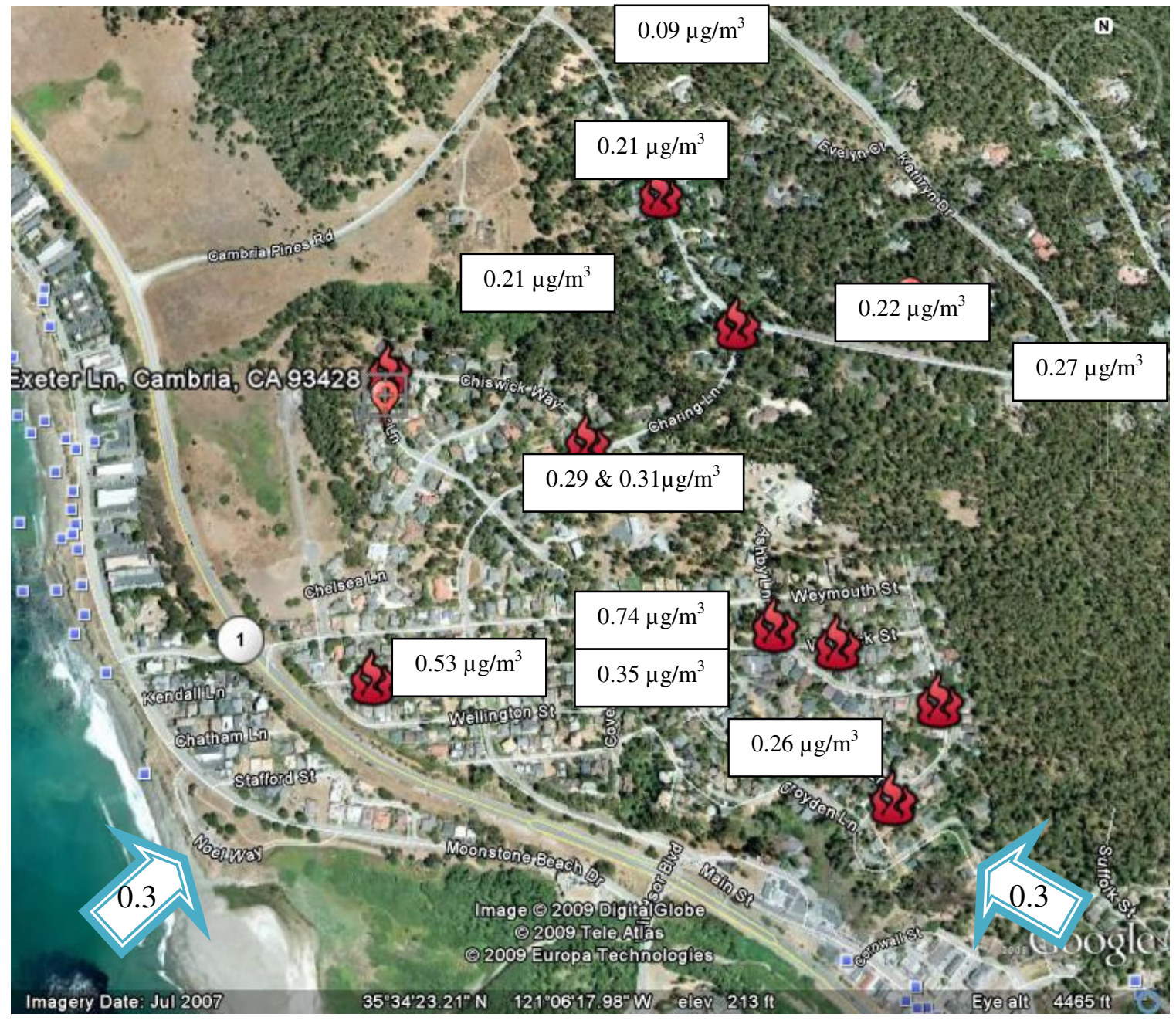

Figure 38: February 27th IOP with 11 PEM locations (concentrations in white boxes) and $0.3 \mathrm{mph}$ southwesterly and southeasterly wind from 6-9 p.m. 


\section{3 .5. Assessment of PEM BC Variability: March 15, 2009 (IOP 7)}

Twelve PEMs were placed within the study area during this IOP (Figure 39). Sixteen homes were sighted burning between 6 and 9 p.m. and the PEMs located east of the homes burning had higher $\mathrm{BC}$ concentrations because of the westerly wind. The 12 hour median $\mathrm{BC}$ concentration was $0.03 \mu \mathrm{g} / \mathrm{m}^{3}$ and the mean $\mathrm{BC}$ concentration was 0.06 $\mu \mathrm{g} / \mathrm{m}^{3}$ (Table 2). Similar to the January $31^{\text {st }} \mathrm{IOP}$, the maximum BC concentration difference was $0.14 \mu \mathrm{g} / \mathrm{m}^{3}$. The standard deviation was $111.88 \mu \mathrm{g} / \mathrm{m}^{3}$, with PEM BC concentrations deviating from the mean by 0.01 to $0.10 \mu \mathrm{g} / \mathrm{m}^{3}$. The strong winds, absence of a surface inversion, and a majority of homes burning north and south of the PEM locations resulted in low 12 hour $\mathrm{BC}$ concentrations, with a minimum 12 hour concentration of $0.00 \mu \mathrm{g} / \mathrm{m}^{3}$ and a maximum concentration of $0.14 \mu \mathrm{g} / \mathrm{m}^{3}$ (relative standard deviation of $111.88 \%)$. 


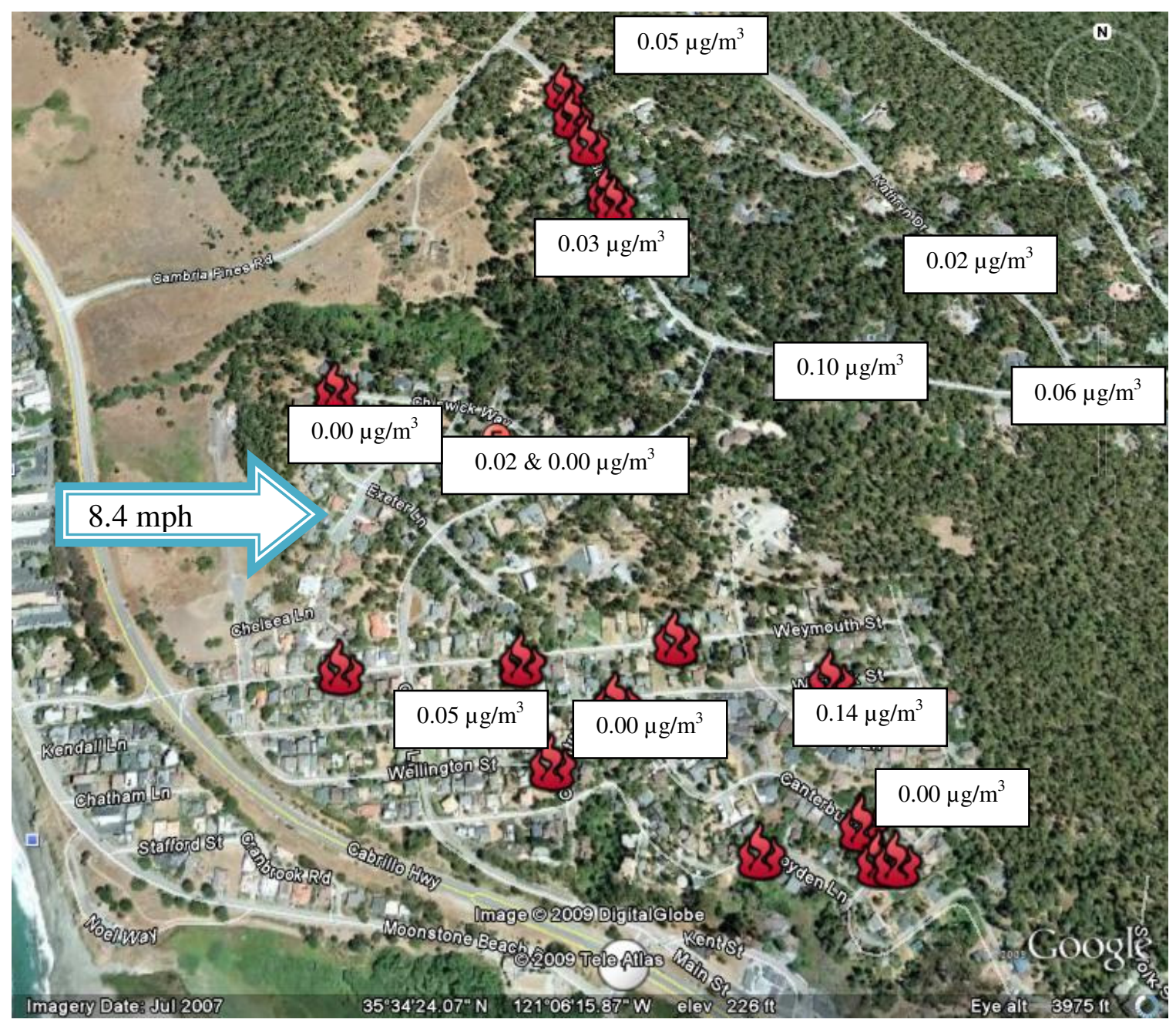

Figure 39: March $15^{\text {th }}$ IOP with 8 PEM locations (concentrations in white boxes) and 8.4 mph westerly wind from 6-9 p.m.

\section{3 .6. Assessment of PEM BC Variability: March 20, 2009 (IOP 8)}

The variability in BC concentration between the nine PEM locations (Figure 40) was not strong on the March $20^{\text {th }}$ IOP. The largest BC concentration difference was $0.05 \mu \mathrm{g} / \mathrm{m}^{3}$, with a maximum 12 hour BC concentration of $0.05 \mu \mathrm{g} / \mathrm{m}^{3}$ (the PEM located in the eastern section of the study area) and a minimum of $0.00 \mu \mathrm{g} / \mathrm{m}^{3}$. Similar to the previous IOP, the absence of a surface inversion resulted in low 12 hour BC concentrations and because of these low values, variability was also low. The 12 hour median and mean BC 
concentrations were each 0.01 and $0.02 \mu \mathrm{g} / \mathrm{m}^{3}$, respectively (Table 2). The standard deviation was $0.02 \mu \mathrm{g} / \mathrm{m}^{3}$ (relative standard deviation of $83.32 \%$ ), with differences between PEM BC concentrations and the mean ranging from 0.00 to $0.03 \mu \mathrm{g} / \mathrm{m}^{3}$. Although this IOP had the smallest wood smoke variability among the IOPs, the particulate concentration difference is still important since every increase/decrease in $\mathrm{PM}_{2.5}$ can influence attainment of ambient air quality attainment standards.

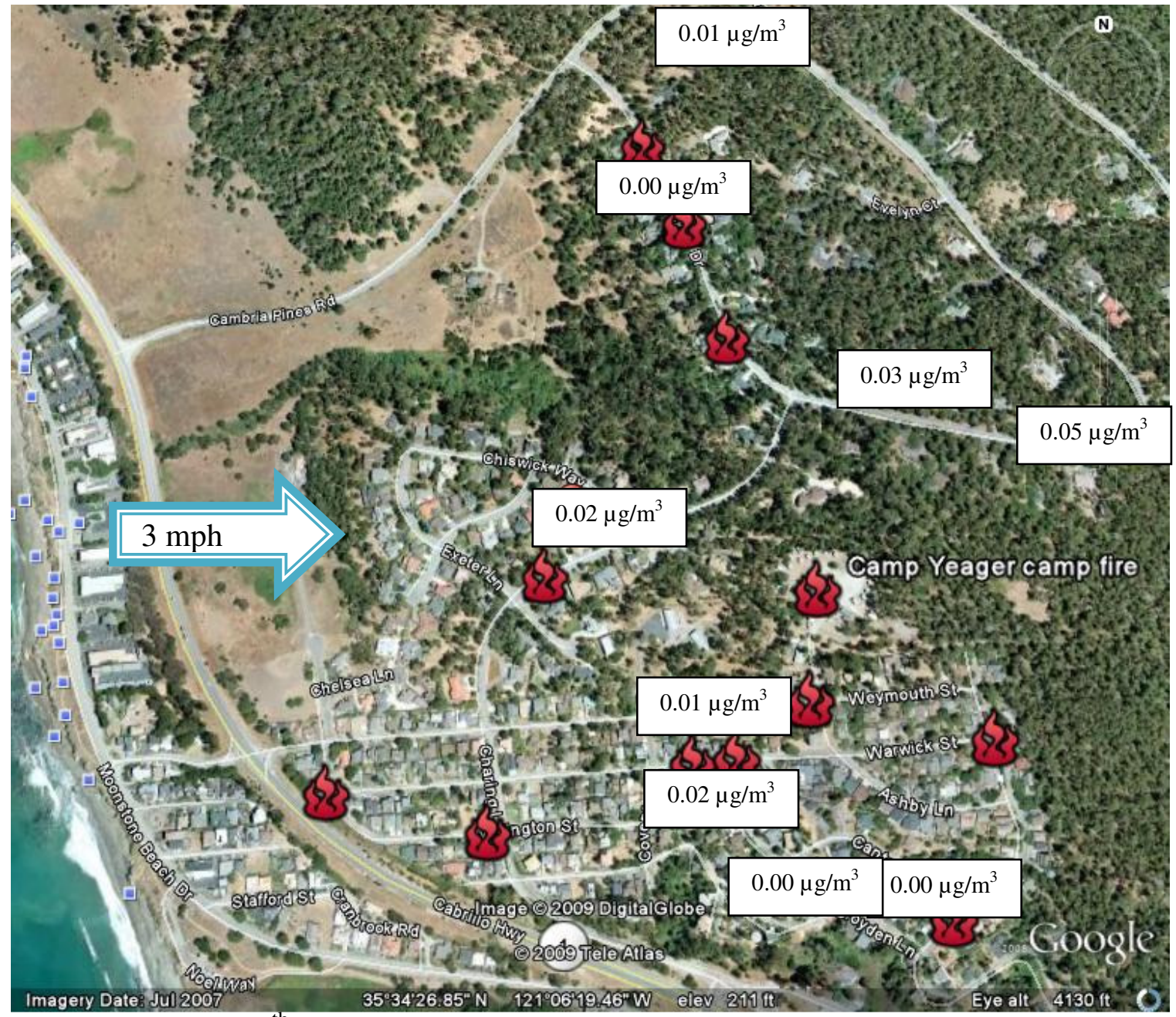

Figure 40: March $20^{\text {th }}$ IOP with 7 PEM locations (concentrations in white boxes) and 3 mph westerly wind from 6-9 p.m. 


\section{4 . PEM and Aethalometer Black Carbon Collection Comparison}

The $\mathrm{BC}$ concentration is determined from an attenuation reading at $880 \mathrm{~nm}$ for both the aethalometer and the PEM. It is difficult for BC concentrations calculated from these instruments to have similar results since the specific attenuation used to derive $\mathrm{BC}$ concentration is very variable (the value is usually derived from thermochemical EC measurements). Table 3 compares PEM and aethalometer BC 12 hour BC concentrations, on four of the dates (with low $\mathrm{BC}$ concentrations), both methods gave similar readings, but on two days the methods gave quite different readings, with differences in $\mathrm{BC}$ concentration ranging from 0 to a factor of 5.5. $\mathrm{BC}$ concentrations displayed in Table 3 compare the aethalometers and PEMs which were placed side-byside in the exact same location. There are many possible explanations for this difference; one explanation is that the assumed optical absorption cross-sectional area used to convert the attenuation to a concentration is incorrect.

Table 3. PEM and aethalometer $12 \mathrm{hr} \mathrm{BC}$ concentration comparison.

\begin{tabular}{|l|c|c|c|c|c|c|c|}
\hline \multicolumn{1}{|c|}{ Location ID \& Date } & $\begin{array}{c}102 \\
2 / 18\end{array}$ & $\begin{array}{c}101 \\
\mathbf{2 / 1 8}\end{array}$ & $\begin{array}{c}103 \\
\mathbf{2 / 2 7}\end{array}$ & $\begin{array}{c}\mathbf{2} / 27 \\
\mathbf{2}\end{array}$ & $\mathbf{3 / 1 5}$ & $\mathbf{3 / 2 0}$ & Avg. \\
\hline $\begin{array}{l}\text { PEM 12hr BC conc. } \\
(\mu \mathrm{g} / \mathrm{m} 3)\end{array}$ & 0.08 & 0.08 & 0.13 & 0.22 & 0.02 & 0.03 & 0.09 \\
\hline $\begin{array}{l}\text { Aethalometer } 12 \mathrm{hr} \mathrm{BC} \\
\text { conc. }(\mu \mathrm{g} / \mathrm{m} 3)\end{array}$ & 0.13 & 0.10 & 0.33 & 0.04 & 0.03 & 0.03 & 0.11 \\
\hline
\end{tabular}

Given that the wavelength versus attenuation spectral attenuation analysis (Appendix N) showed strong spectral dependence with little absorbance near IR and high absorbance near UV, it is evident that the samples were dominated by wood smoke (Kirchstetter et al., 2004). The attenuation versus wavelength graph (Figure 41) compares the spectral 
attenuation obtained if you assume that if you assume that $\mathrm{BC}$ is the only PM component which absorbs and the actual spectral attenuation for the same PEM filter which collected data from 6 p.m. to 6 a.m. on January $31^{\text {st }}$. This graph supports the assertion that the samples were dominated by wood smoke, which is a source consisting of both BC and OC, because the fraction of attenuation attributed to OC increases with decreasing wavelength. The spectral attenuation curve from the PEM filter is greater than the spectral attenuation for solely BC because the PEM filter has light absorbing OC (a component of smoke) in addition to BC.

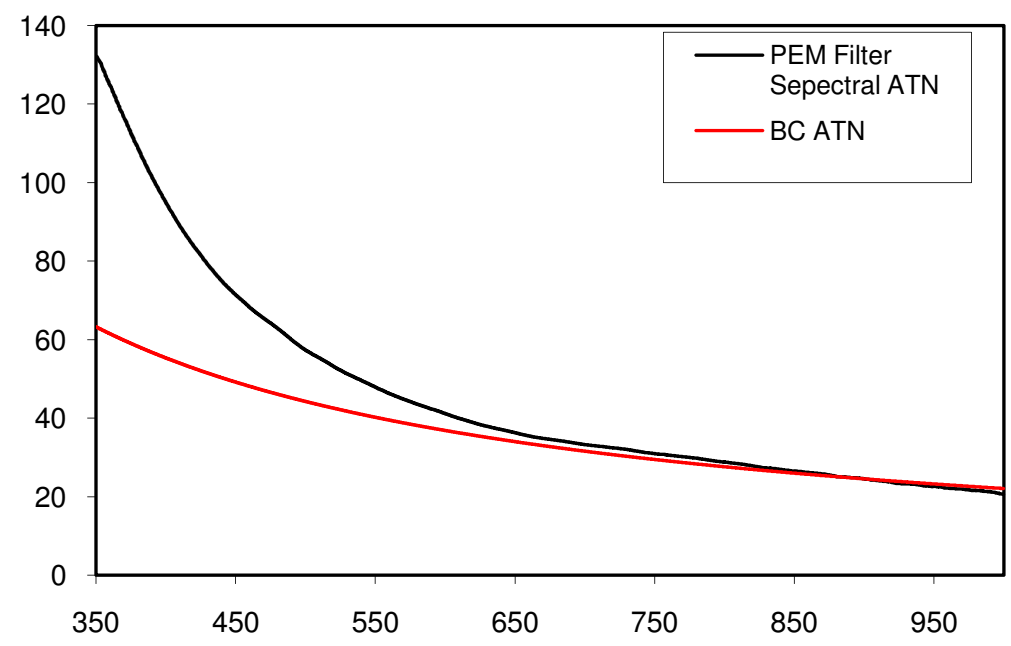

Figure 41: Spectral attenuation from a PEM filter which collected data from 6 p.m. to 6 a.m. (black line) and the spectral attenuation assuming BC is the only absorbing material (red line).

\section{CHAPTER 7: CONCLUSIONS}

Black carbon concentrations, as measured by aethalometers, showed that near-source contributions to average concentrations vary widely within a $1 \mathrm{~km}^{2}$ area with wood smoke sources. Consequently, BC concentrations, and therefore exposures, are dependent upon the location within a residential area and cannot be estimated well using 
measurements from a single location. Measured BC differences up to $3.27 \mu \mathrm{g} / \mathrm{m}^{3}$ (measured March $7^{\text {th }}$ ), or a $\mathrm{PM}_{2.5}$ concentration ranging from 54.5 to $81.75 \mu \mathrm{g} / \mathrm{m}^{3}$, show that intervention measures and regulations based on concentration measurements at one location may not be appropriate or sufficient to assure the health of residents in a nearby location. Additionally, converting $\mathrm{BC}$ concentrations to $\mathrm{PM}_{2.5}$ is a complex process since the $\mathrm{BC}$ fraction of $\mathrm{PM}_{2.5}$ varies, depending on the sources of $\mathrm{PM}_{2.5}$, different characteristics of wood smoke on different days, e.g. black or white smoke, etc. It is imperative that wood smoke concentrations are accurately measured and assessed to ensure that appropriate regulatory action is taken to keep the air clean. Based on the results from this study, it is recommended that the standard method of measuring $\mathrm{PM}_{2.5}$ should be updated by either placing additional monitors throughout the region or estimating the variation of $\mathrm{PM}_{2.5}$ using meteorological data and an understanding of the factors leading to near source variability.

Similar to the aethalometer BC results, the evaluation of the PEMs' BC variability showed that near-source contributions to average wood smoke concentrations vary widely over relatively short distances. Based on the $\mathrm{BC}$ variations between the eight to twelve monitored locations, it is unreasonable to assume that the $\mathrm{BC}$ measurements, and hence wood smoke $\mathrm{PM}_{2.5}$, are constant over a residential area. The maximum PEM BC difference of $0.76 \mu \mathrm{g} / \mathrm{m}^{3}$ (measured on the February $18^{\text {th }} \mathrm{IOP}$ ), or a $\mathrm{PM}_{2.5}$ concentration of 12.7 to $19.0 \mu \mathrm{g} / \mathrm{m}^{3}$ (depending on the $\mathrm{BC} / \mathrm{PM}_{2.5}$ fraction), could result in inappropriate measures being taken to protect the health of local residents. This research showed significant concentration variability associated with wood smoke burning within a 
residential neighborhood, with an average standard deviation of $0.10 \mu \mathrm{g} / \mathrm{m}^{3}$ and a relative standard deviation of $77.2 \%$. Since these average standard deviations and ranges of PEM $\mathrm{BC}$ concentration variability were calculated in Cambria, these $\mathrm{BC} / \mathrm{PM}_{2.5}$ fractions can only be applied to Cambria, in particular, the $1 \mathrm{~km}^{2}$ study area. Using BC concentrations to estimate $\mathrm{PM}_{2.5}$ concentrations is complicated because the fraction varies depending on the wood being burned, efficiency of the burning, additional $\mathrm{PM}_{2.5}$ sources, and other variables. Cambria's $\mathrm{BC} / \mathrm{PM}_{2.5}$ fraction may be larger than other cities' fraction because the Cambria $\mathrm{BC}$ comprises the majority of $\mathrm{PM}_{2.5}$, given that there is no industrial $\mathrm{PM}_{2.5}$ contributor. It is critical to consider the baseline $\mathrm{PM}_{2.5}$ levels when accounting for the $\mathrm{PM}_{2.5}$ concentration variability because the standard deviation will be much larger if the initial $\mathrm{PM}_{2.5}$ concentration is high. The standard deviations seen in this study are especially important for regions that are near the $\mathrm{PM}_{2.5}$ nonattainment level. Given the $\mathrm{BC}$ concentration differences between each PEM measured in the residential study area and the Cambria Fire Station, ranging from 0.09 to $0.45 \mu \mathrm{g} / \mathrm{m}^{3}$, it is evident that the central monitoring station is not a reasonable proxy for the average wood smoke concentrations to which people are exposed. The relative standard deviation between the study area PEMs and the PEM located at the Cambria Fire Station was $16.7 \%$. Information on burning patterns and meteorology must be considered when using regional monitoring site data to estimate residential $\mathrm{PM}_{2.5}$ levels.

Using meteorological data to estimate $\mathrm{PM}_{2.5}$ concentrations from residential wood smoke is difficult because it involves the number of homes burning, distance from burners, wind speed, inversion conditions and other parameters that have spatiotemporal variability. 
The multiple regression analysis between the meteorological predictors and $\mathrm{BC}$ concentration did not detect a significant correlation for any of the meteorological factors or burning conditions. The correlation between meteorological factors and $\mathrm{BC}$ concentration was weak because the meteorological data was unlikely representative of the true conditions within the study area. It was difficult to detect a linear relationship between the meteorological factors and the $\mathrm{BC}$ concentrations due to the weather station data that varies over relatively short distances, the topography, and a lack of repeatable meteorological conditions between IOPs. Based on the meteorological data collected for the IOPs, wind directions and speeds varied considerably from 6 to 9 p.m., between IOPs, with wind directions coming from all directions and surface inversions occurring during half of the IOPs. Only the last three IOPs had relatively similar meteorological parameters, with westerly wind from 3 to $8 \mathrm{mph}$ and no surface inversion. The relationship between meteorological factors and $\mathrm{BC}$ concentrations would be more obvious if the conditions could be repeated; otherwise it is challenging to draw significant correlations. Plotting the 6 to 9 p.m. IOP BC concentrations against the weighted function, $\left(\mathrm{d}^{*} \operatorname{Sin}(\Theta) * \mathrm{Ws}\right) / \mathrm{n}$, resulted in a decrease of $0.86 \mu \mathrm{g} / \mathrm{m}^{3}$ times the mean $\mathrm{BC}$ with each increase of one unit in the weighted function. Therefore, it is evident that the distance from the wood burning source, number of sources wind direction and speed influence the $\mathrm{BC}$ concentrations. This influence is strong based on the range of $\mathrm{BC}$ concentrations collected from the PEMs and aethalometers on each IOP. 


\subsection{Assessment of Objective Attainment}

The primary objective of this research was to assess the variability of wood smoke particulate matter concentrations within a residential area in which local wood burning is common and compare these concentrations to the data collected at a location outside of the study area to represent the chosen central monitoring site. This objective was attained by analyzing the aethalometer $\mathrm{BC}$ variation between locations and comparing the average evening concentration to the concentrations measured at the Cambria Fire Station. Given the differences in mean evening $\mathrm{BC}$ concentrations measured in the residential study area and the Cambria Fire Station, it is evident that the central monitoring station was not a reasonable proxy for the average wood smoke concentrations to which people within the study area were exposed. This research showed considerable concentration variability associated with wood smoke burning within a residential neighborhood. Information on burning patterns and meteorology must be considered when using regional monitoring site data to estimate residential $\mathrm{PM}_{2.5}$ levels.

The multiple regression attempts to explore the influence of meteorological predictors on $\mathrm{BC}$ concentrations resulted in numerous unsuccessful significant linear relationships between the $\mathrm{BC}$ response variable and predictor variables. Wind speed (Ws), distance between the wood burners and aethalometer $(\mathrm{d})$, and the sine $(\sin )$ of the angle $(\theta)$ between the wind direction vector and the homes burning (n) were manipulated into a weighted function (discussed in section 6.2) to attempt to find an influence on $\mathrm{BC}$ concentrations. $\mathrm{BC}$ variability was found to decreases when the distance between the wood burners and the receptor, angle between the wind direction and homes burning, or 
wind speed increased, although the $\mathrm{R}^{2}$ was very low (0.03). Plotting the 6 to 9 p.m. IOP $\mathrm{BC}$ concentration against the weighted function resulted in a decrease of $0.86 \mu \mathrm{g} / \mathrm{m}^{3}$ times the mean BC with each increase in the weighted function (Figure 35).

Researchers were able to inform Cambria residents on the health effects of wood smoke from fireplaces and give strategies to reduce these impacts by handing out handbooks that identified energy efficient heating strategies, health impacts of wood burning, and tips for burning a clean and efficient fire. Assuming that the correct conversion (assumed BC was 4 to $6 \%$ of $\mathrm{PM}_{2.5}$ ) was used when converting $\mathrm{BC}$ to $\mathrm{PM}_{2.5}$, the 24 hour $\mathrm{PM}_{2.5}$ ambient air quality standard of $35 \mu \mathrm{g} / \mathrm{m}^{3}$ was not exceeded during this study. The one 24 hour FRM PM 2.5 sample taken from March $15^{\text {th }}$ to the $16^{\text {th }}$, resulted in a concentration of 3.87 $\mu \mathrm{g} / \mathrm{m}^{3}$. If this study had been conducted in a city with high $\mathrm{PM}_{2.5}$ levels, the variation of $\mathrm{PM}_{2.5}$ could have led to prioritization and control strategies for wood smoke sources. The wood smoke variations within a residential area could lead to "no burn" directives being placed only on homes within a certain section of the area under consideration since this study showed that wood smoke concentrations can significantly increase or decrease depending on meteorological factors and location.

\subsection{Future Research}

When this study is continued next winter, it is recommended that weather stations are placed in the study area to evaluate the accuracy of Cambria Weather Underground metrological data and reduce assumptions that have to be made when using just one weather station. Parameters such as winds speed and wind direction have high variability 
and it is inaccurate to assume that the meteorological parameters are constant throughout a large area. Having a more accurate measurement of the variability of meteorological parameters across the study region will provide additional data to help identify correlations between source and receptor. Additionally, the study could be improved by monitoring the number of homes burning in the morning in addition to the evening since Cambria residents do not only burn wood in the evening. Overall, to improve the estimate of residential $\mathrm{PM}_{2.5}$ levels, meteorological factors and burning habits must be considered since they can create significant wood smoke concentration variations. This research illustrated that characterizing the overall importance of proximity in exposure calculations is an important consideration for other types of sources, such as distributed power generation. Given the significant variability in near field exposure effects, prioritization and control strategies for wood smoke sources as well as potentially for other distributed emissions sources must be executed with an understanding of these issues. 


\section{References}

Andreae, M.O. \& Gelencser, A. (2006). Black carbon or brown carbon? The nature of light-absorbing carbonaceous aerosols. Atmospheric Chemistry and Physics, 6, $3131-3148$

ARB, Strategic Plan for Research 2001 to 2010 (April 2003 update). State of California, California Environmental Protection Agency, Air Resources Board. Retrieved February 16, 2009, from http://www.arb.ca.gov/research/apr/apr.htm

Berry, D. A. (1987). Logarithmic transformations in ANOVA. Biometrics, 4 (2), 439456.

Bi, X. H., Simoneit, B. R. T., Sheng, G. Y., Ma, S. X., \& Fu, J. M. (2008). Composition and major sources of organic compounds in urban aerosols. Atmospheric Research, 88(3-4), 256-265.

Blanchard, C. L., Carr, E. L., Collins, J. F., Smith, T. B., Lehrman, D. E., \& Michaels, H. M. (1999). Spatial representativeness and scales of transport during the 1995 Integrated Monitoring Study in California's San Joaquin Valley. [Jour]. Atmospheric Environment, 33(29), 4775-4786.

Brown, S., Roberts, P., McCarthy, M., Lurmann, F., \& Hyslop, N. (2006). Wintertime vertical variations in particulate matter (PM) and precursor concentrations in the San Joaquin Valley during the California Regional coarse PM/fine PM Air Quality Study. Journal of the Air and Waste Management Association, 56(9), $1267-1277$.

Cambria Chamber of Commerce. (2009). Facts about Cambria. Retrieved May 1, 2009, from http://www.cambriachamber.org/info.php 
Cass, G. R. (1998). Organic molecular tracers for particulate air pollution sources. TrAC, Trends in Analytical Chemistry (Personal Edition), 17(6), 356-366.

Chow J. C., Watson J.G., Lowenthal D. H., Chen L. W. A., \& Magliane, K. L. (2006). Particulate carbon measurements in California's San Joaquin Valley. Chemosphere $62: 337-348$

Chu, S.-H., Paisie, J. W., \& Jang, B. W. L. (2004). PM data analysis - A comparison of two urban areas: Fresno and Atlanta. [Jour]. Atmospheric Environment, 38(20), 3155-3164.

Collett Jr, J. L., Engling, G., Herckes, P., Garcia, C., Henry, C., \& Malm, W. (2004). New techniques for the measurement of wood smoke marker compounds. Paper presented at the Symposium on Air Quality Measurement Methods and Technology 2004, Apr 20-22 2004.

Collett Jr, J. L., Youngster S. B., Lee T., Chang H., and Herckes P. (2005) Processing of Atmospheric Organic Matter by California Radiation Fogs. American Geophysical Union, Fall Meeting 2005, abstract \#A24B-01

Demerjian, K. L., \& Mohnen, V. A. (2008). Synopsis of the temporal variation of particulate matter composition and size. Journal of the Air \& Waste Management Association, 58(2), 216-233.

Engling, G., Herckes, P., Carrillo, J., Kreidenweis, S. M., \& Collett Jr, J. L. (2004). Organic aerosol composition in yosemite national park during the 2002 yosemite aerosol characterization study. Paper presented at the Regional and Global Perspectives on Haze: Causes, Consequences and Controversies Visibility Specialty Conference, Oct 25-29 2004. 
Fang, G. C., \& Lee, J. F. (2008). Study of atmospheric particulates and metallic pollutants in harbor and traffic areas in central Taiwan. Environmental Engineering Science, 25(6), 809-819.

Fine P.M., Cass G.R., and Simoneit B.T. (2001). Chemical Characterization of Fine Particle Emissions from Fireplace Combustion of Woods Grown in the Northeastern United States. Environmental Science and Technology, 35, 2665-2675.

Fine P. M., Cass G. R., Simoneit, B. R. T. (2002). Organic Compounds in Biomass Smoke from Residential Wood Combustion: Emissions Characterization at a Continental Scale. Journal of Geophysical Research, 107 (D21), ICC11-1-ICC119.

Fine P. M., Cass G. R., Simoneit, B. R. T. (2004). Chemical Characterization of Fine Particle Emissions from the Fireplace Combustion of Wood Types Grown in the Midwestern and Western United States. Environmental Engineering Science, 21 (3), 387-410.

Fischer, P. H., Hoek, G., van Reeuwijk, H. (2000). Traffic-related differences in outdoor and indoor concentrations of particles and volatile organic compounds in Amsterdam. Atmospheric Environment, 34, 3713-3722.

Gao, N., Krumhansl, K., Lafferty, K., Hopke, P. K., Kim, E., \& Poirot, R. L. (2004). Sources of fine particulate species in ambient air over lake Champlain Basin, Vermont. Paper presented at the Regional and Global Perspectives on Haze: Causes, Consequences and Controversies Visibility Specialty Conference, Oct 25292004.

Gilbert, N. (2005). Assessing Spatial Variability of NO2 in Montreal with a land use 
regression model. Journal of Air \& Waste Management Association, 55, 1059.

Glasius M., Ketzela M., Wahlina P., Jensena B., Mønstera J., Berkowicza R., and

Palmgrena F. (2006) Impact of wood combustion on particle levels in a residential area in Denmark, Atmospheric Environment 40, 7115-7124.

Gorin, C., Collett, J., \& Herckes, P. (2006). Wood smoke contribution to winter aerosol in Fresno, CA. Journal of the Air and Waste Management Association, 56(11), $1584-1590$.

Graver, B., Eatough, N. L., Hopke, P. K., \& Eatough, D. J. (2004). Measurement of fine particulate mass, including the semi-volatile constituents, with a GRIMM monitor. [Conf]. Symposium on Air Quality Measurement Methods and Technology 2004, 187-197.

Gundel, L.A., Dod, R.L., Rosen, H., Novakov, T. (1984). The relationship between optical attenuation and black carbon concentrations for ambient and source particles. The Science of the Total Environment 36, 197-202.

Hansen, A.D.A. (2005). The Aethalometer. Magge Scientific Company.

Held, T., Ying, Q., Kaduwela, A., \& Kleeman, M. (2004). Modeling particulate matter in the San Joaquin Valley with a source-oriented externally mixed three-dimensional photochemical grid model. [Jour]. Atmospheric Environment, 38(22), 3689-3711.

Hoek, G. (2001). Estimation of long-term average exposure to outdoor air pollution for a cohort study on mortality. Epidemiology, 11, 459-469.

Hoek, G., Meliefste, K., Cyrys, J. (2002). Spatial variability of fine particle concentrations in three European areas. Atmospheric Environment, 36, 40774088. 
Hoek, G. B. B., Goldbohm, S., Fischer, P., van den Brandt, P. A. (2002). Association between mortality and indicators of traffic-related air pollution in the Netherlands: a cohort study. Lancet, 360 (9341), 1203-1209.

Karppinen, A., Kukkonen, J., Elolahde, T., Konttinen, M., Koskentalo, T., \& Rantakrans, E. (2000). A modelling system for predicting urban air pollution: model description and applications in the Helsinki metropolitan area. Atmospheric Environment, 34, 3723-3733.

Kim, E., Hopke, P. K., \& Edgerton, E. S. (2004). Improving source identification of Atlanta aerosol using temperature resolved carbon fractions in positive matrix factorization. Atmospheric Environment, 38 (20), 349-3362.

Kingham, S., Durand, M., Aberkane, T., Harrison, J., Wilson, J.G., \& Epton, M. (2006). Winter comparison of TEOM, Mini-Vol and DustTrak $\mathrm{PM}_{10}$ monitors in a woodsmoke environment. Atmospheric Environment, 40, 338-347.

Kirchstetter, T.W., Novakov, T., and Hobbs P.V. (2004). Evidence that the spectral dependence of light absorption by aerosols is affected by organic carbon. Journal of Geophysical Research 109, D21208.

Kirchstetter, T.W. and Novakov T. (2007). Controlled generation of black carbon particles from a diffusion flame and applications in evaluating black carbon measurement methods. Atmospheric Environment 41, 1874-1888.

Kleeman, M. J., Schauer, J. I., \& Cass, G. R. (1999). Size and composition distribution of fine particulate matter emitted from wood burning, meat charbroiling, and cigarettes. Environmental Science and Technology, 33(20), 3516-3523.

Koenig, J., Larson, T. V., Hanley, Q. S., Rebolledo, V., Dumler, K., Checkoway, H., et. 
al. (1993). Pulmonary Function Changes in Children Associated with Fine Particulate Matter. Environmental Research. 63, 26-38.

Lai, A.C.K., Thatcher, T.L., and Nazaroff, W. W.(2000) Inhalation Transfer Factors for Air Pollution Health-Risk Assessment, Journal of the Air \& Waste Management Association. 50, 1688-1699. LBNL-43712.

Larson, T., Su, J., Baribeau A., Buzzelli, M., Setton, E., \& Brauer, M. (2007). A spatial model of urban winter woodsmoke concentrations. Environmental Science\& Technology, 41(7), 2429-2436.

Larson, T.,Koenig, J. (1994). WoodSmoke: Emissions and Non-Cancer Respiratory Effects. Annual Review of Public Health 15, 133-156.

Liu, W., Hopke, P. K., Han, Y.-J., Yi, S.-M., Holsen, T. M., Cybart, S., et al. (2003). Application of receptor modeling to atmospheric constituents at Potsdam and Stockton, NY. Atmospheric Environment, 37(36), 4997-5007.

M. Glasiusa, M. K., P. Wa hlina, B. Jensena, J. Mønstera,b, R. Berkowicza, F. Palmgrena. (2006). Impact of wood combustion on particle levels in a residential area in Denmark. Atmospheric Envionment.

Manchester-Neesvig, J. B., Schauer, J. J., \& Cass, G. R. (2003). The distribution of particle-phase organic compounds in the atmosphere and their use for source apportionment during the Southern California children's health study. Journal of the Air and Waste Management Association, 53(9), 1065-1079.

Marshall JD and Nazaroff WW (2004) Using Intake Fraction To Guide ARB Policy Choices: The Case of Particulate Matter, unpublished ARB Report. Miller, K. A., Siscovick, D. S., Sheppard, L., Shepherd, K., Sullivan, J. H., Anderson, G. 
L., Kaufman, J. D. (2007) Long-term exposure to air pollution and incidence of cardiovascular events in women. New England Journal of Medicine,356 (5), 447458.

Naeher, L. P., Brauer, M., Lipsett, M., Simpson, C. D., Koenig, J. Q., Smith, K. R. (2007). Woodsmoke health effects: A review. Inhalation Toxicology, 19 (1), 67106.

National Air Pollutant Emissions Trends Update, 1970-1997; Office of Air Quality Planning and Standards, U.S. EPA: Research Triangle Park, NC, 1998. Naval Post Graduate School. (2008, November 3). Coastal wind profiler page. Retrieved May 1, 2009, from http://www.weather.nps.navy.mil/profiler/coastprof.html

Nolte, C. G., Schauer, J. J., Cass, G. R., \& Simoneit, B. R. T. (2001). Highly polar organic compounds present in wood smoke and in the ambient atmosphere. Environmental Science and Technology, 35(10), 1912-1919.

Park, K., Chow, J., Watson, J., Trimble, D., Doraiswamy, P., Park, K., et al. (2006). Comparison of continuous and filter-based carbon measurements at the Fresno Supersite. Journal of the Air and Waste Management Association, 56 (4), 474491.

Poore, MW (2002) Levoglucosan in PM2.5 at the Fresno Supersite. Journal of the Air \& Waste Management Association 52, 3-4.

Rinehart, L. R., Fujita, E. M., Chow, J. C., Magliano, K., \& Zielinska, B. (2006). Spatial distribution of PM2.5 associated organic compounds in central California. [Jour]. Atmospheric Environment, 40(2), 290-303.

Rogge W.F., Hildemann L.M., Mazurek M.A., and Cass G.R. (1998) Sources of Fine 
Organic Aerosol. 9. Pine, Oak, and Synthetic Log Combustion in Residential Fireplaces, Environmental Science and Technology 32, 13-22.

San Luis Obispo Air Pollution Control District. (1993, October 19). Rule 504 Residential wood combustion. Retrieved May 1, 2009, from http://www.arb. ca.gov/DRDB/SLO/CURHTML/R504.htm

San Luis Obispo Air Pollution Control District. (2008). District approved devices. Retrieved May 1, 2009, from http://www.slocleanair.org/programs/woodstovesapproved.php

Schauer, J. J.; Cass, G. R. 2000. Environmental Science and Technology. 34, 1821-1832.

Schwab, J. J., Felton, H. D., Rattigan, O. V., \& Demerjian, K. L. (2006). New York state urban and rural measurements of continuous PM2.5 mass by FDMS, TEOM, and BAM. Journal of the Air \& Waste Management Association, 56(4), 372-383.

Sheesleya R. J., Schauer J. J., Zheng M. , and Wang B. (2007) Sensitivity of molecular marker-based CMB models to biomass burning source profiles, in Press.

Shipp, E. M. (1995). Meteorological characteristics and forecasting of high PM10 days applicable to declaring "ban" and "burn" days for residential wood combustion in northern San Luis Obispo County. San Luis Obispo, CA: Air Pollution Control District.

Simoneit B.R.T., Schauer J.J., Nolte C.G., Oros D.R., Elias V.O., Fraser M.P., Rogge W.F., Cass G.R. (1999) Levoglucosan, a tracer for cellulose in biomass burning and atmospheric particles. Atmospheric Environment 33, 173-182. 
Singer BC, Hotchi T, Hodgson, AT (2002) Air Pollutant Monitoring for The East Bay Children's Respiratory Health Study. Final Project Report, OEHHA Contract No. 00-E0018.

Solomon, P. A., \& Hopke, P. K. (2008). A special issue of JA\&WMA supporting key scientific and policy- and health-relevant findings from EPA's particulate matter supersites program and related studies: An integration and synthesis of results. Journal of the Air \& Waste Management Association, 58 (2), 137-139.

Sykes, R.I., Lewellen, W. S., \& Parker, S. F. (1986). A Gaussian plume model of atmospheric dispersion based on second-order closure. Journal of Applied Meteorology, 25 (3), 322-331.

Thatcher T. L. , Lunden M. M., Revzan K. L., Sextro R. G., and Brown N. J.(2003) A concentration rebound method for measuring particle penetration and deposition in the indoor environment, Aerosol Science and Technology V37:847-864.

Tian, Y. Q., Radke, J. D., Gong, P., Yu, Q. (2004). Model Development for spatial variation of PM2.5 emissions from residential wood burning. Atmospheric Environment, 38, 833-843.

Turkiewicz, K., Magliano, K., \& Najita, T. (2006). Comparison of two winter air quality episodes during the California Regional Particulate Air Quality Study. Journal of the Air and Waste Management Association, 56(4), 467-473.

U.S. Department of Housing and Urban Development and U.S. Census Bureau. (2008, September). American housing survey for the United States: 2007. Retrieved April 17, 2009, from http://www.census.gov/prod/2008pubs/h150-07.pdf

Utts, J. M. \& Heckard, R. F. (2002). Mind on Statistics. Pacific Grove, CA: Duxbury. 
Ward, T., \& Noonan, C. (2008). Results of a residential indoor PM2.5 sampling program before and after a woodstove changeout. Indoor Air, 18(5), 408-415.

Watson, J. G., \& Chow, J. C. (2002). A wintertime PM2.5 episode at the Fresno, CA, supersite. [Jour]. Atmospheric Environment, 36(3), 465-475.

Weather Underground (2009). Marine Terrace, Cambria, California. Retrieved May 22, 2009, from http://www.wunderground.com/US/CA/Cambria.html 


\section{APPENDIX A}

\section{Aethalometer Comparisons}

\section{Before Specific Attenuation Adjustments}

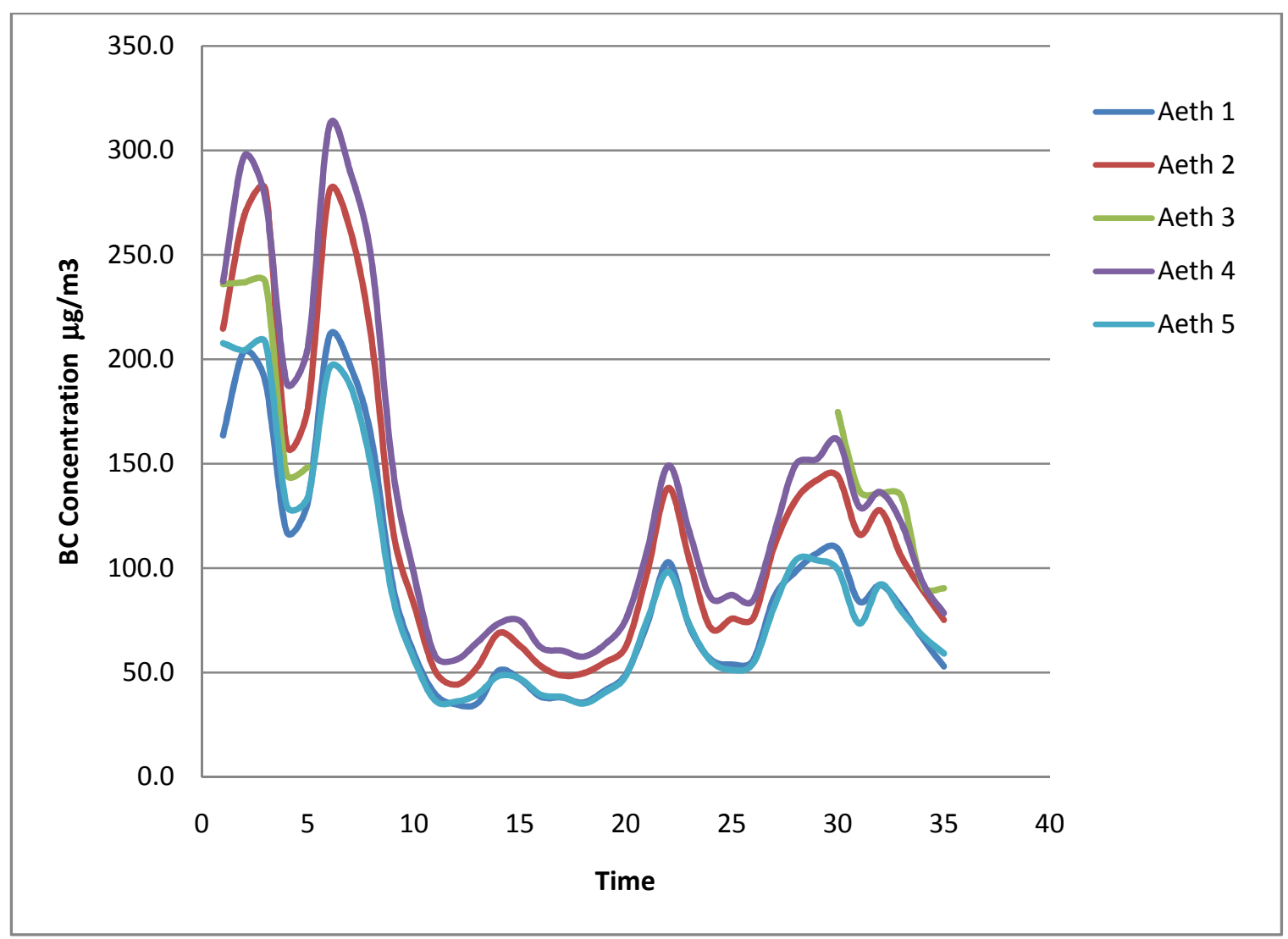


After Specific Attenuation Adjustments

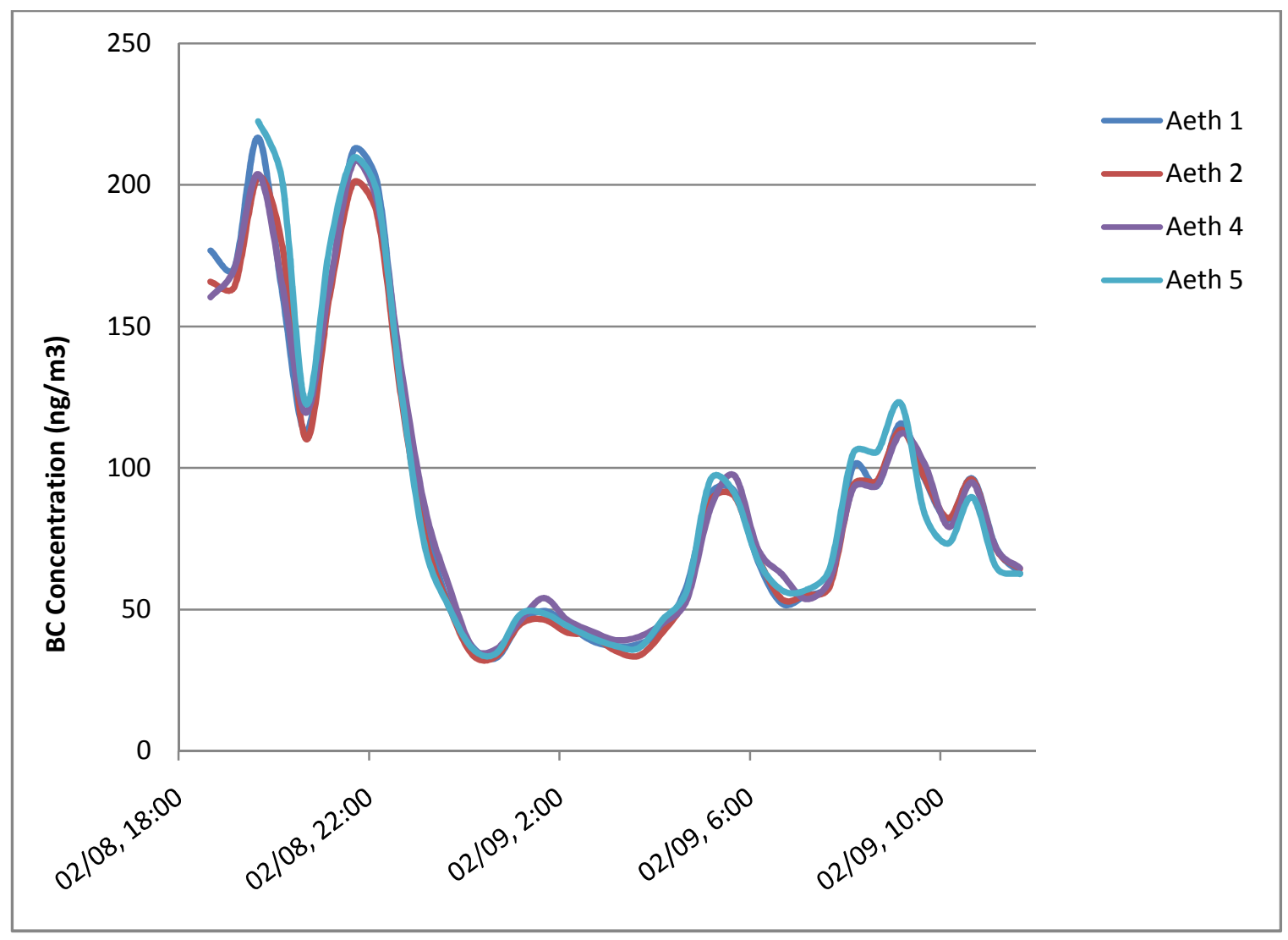




\section{APPENDIX B}

\section{IOP Wind Roses}

January 31, 2009 vector wind rose showing easterly wind.

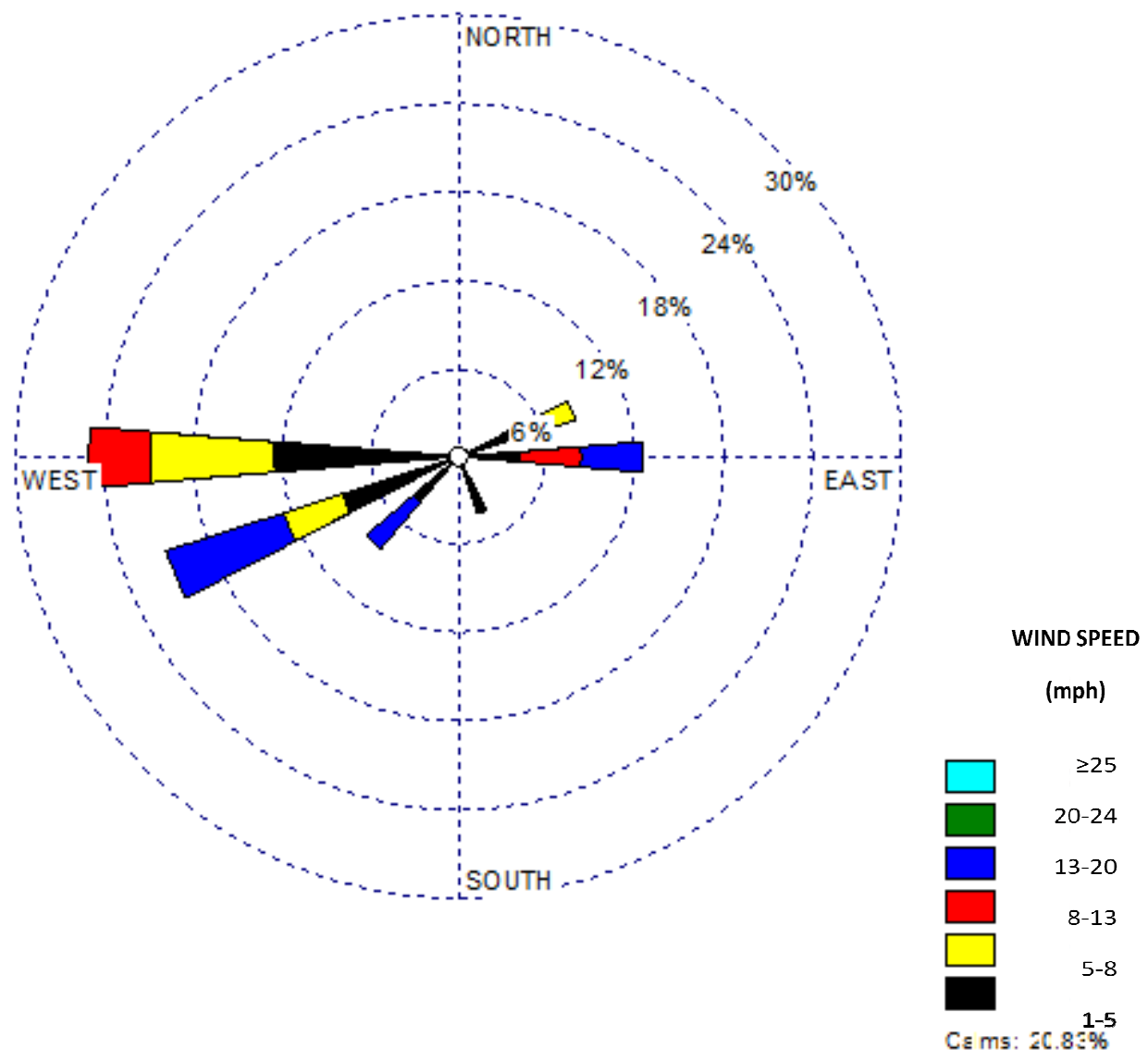


February 18, 2009 vector wind rose showing northeasterly wind.

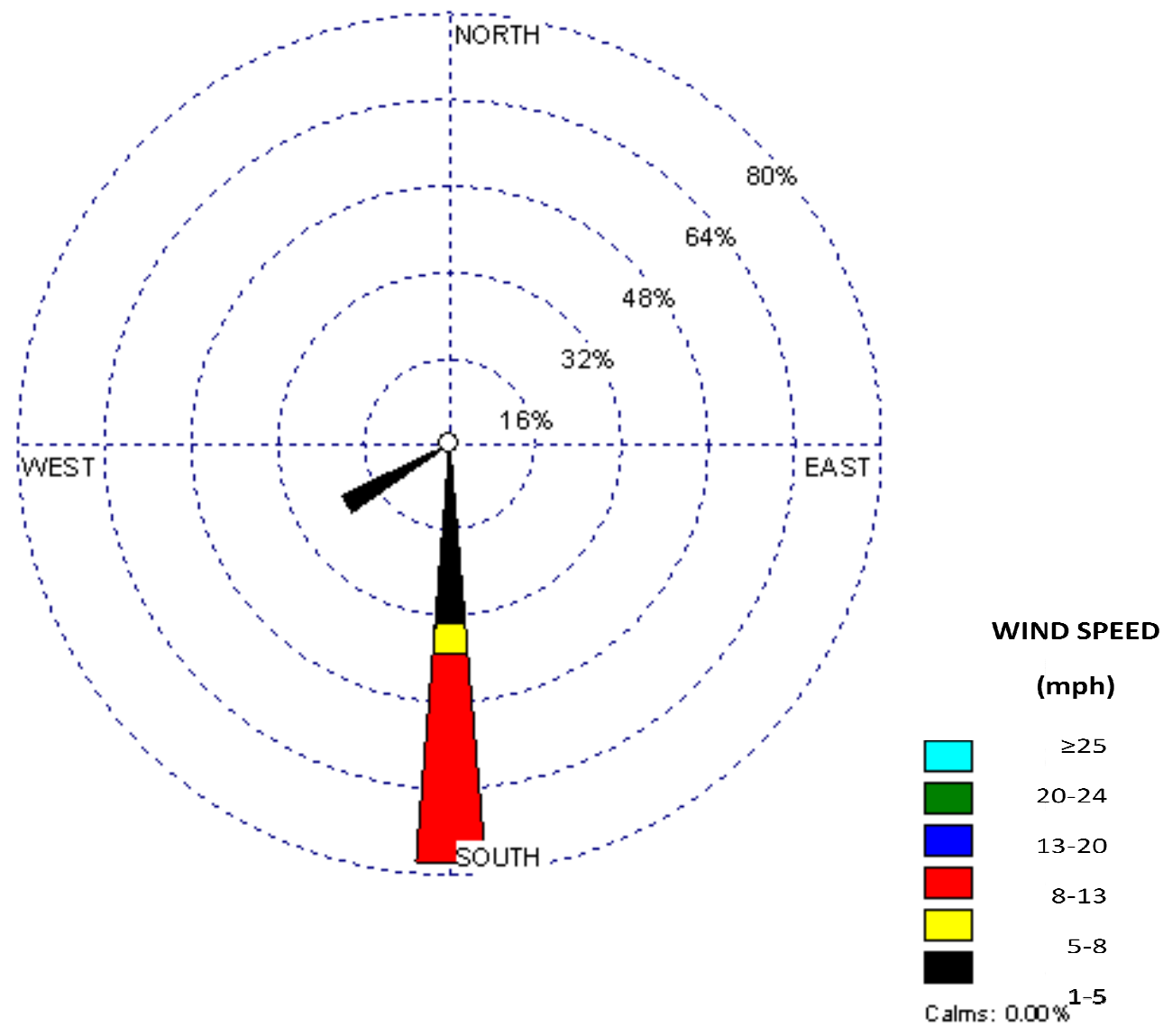


February 26, 2009 vector wind rose showing $17 \%$ strong easterly wind and $34 \%$ weak northwesterly wind.

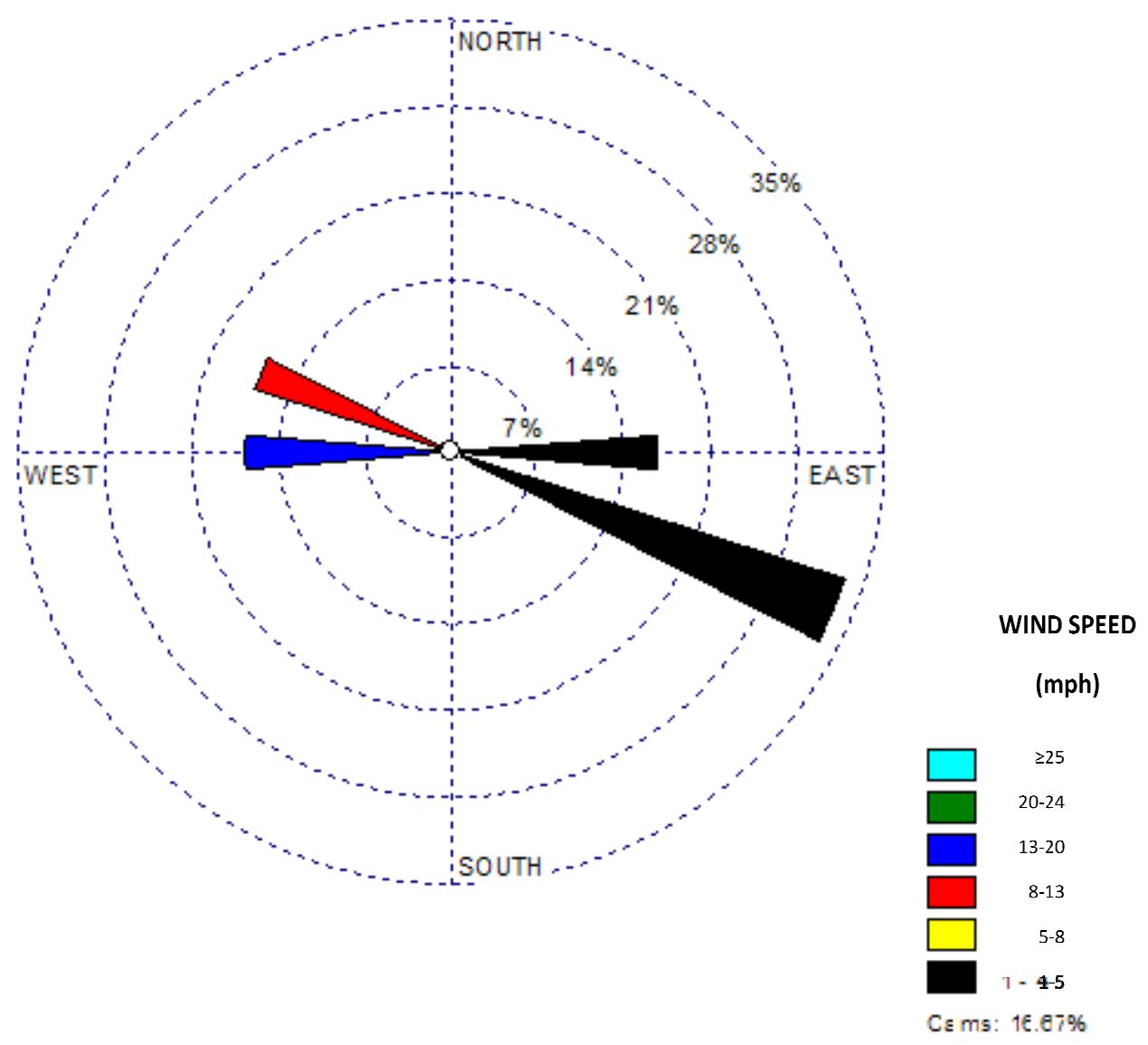


February 27, 2009 vector wind rose showing weak southwesterly and southeasterly wind.

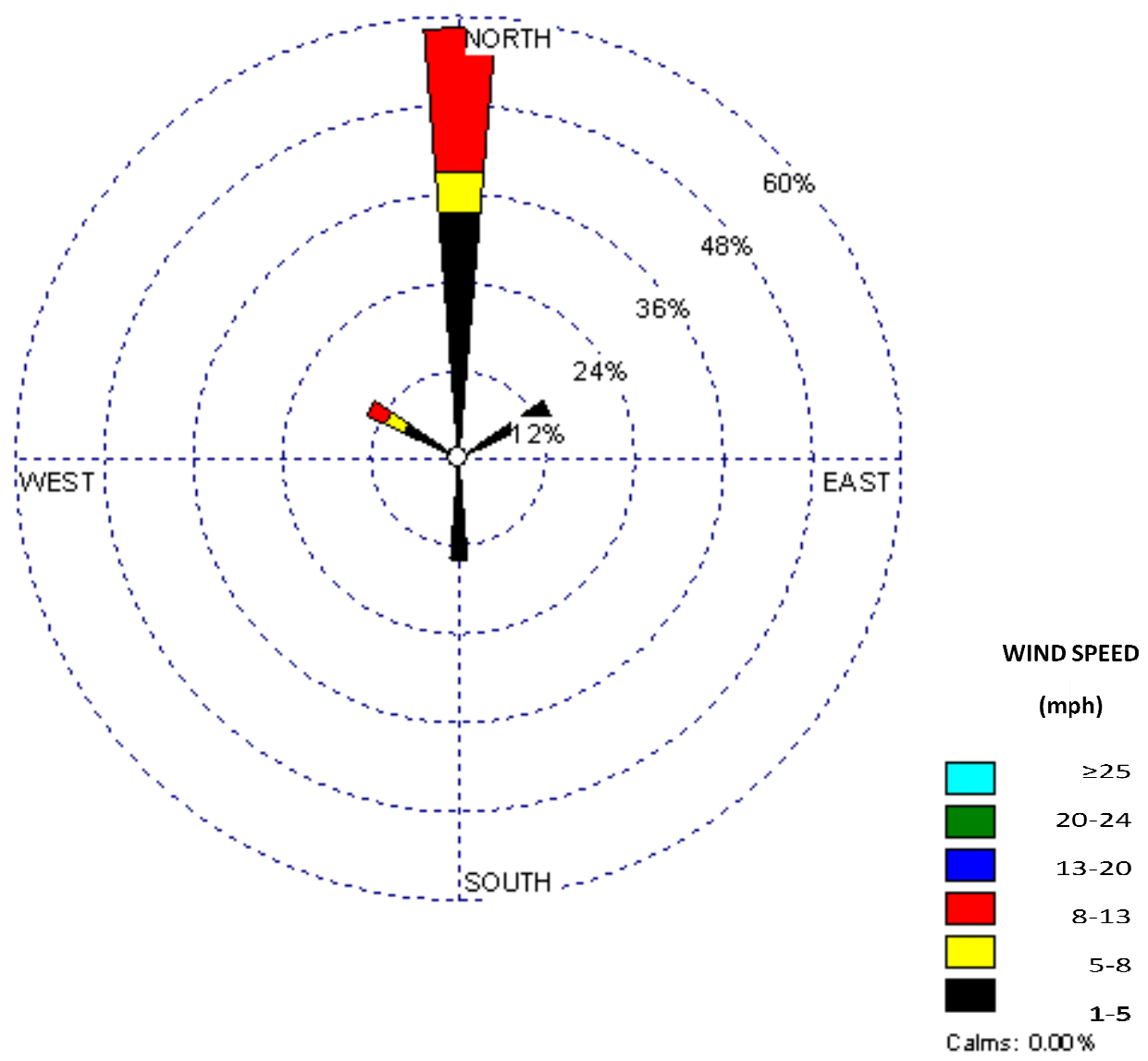


March 7, 2009 vector wind rose showing scattered wind.

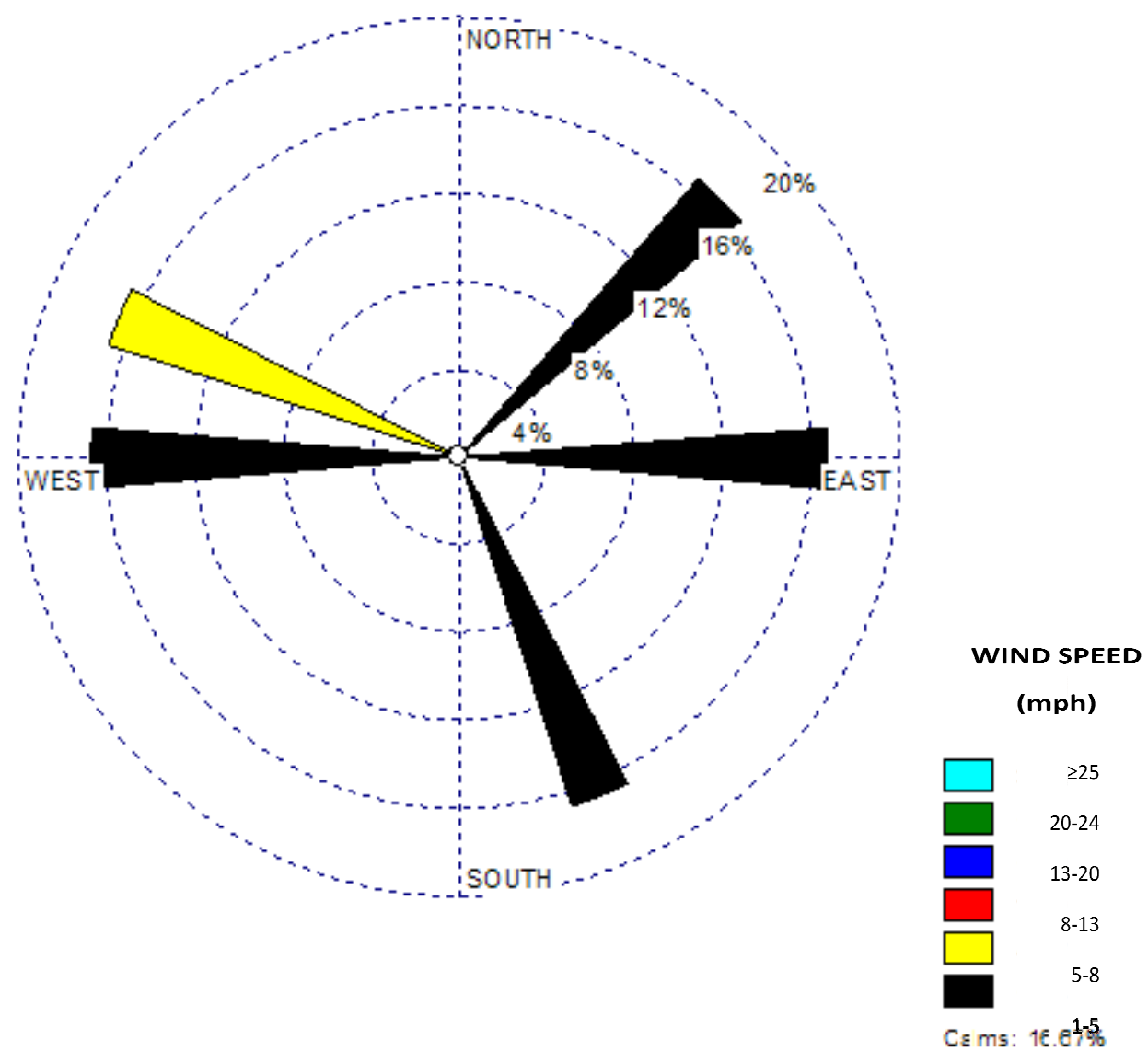


March 13, 2009 vector wind rose showing easterly wind.

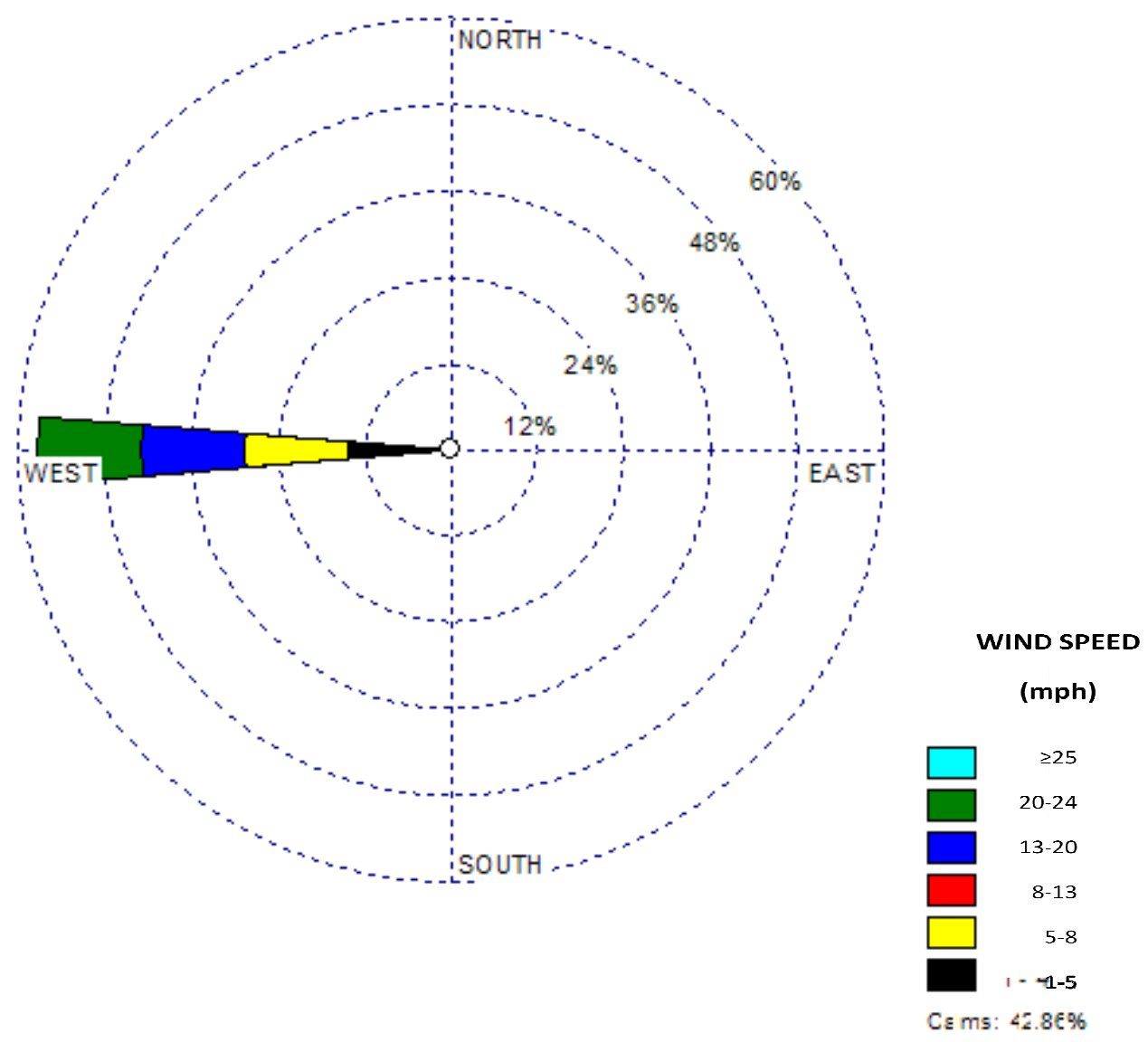


March 15, 2009 vector wind rose showing westerly wind.

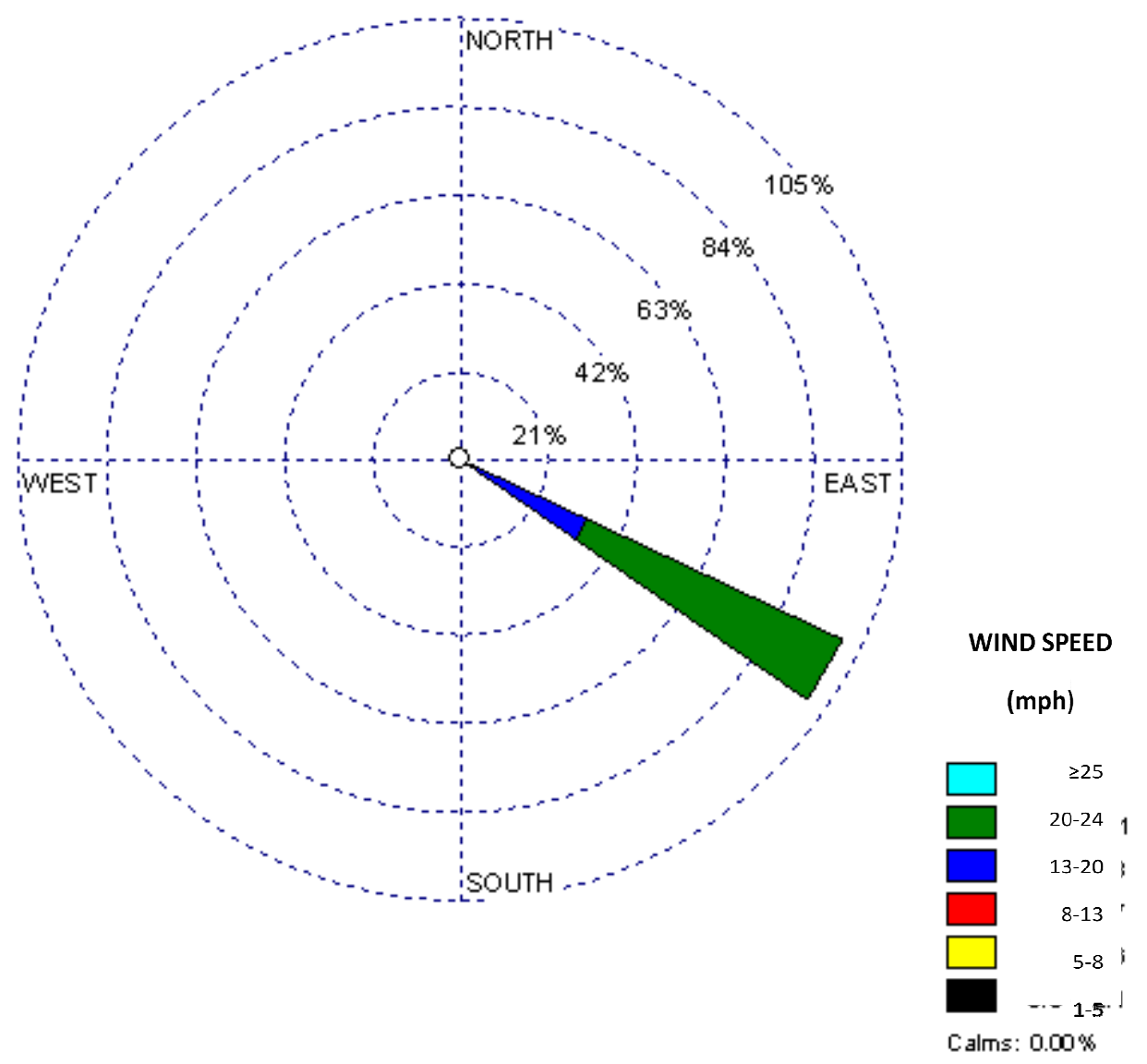


March 20, 2009 vector wind rose showing 3 mph westerly wind.

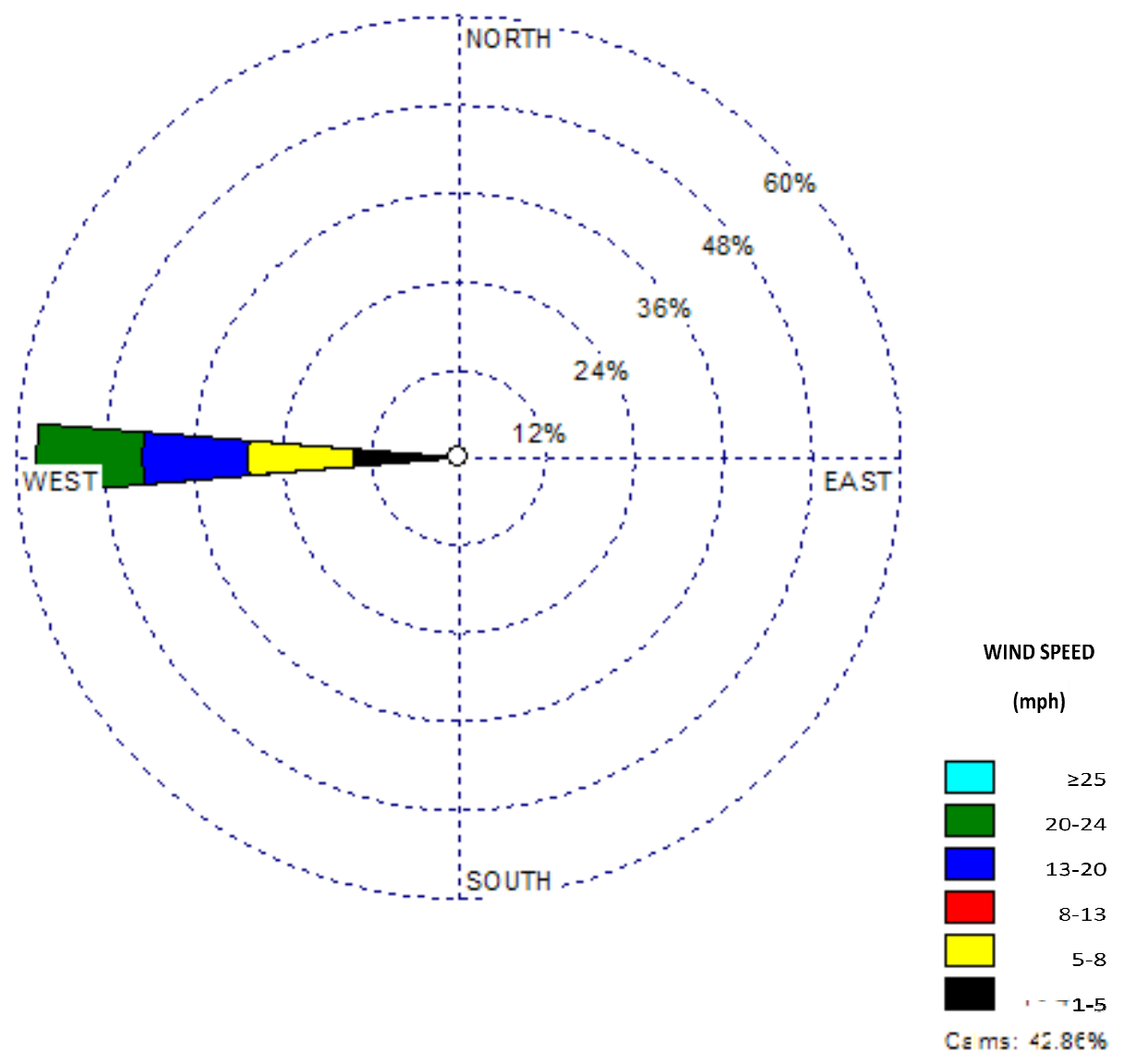




\section{APPENDIX C}

\section{IOP Inversions}

January 31, 2009

ESRL Physical Sciences Division Wind Profiling Radar

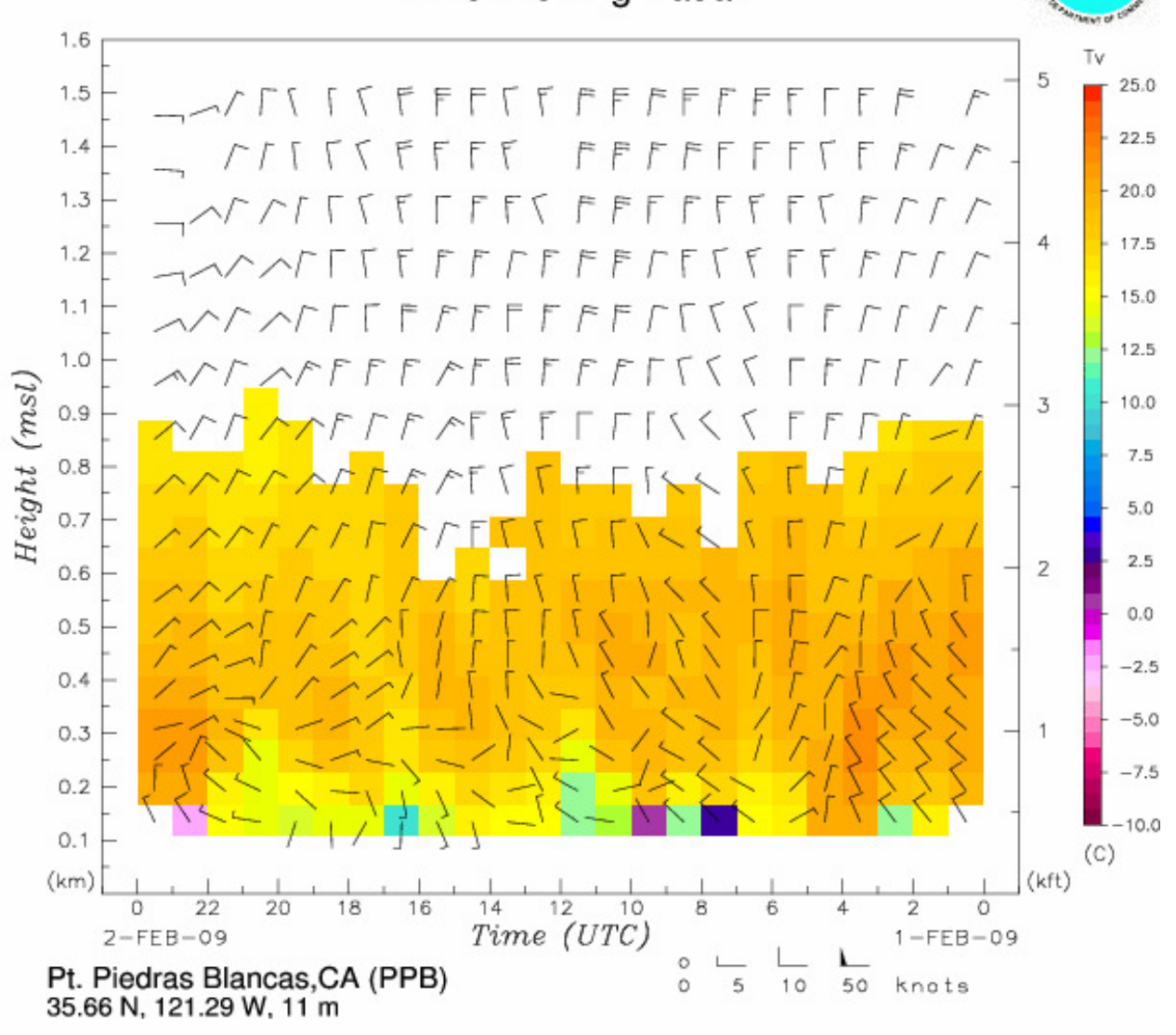


February 18, 2009

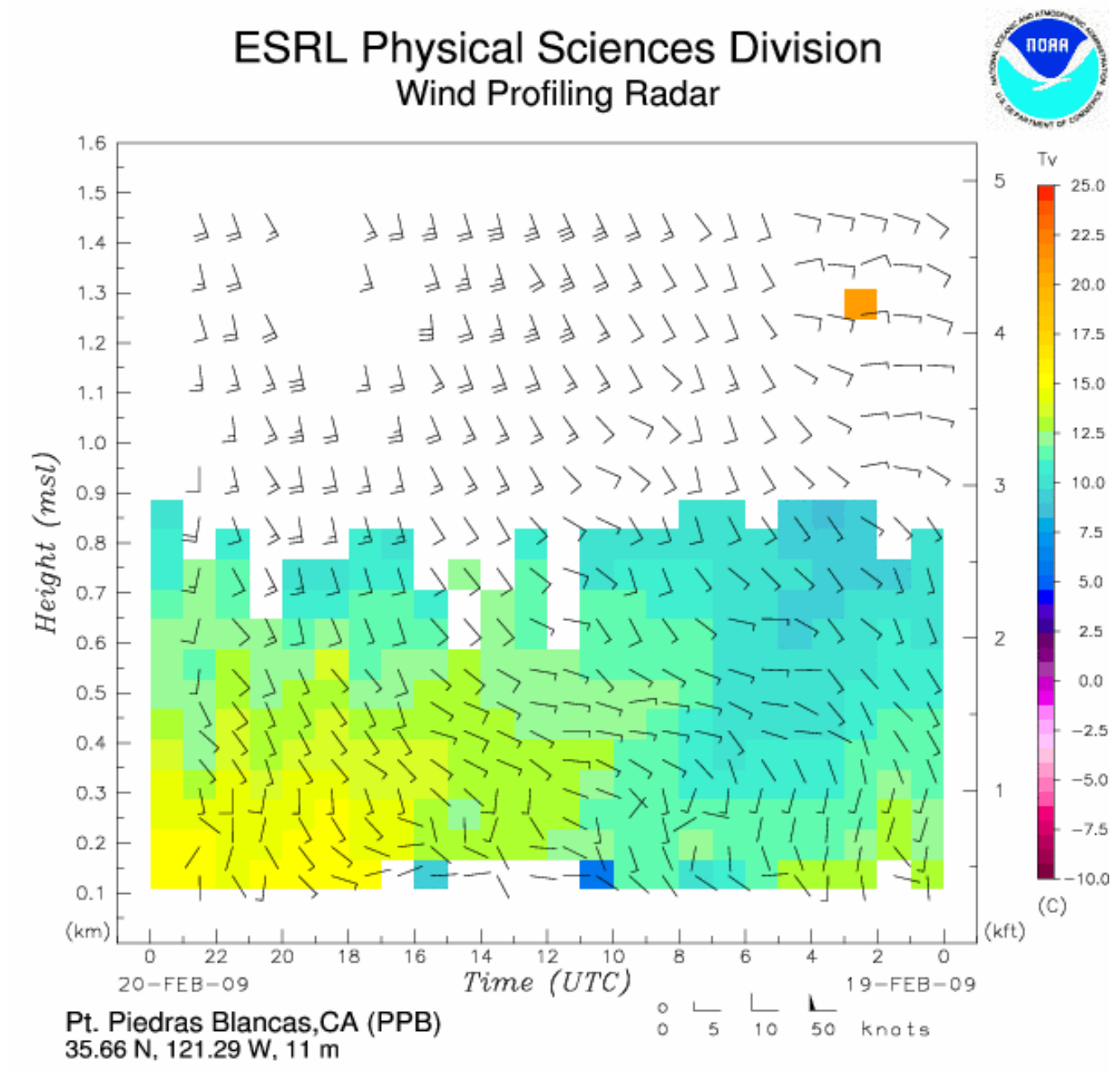


February 26, 2009

\section{ESRL Physical Sciences Division Wind Profiling Radar}

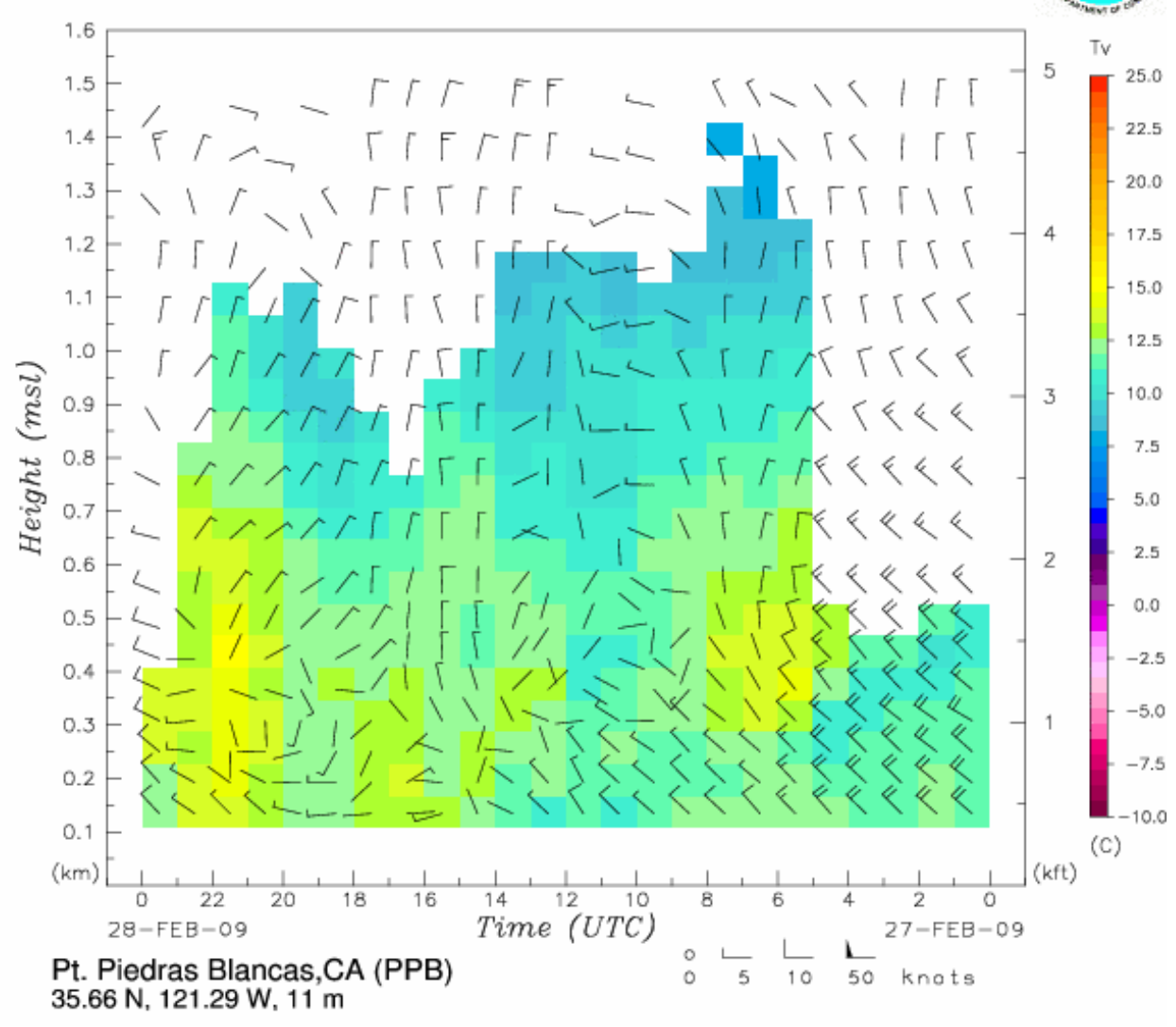


February 27, 2009

ESRL Physical Sciences Division

Wind Profiling Radar

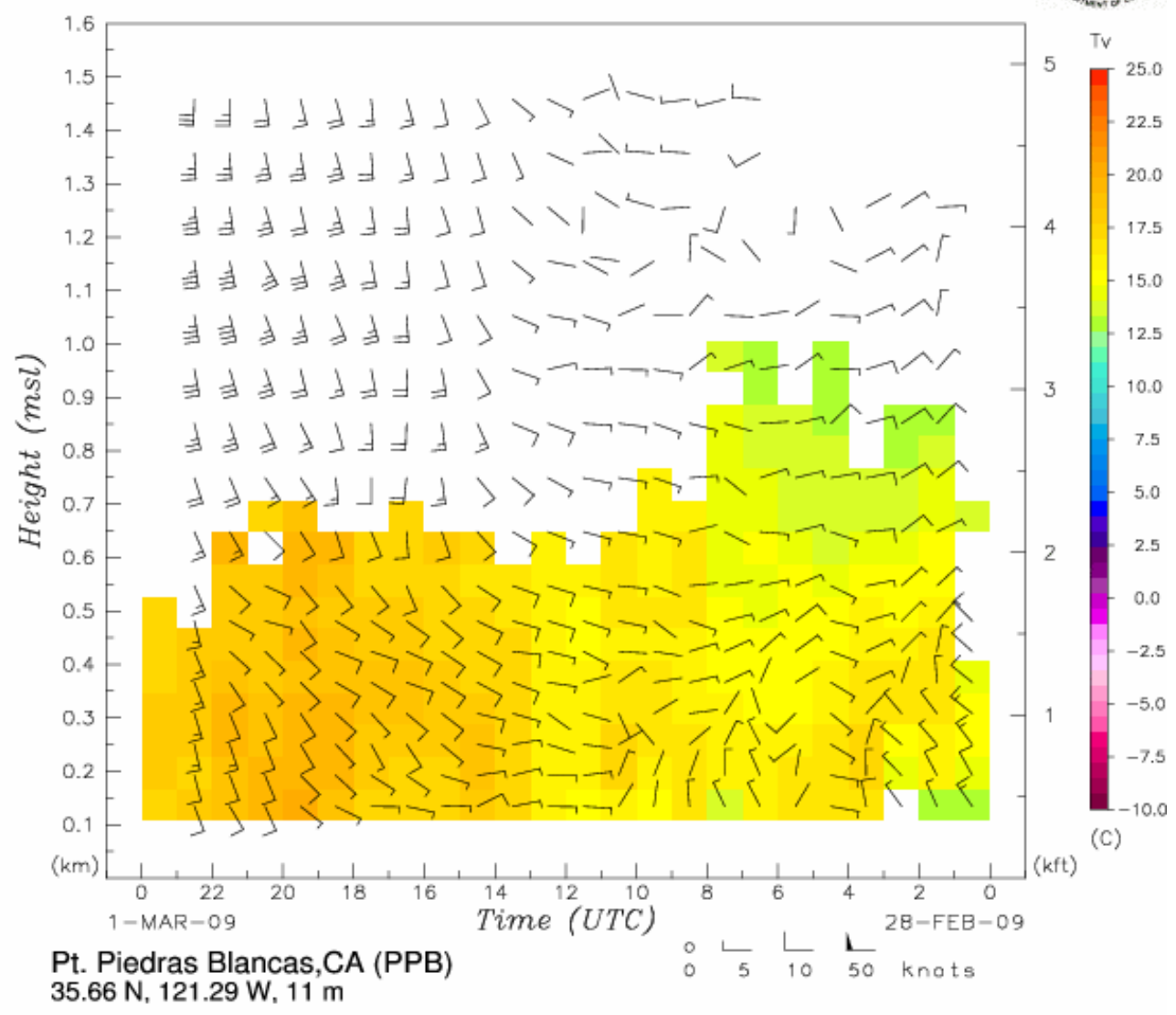


March 7, 2009

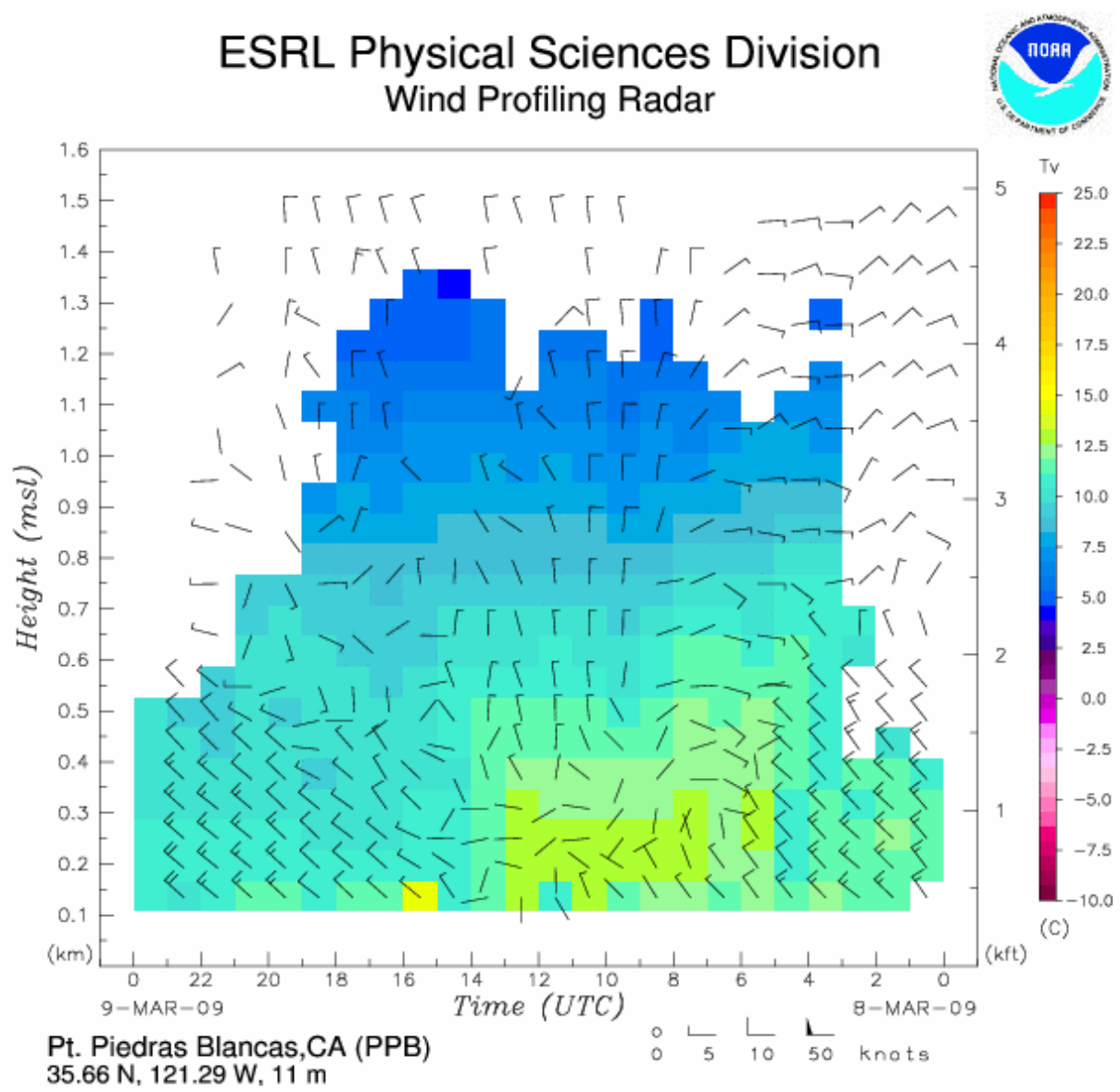


March 13, 2009

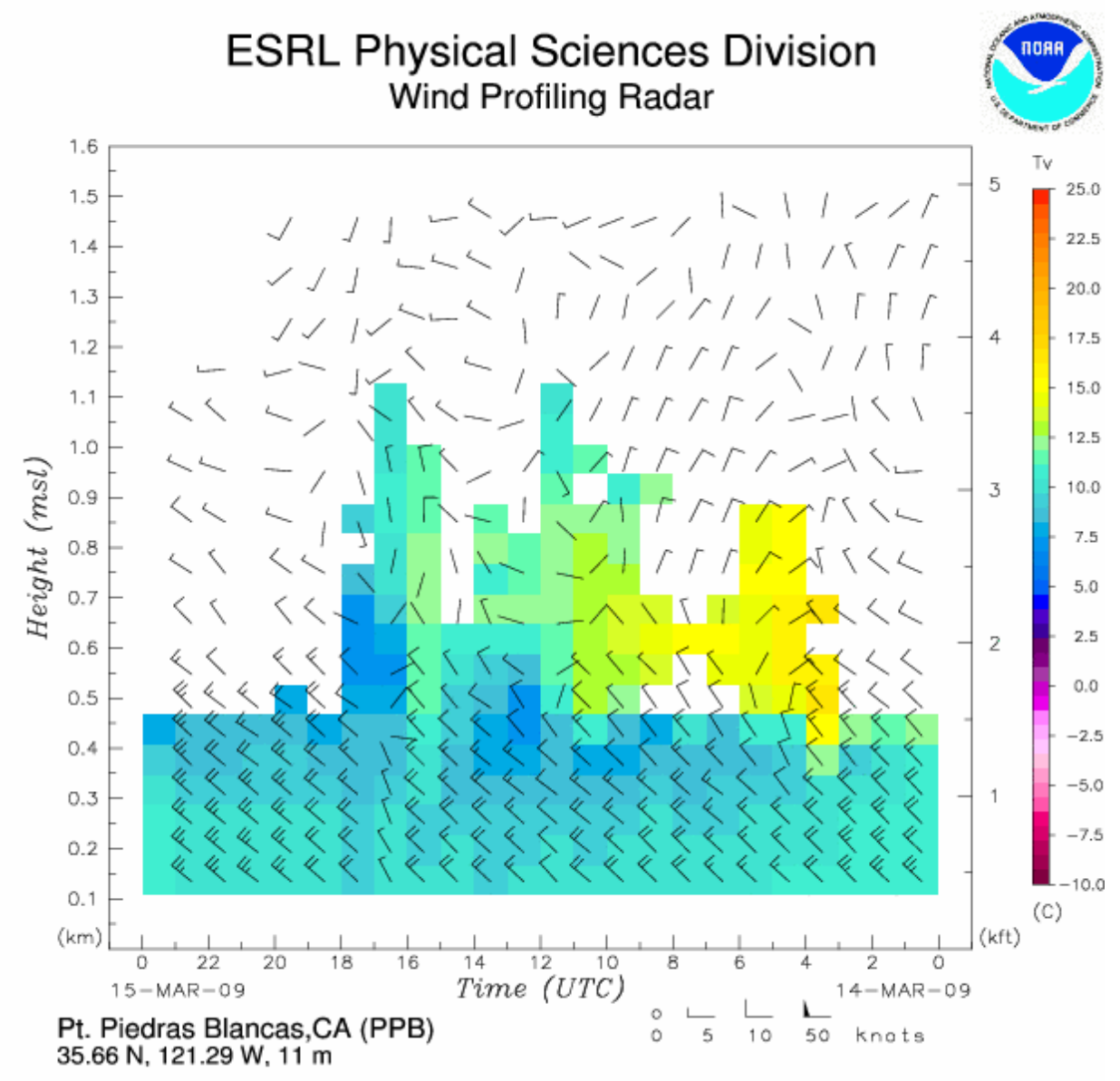


March 15, 2009

ESRL Physical Sciences Division Wind Profiling Radar

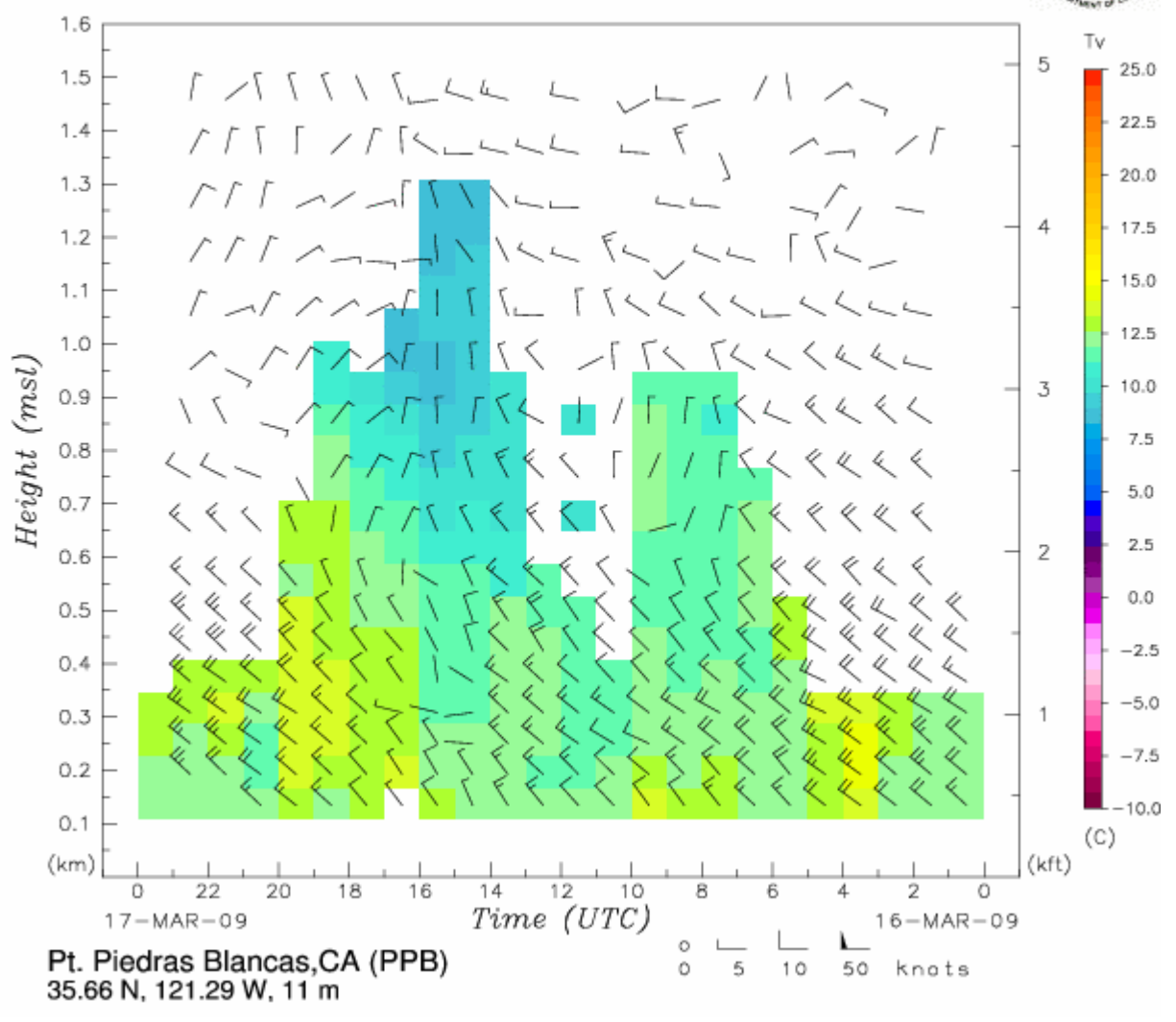


March 20, 2009

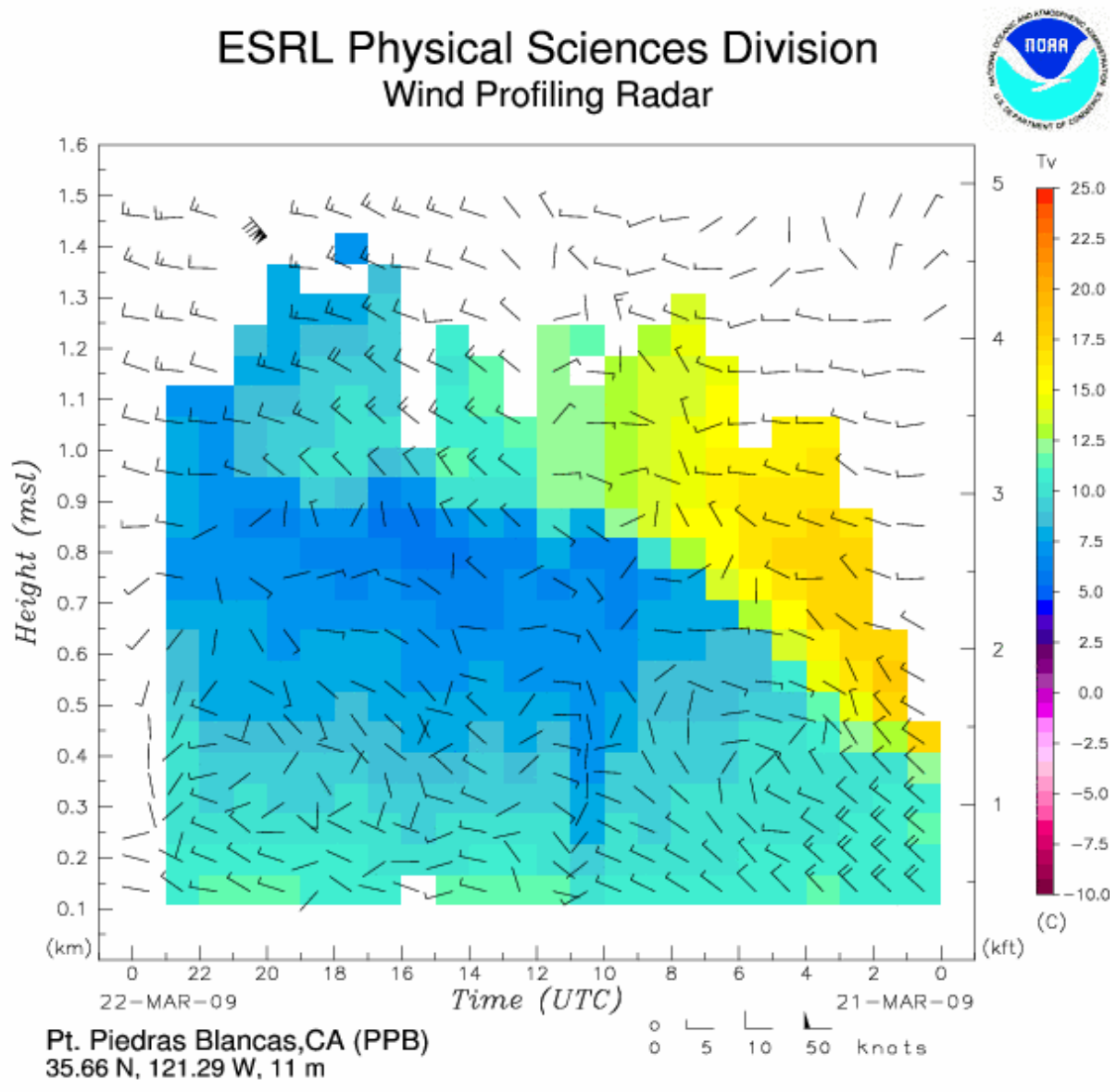




\section{APPENDIX D}

Sunset Lab's EC/OC Determination for PEMs

\begin{tabular}{|c|c|c|c|c|c|c|c|}
\hline Sample ID & $\begin{array}{l}\mathrm{OC}(\mu \mathrm{g} / \mathrm{sq} \\
\underline{\mathrm{cm})}\end{array}$ & $\begin{array}{l}\underline{\text { OC }} \\
\text { unc }\end{array}$ & $\begin{array}{l}\mathrm{EC}(\mu \mathrm{g} / \mathrm{sq} \\
\mathrm{cm})\end{array}$ & $\begin{array}{l}\underline{\text { EC }} \\
\underline{\text { unc }}\end{array}$ & $\begin{array}{l}\mathrm{TC}(\mu \mathrm{g} / \mathrm{sq} \\
\mathrm{cm})\end{array}$ & \begin{tabular}{|l|} 
TC \\
unc \\
\end{tabular} & $\begin{array}{l}\underline{\mathrm{EC} / \mathrm{TC}} \\
\underline{\text { ratio }}\end{array}$ \\
\hline 030708_EOQT_106 & 2.01 & 0.30 & 0.00 & 0.20 & 2.01 & 0.40 & 0.000 \\
\hline 030708_JOQT_103 & 7.26 & 0.56 & 0.00 & 0.20 & 7.26 & 0.66 & 0.000 \\
\hline 030709_MOQT_104 & 2.81 & 0.34 & 0.00 & 0.20 & 2.81 & 0.44 & 0.000 \\
\hline 030709_FSQT_105 & 2.17 & 0.31 & 0.00 & 0.20 & 2.17 & 0.41 & 0.000 \\
\hline 030709_E02_109 & 14.26 & 0.91 & 0.24 & 0.21 & 14.50 & 1.03 & 0.017 \\
\hline 030709_JO2_110 & 19.78 & 1.19 & 3.70 & 0.39 & 23.48 & 1.47 & 0.158 \\
\hline 030709_M02_102 & 5.35 & 0.47 & 0.49 & 0.22 & 5.84 & 0.59 & 0.084 \\
\hline 030709_FS2_114 & 5.97 & 0.50 & 0.36 & 0.22 & 6.33 & 0.62 & 0.057 \\
\hline 030709_FB2_10 & 0.75 & 0.24 & 0.00 & 0.20 & 0.75 & 0.34 & 0.000 \\
\hline 031309_EOQT_112 & 3.44 & 0.37 & 0.00 & 0.20 & 3.44 & 0.47 & 0.000 \\
\hline 031309_JOQT_101 & 2.14 & 0.31 & 0.00 & 0.20 & 2.14 & 0.41 & 0.000 \\
\hline 031309_MOQT_107 & 3.95 & 0.40 & 0.00 & 0.20 & 3.95 & 0.50 & 0.000 \\
\hline 031309_FSQT_116 & 2.01 & 0.30 & 0.00 & 0.20 & 2.01 & 0.40 & 0.000 \\
\hline 031309_EO2_109 & 4.05 & 0.40 & 0.25 & 0.21 & 4.30 & 0.52 & 0.059 \\
\hline 031309_J02_106 & 4.01 & 0.40 & 0.18 & 0.21 & 4.19 & 0.51 & 0.044 \\
\hline 031309_MO2_114 & 4.12 & 0.41 & 0.30 & 0.21 & 4.42 & 0.52 & 0.067 \\
\hline 031309_FS2_110 & 5.34 & 0.47 & 0.44 & 0.22 & 5.78 & 0.59 & 0.076 \\
\hline 031309_FB2 & 2.03 & 0.30 & 0.00 & 0.20 & 2.03 & 0.40 & 0.000 \\
\hline
\end{tabular}




\section{APPENDIX E}

\section{ANOVA MINITAB Results: January 31, 2009 IOP}

\section{GLM: BC Conc versus Day and time, Location ID}

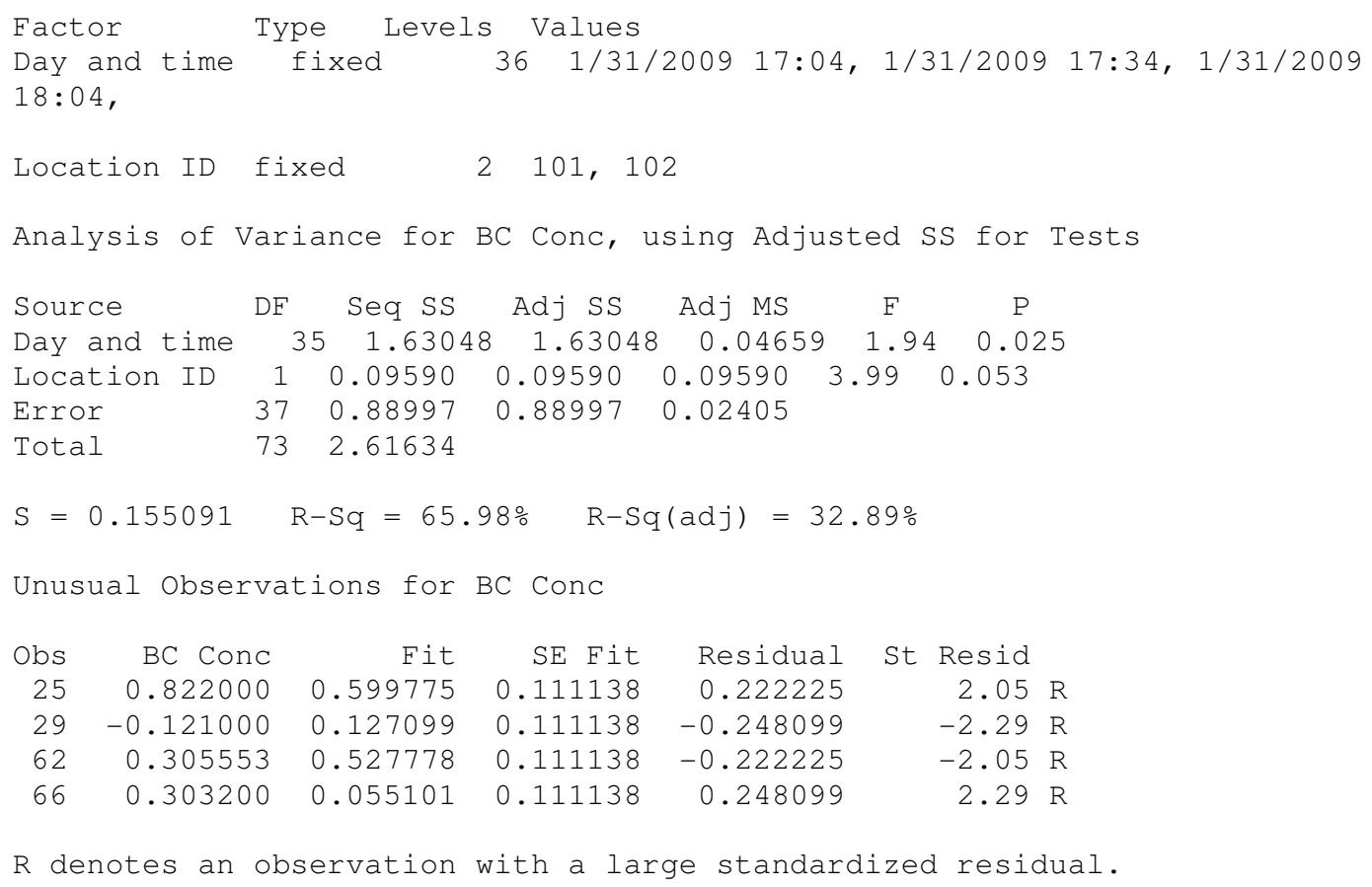

$\mathrm{R}$ denotes an observation with a large standardized residual.

\section{General Linear Model: $\log (B C$ conc) versus Location ID, Day and time}

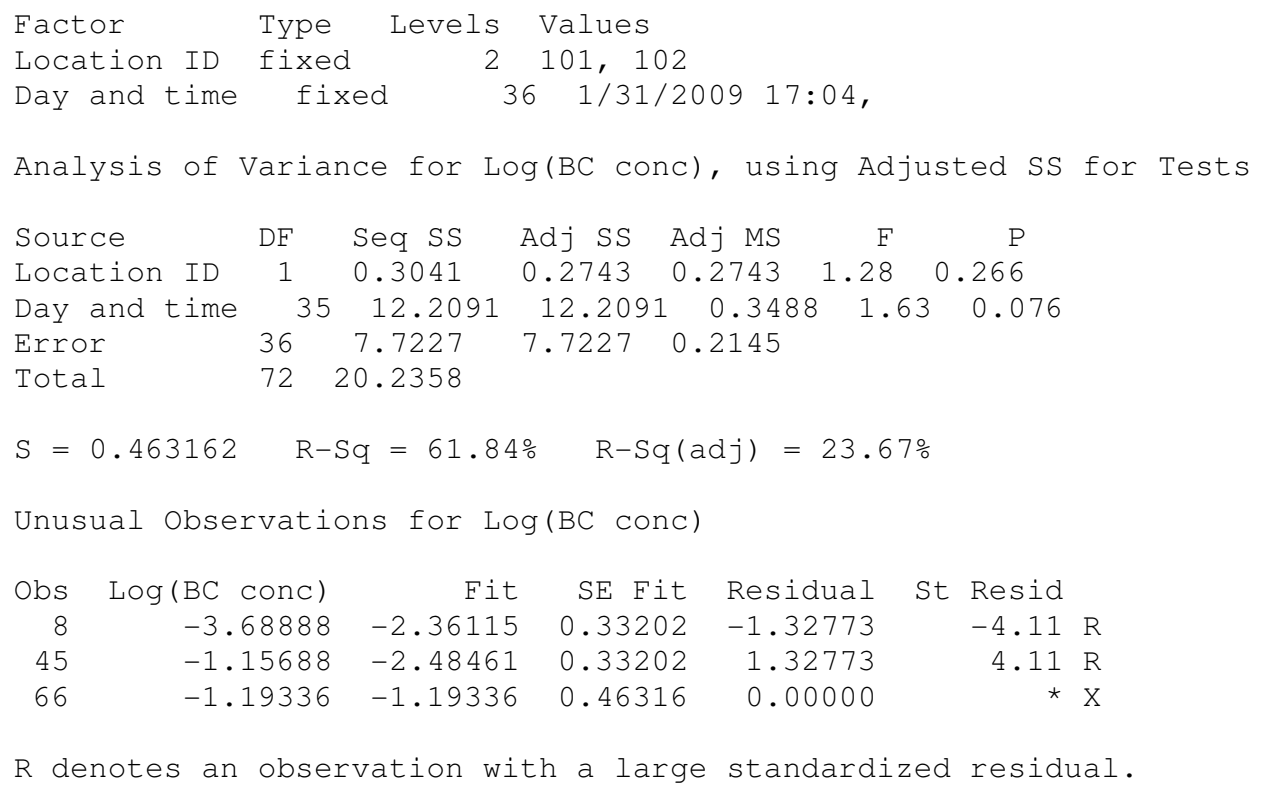



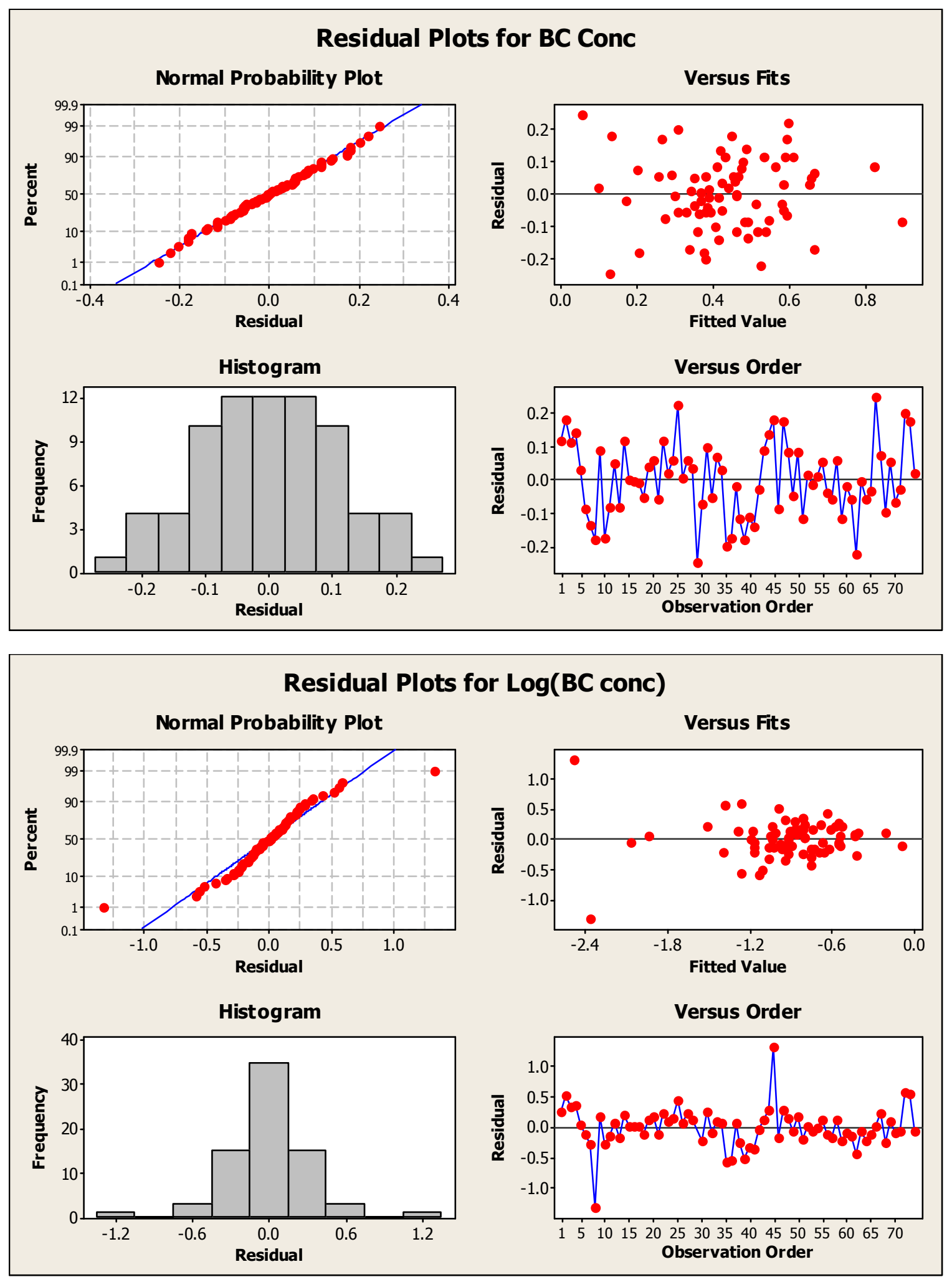


\section{APPENDIX F}

\section{General Linear Model: $\log (B C$ conc) versus Location ID, Day and time}

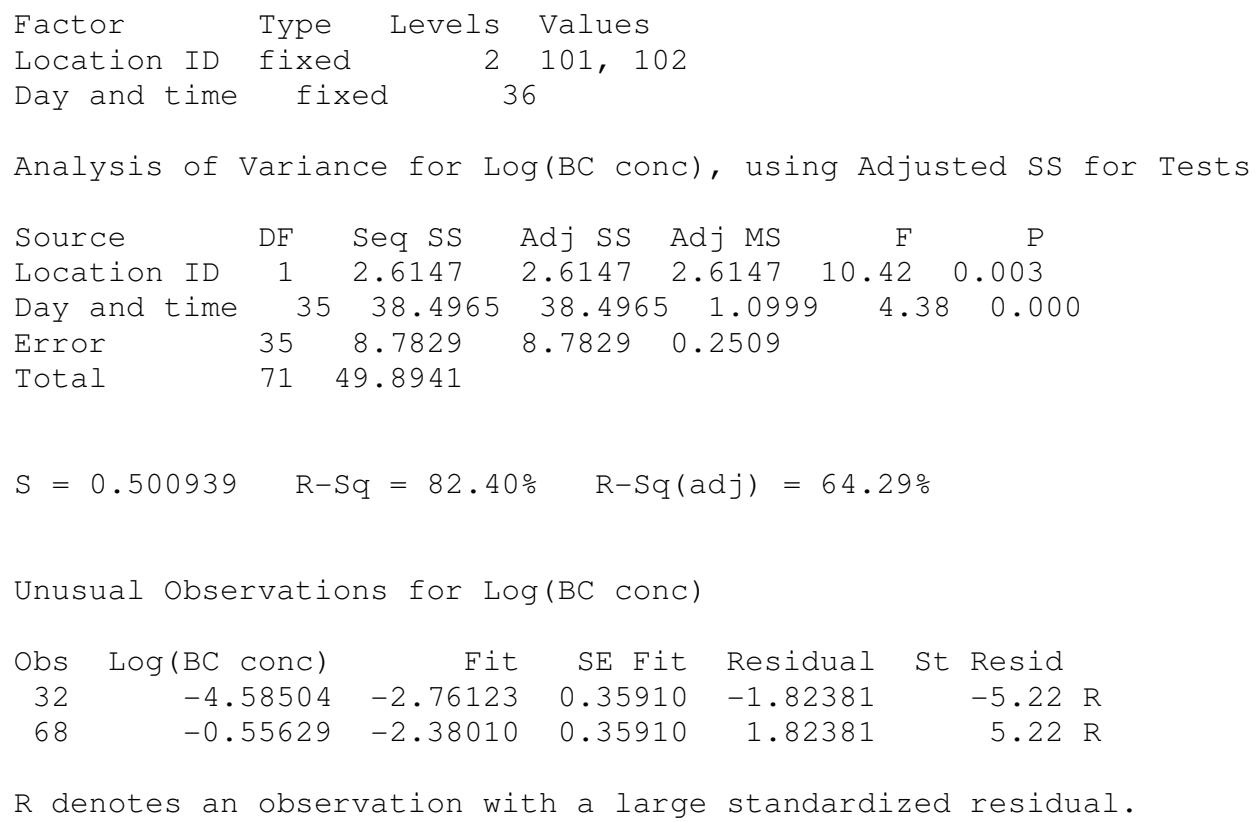



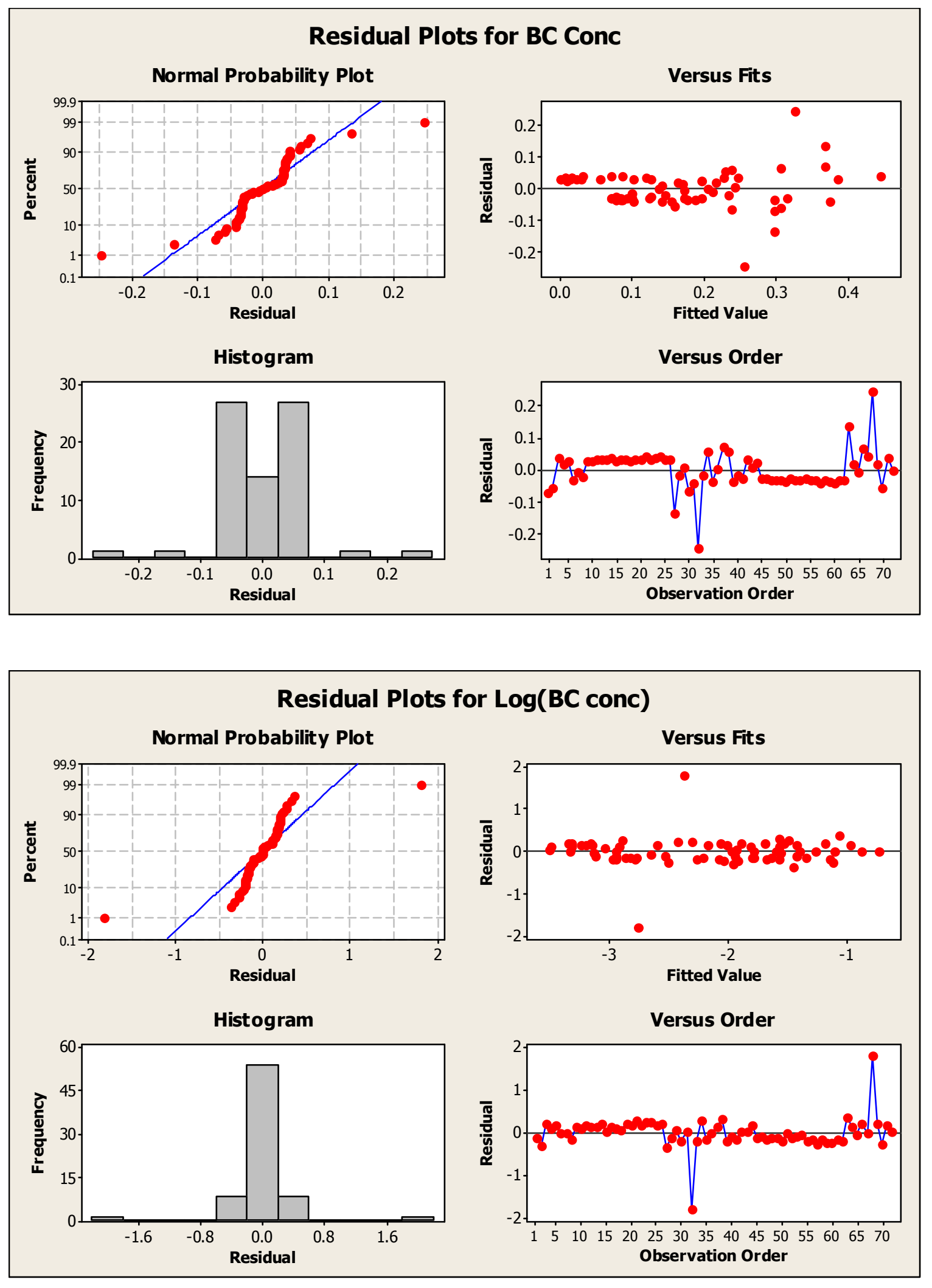


\section{APPENDIX G}

General Linear Model: $\log (\mathrm{BC}$ conc) versus Location ID, Day and time

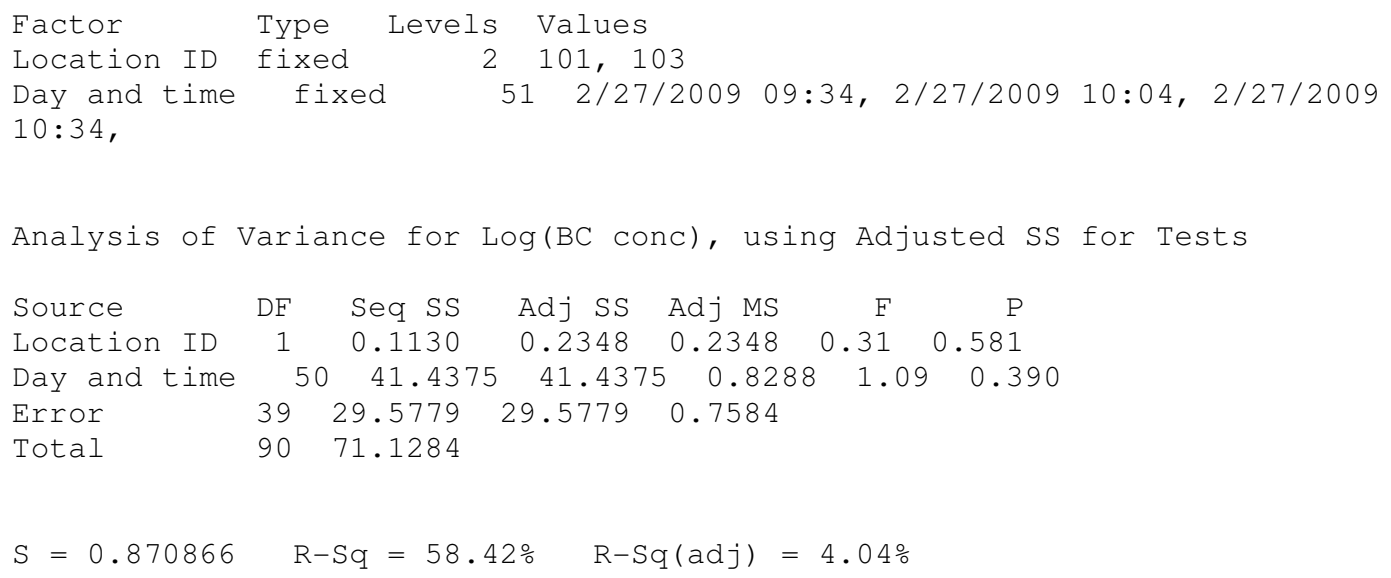




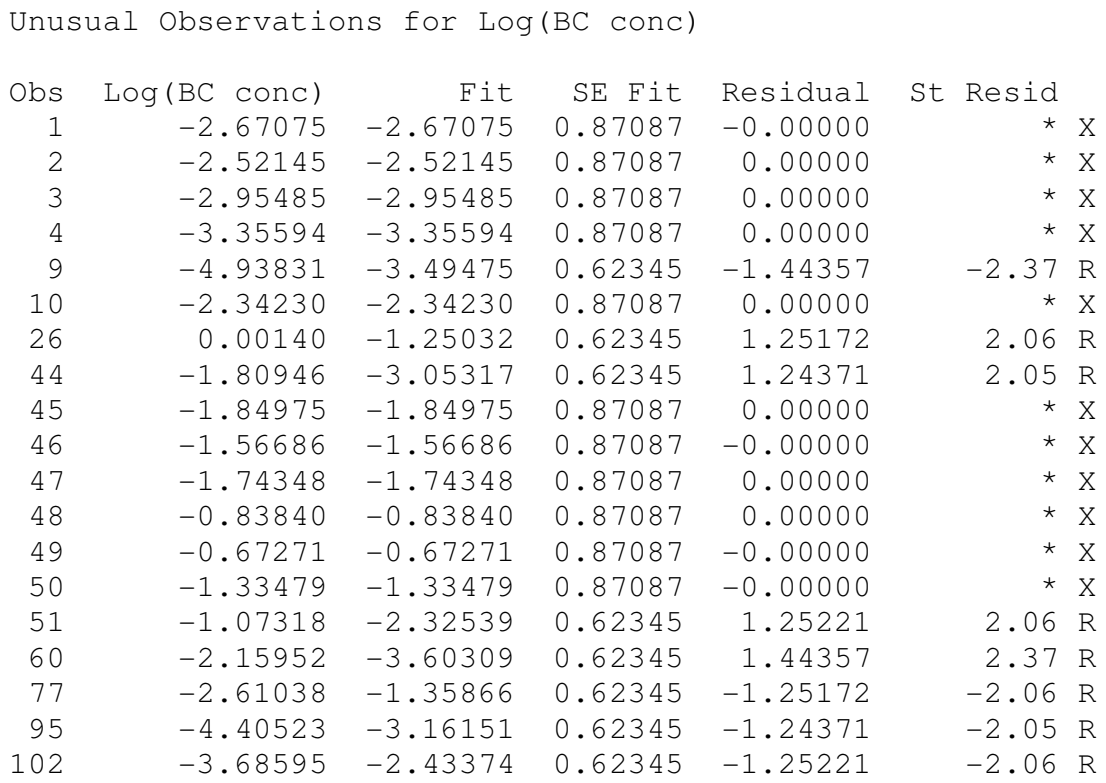

$\mathrm{R}$ denotes an observation with a large standardized residual.

$\mathrm{X}$ denotes an observation whose $\mathrm{X}$ value gives it large leverage.

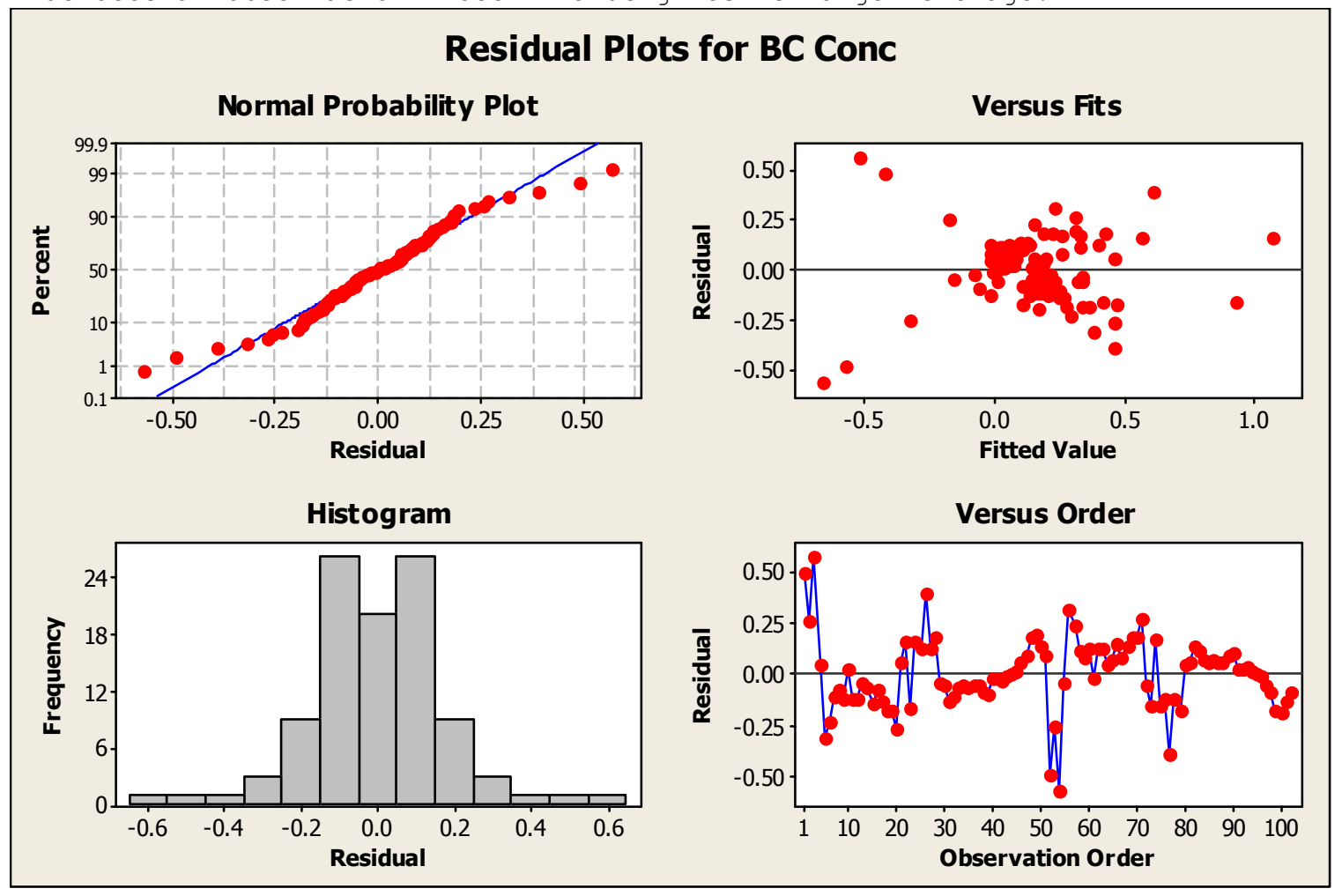




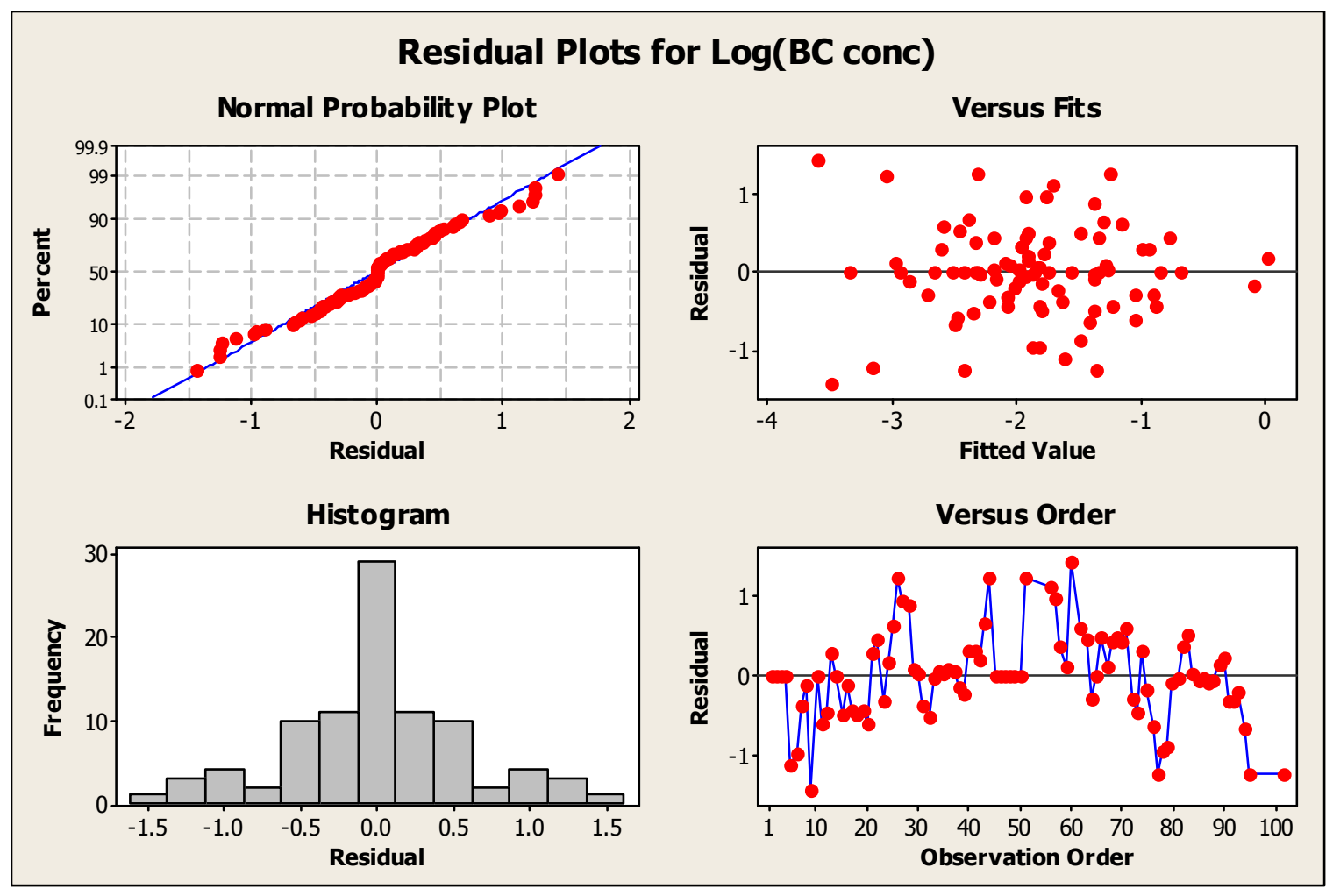




\section{APPENDIX H}

R denotes an observation with a large standardized residual.

\section{General Linear Model: Log(BC conc) versus Location ID, Day and time}

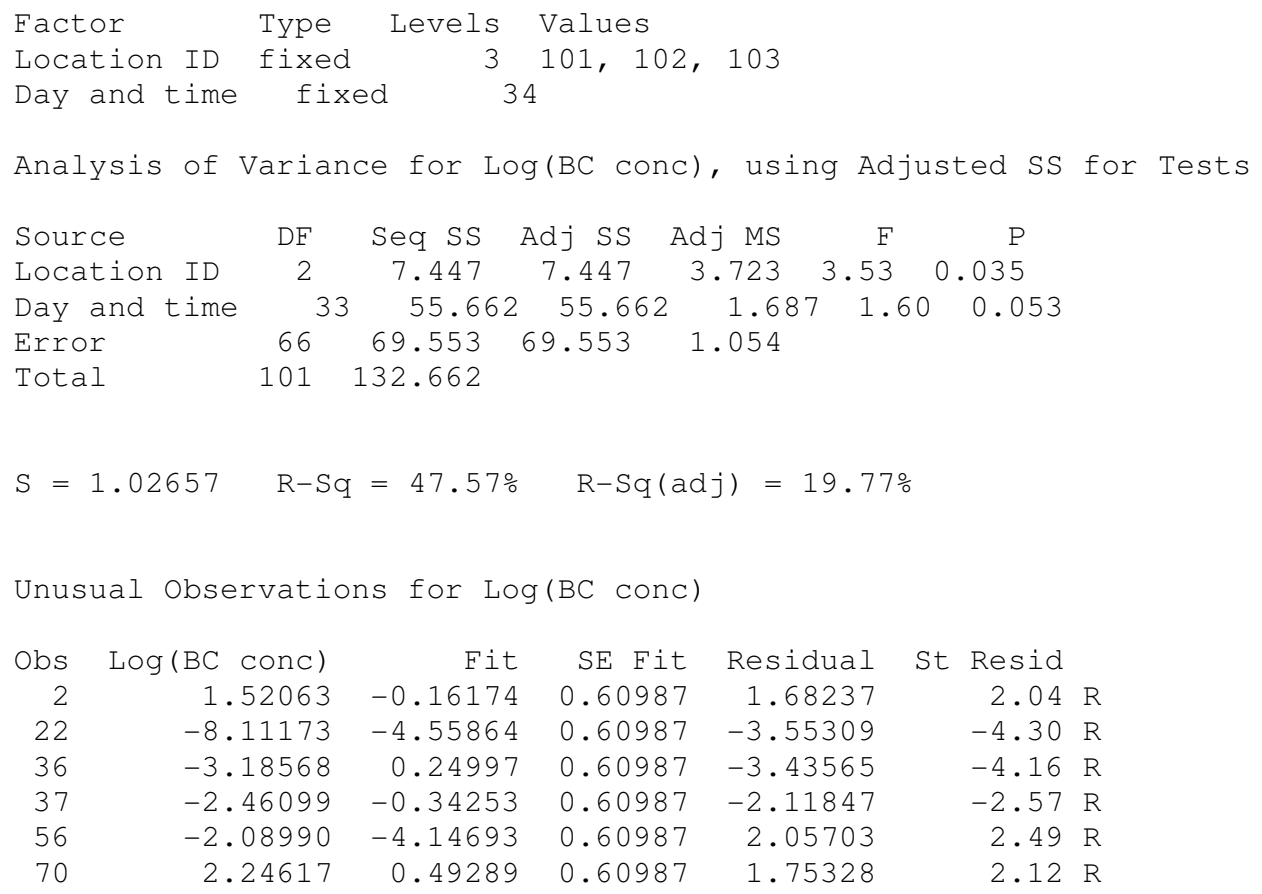




$\begin{array}{lllllll}72 & 1.56136 & -0.31592 & 0.60987 & 1.87728 & 2.27 & R \\ 73 & 1.51240 & -0.16402 & 0.60987 & 1.67642 & 2.03 & R\end{array}$
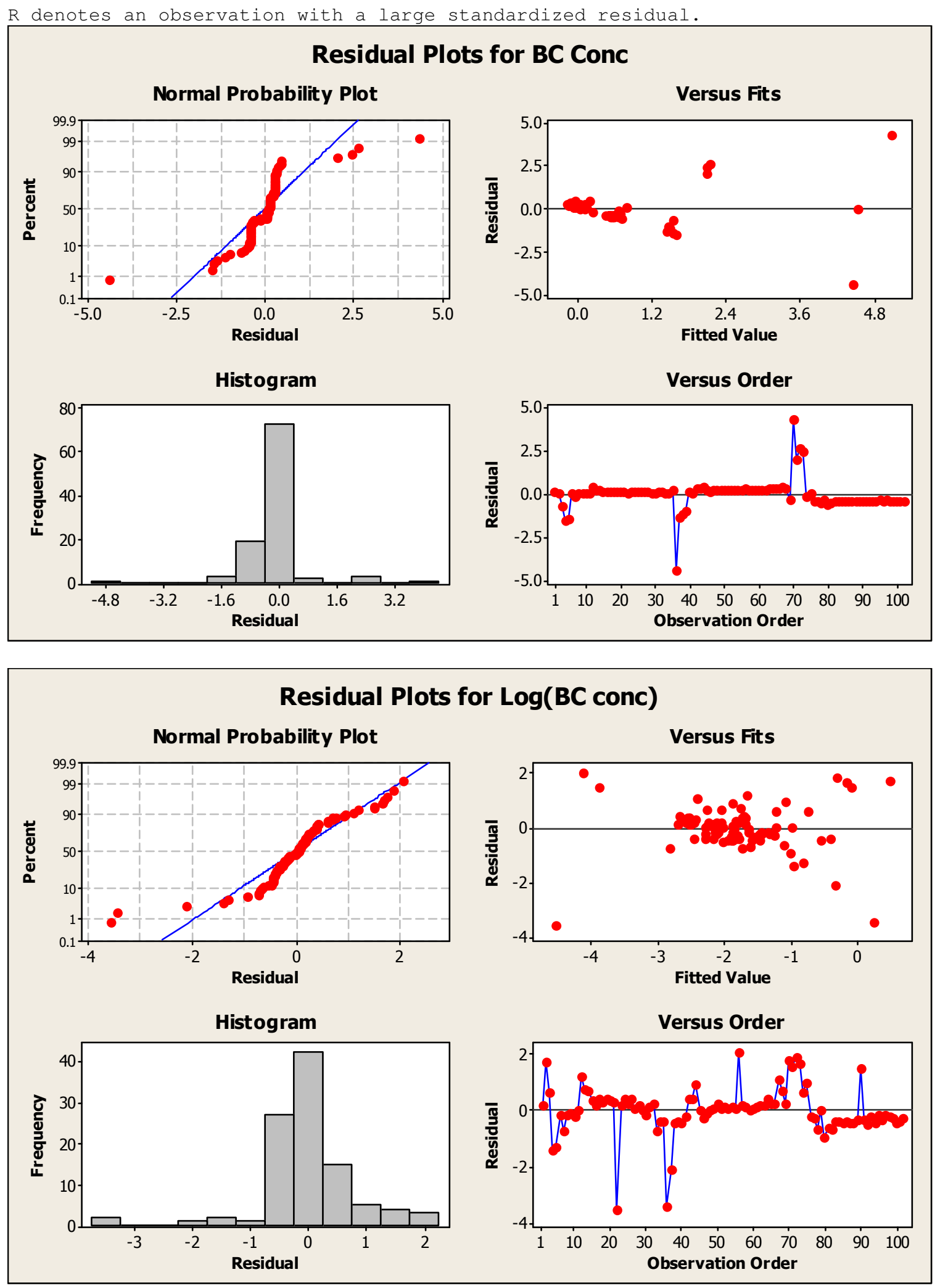


\title{
APPENDIX I
}

\author{
ANOVA MINITAB Results: March 13, 2009 IOP \\ General Linear Model: BC Conc versus Location ID, Day and time \\ Factor Type Levels Values \\ Location ID fixed 2 101, 102 \\ Day and time fixed 67 \\ Analysis of Variance for BC Conc, using Adjusted SS for Tests

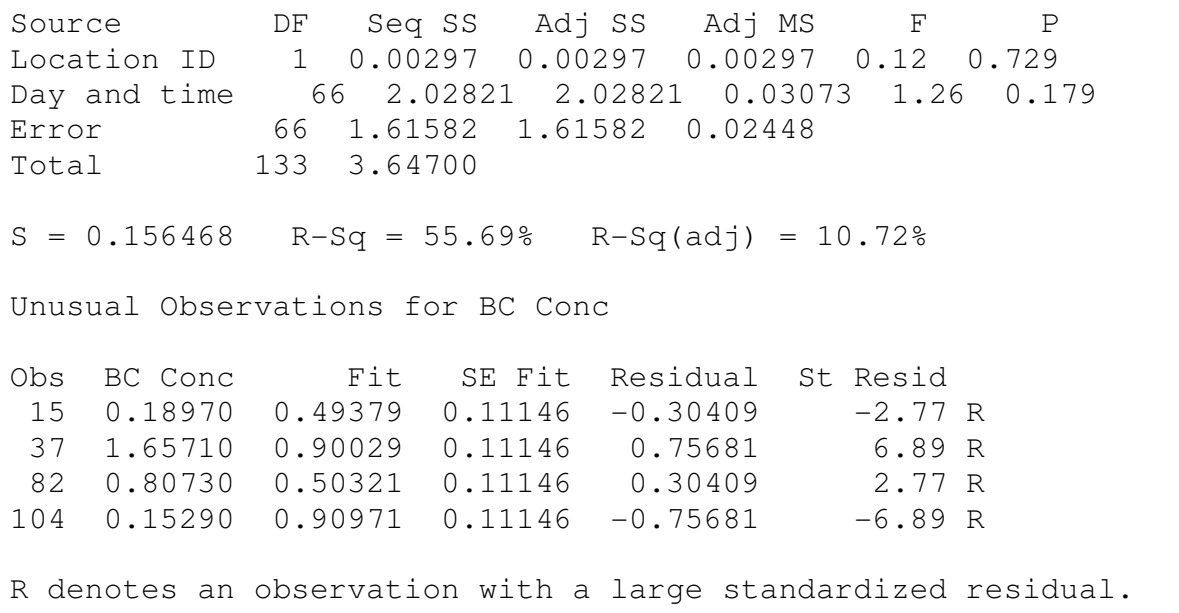

General Linear Model: $\log (B C$ conc) versus Location ID, Day and time

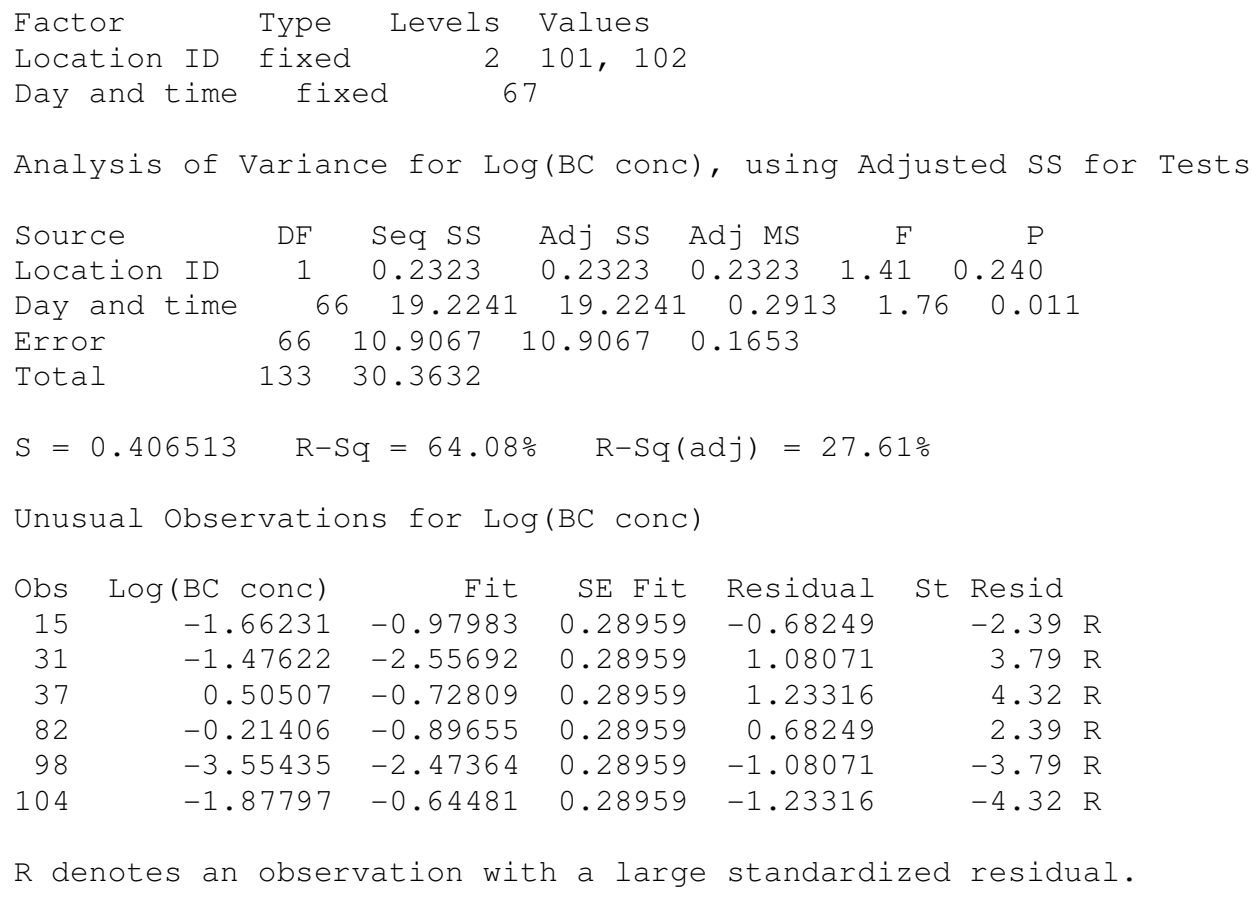



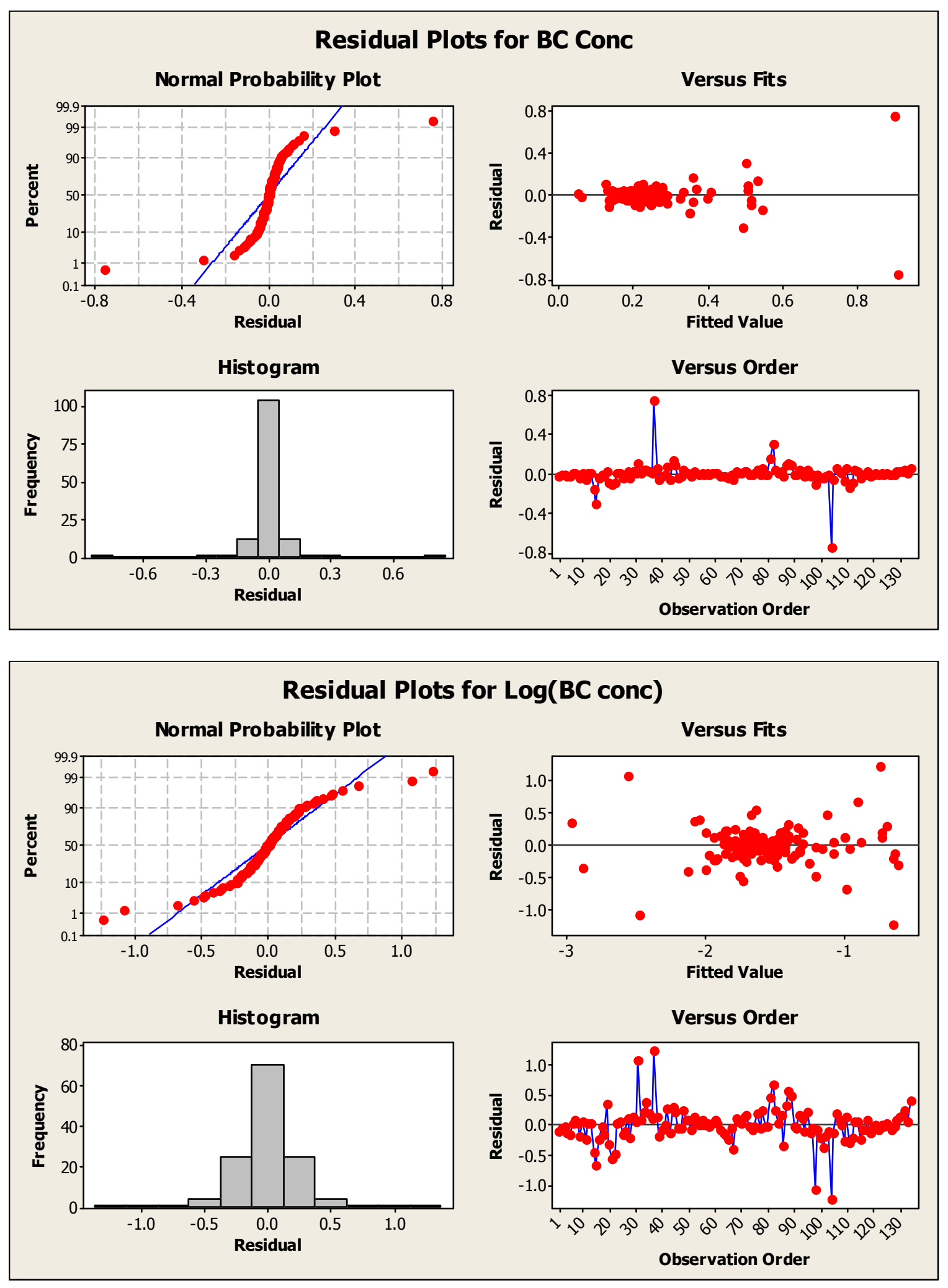


\section{APPENDIX J}

\section{General Linear Model: Log(BC conc) versus Location ID, Day and time}

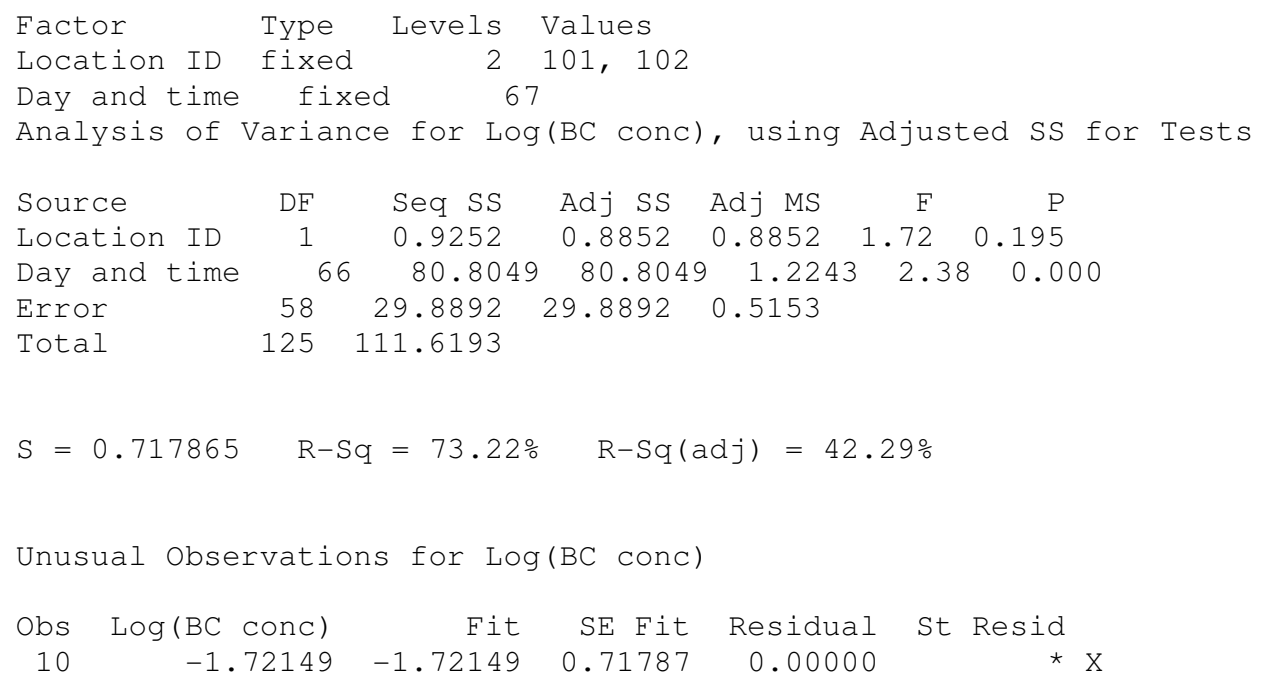




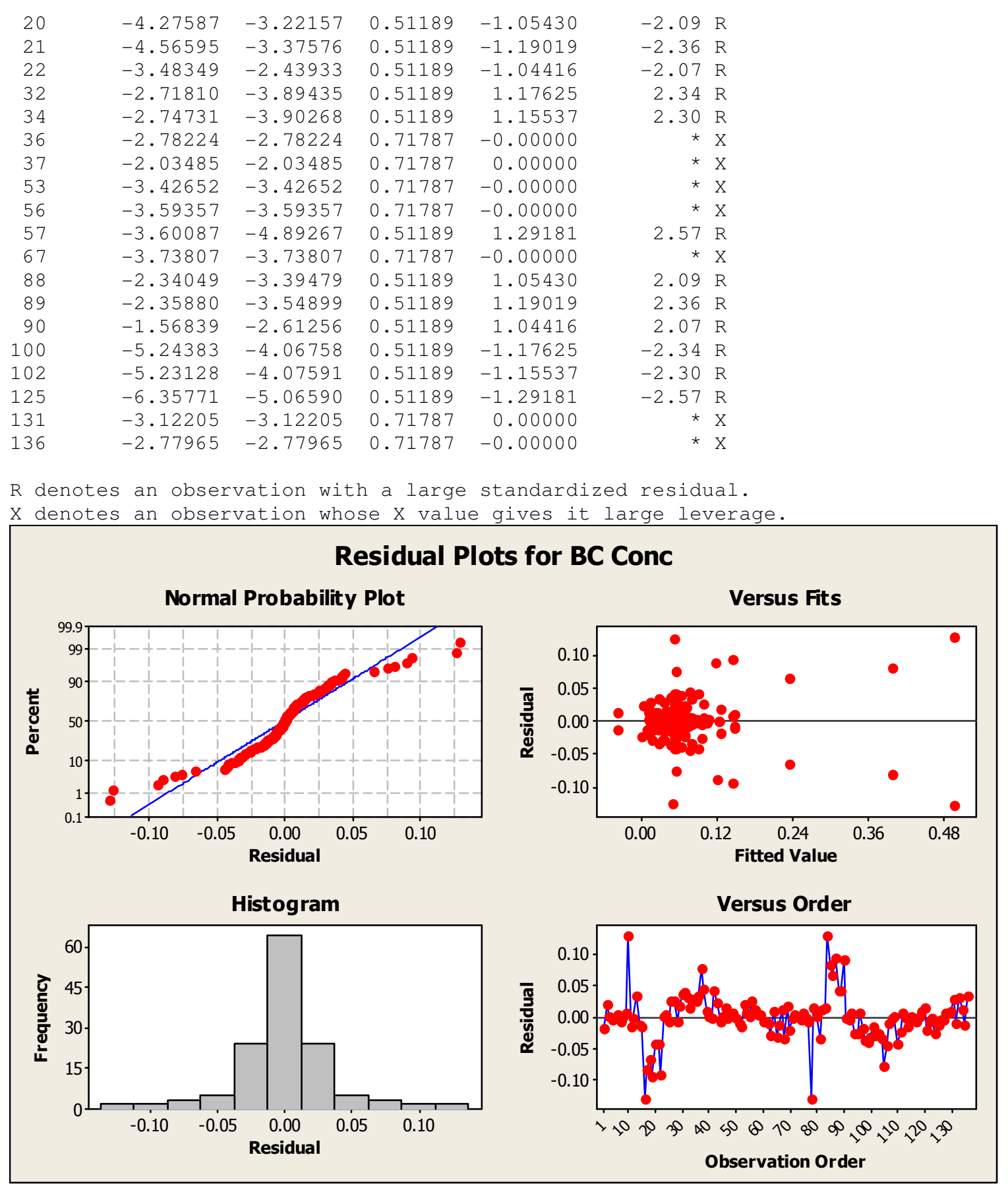




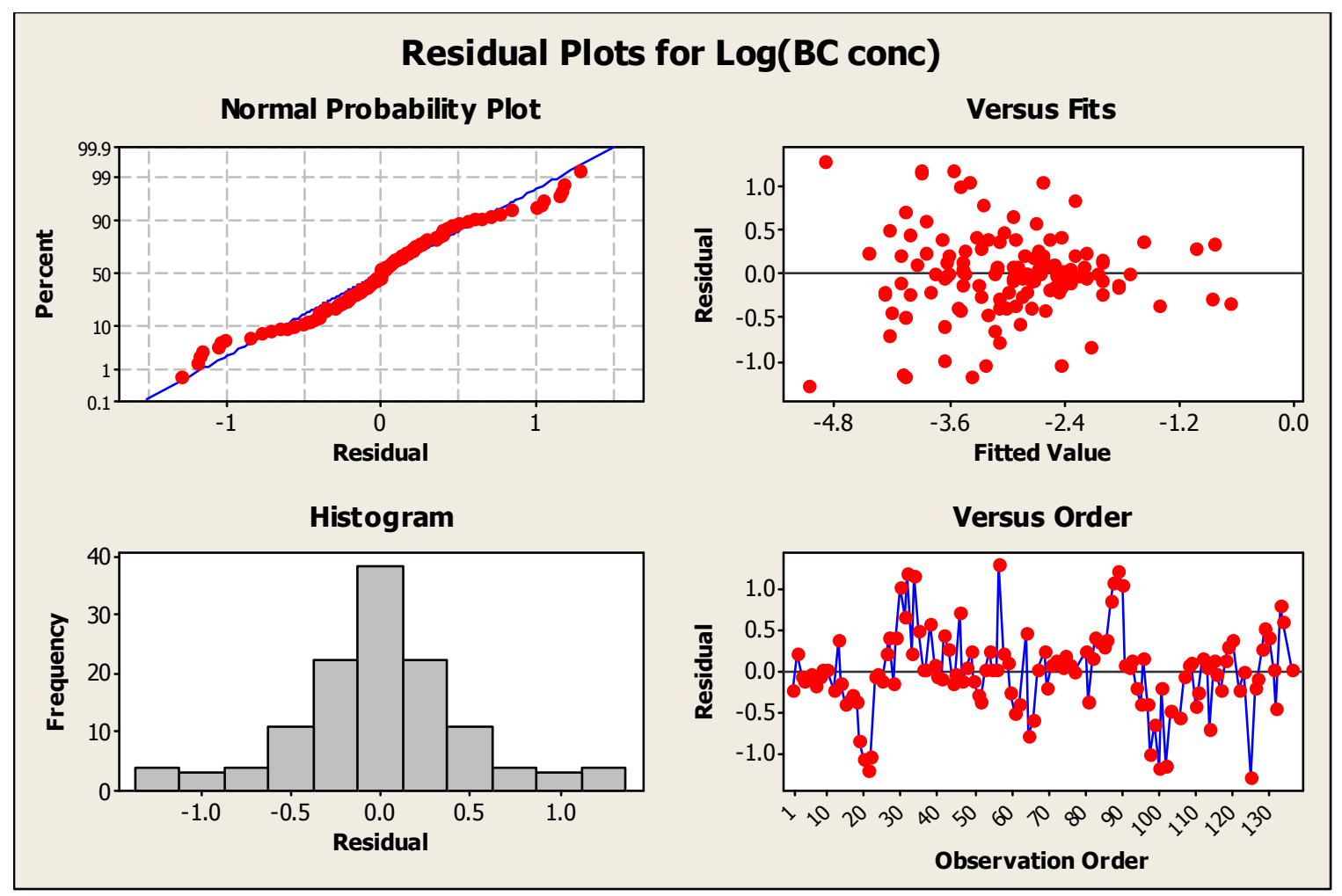




\section{APPENDIX K}

\section{ANOVA MINITAB Results: Combined IOPs}

General Linear Model: BC Conc versus Location ID, Day and time

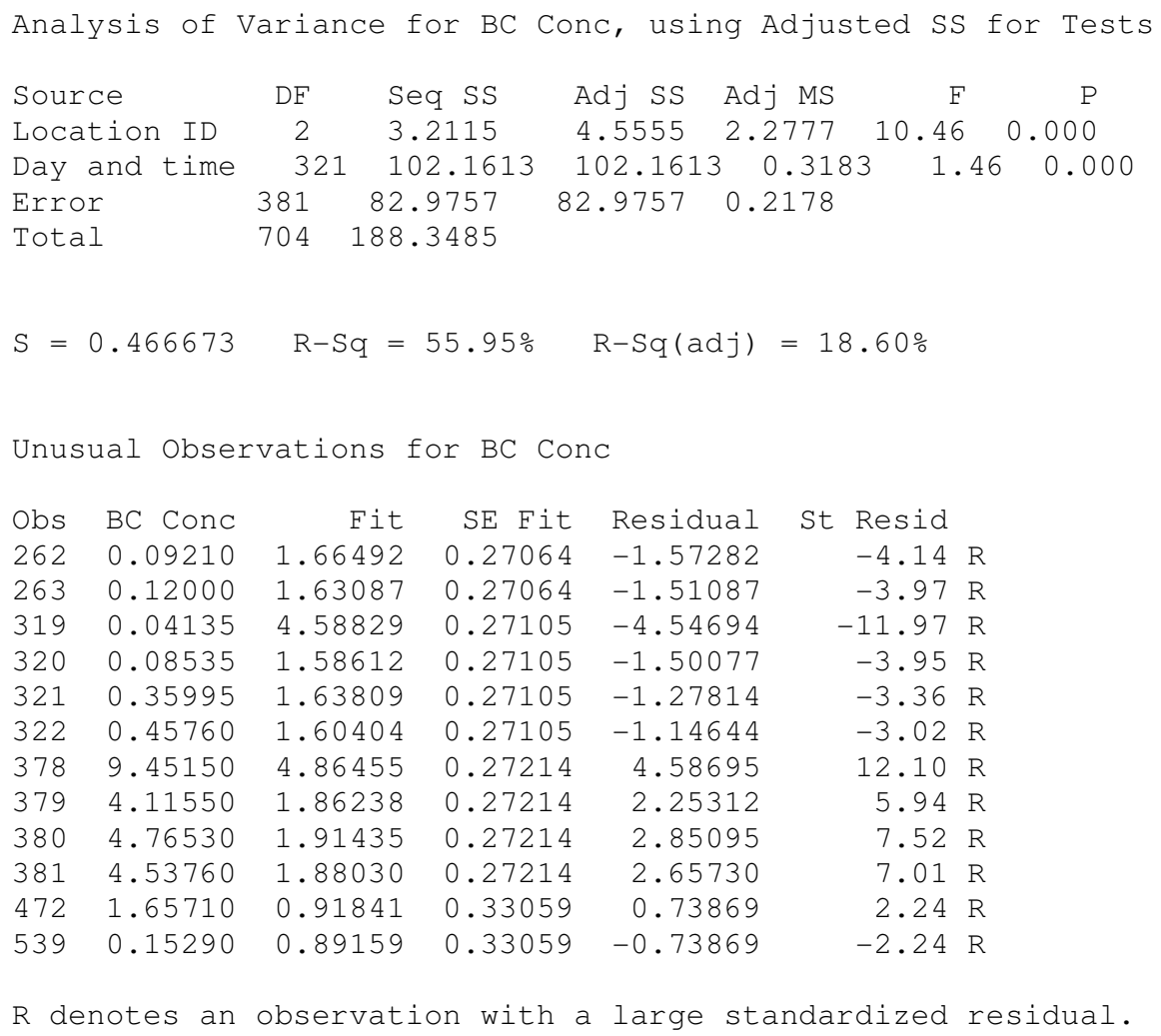

$\mathrm{R}$ denotes an observation with a large standardized residual.

General Linear Model: Log(BC conc) versus Location ID, Day and time

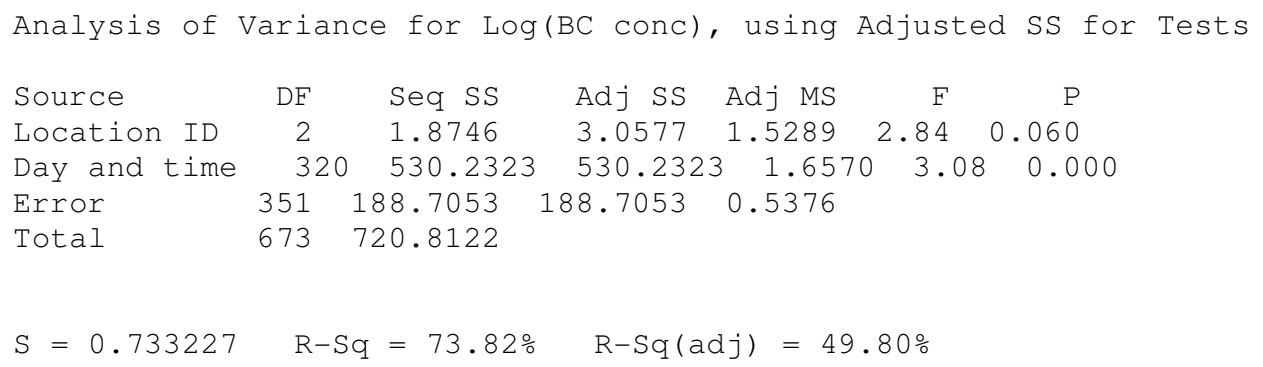



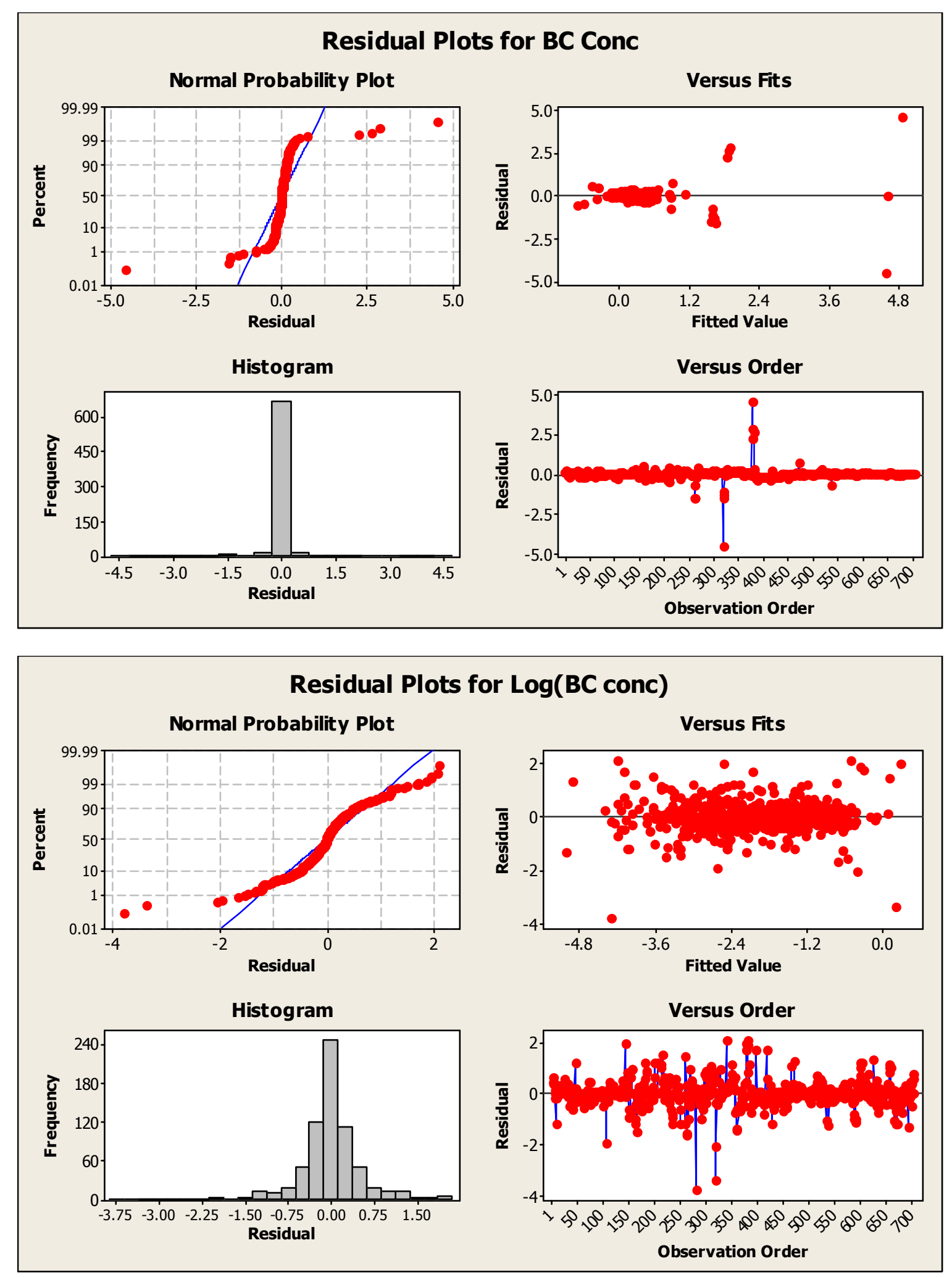


\section{APPENDIX L}

PM $_{2.5}$ Results from Ventura lab for the Mini-Vol and FRM sampler filters

\begin{tabular}{|c|c|c|c|c|c|c|c|c|}
\hline $\begin{array}{c}\text { Location } \\
\text { ID }\end{array}$ & SampleID & DateTime & $\begin{array}{c}\text { Tare } \\
(\mathbf{n g})\end{array}$ & $\begin{array}{c}\text { Gross } \\
(\mathbf{n g})\end{array}$ & $\begin{array}{c}\text { Net } \\
(\mathbf{n g})\end{array}$ & $\begin{array}{c}\text { Volume } \\
\left(\mathbf{m}^{\mathbf{3}} \mathbf{)}\right.\end{array}$ & $\begin{array}{c}\text { Concentration } \\
\text { total for 12-hrs } \\
\left(\boldsymbol{\mu g} / \mathbf{m}^{3}\right)\end{array}$ & Equipment \\
\hline 103 & 1145778 & $3 / 7 / 2009$ & 140.402 & 140.421 & 0.019 & 4.32 & 4.39815 & MV 255 \\
\hline 102 & 1145776 & $3 / 7 / 2009$ & 142.661 & 142.678 & 0.017 & 4.32 & 3.93519 & MV 257 \\
\hline 101 & 1145771 & $3 / 7 / 2009$ & 143.913 & 143.938 & 0.025 & 4.32 & 5.78704 & MV 958 \\
\hline 104 & 1145770 & $3 / 7 / 2009$ & 142.166 & 142.194 & 0.028 & 4.32 & 6.48148 & MV 402 \\
\hline 101 & 1145779 & $3 / 13 / 2009$ & 140.732 & 140.768 & 0.036 & 4.32 & 8.33333 & MV 402 \\
\hline 103 & 1145775 & $3 / 13 / 2009$ & 140.871 & 140.916 & 0.045 & 4.32 & 10.41667 & MV 958 \\
\hline 104 & 1145774 & $3 / 13 / 2009$ & 143.746 & 143.795 & 0.049 & 4.32 & 11.34259 & MV 255 \\
\hline 101 & 1145777 & $3 / 15 / 2009$ & 141.971 & 141.994 & 0.023 & 4.32 & 5.32407 & MV 402 \\
\hline 103 & 1145773 & $3 / 15 / 2009$ & 143.459 & 143.482 & 0.023 & 4.32 & 5.32407 & MV 958 \\
\hline 104 & 1145772 & $3 / 15 / 2009$ & 145.115 & 145.208 & 0.093 & 24.01 & 3.87419 & FRM \\
\hline
\end{tabular}




\section{APPENDIX M}

Spectral Attenuation Analysis (Repeats shown by red dashed line).
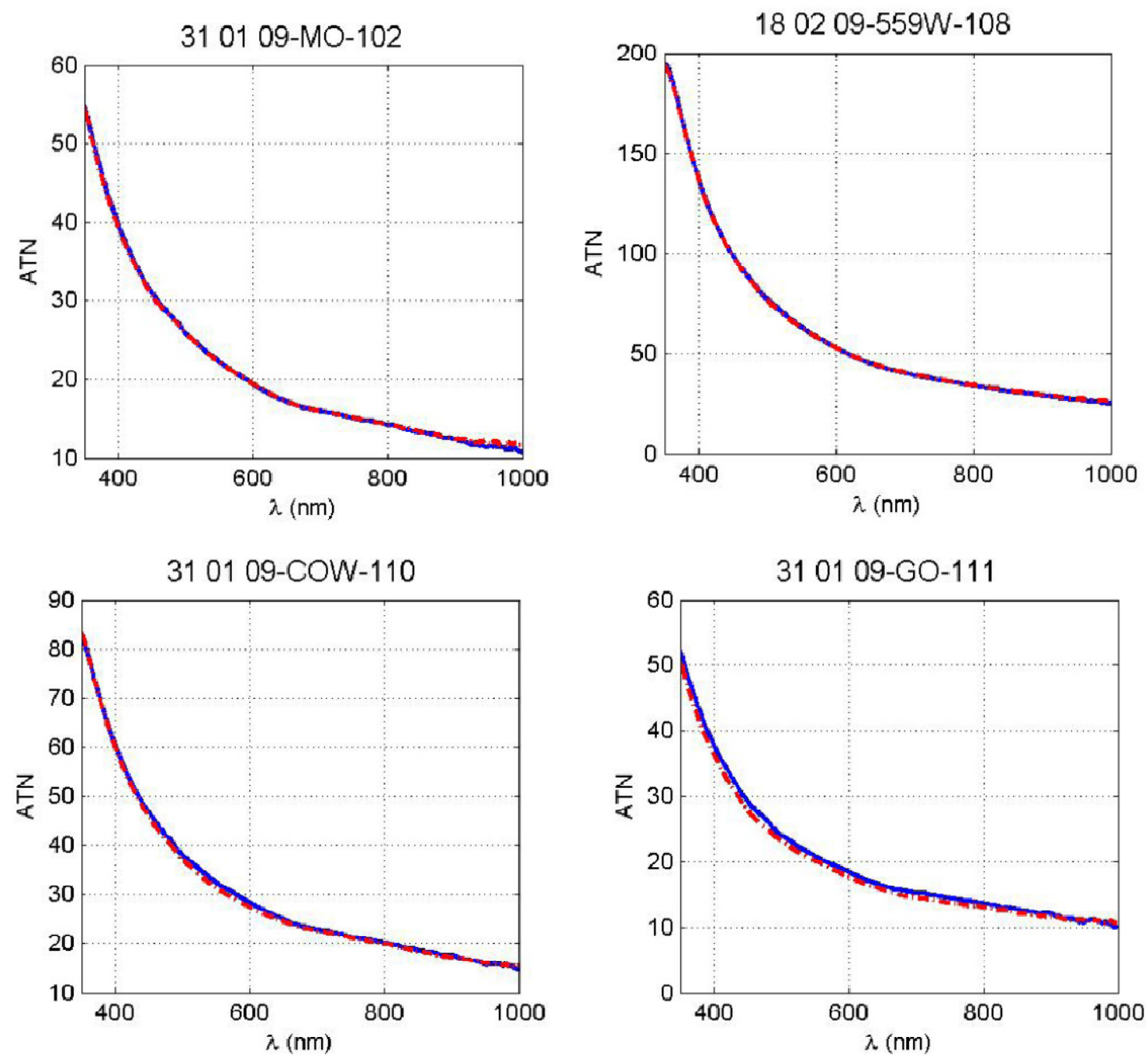

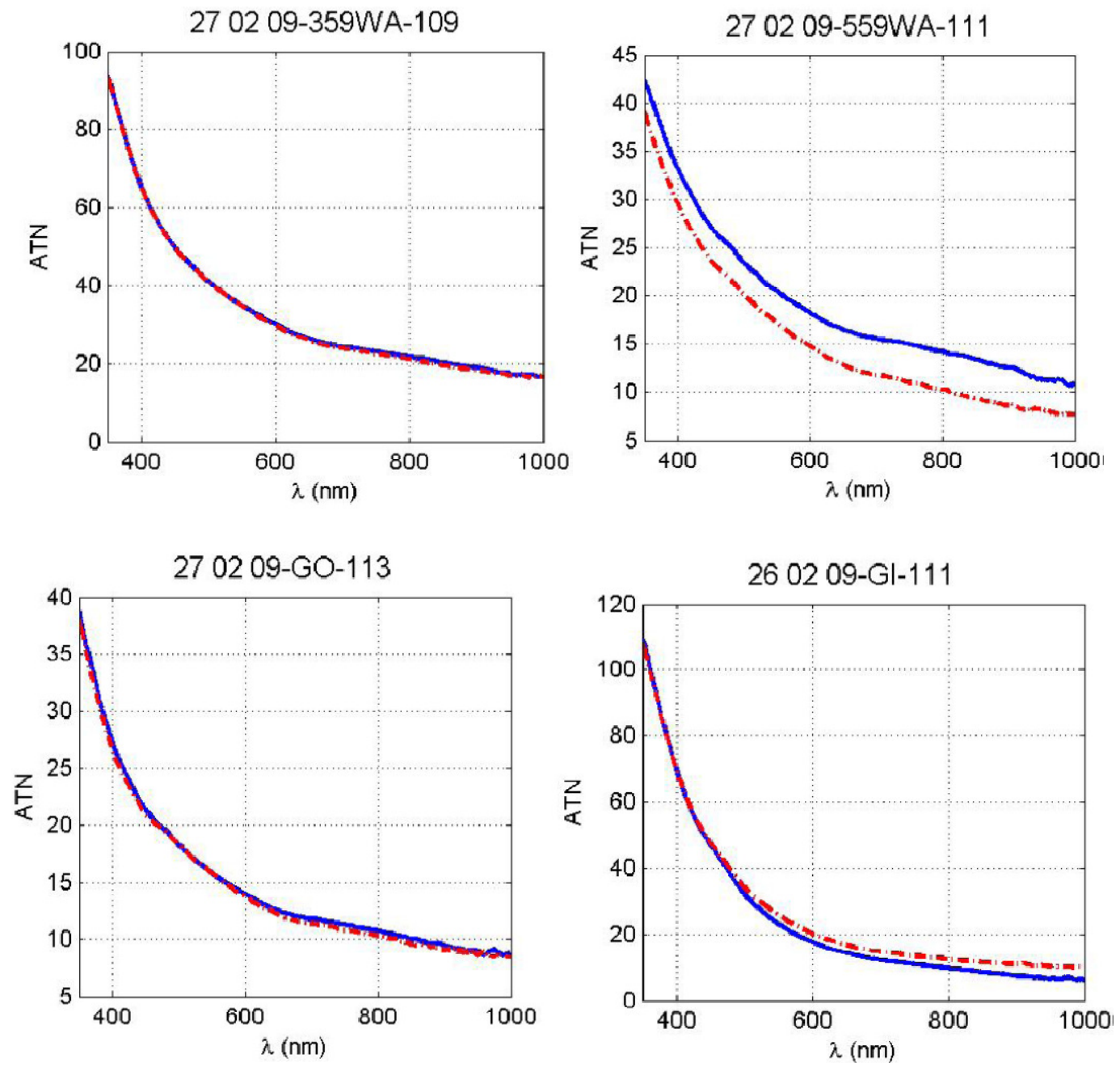


\section{APPENDIX N}

Spectral Attenuation Analysis: Strong Spectral Dependence
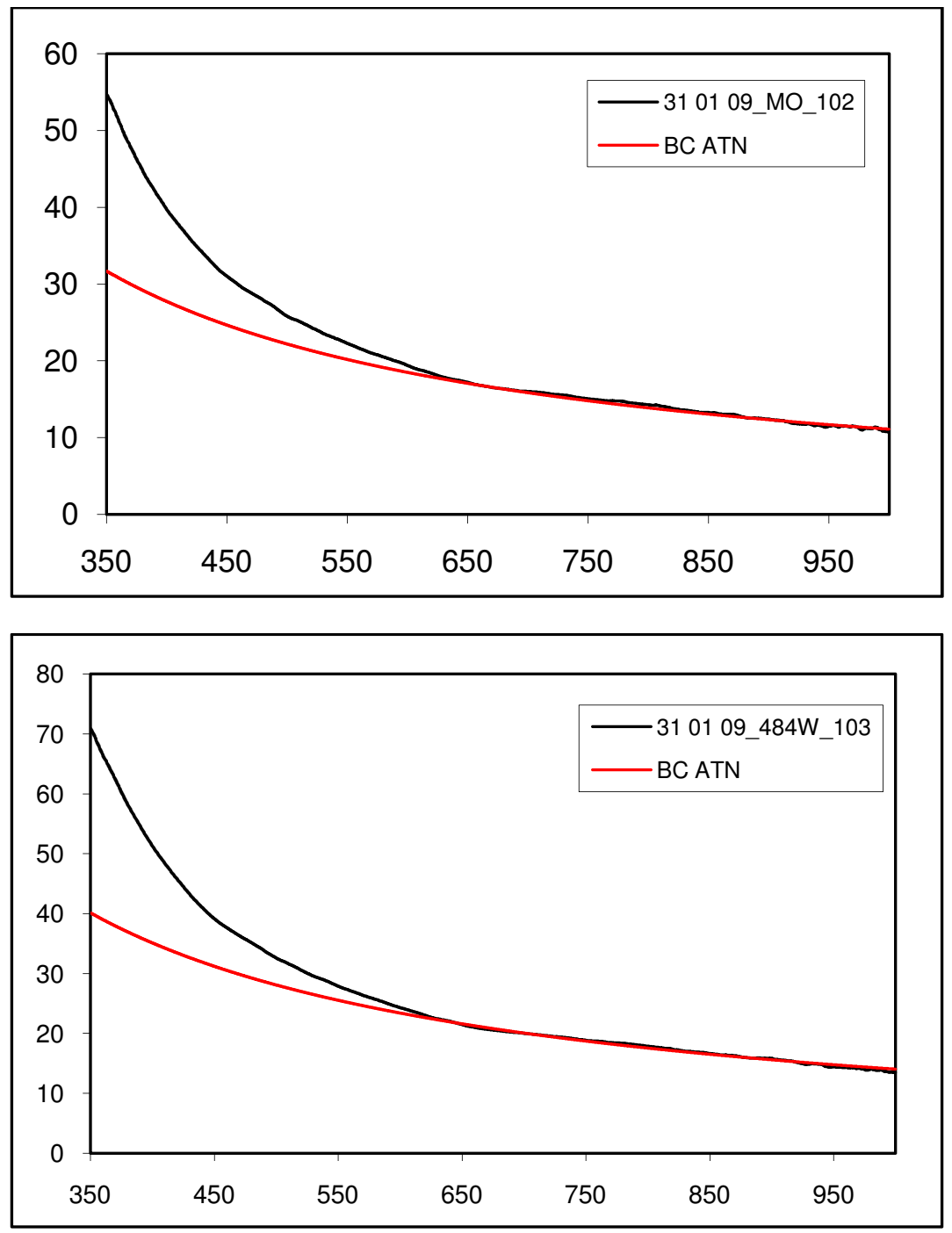

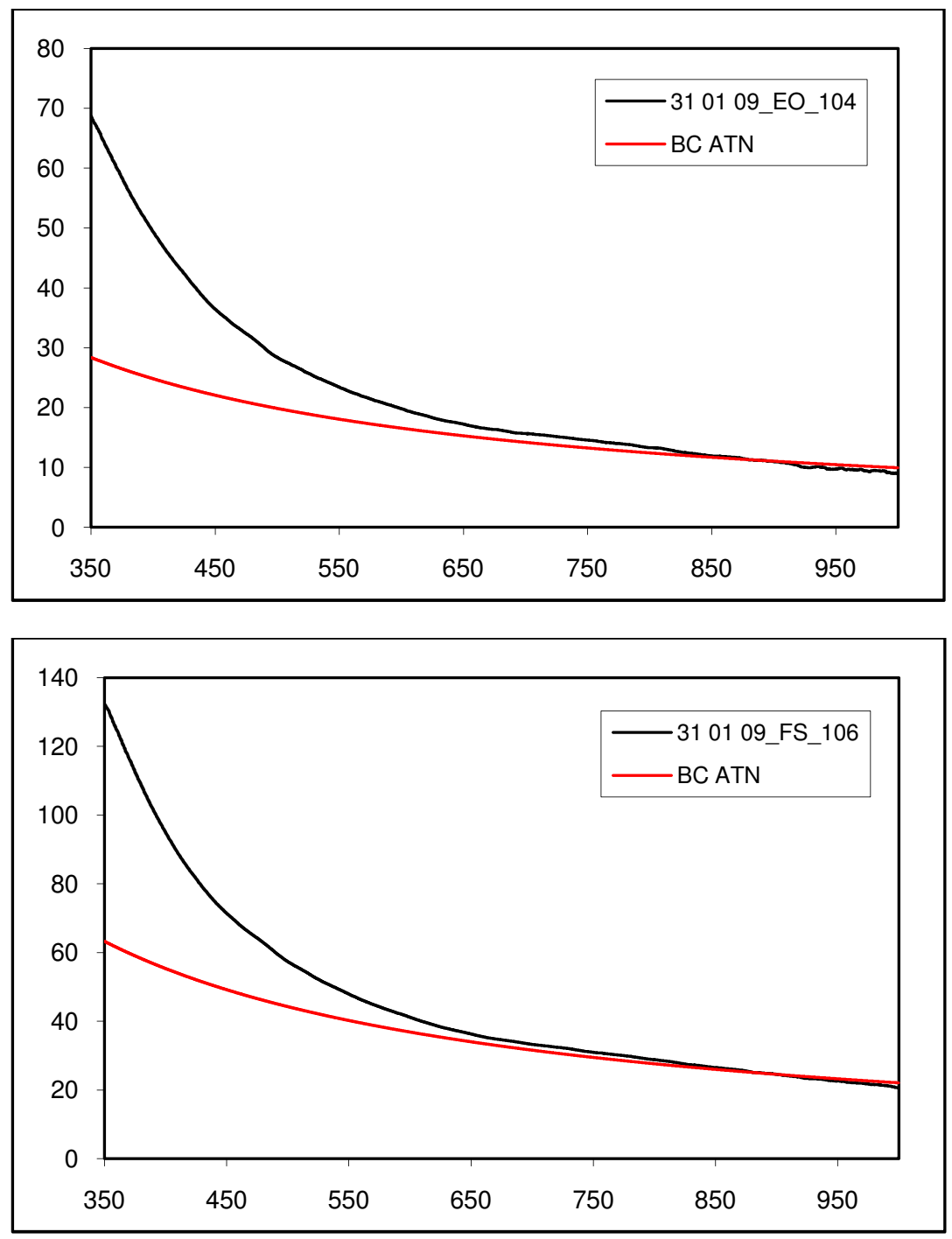